\title{
Rethinking Economic Strategies for First Nations in Canada: Incorporating Traditional Knowledge into Governance Practices
}

\author{
By
}

\author{
Rodney Nelson, MA, C.Dir., PAED, CAPA
}

\author{
A thesis submitted to \\ The Faculty of Graduate and Postdoctoral Affairs \\ in partial fulfilment of \\ the degree requirements of \\ Doctor of Philosophy
}

School of Indigenous and Canadian Studies

Carleton University

Ottawa, Ontario, Canada

2016

Copyright @

2016 - Rodney Nelson 


\section{Abstract}

Abstract: Can Indigenous businesses operate within a capitalist system while maintaining Indigenous traditional values? If so, what model of business governance would promote this balance? This thesis examines how First Nations peoples in Canada can combine their traditional knowledge with conventional corporate governance to effectively create a governance model of business management.

In a post-colonial state ${ }^{1}$, can First Nations businesses maintain traditional values and teachings, such as maintaining a balance (only taking what is needed) and reciprocity while engaging in capitalism? If so, what would this model of business look like from a corporate board perspective?

The premise of this research is that traditional knowledge can be an important aspect of Indigenous corporate governance. The objective of this work is to explore the concept of an integrated approach to governance and First Nations' traditional teachings to create a new model of governance more suited to First Nations businesses. This model of governance combines two systems of governance to produce a new system that is appropriate to First Nation ventures. This research provides a practical approach for interpreting and applying traditional knowledge and governance to create a responsive form of First Nations corporate governance that can impact strategic development and guide the decision-making processes for boards of directors, which govern First Nations businesses. The development of such a model is not only important to the success of Indigenous businesses in Canada but is essential to reducing poverty and the cycle of dependency on government subsidies. Lastly, the use of traditional teachings as foundations for governance may also enhance economic sustainability and self-determination for First Nations communities.

This research contributes to the ongoing decolonization discourse regarding the economic dependency of First Nations on the Canadian government and Indigenous resistance (Alfred, 1995, 2009; Brown and Strega, 2005; Freire, 2007, 2009) and survivance (Ryan, 1999;

Stromberg, 2006; Vizenor, 2008, 2010) discourse focused on the First Nations people's struggles to maintain their cultures and traditions. It also draws on the work of the Harvard Project on American Indian Economic Development (Cornell, 2010) and theories of John Loxley (2000:2007:2010) and Robert Anderson (1989:1999:2006) on Indigenous Community Economic Development.

\footnotetext{
${ }^{1}$ I use the term post-colonial with an optimism of a future that will allow those who have been oppressed by colonial powers the rights of self-determination. We are still gripped in a colonial state and therefore cannot call our situation truly post-colonial.
} 


\section{Dedication}

\section{To my family:}

To my wonderful family who supported me through this entire process Dacia, Cory and Robyn.

To my father, Bud Nelson and mother, Carole Nelson and my brother Craig and his son Scott for a wonderful life.

And to the Corys; Mary and Rick, Steve and Rin, James and Sarah, Pete and Shirley and Zari, my second family.

To all my relations 


\section{Acknowledgements}

Kitchi Miigwetch Nmishoomis Makwa. Miigwetch agaa-bi-iyaajig jibawaa iyaa-yin.

To the many communities I have had the pleasure to work with. I am humbled by the experiences.

Chi miigwetch to my wife Dacia for giving me the opportunity to follow my dreams and being my support and sanity

Chi miigwetch to my children who have never known me not to be a PhD student but love that I

am also a student like them

Chi miigwetch to Nipissing First Nation and Rosebud Sioux Reserve, my homes away from home

Chi miigwetch to the trickster and friend Allan Ryan

Chi miigwetch to mishomis Wally Clement

Chi miigwetch to Elder Jim Albert

Chi miigwetch to my tunkasila Clealls (John Medicine Horse Kelly)

Chi miigwetch to David Newhouse for your wisdom and advice

Chi miigwetch to Dr. Wanda Wuttunee

Chi miigwetch to all the Word Warriors

Special Chi miigwetch to Ashley Sisco for not only editing but altering my life course to chase my dreams

Chi miigwetch to Shelly Davis (Eagleshadow) for your editing

To the Elders who have guided me:

Chief Dan George, Ron Two-Feathers, Wilfred Peltier, Grandfather Percy Rae, Dorothy Meness, Paul Skanks, Thomas Louttit, Annie (Kishkwanakwad) Smith St-Georges, André-Robert "Jacques" St-Georges and Pinnock and others along my journey... Chi miigwetch

\section{To our community leaders:}

Chief Sophie Pierre, Kunxta Kinbasket

Former Grand Chief John Beaucage (Nipissing First Nation)

Chief Gilbert Whiteduck (Kitigan Zibi First Nation)

To others who have inspired me along the way:

Will Beaumont, Kitagan Zibi

Friends at the AFOA with a special thanks to Terry Goodtrack and Paulette Tremblay

To Stephen Cornell for all your dedication and work

Patricia Reynolds, Tim Pychyl (Dokesha ay cha moo ktay) and all my friends and colleagues at the Centre for Initiatives in Education

All the members at Nipissing First Nation and Rosebud Lakota Indian Reserve

All my students and those who have also struggled with education

Aho Mitakuye Oyasin, All my relations 


\section{Contents}

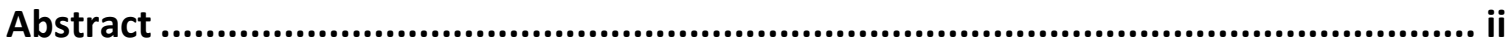

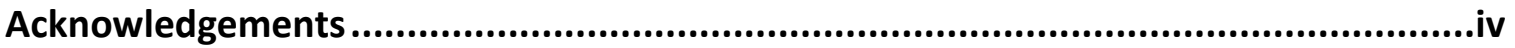

List of Figures ................................................................................................

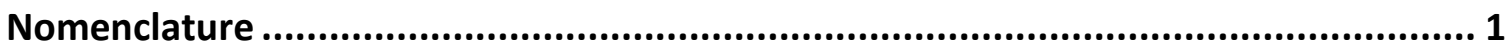

Preface: Indigenous Relationality to Research....................................................... 5

Chapter One - General Introduction .............................................................. 16

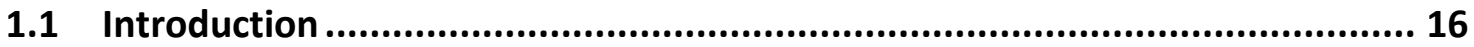

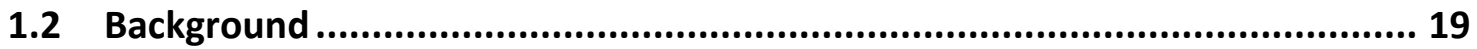

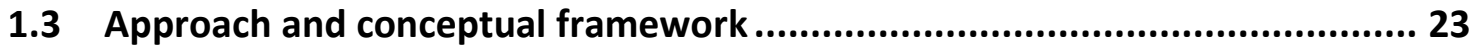

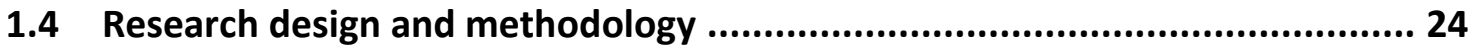

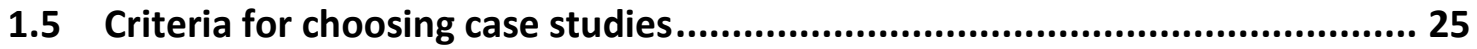

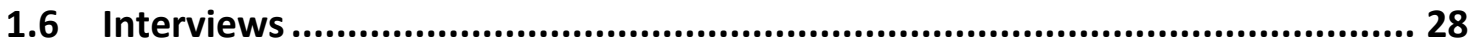

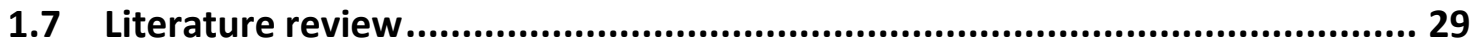

1.8 Purpose and aims of research ................................................................ 40

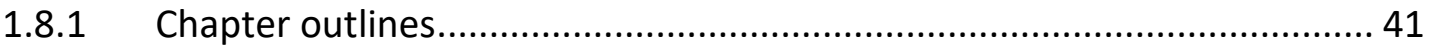

Chapter Two - Research Design and Methodology ................................................ 43

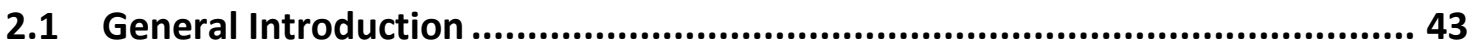

2.2 Intersectionality and political economy ............................................ 44

2.3 PAR, CBPR, and an Indigenous approach as macro methodology ................. 46

2.5 The birch bark basket as a traditional conceptual framework..................... 53

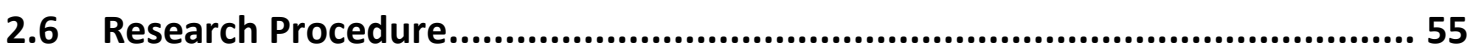

2.7 Community interviews and 'research conversations' ................................. 57

2.8 Storytelling and Traditional Knowledge ............................................... 59

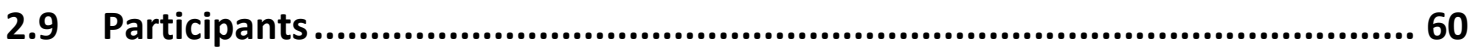

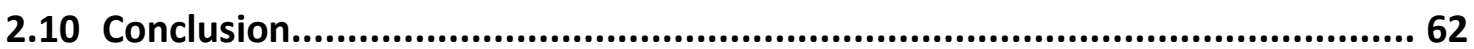

Chapter 3 - Rethinking the Hegemony of Capitalism ............................................. 63

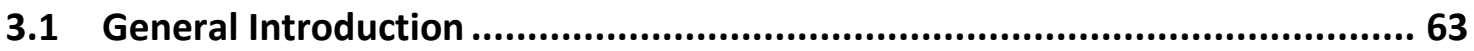

3.2 Political economy and the moral sentiment ........................................ 63

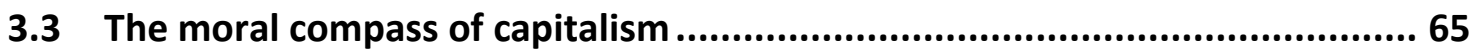

3.4 Modern misinterpretations of capitalist philosophy ................................. 68

3.5 Alternative economies: a new discursive space...................................... 74

3.6 Solidarity economy and Indigenous interests ..................................... 77 


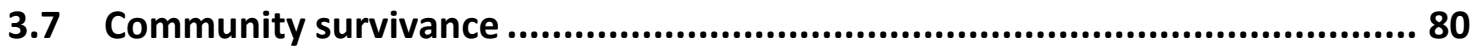

3.8 From old traditional to new traditional economy ....................................... 84

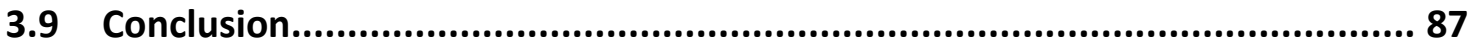

Chapter 4 - Economic Development and First Nations ......................................... 89

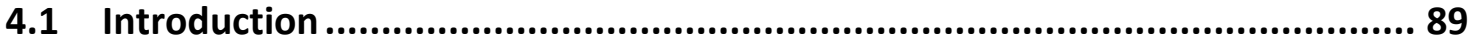

4.2 Traditional theories of economic development ..................................... 89

4.3 Economic development today ........................................................ 93

4.4 Economic development from an Indigenous perspective .......................... 96

4.5 Barriers to economic development ................................................. 97

4.6 Merging of two world views, aditawazi nisoditadiwin .............................. 99

Chapter 5 - Partnerships and Economic Development .........................................104

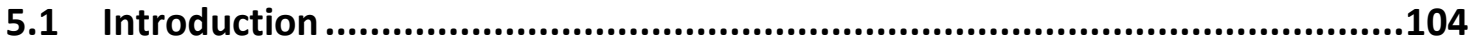

5.2 History of partnerships and alliances .....................................................104

5.3 Entrepreneurship in Native communities ..............................................106

5.4 Corporate partnerships .......................................................................108

5.5 Corporate Canada and social responsibility (CSR) ...................................111

5.6 Aboriginal relations and policy .......................................................113

5.7 Duty to Consult and Accommodate....................................................117

5.8 Sustainable community economic development for Native peoples ............120

5.9 Contrasting Business Philosophies ..................................................122

Chapter 6 - Opportunity Through Economic Development for Native People in

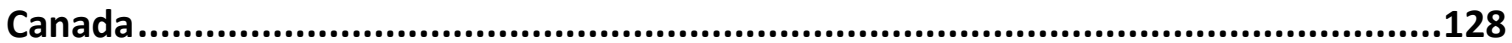

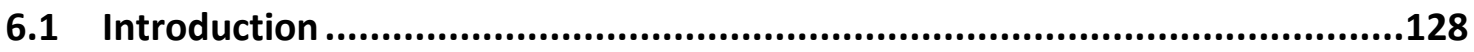

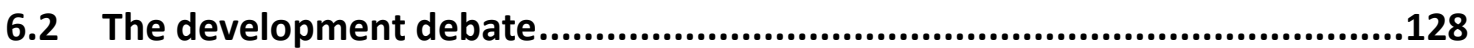

6.3 Resistance and renewal: towards economic development .........................134

6.4 Internal economic development ..........................................................138

6.5 External Economic Development .........................................................140

6.6 Capacity development and the role of education .....................................143

Chapter 7 - Aditawazi Nisoditadiwin: Governance and Indigenous Traditional Knowledge

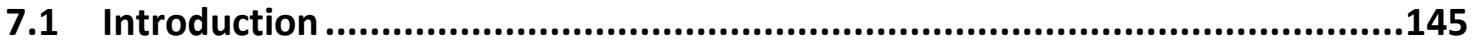

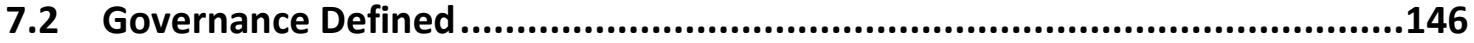

7.3 Political Governance ...........................................................................147

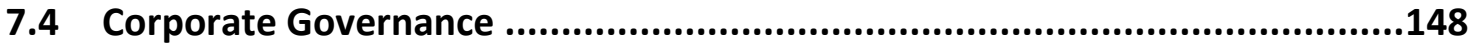


7.5 Traditional Teachings and Governance ..............................................149

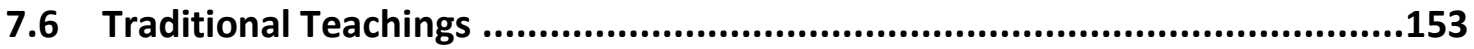

7.6.1 The Medicine Wheel ................................................................... 154

7.6.2 The Tipi Teachings................................................................. 158

7.6.3 The Seven Generations Teachings .................................................. 162

7.7 Looking to Traditional Knowledge and Business .......................................165

7.7.1 Adapted Medicine Wheel and Building an Indigenous Board .............. 165

7.7.2 Tipi Teachings and Corporate Strategy ........................................... 174

7.7.3 Seven Generations Teachings and sustainable practices .................... 177

7.8 Bimodizawin and The Good Life Through Governance................................179

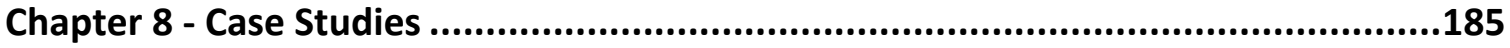

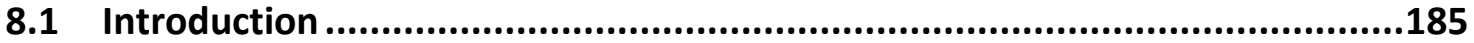

8.2 Community Case: Goodfish Lake Business Corporation, Whitefish Lake First

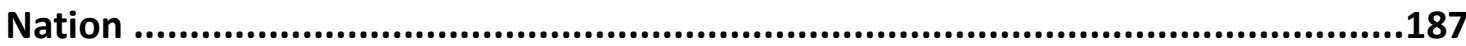

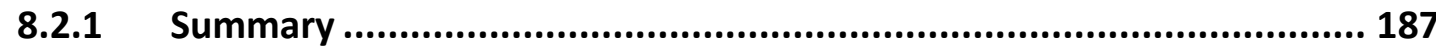

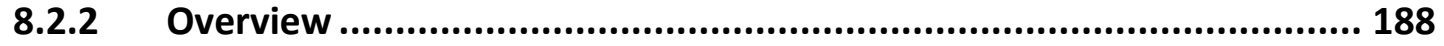

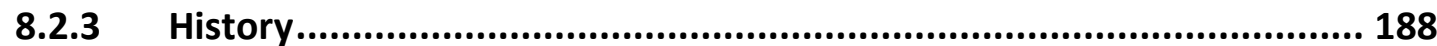

8.2.4 Early vision for economic development a critical transition point ....... 190

8.2.5 A Pragmatic Partnership: Leveraging Community Talents and Nearby Markets 190

8.2.6 Drawing on Elders' Wisdom to Retain Community Values................... 192

8.2.7 Growing the business................................................................... 194

8.2.8 Goodfish today ....................................................................... 194

8.2.9 Telling Their Story ..................................................................... 196

8.2.10 Governance Model .................................................................... 197

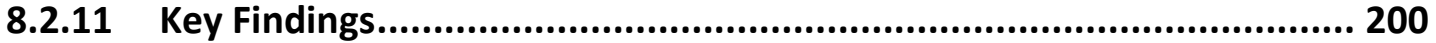

8.3 Corporate Case: First Peoples Group ...................................................203

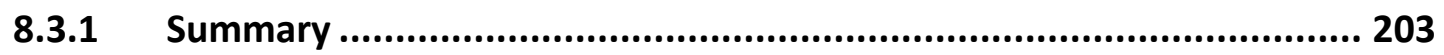

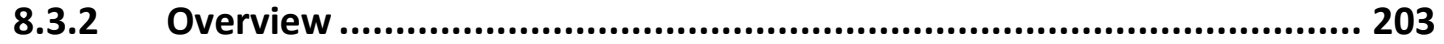

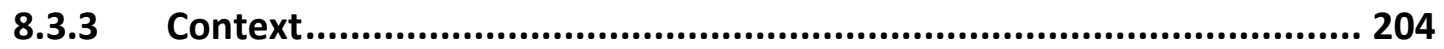

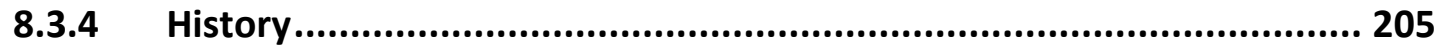


8.3.6 Creating a vision ........................................................................... 207

8.3.5 Critical transition point - adapting their business model ....................... 208

8.3.5 Telling Their Story............................................................................ 210

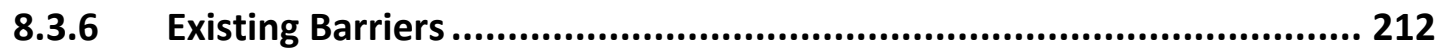

8.3.7 Findings ......................................................................................... 213

8.4 Combined Partnership Case: Ktunaxa-Kinbasket Partnership Strategy...........215

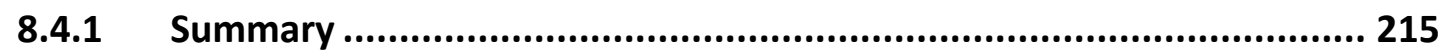

8.4.2 Overview ............................................................................................ 216

8.4.3 History and the St. Eugene Mission School ......................................... 218

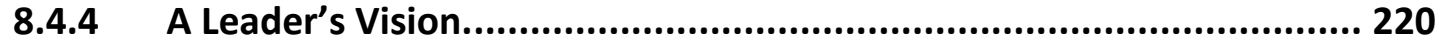

8.4.5 Looking to Ktunaxa traditional knowledge .......................................... 223

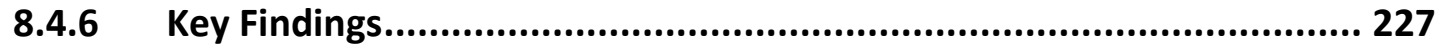

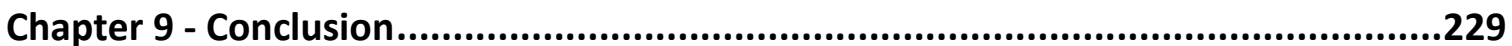

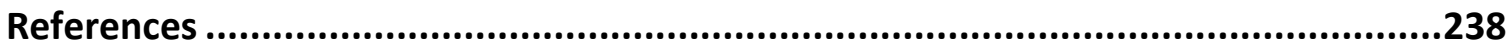

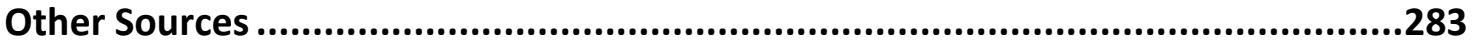

Appendix A - Community Interview and Conversation Participants ...........................292

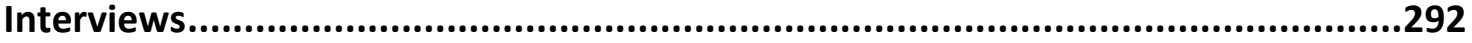

Correspondence and ongoing conversations....................................................293

Wisdom from Elders............................................................................................295

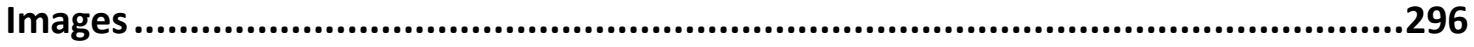




\section{List of Figures}

Figure 1 Traditional Birch Bark Basket Framework. ................................................... 24

Figure 2 Traditional Birch Bark Baskets ................................................................... 54

Figure 3 Medicine Wheel from Curve Lake First Nation Cultural Centre, Anishinabe ... 156

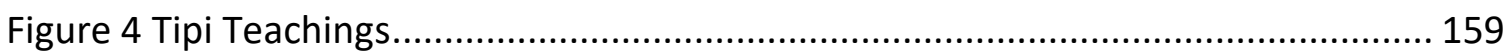

Figure 5 Board Expertise/ Adapted from Brown Governance Model .......................... 167

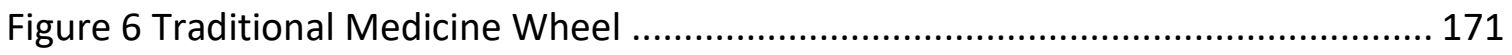

Figure 7 Medicine Wheel adopted for the Global Governance Group ......................... 172

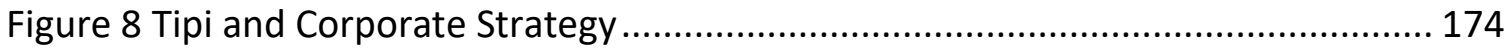

Figure 9 Goodfish Lake Development Corporation Logo .......................................... 187

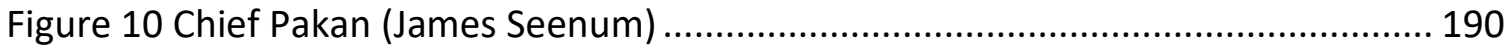

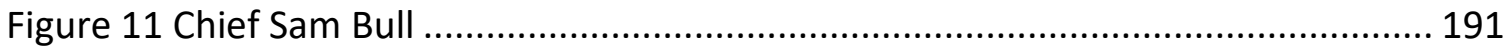

Figure 12 GFLDC Garment Manufacturing and Repair ............................................. 194

Figure 13 GFLDC Industrial Dry-Cleaning Facilities................................................ 195

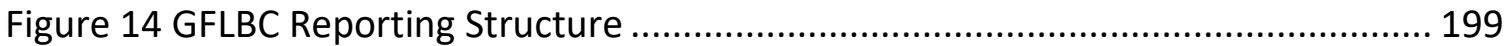

Figure 15 Goodfish Lake Development Corporation's Policy Directives ...................... 201

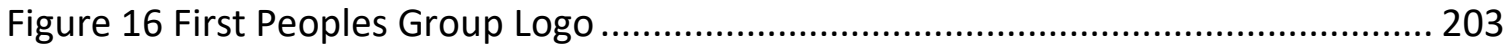

Figure 17 Guy Freedman, First Peoples Group ........................................................ 205

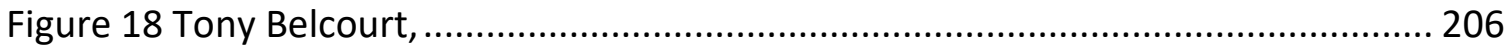

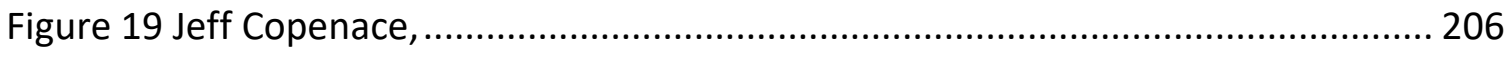

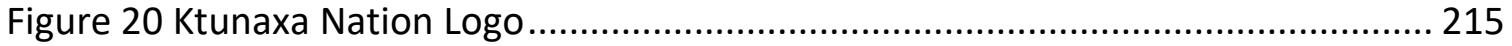

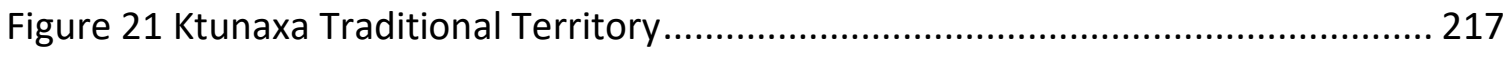

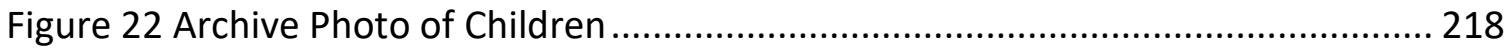

Figure 23 Statue Dedicated to Residential Survivors at St. Eugene Mission ................. 219

Figure 24 Chief Sophie Pierre and the St. Eugene Resort........................................ 221 


\section{Nomenclature}

I have tried to be constantly self-reflexive about colonial undertones in my writing throughout this thesis. Yet, I recognize there are necessary limitations of writing in English, a colonial language, which even the most astute self-reflexivity cannot rectify. Specifically, some Indigenous concepts will be lost in translation between pen and paper, as they cannot be adequately conveyed in English (Lakoff \& Johnson, 2003). Therefore, the purpose of this section is to directly acknowledge the fundamental language and semantics issues upfront with you, the reader.

Writing is political. A writer's words often indicate our sometimes-subconscious political biases (Kristin and Warry, 2011). In any colonial country, language is tied to identity and nation building. A plethora of policies promoting English and French in Canada has left little room for the retention of Indigenous languages and identity. Language is the basis for cultural transference of worldviews, teachings, and cultural identity. While one might argue that learning the English and French languages has empowered Native communities and peoples in some regards, the damage it has caused to Native nationhood, communities, and families has been nothing less than tragic. The systematic destruction of Native languages through policy and forced assimilation has represented a lasting legacy of genocide for many Native communities.

Colonialism also pervades the written word, which in turn, stands to perpetuate colonialism. For example, the English language is saturated with social Darwinist ideologies that serve to subtly but powerfully oppress the original peoples in Canada, or 
more traditionally Turtle Island. Terms of dehumanization which include such archetypal concepts as the "Native warrior", "Indian savage", or "Indian princess". Language around development such as "to civilize", "provide handouts", "improve" and "develop". These examples are all deficit -based language that focuses too greatly on the failure of the original peoples of Canada to assimilate to a particular non-Indigenous norm. Writings are also plagued with possessive and paternalistic phrases such as "Aboriginal/Indigenous peoples of Canada", and language of "helping" Aboriginal/Indigenous peoples that overlooks our agency and necessity for selfdetermination.

Throughout my writing, I use various terms to refer to the original peoples in Canada. I recognize that each term is loaded with symbolic and sometimes derogatory meanings, so I have tried to be as respectful as possible within the confines of an academic thesis written in a colonial language and using accessible words. In general, I try to use the most specific term possible in reference to a group, as I recognize the diversity among and within such groups. For example, I use the terms used by a particular Nation where possible, such as the "Anishinabe" (Ojibwa, Algonquin, Nipissing), “Dené”, “Mi'kmaq”, or “Cree”.

I also use the umbrella terms for the three main subgroups of original peoples in Canada recognized by the Canadian constitution, "First Nations", "Métis", and "Inuit". Lastly, where I am referring to all original peoples of Canada, I use the terms "Native", "Aboriginal", and "Indigenous" somewhat interchangeably, although, I use the term "Native" most often in this regard, as I find it least offensive personally and represents 
the First Peoples of Turtle Island (as North America is referred to by Anishinabe or the people). Aboriginal is an encompassing term in Canada that includes First Nations, Métis, and Inuit people. ${ }^{2}$ While the term Aboriginal is widely used and has legal meaning in the 1982 revisions to the Constitution of Canada, the incorporation of the Latin prefix 'ab' is problematic because it means 'away from' or not, as in the term (ab)normal, or not of the norm. Coupled with original, Aboriginal translates to away from or not original. Indigenous tends to be an increasingly popular term as it is considered more politically correct. However, it can be misleading in the context of Canada, as it has an international connotation as well. Therefore, I often use the term "Indigenous" to refer to many "Native" peoples across the world. Similarly, I use terms such as "Indigenous knowledge" in reference to the many different knowledge systems of Indigenous people worldwide. While the term Native tends to have larger use across the border in the United States, it is also used in Canada, albeit to a lesser extent. None of these terms is intended to homogenize the countless distinct Native groups within Canada, including 250 distinct First Nations, each with unique cultures, languages (or dialects), and histories.

In reference to peoples who are not Indigenous to Canada but live in Canada, I use the term "Settler Canadian" or "Settler ally" to acknowledge the history of settlement and significance of colonial positionality to this work. However, I do not like the terms of Ally or Settler as they create a binary that segregates people rather than

\footnotetext{
${ }^{2}$ For more information about terminology, see the National Aboriginal Health Organization's note on "Terminology": http://www.naho.ca/publications/topics/terminology/
} 
creates inclusiveness. Our people have always been traditionally great adopters of people within their nations regardless of their blood ties, blood quantum, cultural background and race. As long as the adoptees were willing to live and learn the ways of their adopted people with respect and honour they would be granted full citizenship. This is the way of the people.

I also capitalize all of these terms as I do in reference to other terms that refer to a people, such as "Canadians", "Europeans", and "Americans". This is to show not only respect but also equalize the political landscape of nationhood. 


\section{Preface: Indigenous Relationality to Research}

From an Indigenous perspective, situating oneself within the research is foundational to understanding it (Martin, 2008; Smith 2012; Wilson, 2008). A piece of writing is only a reflection of a particular time and place or a particular idea. The reader does not have a good understanding of the author's life, history, and the teachings the author has received, that influence and bias their writing. To understand Indigenous pedagogy is to understand the ongoing 'relationality' one has to their own research (Wilson, 2008). Cree scholar Shawn Wilson defines 'relationality' as the concept that "all things are related and therefore relevant" and argues this concept is foundational to Indigenous ways of knowing (Wilson, 2008, p. 58). Similarly, Noonuccal, Quandamoopah scholar Karen Lillian Martin discusses this concept as 'relatedness theory', which she defines as,

the sets of conditions, processes, and practices that occur amongst and between the Creators and Ancestors, the Spirits, the Filter and the Entities...across contexts and is maintained within conditions that are: physical, spiritual, political, geographical, intellectual, emotional, social, historical, sensory, instinctive, and intuitive (Martin, 2008, p. 69)

The concept of 'relationality' or 'relatedness theory' demands that researchers

ask themselves several questions about their positionality in relation to the work, including: Who is the researcher? Where do they come from? Why are they engaged in this work? What are they saying and where does it come from? Most importantly, is what they are saying respectful? For Indigenous scholars, inquiry is a multi-level 
relationship with the topic, institution, academics, friends, family, community, animals, medicines, and even the Creator. Even if one does not believe in the spiritual nature of research, one can appreciate the teachings and importance of the stories and show respect. So in true Indigenous form, and honouring oral traditions and storytelling, I share with you my story, which has shaped my life and prompted me to write this thesis.

My paternal grandmother was from Nipissing, Ontario, and my paternal grandfather was a hydro man whose family history includes United Empire Loyalists, English, Scottish and Dutch ancestry. My grandmother was a tall, strong woman of six feet with dark hair and a mischievous smile. She always wore some sort of beadwork. She taught me many things when I was with her. She would smile and tell me to have fun but keep out of trouble. She meant it. My grandmother had a huge influence on who I am today. She told me many stories and showed me how to be proud of who I am. I have even heard stories of the Sioux who came over from Alberta after escaping the brutality of Wounded Knee and the ongoing wars against the nation. One man came to Nipissing and married an Anishinabe woman. I am part of that heritage.

My maternal grandparents died around the time I was born. I didn't know them but often reflect on them and who they were. I always felt bad for my mother for being away from her parents and knowing her children would grow up not knowing them. In a strange twist of fate, my wife's parents and grandparents knew my maternal grandmother. It was my wife's grandmother who told me that I have my grandmother's kind smile. It is a small world. 
I was born in Sarcee territory (more properly Tsuu T'ina territory) in what was once an Air Force base in Calgary, Alberta, Canada. It is now part of the Tsuu T'ina Nation Reserve. My father was a military man for the majority of his life. He served in the Canadian military for over fifty years, including in the Middle East during the United Nations (UN) peace missions in the Gaza Strip and the Sinai Peninsula. I never worried when he was called off for duty for some reason because I knew he would come home.

My mother was a hairdresser, although it was hard for her to practice this profession as we were moving around all the time. My mother mainly stayed home looking after my brother Craig and I, taking care of us selflessly as we were moved from place to place, posting to posting. She seemed to like the adventure, but I know it was hard for her to be away from her parents.

When my mother was pregnant with her third child, it was a hard time for us all and very stressful on my mother. We stayed with friends for what seemed like a long time, as my mother was having trouble with her pregnancy. I remember her going into labour, but also remember the confusion when the baby did not come home with my mother. Our baby sister didn't survive. I have always thought of the baby as my sister, and she is always around.

Being a base brat, I lived in many places including an Air Force base in Warner Robins, Georgia. We were always told that in the event of a nuclear attack, we would be the third target attacked, as this was the home of the F15 aircrafts and a major logistics base. This gave us a sense of twisted pride, although we tried not to think of it too much. In Georgia, I spent many nights either roller skating in a roller derby, out in the 
bush, riding bikes, beading in our living room, or going off to powwows all over the United States. My brother and I were fancy dancers, also called feather dancers and my father danced traditional style. We always had community around us, even though we were far from our own. I guess we became more Pan-Indian at that time.

With our constant moving around, I would inevitably lose my friends and later my girlfriends. I realized at a very young age that family was everything because everyone else was temporary. For me this was normalcy. Every three years or so, we uprooted and had to re-establish ourselves somewhere else. We always got to know the local powwows and the people. We were, in essence, transient community members who were always accepted into a new community. This is the Native way. If we were not out at a powwow, we were out in the bush camping, hunting, or just enjoying nature.

I remember being at a school where it was common for the head master and teachers to beat students. I was brought down to the principal's office every day by one teacher in particular and was beaten by the principal, who used a large board to hit me across my back or backside. I dreaded lunchtime because this is when it happened. I admit to acting out sometime early in the term by shooting spitballs with my straw. But, after a while of this, I didn't know why I was being beaten anymore. I was depressed and hated school and my parents never knew until I told them after months of this. It was my father who came to my rescue and basically threatened the head master to stop. I remember him saying "if you lay another finger on my child I will kill you". I guess his military uniform and threat scared him, and the beatings soon stopped. I didn't stay at 
that school long. I had no idea of the implications of those days on my own future and on others.

I also remember growing up on what we call the powwow trail as a fancy dancer. My brother and I made every part of our regalia and took pride in it. Every weekend we would lash down our tipi poles on top of our old '70s Dodge van, which had shag carpet on the walls and a bed in the back. The side doors had built-in disco lights that flashed to the sounds of music playing. There was a sticker on the back that said, "If this van is a-rockin', then don't come a-knockin'" and another that read, "Native pride". My parents often played different kinds of music from Abba to Johnny Cash. I never really liked country music, but this was our special family time, and we would soon be surrounded by friends and community. Our red Dodge van with its unique stickers and tipi poles certainly drew a lot of attention as we raced down the highways trying to make it for the opening procession on a Thursday or Friday night. At the powwows, we set up our tipi and got ready to dance. My brother always seemed to place in the competitive ranks and I didn't, but I was proud of him. He became a great dancer while I became more interested in the drum.

My brother and I received our first eagle feather in an honouring ceremony for our family. The ceremony took place in our own tipi, and several friends, chiefs, and prominent leaders participated. Sitting in the circle was Chief Dan George passing around the pipe. Today I still have that pipe and the eagle feather that I call the Chief Dan George feather. I think I was more interested in getting out of the hot tipi and playing with my friends, however, I do remember the ceremony fondly now. 
Then it all changed. The '70s were a time of social upheaval in many ways. Some say it was continued from the '60s, but it was a time to put into action all the aspirations of equality that the '60s had sought to bring to light. I remember these times with so much confusion as a youth. The Vietnam War came to an end. Racial riots were common in Georgia where I lived; the Atlanta child murders happened where twentyeight African-American children were killed by a serial killer and racial tensions were high. Women's rights were also in the news, and many people started to openly argue against equality. Gloria Steinem was on television advocating for equal pay for women. News stories on TV were about the long lineups for gas, and the politicians were saying it was due to an oil crisis. The Organization of the Petroleum Exporting Countries (OPEC) raised oil prices by $70 \%$ in retaliation for America's foreign aid to Israel. Later, the Stonewall riots took place to try to stop the blatant, open discrimination against the gay community.

I remember this time graphically thanks to the media, and also my own experiences. I was happy and carefree, but these were also my wonder years and soon to become a time of innocence lost. I remember seeing my first rape scene on television at age nine. I was paralyzed with fear and felt so uncomfortable I couldn't even talk about it. The radio and television were also spewing toxicity in the form of fear, in the wake of the Son of Sam and the Atlanta child murders. I knew people in the Ku Klux Klan and heard horror stories about what they would do on weekends but also how they were community members helping the community. I didn't know how to deal with these 
issues, and I didn't want to talk about them. I was, for the most part, blissfully happy in my ignorance.

My only escape seemed to be attending powwows and being in Native communities. But, that also changed. In the late '70s at one of the national powwows in Pensacola, Florida, I witnessed something that changed my family's life forever. There was talk that "they" would be there and to keep your nose clean. I didn't know who "they" were so I ignored it, but "they" turned out to be members of the American Indian Movement. At the same powwow I recall walking through the field where many tipis were set up and saying hello to everyone. One lady offered me some meat; it was boiled cow's tongue, a powwow favourite, but not one of mine. I heard two men arguing loudly, and it drew my attention. One was talking about how powwows were nothing more than a tourist show for white people. A fight broke out, and it was my first look at the divisiveness that politics would play in the Native rights movement.

Then life changed again. We were going to move back to Ottawa, Canada and the 80 's were starting. I had already lived in Ottawa, but I was extremely sad to leave Georgia. My father even thought about taking a job there in order to stay. However, we once again packed up kids, dogs, and our Dodge van to leave our home to become transient. I always felt excitement at the thought of a new home, school, and friends, but it was getting harder to leave the people I loved behind. Yet, the adventure of traveling to get there was also exhilarating. As it turned out, this trip would be different. It was going to be our last. 
In Ottawa we were like any other family. My brother and I went to high school and fit in well. My dad got another promotion and was now a major in the Armed Forces. He was honoured with many awards and became the head of procurement of Canada's foreign military sales. He joked that he was a legal version of Ollie North. My father was a man of high ethics and standards. Duty and honour were important to him, but nothing was more important than family. I think this is why we ended up staying in Ottawa for the remainder of his career, which ended up being fifty years of public service. Throughout his career he received many medals including the Queen's Golden Jubilee medal in 2002 and the Order of Military Merit in 1992 which is the highest military honour one can receive. He didn't want to move us again because it was getting harder on all of us. He was also reaching higher ranks, which would inevitably keep him in Ottawa.

We immediately got involved in the local Native community. We were happy to be back in Algonquin territory and felt like we were finally home. Dad worked all day but would volunteer his time at the local friendship centre. He became the treasurer. It was this unfortunate turn of events that officially ended our "Nativeness". Dad was accused of stealing money from the centre and was asked to alter the books. He refused and proved that the president had indeed stolen the money, showing his signature when removing the money from the bank. Even though he was not guilty, he was angry and left it all behind, never to speak of "those Indians" again. We were even told by the powwow committee that we could not dance and were asked to leave our tipi, regalia, 
and belongings at the powwow for display and go home because we didn't look Native enough - so much for community acceptance.

So we "whitewashed" our existence and never spoke of it for years. That was the norm then, to hide your heritage as much as you could. Fitting into mainstream Canadian society was considered better for you. I now know this as colonial assimilation. Even into my early university years, I hid.

It was not until I began in my master's degree in the mid 1990's at Carleton that I decided not to hide this part of my identity anymore. I met a remarkable young man who had beautiful, long black flowing hair and an uncanny pride in his Anishinabe heritage. His name was Gerald McMaster, and he did not hide his identity. For me, this was a turning point for both myself and another friend, Lee Grigas. We would not hide anymore. Gerald is a renowned artist and curator with a PhD and the Order of Canada. He is now a Tier 1 Canada Research Chair (CRC) in Indigenous Visual Culture \& Curatorial Practice at OCAD University (formerly the Ontario College of Art and Design). Lee went on to become a senior negotiator for Indian Affairs. It was still a difficult time for all of us, reforming and reimagining our identities in a time when it was easier to hide our heritage.

I am older now and have a family of my own. I met my beautiful wife Dacia while I was working for the Government of Canada. We fell in love and we have never looked back. We now have two beautiful children whom I love dearly, Cory and Robyn who see the world in ways we have all but forgotten. They make me feel young again and cause me to reflect on my own childhood and life in general. They are both proud of their 
Anishinabe heritage and we celebrate it every chance we can by attending powwows and ceremonies, traveling to communities and crafting. They don't have to hide, being Native is now even fashionable.

During the writing of this thesis, much in my own life has changed. I changed my career and started my own successful business. I ended up going back to school to get my Ph.D. Then my father passed away, and I am stuck with the overwhelming guilt and sadness that my children will not know this great man. He was able to hold them both as babies and loved them dearly. I can only keep him alive in stories. My wife and I lost a child. It was devastating to say the least, and I still wonder what that child would have been like. I guess that is why it took a little longer than planned for me to complete this thesis.

I have seen many changes since the time when people were made to feel ashamed of their Native identity. There is an increasing focus on urban Native people and even what I call the Native hipster, where it is "cool" or hip now to be First Nation or have any Indigenous heritage. Times have certainly changed.

I have also seen enormous changes in Native businesses over the years. Many businesses are now multimillion-dollar enterprises. Some have partnerships with large corporations or even international businesses.

I am reminded of the Anishinabe prophecy of the Seven Fires where eight prophets came to the people of Turtle Island and spoke of different time periods that will have an effect on the people. The last is the time of the Seventh Fire where new people will arise and find their way back to the Elders and the teachings. It is a time 
when all may join the journey to discovery of the old traditional ways. We are certainly close to the time of the Seventh Fire ${ }^{3}$ and one where Native pride will not only mean pride, but participation and prosperity based on traditional ways and values with everyone who is willing to respect the teachings.

I am now a firekeeper, knowledge holder, storyteller, flute player, professor, and family man. All of these elements of who I am and how I came to be influence my writing and situate me in this time and place. It is a reflection of those that came before me and those that will come after. We are the ancestors of tomorrow's children and have to act accordingly to a good way of living. In other words, we are already ancestors today. We may be ignorant of the future and language and ideas may change, but this is part of the cycle of life. This is my story and these are my thoughts based on my experiences, family, education, ideology, beliefs, and traditions. They situate me with all my relations.

\footnotetext{
${ }^{3}$ Grandfather William Commanda of Kitigan Zibi Anishinabeg held the Seven Fires Wampum Belt dating back to the 1400s. Within the Anishinabe Seven Fires prophecy, each fire represents an era in human history. Today we are in the Seventh Fire, which is a time for all people to come together in cooperation. If cooperation does not happen, then the eighth and final fire cannot be lit, and the Anishinabe people, along with others, will have no future.
} 


\section{Chapter One - General Introduction}

\subsection{Introduction}

One of the most important issues in Canada today is the colonial, neo-liberal body Politics' marginalization of Native people and the consequential cycle of Native dependency on the Settler state (Helin, 2009). Many Native communities are looking towards self-government as a way to exercise self-determination and overcome this cycle of poverty and dependency (Helin, 2009; Loxley, 2007). The Harvard Project on American Indian Economic Development ${ }^{4}$ indicates that self-government is the key to economic self-sufficiency (Cornell et. al., 2004). Native leaders are increasingly turning to self-government to promote economic development, entrepreneurial growth, and business partnerships to increase wealth and generate local economies in their communities (Nelson \& Sisco, 2008; Sisco \& Stewart, 2009; Loxley, 2010).

However, the Settler state's history of using colonial institutions to promote Native assimilation and genocide raises some important questions for consideration. To what extent does Native engagement in the capitalist economy necessarily promote assimilation? Can Native people engage in capitalism while maintaining their own cultural practices and traditional economies? Is the current Settler state's capitalist system compatible with the philosophical reality of Indigenous people? Or, are they

\footnotetext{
${ }^{4}$ In 1987, the Harvard Project on American Indian Economic Development was launched by Professors Stephen Cornell and Joseph P. Kalt at Harvard University. It aimed to "understand and foster the conditions under which sustained, self-determined, social, and economic development is achieved among American Indian nations through applied research and service" (Cornell and Kalt, 2010). It still is considered the benchmark of economic development for Native communities and nations.
} 
incommensurable, as suggested by several theorists (Barkin, 1988; Gibson-Graham, 2006; Wuttunee, 1987)?

This thesis investigates the role of economic development within Native communities in Canada and proposes a new governance model for economic engagement that creates an equal and complimentary model of governance that brings together European and Indigenous philosophies of economic development and community sustainability to create wealth and jobs in Native communities while maintaining and revitalizing their languages, cultures, and traditions. The aim of this research is to assist Native communities in Canada in becoming self-determining, healthy, and prosperous through the provision of this customizable community-based model.

This research sheds light on how approaches to governance for economic engagement in Native communities can be enhanced to better meet communities' needs. In this regard, it builds on the work of Indigenous and Settler ally scholars who call for Indigenous approaches to economic development as well as research that is respectful of Native values, including social responsibility to Native communities generally, and direct benefits to participating Native communities specifically (Tuhiwai Smith, 2001; Orr, 2013). Importantly, it contributes to growing Indigenous scholarship on Indigenous political economy and Native economic development. It also fills important gaps in the scholarship through introducing complex and varied concepts that debunk the false notion, which has dominated Native economic development literature, that Native people are anti-development. Specifically, it responds to Gibson-Graham 
(2006) and Helin's (2009) call for the deconstruction of the myth that Native people have not traditionally engaged in business, and Gerald Vizenor's (2008) call for 'survivance', which he defines as "an active sense of presence over absence, deracination, and oblivion" (Vizenor, 2008:1) To apply this to Native political economy is a movement from Native economic dependency on the Settler state to economic selfdetermination through strong alternative systems that are rooted in traditional ways. In this regard, it also contributes to a growing discourse (Abele, 2010; Barkin, 2005; Gibson, 2006; Graham, 1996; Harvey, 2011; Loxley, 2010) on the important role of alternative economies to challenge the dominant belief that all economic activities are just part of capitalism. Loxley (2007) also argues that development is "much more likely to be successful if it is rooted in the reality of, and is the product of, the conscious decisions of the community (pp. 6)".

Alternative economies have a role in the practices, approaches and strategies to strengthen, create or restore localized Indigenous economies, including those involving Indigenous interaction with capitalism. It is not just beyond rejecting a singular academic perspective on knowledge production, as a community-based project, this work also foregrounds the voices of Native communities through the use of storytelling. It adds to a growing literature of inspiring Native success stories that serve to counter the predominant, deficit-based development literature on Native issues in Canada.

The purpose of this chapter is to provide a general introduction to this thesis by discussing the background of the topic, as well as the thesis' purpose and contents. First, it provides the background and significance of the topic of a new governance 
model for Native community economic engagement that draws on Traditional Knowledge. Second, it provides a brief overview of the research design and methodology. Third, it situates this research within the broader discourse in the field by summarizing previous research and identifying the gaps in research. Fourth, it states the purpose and aims of the research, as well as the guiding research questions. Lastly, it briefly outlines each chapter in the thesis.

\subsection{Background}

Native peoples in Canada are commonly misrepresented as unilaterally antidevelopment and/or as passive victims of development. In reality, many Native communities are actively developing economic development plans and engaging in partnerships with external businesses and governments. Native people have been doing business for thousands of years (Helin, 2009; Nelson \& Sisco, 2008). I have heard this statement from many people over the years and have said it myself while teaching in the classroom and while presenting to communities or businesses to demonstrate that Native people can be business people. However, the current predominant Native cycle of dependency upon the Settler state in Canada can only be understood within the context of Canada's colonial history, which has served to marginalize Native peoples and communities and exclude us from economic development specifically (Helin, 2009).

Today there is an increasing acknowledgment that in pre-contact times, there was a thriving economy on Turtle Island (as North America is referred to by Anishinabe peoples) that included a sophisticated system of barter, exchange, and trade among 
diverse nations across the continent (Dickason \& McNab, 2009). One of the largest precontact cities in the world was Cahokia, located in 1250 A.D. along the Mississippi River near what is now St. Louis, Missouri. Cahokia was larger than London, England (Cahokia Mounds State Historic Site, 2008; Mann, 2005). This sophisticated society had "marked social ranking whose agricultural economies were characterized by a strong reliance on the cultivation of maize (Rasmussen, 2000:341)." Given this level of civilization, there was an established hierarchy, laws, and a form of justice system to provide the people with governance.

Large Mississippian settlements, such as Cahokia, Etowah, and Moundville, were dominated by the presence of massive, pyramidal mounds of earth that served as the bases for temples and residences of powerful individuals. (Rasmussen, 2000:341)

How could such a state exist and yet most people have never heard of it? The answer lies in the deliberate exclusion of a people's history, a people that have occupied this land for much longer than recorded history. The existence of these types of civilizations challenges the validity of the Doctrine of Discovery and Terra Nullius upon which the colonial metanarrative that was used to justify the colonization of this land was premised (Moreton-Robinson, 2011). Not only was the land inhabited, but a diverse network of hunters and gatherers, agriculturalists, and merchants inhabited it.

Colonization has included the Crown's imposition of identity and associated rights upon Indigenous peoples and exclusion of others. In Canada, this was exacted through the Indian Act of 1876, which sets out the criteria for who is considered a 'status Indian' as well as what rights this group enjoys. This act was designed to 
eventually eradicate all Native peoples by an assimilation policy that worked to exclude people from status or to provide incentives for enfranchisement in Settler society.

Examples of assimilative policies and practices include the Gradual Civilization

Act of 1857 which removed status from Native peoples who pursued higher education; earlier versions of the Indian Act, which prohibited the gathering of three or more Native people for ceremonies and implemented a 'pass system' that prohibited outsiders from conducting business with Native people on reserve; and the residential schools ${ }^{5}$ and Sixties Scoop, ${ }^{6}$ which were designed to 'whitewash' Native children through removing them from their families and communities and placing them in schools and with white families, respectively (Aboriginal Affairs and Northern Development, 1996; Budgell, 1999; Cassidy, 2006; Government of Canada, 1996; Graham, 2013; Popic, 2007). These policies served to target the heart and spirit of Native communities with a focus on children and ceremony, and to exclude Native peoples from education and business ownership through threatened or actual removal of status.

\footnotetext{
${ }^{5}$ In Canada, churches created missionary schools in the 1600 s designed to assimilate Indigenous children into 'white' society by removing them from their families, communities, language, and culture. The federal government popularized these schools in the late 1800 s when they began to partner with churches to run them, and assumed authority over them in 1969. The government focused on First Nations with status under the Indian Act (referred to as Status Indians), but non-status First Nations, Inuit, and Métis children were also affected. The last Canadian residential school was closed in 1996 (Aboriginal Affairs and Northern Development Canada, n.d.a; Cassidy, 2006; Popic, 2007).

${ }^{6}$ The Sixties Scoop refers to the systematic apprehension of Aboriginal children from their families and communities and placement for adoption in primarily non-Aboriginal households in the 1960s (and ongoing today) by social workers lacking the historical and cultural contextual knowledge to adequately assess a child's well-being (Budgell, 1999; Government of Canada, 1996; Graham, 2013).
} 
This long history of colonial control over 'Nativeness' has led to the development of political factions - of status and non-status as well as on and off reserve -within Native communities. The resulting division and conflict among these Native factions has made controlling and oppressing the population easier. According to the teachings I have received, prior to European contact, Native peoples were great adopters who took anyone into their communities; as long as one respected the culture and learned the ways, they were given full citizenship. This was the way of Hunkapi, or making of relatives, among the Lakota's seven sacred ceremonies. Becoming a family member by adoption through the Hunkapi ceremony brings everyone together by relations and the individual is considered Lakota from that moment on (Black Elk and Brown: 1989). Today band membership takes on new meaning in terms of political economy; a monetary value is attributed to every band member and status card, making bands more particular in whom they consider community members. Each new member means a smaller piece of the pie to go around. In this regard, blood quantum or other colonial prejudicial and discriminatory practices have fractured communities.

However, Native communities across Canada are increasingly demonstrating resilience in their ability to overcome colonial oppression and draw on traditional approaches to governance that result in localized economic development. While these success stories are often overshadowed by deficit-based development rhetoric in Native discourse, sharing them stands to profoundly change both the common perception and reality of Native Canada (Nelson \& Sisco, 2008; Sisco \& Stewart, 2009). 


\subsection{Approach and conceptual framework}

The approach to writing this thesis combines intersectionality and critical Indigenous philosophy with macro methods that allow for localized inquiry more appropriate to Indigenous context, including Grounded/Critical Theory, Participatory Action Research (PAR), and Community-Based Partnership Research (CBPR). It is drawn from lessons learned from the work being done today within Indigenous communities to create economic development (Anderson, 1999; Barkin, 2005; Burrows, 2005; Cornell, 2007; Cornell and Kalt, 2003:2010; Shanks, 2005; Wuttunee: 1987, 2004; Nelson, 2010) as well as both classic political economy theory (Malinowski, 1920; Polanyi, 1957; Rostow, 1960; Rousseau, 1762; Schumpeter, 1934; Smith, 1759, 1776) and modern political economic thought (Albert and Hahnel, 1991; Clement, 1997; Gibson-Graham, 2006; Rosser: 2005).

I use the birch bark basket as a specific conceptual framework for this research. I developed this framework through a teaching I received from Oji-Cree Elder Percy Rae. As illustrated in Figure 1, the basket combines traditional and Western governance knowledge to enhance Native governance and allow Native people to simultaneously engage in capitalism and alternative markets while maintaining their traditional values. 


\section{Combining Western knowledge with Indigenous traditional Knowledge}

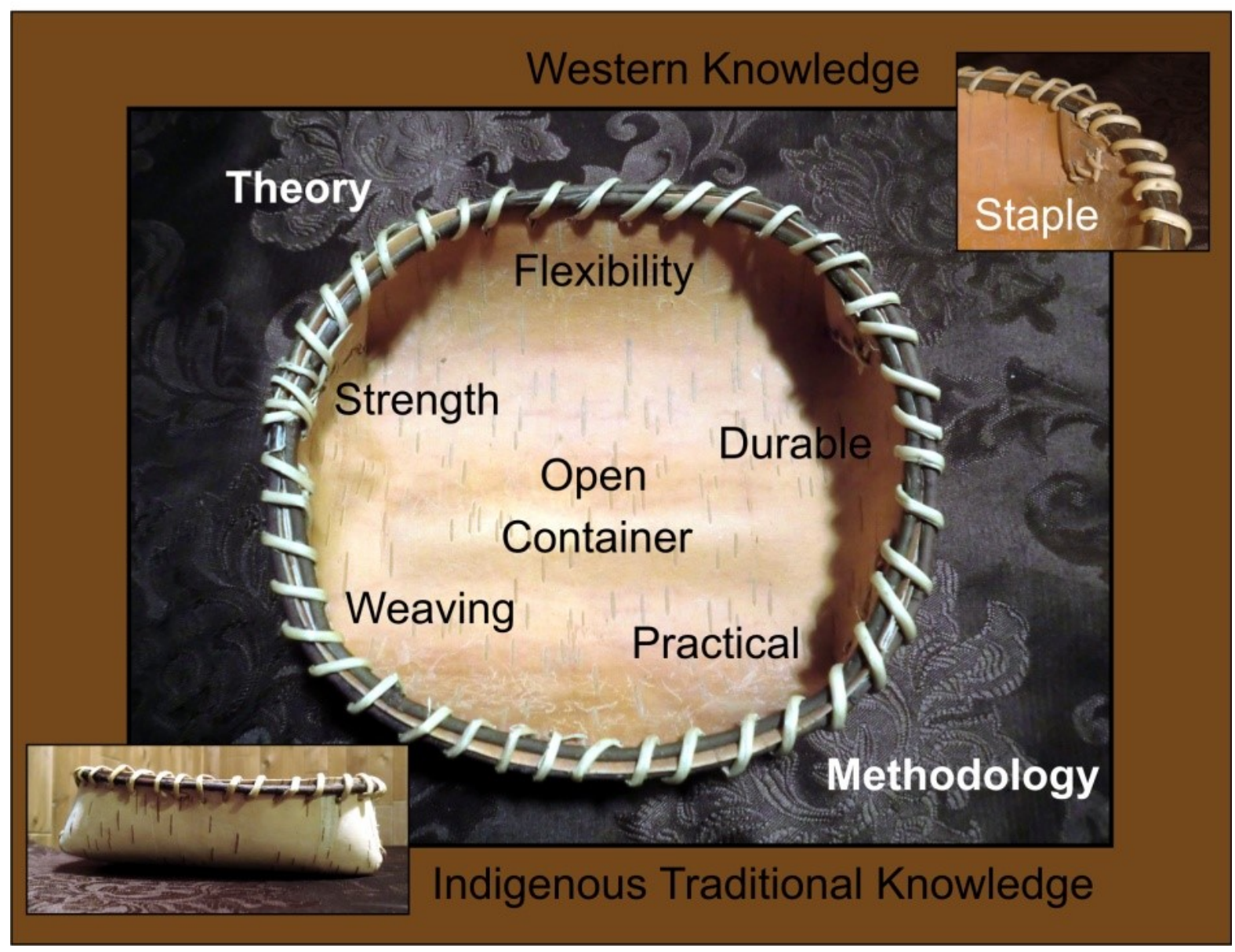

Figure 1 Traditional Birch Bark Basket Framework.

Source: Oji-Cree traditional teaching and framework developed by Percy Rae and Rodney Nelson.

\subsection{Research design and methodology}

Consistent with my approach and conceptual framework, this thesis'

methodology reflects both my traditional cultural lens and a rigorous academic

approach. The underlying methodological approach to this thesis respects Indigenous

epistemology (Barkin, 2005; Battiste, 2002; Wilson, 2008; Wuttunee, 1987). This implies 
a holistic and relational approach to the world we all live in and with which we have an ongoing relationship (Tuhiwai Smith, 2001; Wilson, 2008). This approach is an extension of my worldview as an Anishinabe person, and the perspectives of many of the Native peoples and communities who participated in this project.

\subsection{Criteria for choosing case studies}

The methodology used a narrative inquiry approach that includes case studies, past experiences working in community development, interviews, surveys, and ongoing correspondence. A case study approach was used as a means to collect rich, qualitative data through narrative (Creswell, 2003), consistent with PAR and Indigenous research approaches.

Three diverse, sustainable, profitable, and socially responsible businesses/communities were selected as case studies, based on existing relationships and purposeful sampling (Patton, 2002).

Three prominent Aboriginal businesses including band owned enterprises were chosen. Each has had its own challenges but also successes in creating wealth, jobs and business development within its nation. The three chosen cases are based on different corporate models: a band owned enterprise, a private company and a band owned enterprise partnered with an external corporation. This shows not only the diversity in business practices but also gives unique perspectives on adaptive governance practices. Each case study also has publicly stated that traditional knowledge is an important 
influence on how they conduct their business. My criteria for choosing these case studies is as follows:

1) The business has to be owned or partially owned by a First Nations individual or band. I am not using the Aboriginal Affairs and Northern Development Canada (AANDC) model of determining Aboriginal quantum in a business but rather recognition by the community(s) and/or national Aboriginal organizations.

2) The business has to have an element of corporate social responsibility, and has been recognized by the community(s) and/or national Aboriginal organizations as effective in economic development.

3) The business has been recognized as a leader in economic development by a national Aboriginal organization such as: AFOA (formerly the Aboriginal Financial Officers Association), Council for the Advancement of Native Development Officers (CANDO) and the Canadian Council for Aboriginal Business (CCAB) and their Progressive Aboriginal Relations certification (PAR)

The three businesses chosen as case studies are:

1) Community Case: Goodfish Lake Development Corporation, Whitefish Lake First Nation, Alberta 
Goodfish Lake Development Corporation is a band owned enterprise that maintains a large dry-cleaning business within the area of the Alberta oil sands. They have been recognized as leaders in environmental sustainability by attaining Environmental ISO 14001-2004 standards. They have been recognized by CANDO and CCAB as outstanding businesses.

\section{2) Corporate Case: First Peoples Group, Ottawa, Ontario}

First Peoples Group is recognized by CCAB for service excellence. It is a group of Aboriginal consultants who offer a variety of services including Aboriginal awareness training. They have varied mixed heritage backgrounds, including Mohawk, Ojibway, Saulteaux, Sto:lo and Métis. Their governance structure is based on common practices but they also draw on their cultural backgrounds to ground themselves in traditions. They have been recognized by the AFOA and CCAB as a successful Aboriginal business.

\section{3) Combined Partnership Case: St Eugene Golf and Resort, Ktunaxa-Kinbasket Partnership Strategy, Cranbrook BC}

Ktunaxa-Kinbasket converted their residential school into a 5-star golf resort. Today in partnership with SEM Resort Limited Partnership the St. Eugene Golf Resort \& Casino has won many awards and provides economic and employment benefits for the community. St. Eugene has won many awards and been honoured by the AFOA, CANDO and $C C A B$ as a successful Aboriginal business. 
All of these businesses have stated publicly that they have drawn upon

traditional knowledge and teachings to formulate their business strategies. These case studies will provide examples of how they applied their traditional knowledge, why they applied it to their business and if they attribute it to their success. While all of these cases are based on partnership development, each offers unique insights into differing levels of partnership agreements. While this is a small sample for case studies, the research is more about the story of business development rather than overall statistical analysis of profits and investments.

\subsection{Interviews}

Research participants with experience and knowledge of Aboriginal economic development, business development, and government generally, and/or of the featured businesses specifically, were also selected for interviews based on existing relationships and purposeful sampling (Patton, 2002), including:

1. Native elders,

2. Native business owners and entrepreneurs,

3. Native leadership, including chiefs and councilors and grand chiefs,

4. Native business leaders, including presidents and CEOs of Native businesses,

5. Aboriginal economic development officers, including directors and managers of community economic and business development,

6. Government, corporate, and Crown corporation Aboriginal relations officers,

7. Native and non-Native lawyers involved in Aboriginal law relevant to governance and economic development, and

8. Academics with expertise in Native economic and business development. 
Interviews with businesses/communities were conducted via phone, in person, and email, as well as ongoing communications and relationships.

Consistent with the relational approach to this research, specific methods included interviews and research conversations with a total of seventy-five research participants and storytelling as a means to convey the success stories drawn from community/business interviews and research conversations. I analysed the data collected from interviews using thematic content analysis to systematically generate key themes and commonalities in the rich data generated from this research, and narrative methodology to co-construct narratives with participants (Creswell, 2003).

It is important to note that all of the research material is public knowledge and is either published or available online. The interviews were open-ended conversations around the key concepts of this research. Many of these conversations were with elders who have passed on yet their stories have been shared through storytelling. Secondary sources make up the bulk of the material used to review the historical facts and figures and revealed the colonial history and the impacts on development.

\subsection{Literature review}

Overall, there is a wealth of literature on political economy which pertains to Indigenous economic development that stems mainly from two streams: 1) the individualist, liberal-capitalist, and political economy philosophies of John Locke and Adam Smith (1759), and 2) more communal critical Marxist theory (1909), which 
critiques liberal and neo-liberal capitalism and provides a foundation for scholarship on alternative economic systems.

Canada's current economy can be characterized as capitalist. It is founded on neo-liberal ideologies that represent a continuation of Locke and Smith's philosophies, which promote the privatization of land and commodification of its resources for profit to the benefit of the minority upper class, with a state-administered social welfare system in place to support the majority working class (Marx, 1909; Smith, 1759). As a result, Canada's current economy reflects a modern interpretation of the feudal system upon which it is based, with the Industrial Revolution transforming landholders into the owners of the factories and means of production (Marx, 1909; Schumpeter, 1943). Smith's (1759) sentiment that oppression is a necessity to perpetuating this system and, therefore, the more fortunate should not feel a moral obligation toward the lesser fortunate, has led to the marginalization of the less fortunate and those considered outside of the system. Both Smith (1759) and Engels (1956) warn that greed and capitalism will abandon human values in the pursuit of profit. This is apparent in the neo-liberal view that public services and state welfare are a state burden rather than a necessary function of the capitalist economy to ensuring state welfare.

Together with Indigenous political economy - the study of production and distribution within Indigenous communities from a worldview and value system that seeks to protect one's resources for future generations-Marxist critiques of liberal capitalism create a space for scholarship on alternative economies, many of which are more suited to Indigenous realities and perspectives. There are three main critiques of 
modern capitalism. First, corporate political protectionism, in which governments are becoming more involved in regulating markets and controlling corporations, interferes with both the free market and the state's role in providing welfare for the less fortunate (Bhagwati, 2000; Busch, Krzysztof, 2014; Dimon, 2009; Farazmand, 1996; Stevens, 1993; Osborne and Gaebler, 1992; Schumpeter, 1947; Shull, 2010;). Second, the business philosophy of perpetual growth as a business model for capital accumulation is unsustainable (Gladwin, Kennelly, Krause and Kennelly, 1995; Streimikiene \& Girdzijauskas, 2008). Third, capitalism is treated as the apex of economic systems and the hegemony of capitalism subverts and marginalizes alternative economies. ${ }^{7}$ As a result, the local economies of many Indigenous communities are dismissed and unsupported (Mandler, 2006).

Nevertheless, much scholarship (Graham, 1996; Barkin, 2005; Gibson, 2006, Abele, 2010; Harvey, 2011) is focused on the importance of restoring alternative economies within Indigenous communities that will embrace socially just, egalitarian, and fair methods of wealth, goods, and services redistribution (Abele, 2010) to address food security, environmental, health, and social concerns (Gosh, 2011).

Carl Polanyi's Solidarity economy is an alternative economy grounded in resistance to capitalist oppression through the convergence of class and wage discrepancies and valuing of the third social sector as a means to achieve community

\footnotetext{
${ }^{7}$ Alternative economies are those that fall outside what is considered capitalist economic activities (e.g. cooperatives, non-monetary currency, fair trade, ethical investment, credit unions, trade and barter, cultural production, and other 'social economies' or 'third sectors') (Albert, 1991; Barkin, 2005; Daya \& Arthar, 2012; Gibson-Graham, 2006; Hillebrand \& Zademach, 2013; Loxley, 2010; Ratha, 2000)
} 
social well-being and sustainability (Albert, 2007; Deb, 2009; Escobar, 2003; GibsonGraham 2006; Hart, et al. 2010). Barkin (1998) argues that alternative economies exist that incorporate social and ethical considerations surrounding interactions and resources. Moreover, he asserts that localized Indigenous economies can promote community sustainability and well-being through the production of goods and services, while maintaining environmental stewardship (Barkin, 1998). While this sometimes calls for resistance to the capitalist state, the Canadian Senate Committee on Aboriginal People states that, "Most communities want to benefit from economic development. However, they want to do so on 'their own terms'" (2007, p. 4).

Anishinabe scholar Gerald Vizenor (2008) introduced the concept of cultural 'survivance', which is both resistance and survival of cultural practices. Expanding on this idea, economic survivance in Native communities is about resistance and survival within a dependency cycle that seeks to gain self-reliance through strong, alternative economies rooted in traditional ways. While Indigenous peoples certainly participate in both traditional subsistence economies and the capitalist economy (Altman, 2009), they remain marginalized within this system. The Harvard Project on American Indian Economic Development indicates that self-government is the key to economic selfsufficiency (Cornell et. al., 2004), and Gibson-Graham (2006) calls for the construction of alternative economies to strengthen Indigenous resistance to and interaction with capitalism.

However, the traditional economies of Native communities are often subverted and marginalized. These economies are complex systems concerned with the 
perpetuation of cultural traditions and community well-being and that involve subsistence and other non-monetary forms of wealth; equality, democracy, cooperation, reciprocity, and wealth redistribution; and householding (kinship goods or service production and bartering); and environmental stewardship and shared wellbeing (Kawano \& Millar, 2008; Polanyi, 1944). Moreover, scholars (Rosser \& Rosser; 1998; 2005) are also acknowledging the emergence of 'new traditional economies' that use modern technology while respecting and preserving traditional social practices. Indigenous New Traditionalism looks at economic behaviour rooted in Indigenous cultural traditions, which strives for sustainable community well-being over perpetual growth (Rosser \& Rosser; 1998; 2005).

In close connection with political economy literature, development theory literature has also been highly influential to scholarship on Indigenous economic development. While development scholarship is diverse, there has been a general rise of neo-liberal strategies surrounding globalization and the economic realities of a global economy since the decline of post-World War II Keynesian ${ }^{8}$ economic development (Carino, 2009; De Angelis, 1988; Harvey, 2010). Neo-liberal development theory reduces governance to management of capital gains and profits and development to a modern economic tool for exploiting productivity or natural resources.

Neo-liberal development theory tends to marginalize Indigenous traditional economies. For example, influential early liberal theorist Walt Whitman Rostow (1960)

\footnotetext{
${ }^{8}$ Keynesian economics is a theory of total spending in the economy (called aggregate demand) and its effects on output and inflation (Blinder, 2008).
} 
takes a Social Darwinist approach to development, categorizing subsistence economies, commonplace to Indigenous communities, as the most 'underdeveloped' in comparison to the industrialized economies of mass consumption as the apex of development. Other influential theories such as the Harrod-Domar Model (Harrod, 1939; Domar, 1946), which showed a correlation between labour and investment and Schumpeter's (1934) work on the technological and business 'boom and bust' cycles of economies overlook issues of systemic poverty and structural capacity.

The emergence of Dependency Theory introduced the importance of governance to economic dependence. Economists Raul Prebisch and Hans Singer pointed to the absence of certain governance structures as perpetuating dependency (Ardeni \& Wrigth, 1992). This early dependency theory evolved into Wallerstein's World Systems Theory, which divides countries into core economies that manufacture and consume goods and periphery economies that provide resources and cheap labour to support core economies. However, World Systems Theory fails to account for the role of Native communities, which are neither core nor periphery.

Liberal and neo-liberal theories most influential to modern economic development thought have been largely inappropriate for Indigenous political economy and rejected due to their unsuccessful implementation in various forms (De Angelis, 1998; Harvey, 2010; Teubal, 2004; Thomas, 2007). However, modern development theory provides some insights more useful for Indigenous contexts. For example, modern economic development theorists such as Abhijit Banerjee (2012) and Amartya Sen (1999) argue for an approach that deals with the economic facets of the 
development process in low-income areas, not simply as a unified country. They suggest not only focusing on promoting economic development, economic growth, and structural change, but also on improving social conditions such as health care, education, and workplace conditions to drive the developmental desire.

Moreover, Max-Neef $(1986,1992)$ argues that current economic approaches objectify people, marginalize 'invisibles' that fall outside of the capitalist system, and lack understanding of those who suffer. Max-Neef $(1986,1992)$ argues against capitalist notions of perpetual growth in favour of recognition that the economy depends on the eco-system on which it is based, and therefore, economic thought needs to shift from a focus on perpetual growth to the reverence for life above all economic interests. Sen (1999) argues for greater consideration of social and economic determinants in the calculation of economic outputs; Sachs (2005) argues that poor countries are stuck in poverty and dependency traps; and Helin (2008) argues that First Nations ${ }^{9}$ in Canada share in this situation. Specific barriers to economic development that contribute to this cycle of First Nations poverty and dependency on the Settler state include lower education and income levels, as well as lower-level employment opportunities (Usher, 2009; Wilson, 2010a). Loxley (2010) argues, "The marginalization of Aboriginal communities that accompanied Canadian economic development in general...provides the rationale for many community [economic development] initiatives" (p. 21).

\footnotetext{
${ }^{9}$ This is also true for Inuit and Metis who share similar dependency traps. Helin writes from a Tsimshian perspective as a First Nation.
} 
Importantly, 'development', including economic development (a sustained community effort to improve both the local economy and the quality of life by building the area's capacity to adapt to economic change (Loveridge, 1991) and community economic development (economic development involving community participation in its social welfare, economic activities, and in the development of its locality (Fontan, 1993; Shipley and Snyder, 2013; Shragge, 1997), carries both positive and negative connotations for Native communities in Canada. On one hand, community economic development can create opportunities for jobs, wealth, and greater well-being in communities, including through revitalization of language and culture (Anderson, 1999; Asch, 1982; Cornell, 2010; Orr, 2013). On the other, development has a history of forced relocations, segregation, a welfare economy, a lack of competitiveness within global markets, and the imperative of resource exploitation and environmental degradation for profit, all of which have contributed to the cycle of poverty and dependency of many Native communities (Kirmayer, et al., 2007; Loxley, 2010). Development efforts have actually been shown to increase poverty around the world, especially among Indigenous peoples (United Nations Development Project, 2011; World Bank, 2010) because aid efforts fail to account for the need for self-governance. Indeed, many Native peoples are interested in improving their socio-economic situations through community economic development, including through business development, but understand that this requires meaningful control of their own lives, lands, and development (Anderson, 1999; Loxley, 2010). 
Canada as a nation-state was built upon trade relationships and military alliances between European Settlers and Native peoples (Dickason, 2006; Furniss, 2002; Keyser \& Klassen, 2001). However, as Europeans became more settled and self-sufficient in Canada, and the pressure increased to accommodate newcomers from Europe (Rich, 1960), their relationships with Native peoples shifted from one of peace and friendship treaty-making to oppression and dispossession of land, resources, children, languages, and cultures (Donovan, 2008 \& Havemann, 1999 as cited by Sisco, 2015). Native peoples were segregated on reserve lands, and through legislation creating an inequality within the social fabric of Canada (Bannerji, 1996). This systematically excluded Native people from participation in the market economy.

Today, some of these legislative barriers have been removed, and many Native communities are developing successful Aboriginal businesses. Indeed, Heathrington (1972, pp. 14-15) argues, "To people who have been denied access to economic opportunity, ownership of a business is a symbol of personal emancipation" (as cited by Loxley, 2010, p. 31). In 2001, the last year the Aboriginal business survey was administered, more than 27,195 Native peoples were self-employed, an increase of 30.7\% since 1996 (Statistics Canada, 2002), and this figure is projected to increase dramatically commensurate with the rapid growth of the Native population (Frost, 2007). However, compared with their non-Native counterparts these businesses continue to face unique challenges that can inhibit their competitiveness, including limited access to capital for business loans, capacity challenges, small community size, 
remoteness of location and limited access to resources, and discrimination (Nelson \& Sisco, 2008; Sisco \& Stewart, 2009).

One strategy that is helping many Native businesses to succeed in Canada is partnering with firms that can assist in providing capital, capacity building, access to resources and the market, and strong branding and marketing strategies (Nelson \& Sisco, 2008; Sisco \& Stewart, 2009). Many businesses are looking to partner with Native communities as a means to access resources (Nelson \& Sisco, 2008; Sisco \& Stewart, 2009), and as a measure of corporate social responsibility (CSR) (Gasse \& Bhererl, 1990; Sankar \& Bhattacharya, 2001), which can be helpful to corporate branding and compliance with legal obligations (Anderson; 1989; Beesley, 1978). Moreover, partnerships are emerging as a result of Canada's legal Duty to Consult and Accommodate Native communities when the government contemplates actions that could potentially infringe on an Aboriginal right to title (Department of Aboriginal Affairs and Northern Development Canada, 2011; Edmond, 2007; Mullan, 2008; Newman, 2009a as cited by Sisco, 2015, p. 38). Partnership agreements often include shared ownership, revenue sharing, and/or measures of procurement for local Native businesses, and employment of local Native people (Chiste, 1996; Anderson, 1999). However, only a small minority of Native businesses partner in this regard $(10 \%$ on reserve; $19 \%$ off reserve) (Aboriginal Business Canada, 2005), and the especially low percentage of Native business partnerships on reserve is disconcerting because such partnerships stand to create jobs and wealth in communities (Nelson \& Sisco, 2008; Sisco \& Stewart, 2009). Moreover, corporate partnerships are often fraught with 
inequities around many of the associated benefits for Native partners (Lockhart, A. and D. McCaskill, 1986; Ivison and Patton, 2002; Behrendt \& Kelly, 2008). Lastly, the juxtaposition of Native and neo-liberal capitalist values often makes business partnerships and participation within the capitalist market challenging for Native businesses. Specifically, the European cultural values of individualism, capitalism, and the commodification and commercialization of land clash with Native values of collectivism, land custodianship, balance, and reciprocity (Sisco, 2015). As a result, Native businesses are often concerned with community sustainability and well-being more than bottom-line profitability (Halfe, Personal Communications, 2008; Redsky, personal communications, 2011).

Another strategy Native communities are embracing to promote economic development is skills based capacity building or simply capacity building. However, Canada's residential school history raises concern about the use of education as a tool to assimilate Native children (Haig Brown, 1998; Milloy, 1997, 1999; Ward, 2004). Educational institutions are often viewed as hostile environments and are not trusted in communities given this long history of abuse and assimilation. There is little wonder why there is suspicion of education.

While many Native youths still have to leave their communities to pursue education (AFN \& AUCC, 2014b), education reform in Canada has finally led to the implementation of curricula that are more culturally relevant to Native peoples (BentonBanai; 2004). Native knowledge and practices can offer a strong foundation for socially responsible investments, entrepreneurship and business partnerships (Nelson, 2010). 
Moreover, Canada's track record of imposing outside development without building community capacity to engage in efforts raises concern about development being used to exploit communities and promote development that is not sustainable.

What is needed to promote economic development that is in keeping with Native traditional values is a community control model of economic development that promotes self-determination over the process. This model must include capacity building, equal revenue sharing, partnerships, and community control. This may also include limited economic encroachment or community-controlled economic development, which allows communities to adjust to change and provides them with a more rigid control of land use and environmental impacts (Campbell, 1999)

\subsection{Purpose and aims of research}

The purpose of this research is to understand how Native businesses can incorporate traditional knowledge into their governance practices. The aim of this model is to assist Native communities in becoming self-determining, healthy, and prosperous. Therefore, the primary research question guiding this research is as follows;

- How can traditional knowledge be incorporated into a governance model for Native businesses or local government?

The secondary aim of this research is to answer the following questions;

- Is Traditional Knowledge applicable in today's businesses and if so what would that look like? 
- Can communities benefit from a combined model of traditional and western governance practices?

Thirdly, the findings of this thesis have to be born out of a need within communities. The findings represent applied work and have to have practical applications for communities. It also showcases positive role models and stories of those that are leading the way.

\subsubsection{Chapter outlines}

This thesis is broken down into nine chapters, including this one. Chapter TwoResearch Design and Methodology discusses the specific research design and methodology used for this research. This includes interactionality and political economy as influential theories, the macro methodology of participatory action research (PAR) and Indigenous approaches to research, grounded theory as a means to foreground Native voices, and the birchbark basket as a traditional conceptual framework. It also discusses the overarching strength-based case study methodology and specific community interview and conversation methods, as well as the importance of storytelling and the use of narrative inquiry for data analysis.

Chapters Three through Six position this thesis within classic and modern political economy, critical Indigenous philosophy, and Native economic development discourses. Specifically, Chapters Three, Four, Five, and Six focus on rethinking the hegemony of capitalism, economic development and Native peoples, partnerships and 
economic development, and opportunity through economic development and education for Native peoples, respectively.

Chapter Seven-Case Studies includes case studies of successful Native-owned businesses that have embraced governance models that draw on traditional knowledge. These rich narratives are co-constructed with participating communities.

Chapter Eight-Towards a New Native Business Governance Model draws together the findings from the case studies and interviews to develop a model for Native governance that draws on both best business practices and traditional knowledge.

Chapter Nine-Conclusion summarizes the research findings and provides recommendations for future research and actions, including implementation. 


\section{Chapter Two - Research Design and Methodology}

\subsection{General Introduction}

Selecting an appropriate research design and methodology was critical to my research process, as research has a dangerous history of colonizing Indigenous perspectives (Tuhiwai Smith, 2001). At the same time, there is merit in drawing from existing research approaches and methodologies for this study. Importantly, the research must be framed and implemented in a way consistent with and conducive to respectful research with Native communities. Therefore, I have drawn from theories, philosophies, macro-methodologies, and methodologies that can be decolonizing and articulate Indigenous perspectives within a conceptual framework that creates an overarching approach to working respectfully with Native communities and participants. First, this chapter discusses the role of intersectionality and political economy in shaping my approach; the use of Participatory Action Research (PAR), Community Based Participatory Research (CBPR), and an Indigenous approach as a macro-methodology; and the use of grounded theory in this research. Second, it discusses how I wove these elements together into the birch bark basket as a conceptual framework. Third, it outlines the research procedure I used for this project, including the specific methods for data collection and analysis. Fourth, it outlines the number and type of case study business/community participants, as well as the selection criteria and recruitment methods used for their selection. Lastly, it concludes with a summary of the chapter. 


\subsection{Intersectionality and political economy}

The nature of this research is interdisciplinary in that it draws from several disciplines such as anthropology, sociology, business, and political economy. It is also interdisciplinary in expanding the traditional concepts of social science academic enquiry by including traditional forms of Indigenous knowledge and learning (Wilson, 2008; Tuhiwai Smith, 2001, Kovach, 2009). For Indigenous scholars there is high value in bias towards relational epistemology (Tuhiwai Smith, 2001; Wilson, 2008). Indigenous epistemology moves away from traditional academic coding and categorizations (Kovach, 2009:55), and grounds itself in understanding the relationships between people, knowledge, language, the environment, and spirituality (Tuhiwai Smith, 2001; Wilson, 2008).

The dynamics of these relationships serve as a guide to researching with Native communities. Gone are the days of academic posturing and imposing Western theoretical frameworks that can be colonizing on Native peoples and communities. Research is now moving towards a holistic and relational approach of applied research to help support communities in achieving their goals. Relational research can be found in several theoretical and methodological positions such as intersectionality (Crenshaw, 1991; Collins, 2000; Daly, 1996; Davis; 2008; Harding, S. \& Norberg, 2005), participatory action research or PAR (Lewin, 1997; Selener, 1997; Zuber-Skerritt, 1996; Argyris and Schon, 1989; Boston and Jordan, 1997) and Grounded/Critical Theory (Charmaz, 2003; 2005; 2006; Glaser \& Strauss, 1967; Strauss, 1978; Kovach, 2011). 
Intersectionality is born out of feminist theory to deconstruct oppressive identities through the relationship of categorization. For Indigenous people, there is no greater problem than that of constructed identities by colonial institutions. Canada legislated culture, and places Native people into categories not consistent with their traditions, self-identity, or relationships with lands or other people. By taking an approach of deconstructing categories and, in a sense, deconstructing theory, we are able to understand Indigenous methodologies, epistemologies, and pedagogy. Wilson (2008) describes doing research as life-changing, and if it doesn't change one's life, then you have done it wrong. Wilson's concept of life-changing is tied to the relationships formed during research. One cannot simply divorce oneself from a community and the people within it without leaving some sort of impression. Deeper structures of relationships are also formed in understanding how we think and perceive the world around us.

There is also a growing body of research that is grounded in anti-oppressive and colonial resistance approaches to social science research (Brown, Strega, 2005; Barkin, 1998). The subaltern voices are now given space to tell their stories from their own perspectives. It is not just about survival but also of resistance to the powers that oppress a population. Gerald Vizenor (2008) calls this survivance a form of survival and resistance combined to give voice and continuation of cultural expression. From a political economic point of view, the ongoing struggle against hegemony for Native people in Canada is one of survival, resistance, and engagement. Native people are no 
longer willing to be passive recipients of economic suppression through legislation and bureaucratic dogma.

Gibson-Graham (2006) and Helin (2009) highlight the need to create a new space for dialogue amongst Native people to deconstruct the mythology that Native people have not traditionally engaged in business. As Calvin Helin constantly reminds anyone who will listen, "We have been doing business for thousands of years" (2010). While this is true, Native people have been left out of mainstream economic advantages and markets. There needs to be an open dialogue that is community-focused on how Native people can engage in the global economy on their own terms. Indigenous people have the right to engage in a capitalist economy if they choose to. Yet, there needs to be an adaptation of governance structures while maintaining traditional values and teachings.

\subsection{PAR, CBPR, and an Indigenous approach as macro methodology}

This thesis is based on the ongoing post-colonial dialogue that deconstructs the impact of the legacy of colonialism for Indigenous people ${ }^{10}$. In this case, 'post' is the academic term to describe a theoretical position moving away from the common dialogue found in colonialism as written about and described by the colonizers. This post-colonial position calls for Indigenous voices to be heard. Borrowing from Edward Said's seminal theory of subalternism (1978), there is a need for the voice of those silenced during colonization to be added to the dialogue. Said (1978) borrows from Gramsci's concept of subaltern as a person or a group politically and socially outside the

\footnotetext{
${ }^{10}$ The concept of post-colonialism is problematic due to the ongoing state of colonialism and the differing stages of colonialism that cultures are experiencing.
} 
hegemonic power structure of the state. Said calls this group "the other" (1978) and calls for the subversion of this marginalization through the foregrounding of these marginalized voices.

This research is part of the post-colonial discussions (Bhaba, 1994; Loomba, 1998 \& Razack, 1998; Spivak, 1985, 1990) that foreground Indigenous critiques of Western ways of knowing and the misrepresentations of the subaltern. For Indigenous scholars, post-colonialism is an opportunity to deconstruct colonialism and reintroduce Indigeneity into academic inquiry and the historical understanding of those involved. As Paulo Friere (2007) states,

great humanistic and historical task of the oppressed: to liberate themselves and their oppressors as well. The oppressors, who oppress, exploit, and rape by virtue of their power; cannot find in this power the strength to liberate either the oppressed or themselves. Only power that springs from the weakness of the oppressed will be sufficiently strong too free both.

The oppressed need to use education as a tool of change and not oppression. Education offers a voice to the subaltern and gives rise to resistance to total colonization. From a theoretical perspective, post-colonial dialogue must give voice to those that have been oppressed and challenge Western misconceptions.

Drawing from Freire's work, Haudenosaunee scholar Dale Turner (2006) developed Critical Indigenous Philosophy as a means to redefine the power relation with the Settler state by using academic and pseudo-academic realms to reassert the rights and interests of the communities. Specifically, Turner (2006), states that this involves recognizing colonization and decolonizing, protecting Indigeneity and 
Indigenizing institutions, and effectively engaging the state through legal and political means. This research is a part of that ongoing dialogue of an incomplete colonial process.

The thesis also draws on "macro methods" as overarching approaches, which, according to Sisco (2015), "provide an informal, contextual, and dynamic approach to applying methods to localized derivative knowledge gathering" (p. 104). These include: 1) Participatory Action Research (PAR), and 2) Grounded/Critical Theory. PAR originated in the 1940s in the writing of Kurt Lewin (1997). Lewin took the Gestalt theory of psychology and applied it to practical social science research. Researchers often see the whole before they see the parts as early Gestalt theory suggests (Koffka, 1935; Kohler, 1947; Wertheimer, 1938). PAR became more readily used in the 1960s with the formation of the International Participatory Research Network in 1976, as a mode of enquiry-based knowledge that validates academic rigor with on-the-job professional inquiry (Coombs and Fletcher, 2005).

PAR also allows a relationship between inquiry and practical or political activity, positioning advocacy as strength (Hammersley, 2002). PAR's main goal is to create positive social change, and it recognizes agency as an important aspect of data collection and analysis that can close the gap between research and practice (Wood, et. al., 2008). It demands a dialogue between researcher and those involved in the research. PAR promotes research relationships wherein "equal partners meet, enter into dialogue, and share different kinds of knowledge and expertise on how to address issues of exploitation and oppression" (Jordan 2003, 190). PAR is overtly committed to a 
politic of equity and an ethic of social transformation that many other research traditions would dismiss as ideological (Jordan 2003).

Community Participatory Action Research (CPAR) above all recognizes the inherent bias towards working from an advocacy position to help a community solve an issue it deems is important. As Paulo Freire (2007) expresses, reflection without action is pure verbalism and yet action without reflection is simply action for action's sake. This reflects the true heart of action research as a means to intellectually encourage meaningful action to benefit a group or community (Tetley \& Hanson, 2000). According to Sisco, (2015), "Scholars define PAR as a dynamic and highly contextual, pragmatic, political, democratic, collaborative research approach of co-operative inquiry, which involves participants in addressing a shared problem through sequential reflexivity/selfcriticality and action toward social justice outcomes" (p. 141).

Importantly, Kovach (2009) states that action research gives purpose to research, allowing Indigenous philosophies and knowledge to emerge. It legitimizes the marginalized voice and is inclusive in its worldview. This is consistent with Paulo Freire's view on action research.

Action research is guided by Paulo Freire's concept of conscientization. This is a critical approach to liberatory education that incorporates helping the learner to move towards a new awareness of relations of power, myths, and oppression. By developing critical consciousness in this way, learners work towards changing the world (Sinclair, 26:2007).

PAR is consistent with an Indigenous approach to knowledge collection presented by Kovach (2011) allowing for: 
- an Indigenous epistemology to guide research

- Indigenous theory to guide interpretations

- analytical techniques that honour oral knowledge through participant stories

- an integrationist and inductive approach

- techniques (such as coding and memos) that can serve a holistic sensibility

- the importance of researcher's knowledge of subject area

- analysis to be pragmatic with the potential to develop theory as well as offer practical recommendation, and

- an interpretation of findings that are consistent with Indigenous sensibilities

In engagement with communities, this project employs Community-Based Partnership Research, which is a specific type of PAR research designed for collaborating with Indigenous communities (Barnhardt \& Harrison, 1993; Castleden, et al., 2012; Koster, et al., 2012; Sisco, 2015). According to Sisco (2015), "The main contribution of CBPR to PAR research conducted with and for Indigenous communities has been Kirkness and Barnhardt's (1991) 4-R's, which include:

1. respect for local Indigenous knowledge, community protocols, and multiple perspectives

2. relevance of research to local culture and community

3. reciprocity in knowledge exchange as well as capacity building between and mutual benefits to academic and community research partners, and

4. responsibility of academic researchers to empower community research partners through the development of a formal agreement outlining the research relationship, engage them throughout the process, and disseminate research outcomes 
that are accessible and respectful for audiences (as cited in Archibald, Jovel, McCormick, Vedan, \& Thira, 2006; Koster, et al., 2012).

In the spirit of PAR and CBPR, this research is based on an ongoing dialogue with various Native communities to decrease dependency on government payments and increase economic development in the communities. Academic research also confirms the position that Native communities need to reduce dependency and increase economic development (Cornell, 2006; Helin, 2009; Shanks, 2005). The research questions are action-based and were formulated based on both the research and community input from the outset. This PAR approach to co-constructing the research approach and methodology emerged organically through my existing relationship with communities and businesses. Many of the questions arose from previous engagements with participating communities/businesses and were substantiated as more broadly applicable areas for enquiry to other Native communities through research. While we did not sign formal agreements to outline our collaboration on this research project, our relational accountability (Tuhiwai Smith, 2001) to one another has served as an unwritten contract that governs our relationship.

The rationale for adopting an action theory approach was based on the need to improve the health and welfare of Native people in Canada, which I have observed through my lived experience as an Indigenous person. PAR and CBPR advocate a need for improving the conditions of economic development. With more Native communities advocating for economic development as a key element to wealth creation, which 
would then allow for funding of social programs, PAR and CBPR fit well together. In taking a PAR and CBPR approach, one area identified by Native business owners and band councils as a major risk for band-owned businesses is governance. Governing bodies that serve to provide community, political, and business oversight face challenges in managing various conflicts of interest. Cornell (2006) points to the need for a separation of business and politics in how strategy is developed, but also in the structures of accountabilities.

\subsection{Grounded theory}

Founded mainly in education and health research, grounded theory is an inductive, flexible approach to data collection and analysis that allows theory to be derived from data rather than theory-guiding data. From the seminal work of Glasser and Strauss in 1967, grounded theory has grown in popularity and use. The theory encourages flexibility around analytic guidelines (Charmaz, 2005) and allows an inductive approach that encourages simultaneous data collection and analysis (Charmaz, 2003). Taking on a mixed grounded theory approach, this research embraces

a combination of Glaserian (1967) and Strauss and Corbin $(1990,1998)$ approach of multiple interpretations of data, alongside the constructivist approach of Charmaz $(2003,2005,2006)$, which offers a pragmatic view of the researcher as an important part of the research in a highly biased approach.

Charmaz (2006) recognized that the data sets reveal multiple perspectives reflecting diversity, power issues, and hidden networks. Expanding on the Charmaz 
approach, this thesis takes a perspective that bias in research can be a position of strength and not weakness. This position diffuses the debate in grounded theory on how to negate the researcher's bias and multiple interpretive models. This gives the researcher the ability to allow Indigenous voice and worldviews to be highlighted in the data.

This indigenization of the process allows for input at any time during the research process and is organic in its conception. More importantly, grounded theory allows one to adjust a process and explain the ongoing data gathering findings to the community. It also allows for presentation of the data in alternate forms, giving flexibility to alternative views on the data. It is interactive and blends well with action research because the data can be communicated and discussed with the community at the time of collection. They become an important part of analyzing and formulating data sets from the knowledge gained.

\subsection{The birch bark basket as a traditional conceptual framework}

In my academic journey or nindo-kik-aendumoowin, ${ }^{11}$ it was important to me that I combined the traditional cultural lens I bring to this work as a framework for understanding my thesis with a conceptual framework that is academically rigorous. Conceptual frameworks convey worldviews and perspectives (Kovach, 2009). They allow an alternative exploration of the researcher's intentions, concepts, and values (Kovach, 2009). As Kovach (2009) explains, they also provide insight into the researcher's beliefs

\footnotetext{
${ }^{11}$ Anishinaabemowin meaning "to seek to know, to research, to use one's own experiences and perspectives while gaining knowledge."
} 
about knowledge production. From a post-colonial perspective, conceptual frameworks reveal the privileged epistemologies in Western methods and create a space for Indigenous voices that empower traditional ways of knowing or experiences (Kovach, 2009; Silttoe, et. al, 2006; Wilson, 2008). This conceptual research framework helps to guide the subaltern voices, giving rise to the struggle of the oppressed against the elite (Freire, 2007; Said, 1978; Spivak, 1991). Given that this research is based on an adaptation of traditional knowledge systems, it is only fitting to adopt a traditional conceptual framework. Based on an adaption of Graham Smith's (2005) model, this will include the following elements:

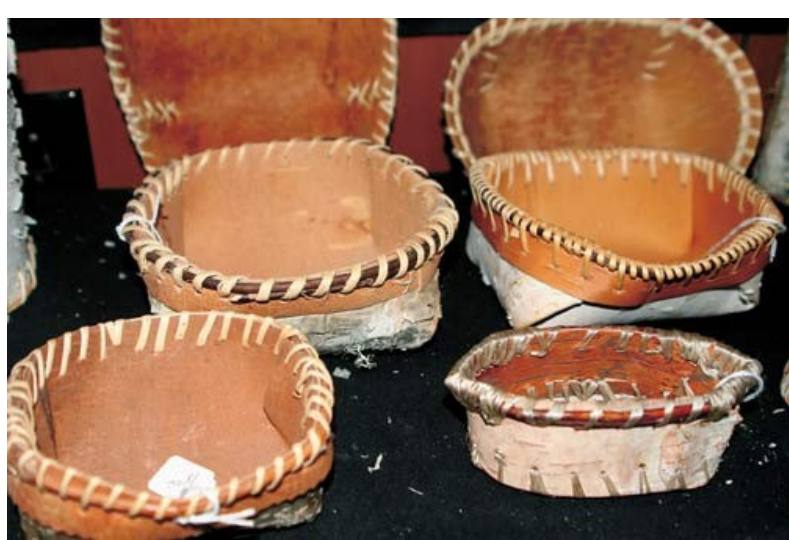

Figure 2 Traditional Birch Bark Baskets

- Locating the research within a cultural context

- Employing participatory action-based methodology

- Ensuring community process of understanding the research

- Breaking down systemic barriers in traditional academic methodology

- Creating a new discursive space (p. 10)

In the spirit of PAR and my traditional cultural framework, I spent time researching my topic and discussing it with several elders from different communities. In one community (Sandy Lake First Nations), I met Elder Percy Rae, who shared with me a traditional teaching on how to make birchbark baskets. He went into great detail 
describing the traditional methods used to take a tree, the offering of tobacco, and how to use the materials it provided. While sitting around a wood stove in his house, he showed me several of his creations. I noticed one of the baskets had staples in the corners. I joked and said, "this doesn't look traditional"! He laughed and said that "white men have some good tools and inventions that make his job easier". He explained that he now uses a truck, chainsaw, buckets, and staples to help hold his baskets together while he weaves the roots. We both agreed that two cultures that are so closely linked can offer each other both practical technology and wisdom. We developed a teaching around this, and I said I would pass this teaching on to others. He gave me the basket and said he would be honoured if I used it for teaching and bringing the two cultures together.

I immediately saw my thesis paradigm in this teaching. As the elder combined the use of both technologies and knowledge to create a better basket, it became apparent to me how this teaching could be applied to combining traditional and Western governance knowledge to enhance Native board governance. Using a combination of traditional knowledge and Western knowledge will form a stronger foundation for sound business governance that makes sense to Native people.

\subsection{Research Procedure}

Flowing from the PAR and Critical Indigenous Philosophy-focused macromethodology and birchbark traditional conceptual framework, this thesis' methodology reflects both my traditional cultural lens and an academically rigorous approach. The 
methodology used is a narrative inquiry approach that includes both case studies and community interviews and conversations. A case study approach was used as a means to collect rich qualitative data through narrative (Creswell, 2003), consistent with PAR and Indigenous research approaches. A diverse sample of case studies was selected to ensure the representation of diverse Native groups and business models across Canada. This sample included a community-owned business, an Aboriginal corporation, and a Corporate-Aboriginal partnership from Alberta, Ontario and British Columbia, respectively. Specifically, the case studies included:

1. Goodfish Lake Development Corporation in Whitefish Lake, Alberta (Community and partnership case),

2. First People Group, Ottawa, Ontario (corporate case), and

3. Ktunaxa-Kinbasket Partnership Strategy, Cranbrook, British Columbia (Community and Partnership case).

Consistent with relational research, the three case study businesses were selected based on existing relationships and purposeful sampling (Patton, 2002). Specific selection criteria for the purposeful sampling of the case studies included the organizations that consistently demonstrated:

- business sustainability (more than ten years in operation)

- profitability and growth, and

- benefits to Native communities (contribution to health, well-being, and prosperity of Native communities through the creation of jobs, wealth, and/or other benefits). 
Case study communities were recruited for participation via phone and email as a continuation of our ongoing relationships.

Specific methods for the case study research included: 1) community interviews and conversations, and 2) storytelling. I selected these methods as they honour the overarching 'relational' (Tuhiwai Smith, 2001; Wilson, 2008) approach that is foundational to Indigenous research methodologies and fit well with both PAR and grounded theory. Specifically, they provided ongoing opportunities to organically coconstruct a project that would directly benefit participating Native communities through raising critical consciousness about their governance models for economic success, and the Native community in Canada broadly by sharing these models as a means to inspire further examples of success in this regard.

\subsection{Community interviews and 'research conversations'}

In total, seventy-five in-person and phone community interviews and conversations were conducted using a semi-structured and structured, open-ended key informant interviewing process. This process included two stages. The first stage of the interview process was oriented towards gathering knowledge and understanding of practices currently employed by communities in the area of economic development. Research materials for this first stage included semi-structured, open-ended conversations with emphasis placed on the employment of governance techniques, understanding of community economic development, traditional teachings, roles, and success stories, including those involved with case study businesses. Consistent with 
PAR and CBPR, many of these interviews could be characterized as what Sisco (2009;

2015) refers to as 'research conversations', which she defines as,

...different from an interview because it takes place between two human beings instead of interviewer and interviewee... power relations in a research conversation are equalized to the greatest degree possible... a research conversation allows research participants to provide input not only in response to the questions asked but related to the overall project including research tools, findings and how the information might be shared or used. It begins when you begin, and continues throughout the research process and beyond (Sisco, 2009, p. 87 as cited by Sisco, 2015).

The second stage of the interview process was directly involved in collecting information on the case studies. This included in-person and phone interviews using a structured interview guide with five items specifically designed to gather best practices as well as examples or issues surrounding governance and economic development in their communities. Informants were asked to provide examples of both successes in their communities and any obstacles that were overcome to attain this success while talking about their companies. Employing an advocacy approach to the interviews consistent with PAR implied this strength-based approach to celebrating these success stories with the communities.

I analysed the data collected from both interview stages using a thematic content analysis to systematically generate key themes and commonalities in the rich data generated from this research and narrative methodology to co-construct narratives with participants (Creswell, 2003). These open-ended interviews and research conversations were not tape recorded, in order to allow a free flow of information. My decision to instead take notes during interviews and research conversations was guided by my 
relational accountability to participants; many elders and community members do not like to be taped and feel uncomfortable being asked. Moreover, in most situations it is inappropriate to ask for written permission to use traditional knowledge. See Appendix A for a list of interview participants.

\subsection{Storytelling and Traditional Knowledge}

Storytelling is an important way to transmit knowledge within any culture, even those that may favour the written word. For Indigenous people, stories are a traditional method of knowledge transfer and are often based on oral legends or myths.

Anishinabe call these stories aadizookaanan and are told by debaajimod or story-tellers. Stories are passed on from generation to generation and yet may change slightly in their telling unless specified by the story teller that is should be passed on word for word.

Storytelling is also an important way to pass on traditional knowledge.

Traditional knowledge is a way of knowing and behaving in the world. The Alaska

Federation of Natives describes traditional knowledge in a holistic way;

Most Indigenous people have traditional songs, stories, legends, dreams, methods and practices as means of transmitting specific human elements of traditional knowledge. Sometimes it is preserved in artifacts handed from father to son or mother to daughter. In Indigenous knowledge systems, there is usually no real separation between secular and sacred knowledge and practice - they are one and the same. In virtually all of these systems, knowledge is transmitted directly from individual to individual.

Yet, traditional knowledge is more than just a land based knowledge, it extends to every aspect of human existence. It is not colloquial but just as relevant in today's society than ever before, perhaps even more so. Chapter 7 will explore some common traditional knowledge philosophies and how they relate to today. What is important in 
understanding this research is that traditional knowledge and storytelling are two valid forms of knowledge production. Honouring the transmission and validity of this knowledge is important to respecting and understanding traditional ways of knowing.

The writing of an academic paper is also telling a story through research. In Shawn Wilson's seminal work Research is Ceremony (2008), the author describes research as a ceremony and explains that, like ceremony, when research is done correctly it is transformative. Taking this concept further, by telling stories as Wilson does, the text itself also becomes a ritualized transformative narrative that hopefully will carry on its meaning after it is published. It is important to honour storytelling as an important way of knowledge transmission for Native people.

As an extension of the PAR and CBPR approach to this work, the success stories drawn from community/business interviews and research conversations were coconstructed with participants and for participants using narrative methodology. These stories are those of individuals that live and work with and for their communities or organizations.

\subsection{Participants}

Participants included the following groups, representing the three featured Native business and associated communities as well as the community interview and conversation participants located across Canada:

1. Native elders

2. Native business owners and entrepreneurs

3. Native leadership, including chiefs and councilors and grand chiefs 
4. Native business leaders, including presidents and CEOs of Native businesses

5. Aboriginal economic development officers, including directors and managers of community economic and business development

6. Government, corporate, and Crown corporation Aboriginal relations officers

7. Native and non-Native lawyers involved in Aboriginal law relevant to governance and economic development, and

8. Academics with expertise in Native economic and business development.

Consistent with relational research, the three case study businesses were also selected based on existing relationships and purposeful sampling (Patton, 2002). Specifically, selection criteria for the purposeful sampling included, demonstrated:

- experience and knowledge about Aboriginal economic development, business development, and/or governance

- experience and knowledge about one or more of the businesses, specifically

- experience and knowledge about one or more of the businesses' governance models specifically

- traditional knowledge about governance, economic development, and/or community well-being, and

- experience and knowledge about the impacts of one or more of the businesses on Native communities.

Like case study communities, specific participants were also recruited for participation via phone and email, as a continuation of our ongoing relationships. 


\subsection{Conclusion}

This chapter explains how this project's methodology and individual methods were thoughtfully selected in collaboration with participating communities/businesses. The overarching relational, PAR, and CBPR approach to this research project informed the decision to take a community/business case study approach and to use research conversations, storytelling, and narrative inquiry as research methods. The chapter also explains the rationale for the methodology employed in the interviews and correspondence. 


\section{Chapter 3 - Rethinking the Hegemony of Capitalism}

\subsection{General Introduction}

Capitalism is a divisive topic, especially in Aboriginal economic development scholarship. Central to the controversy is its hegemonic propensity to clash with Indigenous values and oppress Indigenous traditional economies, including those in Native communities in Canada. However, understanding how capitalism has departed from the moral aspect of early liberal philosophies sheds light on how there may be opportunities for Indigenous communities to engage with capitalism, as originally conceptualized, without compromising traditional values. In particular, the rise of Indigenous self-governance alongside alternative economies, including those that include old and new traditionalism, offers opportunities for Indigenous communities to engage with both the market capitalist economy and old and new traditionalism. First, this chapter discusses the moral aspect of liberal philosophy, which modern capitalism and political economy fail to recognize. Second, it discusses alternative economies, including solidarity economy, and Indigenous interests and community survivance. Third, it discusses old and new traditionalism. Lastly, it concludes with a summary of the chapter.

\subsection{Political economy and the moral sentiment}

Scottish philosopher Adam Smith has been canonized as the father of capitalism as he was the first to write about it. Yet, he was foremost a moral philosopher, a fact 
that Francis Abele writes, "is nearly lost to the injuries of time" (2010:162) and, one can argue, modern capitalism. Smith defined political economy as a way in which a nation manages its resources to generate wealth (1759). Smith's definition of political economy and who benefits from it seems to include both individual and community well-being:

Political economy, considered as a branch of the science of a statesman or legislator, proposes two distinct objects: first, to provide a plentiful revenue or subsistence for the people, or more properly to enable them to provide such a revenue or subsistence for themselves; and secondly, to supply the state or commonwealth with a revenue sufficient for the public services. It proposes to enrich both the people and the sovereign. (1776, IV, I,1).

While Smith suggests a different approach to individual wealth compared with community well-being, he argues that they share a moral sentiment. He (1776) describes the lack of moral sentiment as the wretched, who attain wealth and station through coercive means without honour. This can be through war, thievery, murder, or even the use of politics to oppress others and divest them of their own freedoms and labours (Smith, 1776).

Engels (1956) writes about the realization of Smith's (1776) prediction about capitalism in practice, by characterizing the bourgeoisie's loss of moral sentiment toward the proletariat as shameful in the face of capital gain. According to Engels (1956), human greed and obsession with capital accumulation are responsible for the moral corruption of capitalism. Ultimately, both Smith (1776) and Engels (1956) warn that greed and capitalism will abandon human values in the pursuit of profit. More 
recently, political economy scholarship, such as the work of Mosco (2009), has evolved to account for the role of social relations.

\subsection{The moral compass of capitalism}

Capitalism is a complex system based on individual rights of ownership in a free market (Schumpeter, 1947; Smith, 1776). The Merriam Webster Dictionary (n.d.) defines capitalism as "a way of organizing an economy so that the things that are used to make and transport products (such as land, oil, factories, ships, etc.) are owned by individual people and companies rather than by the government" (par. 1). These definitions encompass the theory of capitalism and the concept of private land or production ownership.

Schumpeter (1943) states this idealistic notion of capitalism is more philosophy than reality. In practice, capitalism is a highly complex system that is ever changing and is constantly at odds with other economic systems, and that is devastating to both economic and social systems of Native people because Indigenous communities are seeking to produce and distribute goods and services from a worldview and value system that seeks to protect one's resources for future generations ${ }^{12}$. Then, how did modern economics arrive today in such a state of peril and divergence from this Indigenous philosophy that probably existed within all cultures? The answer is in the great split between market economies and the welfare of the state.

\footnotetext{
${ }^{12}$ From the teachings of the Seven Generations philosophy. This ancient Native belief states that in everything we do today we must think of how it will affect our descendants seven generations in the future. It was also recorded in the Haudenosaunee Gayanashagowa or the Great Law of Peace of the Iroquois Confederacy.
} 
Pre-colonialism, economies around the world including India, China, and many Indigenous groups maintained the concept of shared ownership or stewardship of land. Individual ownership was not practiced. Capitalism grew out of European feudalism as a mechanism of social stratification tied to private property (Marx, 1909; Schumpeter, 1943; Nelson, et al., 2015). Around the world, colonialism replaced communalism with the concept of private land ownership using "direct political and economic power as rulers and landlords, for the purpose of disrupting these small economic organisations" (Marx, 1909, p. IV.XX.28).

This removal of communal land ownership led to the stratification of society into the bourgeoisie, wealthy landowners who used military enforcement to gain providence over the land, and the proletariat, who worked as indentured servants for the bourgeoisie (Marx, 1909). With the overarching shift from communal prosperity and sharing to indentured servitude, welfare became necessary to assist the less fortunate in subsisting. According to Smith's two seminal texts, The Theory of Moral Sentiments (1759) and An Inquiry into the Nature and Causes of the Wealth of Nations (1776), this social stratification persisted through the Industrial Revolution and the birth of mass production and distribution. The bourgeoisie landholders became factory owners and otherwise controllers of the means of production, and proletariat indentured-servants became factory workers (Smith, 1759; 1776). There was little room for social welfare where profit was to be made. Thus, there was a great move away from the duty of care causing a great split from business, state and church. Social welfare became the responsibility of the state or monarchy-based economies. The state would then be 
responsible for the welfare of the people, and businesses could concentrate on profits and distribution of products to generate wealth.

With the creation of the welfare state in Canada, there also came the Native welfare state. In the 1880s Canada launched a massive campaign to treaty with Indians in order to settle land disputes for ongoing settlements and to complete its nationalist agenda of confederation. The dictatorial state embarked on a long road of cultural genocide (TRC, 2015) to rid itself through assimilation of the "Indian problem" (Miller, 2009).

The happiest future for the Indian race is absorption into the general population, and this is the object of the policy of our government. In the Indian communities now under discussion, we see the Natives advanced more than halfway towards the goal, and the final result will be this complete absorption. The great forces of intermarriage and education will finally overcome the lingering traces of Native custom and tradition. It may be some time before reserves disappear and the Indian and his lands cease to be marked and separated (D. C. Scott, 1920).

Ongoing policies such as the creation of the reserve system, ceremonial banning, residential schools, the Sixties Scoop, and human experimentations such as forced sterilization of women (Lawrence, 2000) and experiments on the effects of starvation on Aboriginal communities (Mosby, 2003), were all designed to either assimilate, eradicate, sterilize, or by any means prevent the Indian from continuing to be a burden on the state (TRC, 2015). The Canadian state fully embraced the marginalization of the Native population in order to control and assimilate them as well as gain access to lands and resources. 
In practice, modern economies and governments often marginalize people and cultures to gain resources and wealth. This represents a stark departure from Smith's Theory of Moral Sentiments (1759), which states that observers have a moral duty of care of those that have suffered, based on our sympathy and morality. Indeed, capitalism today has lost its moral compass and has forsaken the tenets and warnings of Smith's writing. The binding element of the economy to provide for the welfare of the community or nation has been lost. Public services and state welfare are now seen as a burden on the state rather than a necessary function of the economy.

Smith (1759) also argues that geographic or even socially-based distance minimizes the virtue of care and that the doctrine of casuists or basic reasoning removes the duty of care of the observers from those sufferers to a higher power or morality, often based on religion. Social and physical stratification and religion have been used to absolve people of suffering from the responsibility to care for the less fortunate and those considered outside of the capitalist economy. As a result, consistent with Smith's (1759) warnings about the pursuit of capitalistic virtues of greed and growth without moral sentiment, Indigenous populations, among others, have been marginalized within capitalism.

\subsection{Modern misinterpretations of capitalist philosophy}

Modern capitalism is plagued by several philosophies, which have moved it away from Smith's thoughts on the moral fabric of capitalism. According to Schumpeter (1943), political economy is concerned with how capitalism affects business, society, 
and economics. First, corporate political protectionism has become routine in capitalist economies, based on politics and economic need (Bhagwati, 2000; Busch, Krzysztof, 2014). Governments are becoming more involved in regulating markets and controlling corporations. Second, perpetual growth as a business model for capital accumulation has become a staple of modern capitalism, which threatens long-term business sustainability. While growth may be necessary at times to maintain market value and ensure competition, perpetual growth is unsustainable and will inevitably result in collapse (Gladwin, Kennelly, Krause and Kennelly, 1995; Streimikiene \& Girdzijauskas, 2008). Third, capitalism is viewed as the apex of economic systems by most economists, politicians and businesses. As a result, alternative economies are dismissed and unsupported, having major negative impacts on Indigenous communities and their local economies.

Corporate political protectionism is becoming more common today than ever before. Public enterprises, such as state-owned and -governed corporations, known as crown corporations, are on the rise in almost all countries (Farazmand, 1996; Stevens, 1993). Crown corporations give an element of control and financial revenue to the government. However, they are inherently in a state of conflict of interest, as bodies that are responsible for both state welfare and fiscal control (Loxley, 2010; Osborne \& Gaebler, 1992). Theoretically, community owned enterprises should involve the community in the decision-making process (Osborne and Gaebler, 1992). Yet, the neoliberal philosophy of decentralization opens the door for existing monopolies rather than community-based enterprises. This presents a problem for communities pursuing 
alternative economic means of sustainability. Without some form of protectionism, a crown corporation or community-owned business would constantly be under threat if it pursues a more sustainable business philosophy of community needs over growth. Therefore, according to neo-liberal philosophy, public enterprises should be discouraged and competition encouraged. For Indigenous community-based economic approaches, this is problematic as it opposes the fundamental philosophy of shared communitybased business.

Smith (1776) argues that the markets will regulate themselves if left alone. This concept has been evoked in today's neo-liberal economy to attack protectionism in favour of open global markets and multilateral trade. According to this school of thought, open global markets encourage a sort of 'creative destruction' in which entrepreneurs are continuously "wield[ing] the really effective weapon of competition," and businesses will either fail or succeed based on merit, as opposed to corporate protectionism, which provides disincentives for good business practice (Schumpeter, 2008 , p. 89). This ongoing process regulates markets and affects those who are dependent on their goods or services. Yet it also impedes small-business growth and public enterprises which are at the heart of economic development.

In today's market, there is an element of protectionism for corporations that are about to fail. This political blockade of the cycle of creative destruction, through government bailouts and protection of large corporate takeovers, is driven by economic and political purposes. The current climate of too big to fail has to end (Dimon, 2009; Shull, 2010). It has gone beyond financial institution protection to encompass national 
business interest. Shull (2010) calls for reforms to contain the climate of continued absolute and relative growth that has come to characterize economic and political sovereignty. Schumpeter (2008) also argues that certain political monopolies are carefully conceived and controlled even while running "counter to the public's sense of fair play" (p, 89). We also see the rise of what Wolff (2012) describes as state capitalism where state ownership and planning can also be exploitive and even oppressive. Stateowned businesses are often political in their mandates and operations and preclude a true arm's-length relationship. This allows large state monopolies to control and destroy competition.

In addition to arguments against state interference, many scholars are scrutinizing an ongoing capitalist social experiment that promises riches to those who work hard. Schumpeter (1947) describes this as a social arrangement of the bourgeoisie, creating a schema of motives that promises wealth and the threat of destruction. He explains, "Whenever the bourgeois way of life asserts itself sufficiently to dim the beacons of other social worlds, these promises are strong enough to attract the large majority of super normal brains and to identify success with business success" (Schumpeter, 2008, p. 73). However, given that the bourgeoisie have lost their moral sentiment within a capitalist economy, and the proletariat have limited influence within a capitalist system in general, including over business morality, conformity to business as a measure of success stands to perpetuate current power differentials that oppress segments of the economy, such as many Indigenous communities and peoples. 
While the fallacy of meritocracy that this "hard work promises success" philosophy promotes is disconcerting, many businesses demonstrate Corporate Social Responsibility (CSR) (or simply social responsibility) to maintain a fragile balance between profitability and financing social welfare projects that 'give back' to the community. Like government social welfare programs, this strategy is designed to create complacency among the proletariat while satisfying the needs of the bourgeoisie. While this may appear to resemble a moral sentiment, it has become an industry standard among large corporations that routinely exploit cheap labour and consumers, as well as a matter of compliance with Impacts and Benefit Agreements among resource companies operating in Indigenous communities (Anderson, 1989; Beesley, 1978; Sisco, 2014). In this way, CSR is either a social obligation-a branding strategy designed to create the perception of moral business conduct for the purpose of corporate appealand/or a legal obligation.

Given this climate of corporate takeovers, globalization, regulated monopolies, and feigned moral sentiment, the capitalist axiom of perpetual business growth is unsustainable (Gladwin, Kennelly, Krause and Kennelly, 1995; Streimikiene \& Girdzijauskas, 2008). Nevertheless, even current models of business sustainability, such as the logistic growth model (Streimikiene \& Girdzijauskas, 2008) and business/economic systems theory (Smith, 1967; Sterman, 2000; Gereffi \& Korxeniewicz, 1993), are driven by the concept of growth. Perpetual growth fuels a climate of creative destruction within which CSR is used to create the illusion of social 
welfare and maintain the status quo of capitalism oppressing the proletariat, including many Indigenous communities and peoples.

Yet, however oppressed, local alternative economies exist within this cycle of creative destruction. These alternative economies tend to share some degree of resemblance to Polanyi's concept of economic "embeddedness", a holistic economic approach to understanding the relationships between politics, social or cultural reality, and the economy. Specifically, embeddedness includes redistribution based on custom, law, or ad hoc decision-making, and householding or family production of goods and consumables for their own use (1957). It calls for a reclaiming of the economy based on market relations, redistribution, and reciprocity, and is directly tied to community wellbeing (Polanyi, 1957). This concept describes Indigenous economies and how they function. However, the dismissal and underrepresentation of these economies by economists, politicians and business owners further marginalizes Indigenous economies. Polanyi has been criticised for not expanding on householding's impact on the economy, which has led it to be simplified as referring to 'cottage industries'. However, householding conveys a complex system of economic exchange based on kinship, and often involving traditional economies, especially subsistence. Ultimately, Polanyi redefined economic activity as it relates to the economy and to development, which has invited a new dialogue on what is known today as political economy. To consider alternative forms of economic activity as relevant to the economy allows new discussions on economics and creates a new discursive space. This space will provide intentionality for subaltern Indigenous voices. 


\subsection{Alternative economies: a new discursive space}

Polanyi's seminal work on rethinking economics from a social, political, and economic basis has helped to pave the way for a body of work to challenge the oppressive force of capitalism on alternative economies, which are those economic pursuits that fall outside what is considered capitalist economic activities (e.g. cooperatives, non-monetary currency, fair trade, ethical investment, credit unions, trade and barter, cultural production, and other ' social economies' or 'third sectors') (Albert, 1991; Barkin, 2005; Daya \& Arthar, 2012; Gibson-Graham, 2006; Hillebrand \& Zademach, 2013; Loxley, 2010; Ratha, 2000). As mentioned, creative destruction can have a great effect on local economies. According to Shrivastava and Hart (1995), creative destructions impact on countries is especially significant for those that are not wealthy enough to participate on a meaningful scale. It will also have significant effects on local Indigenous economies throughout the first and third world:

No communities of peoples on this earth have been more negatively impacted by the current global economic system than the world's remaining 350 million Indigenous people. (Mandler, 2006, p. 3)

Today, many scholars (Abele, 2010; Barkin, 2005; Gibson, 2006, Graham, 1996; Harvey, 2011) are discussing the importance of alternative economies within an Indigenous context to create or restore local economies. Food security, ecosystems, resources, access to healthcare, and other social concerns predominate the ongoing dialogue in local communities (Ghosh, 2010). While alternative economies stand to act 
as a protective measure against creative destruction and a supportive measure to ensure community sustainability, current capitalist thought casts these alternative economies as insignificant and an old 'throw-back' to primitive economies (GibsonGraham, 1996, 2006).

Therefore, as mentioned, alternative economies are subverted by the hegemony of capitalism, and either marginalized as part of the whole economic system outside of, yet dismissed by, capitalist hegemony (Barkin, 2005; Gibson-Graham, 2006) or unable to participate in meaningful ways (Ratha, 2000; Albert, 1991). Alternative economies look to sustain local communities and seek sustainability to protect the social and economic welfare of its participants. Within alternative economies, the redistribution of wealth, goods, and services to society, coupled with meaningful social justice, fairness, and egalitarian methods of compensation, have the potential to realign administration with societal values (Abele, 2010). In this regard, alternative economies offer a space for moral sentiment.

A new discursive space must be created for dialogue about the value of alternative economies. Moreover, this dialogue must also include discussion of how alternative economies can thrive within the broader capitalist economy in Canada and/or whether the capitalist system needs to change to be more inclusive of alternative economies and some of their strengths, such as this return to a moral sentiment concerned with community welfare. The demand today for alternative thinking around the economy is at an all-time high. With movements such as Occupy 
Wall Street ${ }^{13}$ calling for more democratic control and equitable distribution of wealth through renewed interest in sustainable practices, the time is ripe for alternative economies to gain greater public interest and mobilization, although talk of alternatives to capitalism often turn to fears and critiques of communism and socialism.

Social scientists are now imagining alternatives to capitalist globalization in order to support local and community economies (Barkin, 2005; Harvey, 2011). David Harvey (2011) even extends a Marxist view on alternate economies, arguing that we are no longer in a Fordist era of state regulation but a mobile and flexible one in which economies are turning away from the urban centres of industrialized nations and turning towards suburban, rural, and even underdeveloped countries (Harvey, 2011). While Harvey's theories may be controversial, they reflect Canada's, and other colonized countries', globalized state of economic domination of Indigenous communities and people. As a result, Indigenous communities have sought alternatives to capitalism through forms of resistance and struggles to maintain solidarity and community cohesion. Community empowerment is about taking back some control over self-determination in order to avoid ongoing colonial powers asserting dominance over their own rights and freedoms both economically and socially. For Indigenous communities this is a path to self-determination and even sovereignty.

\footnotetext{
13 “Occupy Wall Street (OWS) is a people-powered movement that began on September 17, 2011 in Liberty Square in Manhattan's Financial District, and has spread to over 100 cities in the United States and actions in over 1,500 cities globally. OWS is fighting back against the corrosive power of major banks and multinational corporations over the democratic process, and the role of Wall Street in creating an economic collapse that has caused the greatest recession in generations. The movement is inspired by popular uprisings in Egypt and Tunisia, and aims to fight back against the richest $1 \%$ of people who are writing the rules of an unfair global economy that is foreclosing on our future" (OccupyWallStreet, n.d.).
} 


\subsection{Solidarity economy and Indigenous interests}

Solidarity economy is an alternative economic theory (inspired by Polanyi) that is grounded in a dialogue of grassroots resistance to the oppressive constraints of capitalism and includes the promotion of a third social sector (Albert, 2007). Foremost, solidarity economy is based on the use of community solidarity-including the convergence of class and wage discrepancies and the development of common ethics or values among community members - to promote community social well-being and sustainability (Deb, 2009; Escobar, 2003; Gibson-Graham 2006; Hart, et al. 2010). Thus, solidarity economy encompasses the economic, cultural, and social spheres of the economy (Polanyi, 1957).

Malinowski's (1920) study of the Trobriand kula system was an early attempt to recognize this alternative socio-economic system that does not place a direct value on exchange but rather a complex system of reciprocity that creates cohesiveness within the society. Within this system, one may give an object or service without accepting immediate direct payment or reciprocity. Instead, some form of compensation is offered at some other place and time to maintain the community social and cultural equilibrium.

From an Indigenous perspective, the theory of solidarity economy opens up a space for Indigenous alternative economies as part of the whole economic system. It places cultural production on the same level as other economic functions. For Indigenous people, capitalism is an incomplete colonial process and resistance comes in the form of a struggle to maintain community economics (Neill, 2001). Solidarity 
economies promote community cohesion and create a united force against global domination over Indigenous resources and inevitably cultures as well. In contrast, Indigenous communities and peoples tend to be marginalized within capitalism, unable to remain competitive due to ongoing colonization. The pervasiveness of capitalism on a global scale means there is no one state or collective that Indigenous peoples can oppose; it has always been a globalized movement of assimilation or eradication. Therefore, global resistance must be taken into account in Indigenous resistance to capitalism's hegemony. Vizenor's (2008) survivance comes into play from an economic point of view where alternative Indigenous economies must not only resist capitalist hegemony but also survive. However, dealing with international organizations, which have little or no authority over nations, represents a challenge for Indigenous peoples in pursuing global survivance.

Moreover, the conceptualizations of economic theories that exclude local and alternative economies, such as Immanuel Wallerstein's World System Theory (1974, 2011), is unthinkable for Indigenous peoples worldwide. World Systems Theory (WST) holds that there are three types of countries: core, semi-peripheral, and peripheral (Wallerstein, 2011). Core nations are capitalist nations with high industrialization and urbanizations. Canada, United States, England, and Australia are all part of the core nations yet also have Indigenous populations that live in peripheral conditions. Wallerstein (2011) says semi-peripheral nations are those with lower wages and increasing industrialization but that lack the technology or urbanization that core countries have. They often produce raw materials for core nations. Peripheral countries 
are more dependent on core nations and are more agrarian with low wages, education, and industrialization. Yet Indigenous communities and nations fall outside of these categories and may be considered in a fourth category of external or exclusionary nations.

While there is strong data to show that the world has been involved in a global economy for some time (Schumpeter, 1934, 1939; Wallerstein, 1991), Indigenous economies have been marginalized or co-opted within this global economy. Drawing on a WST analysis, core countries are using their power to dictate policy and exert control over the global economy. This puts Indigenous people in a place of resistance and opposition to the nation states in which they reside. Michael Albert, an American activist and economist, calls for the "dismantlement of constituencies of people and classes" that hold opposing interests (Allard, 2008, p. 57). However, as long as there is the formulation of negotiated power, there will be conflict, which does not preclude the development of mechanisms of negotiated power or partnerships. For example, while full autonomy may be impossible, given the constant interaction of economies and the interests of external stakeholders, a measured autonomy that allows for sustainable local economies may be an option for Indigenous communities.

David Barkin explains that the structure of a local economy can allow communities to work in sustainable ways by producing needed goods and services while maintaining the value of environmental stewardship (Barkin, 1998, p. 7). While this optimistic view may seem difficult to hold, given the state of many Indigenous communities, it may be the future of Indigenous economies to influence true 
sustainability in capitalism. Yet, given the failure of the state to recognize Indigenous rights and freedoms, including Indigenous sovereignty, a barrier remains. Colonialism has destroyed these principles and left them at the mercy of capitalism without what Harvey (2011) refers to as the necessary regulations to control competitive capitalism in certain nations. This is likely, in part, because Indigenous people have not been engaged in regulating capitalistic economic encroachment.

\subsection{Community survivance}

The body politic or sovereign, deriving its existence only from the contract, can never bind itself, even to others, in anything that derogates from the original act, such as alienation of some portion of itself, or submission to another sovereign. To violate the act by which it exists would be to annihilate itself, and what is nothing produces nothing (Rousseau, 1962, p. 15).

According Rousseau's (1962) assertion, the Canadian state is destined for annihilation, as it has certainly alienated Native communities. While this dramatic phrase may seem unrealistic today, it holds a truth that cannot be ignored. Canada as a state cannot continue to exist in its current form while holding Native people in a state of dependency. International criticisms and internal movements of its citizens, to be fair and just, will inevitably drive the state to change. For example, Canada's Idle No More (INM) grassroots movement, which started in 2012 (Idle No More, n.d.), has served to encourage countless protests in opposition to the treatment of Native people in Canada, and in 2013 the United Nations' Special Rapporteur on the rights of Indigenous peoples, 
James Anaya, declared, "Canada faces a crisis when it comes to the situation of Indigenous peoples of the country."

Native communities have been fighting a battle of resistance ever since Settlers arrived on their shores. This resistance among Native communities stems from a desire for the opportunity for their citizens to live healthy and productive lives while maintaining their cultural practices.

For Native communities, a healthy community creates a healthy state, which in turn, supports a healthy economy. This community focus often places communities at odds with current capitalist approaches to profits and individualistic wealth generation. Due to their general state of economic dependency (Helin, 2009), capitalist thinkers place Native communities outside or at the bottom of the economic ladder, partly because they tend to dismiss Indigenous economies as secondary or nominal economies. As mentioned, this thinking perpetuates capitalist hegemony, which locates capitalism as residing at the apex of economic systems (Gibson-Graham, 2006). It is precisely this ongoing dominant discursive that undermines and dismisses alternative economies like those in which Native people are actively involved. Native communities are looking for new ways to combat capitalist apex thinking and capitalist hegemony.

Borrowing from Gerald Vizenor's (2008) concept of cultural survivance, a movement from dependency towards cultural and community survivance is needed. This can also be extended to include strong alternative economic systems that are rooted in traditional ways. Alternative economic systems that incorporate social and ethical considerations surrounding interactions and resources exist (Barkin, 2012). 
Counter to the theories of economic development that call for engagement in a global economy, the preservation of local non-monetary-based economies is often viewed as crucial to maintaining a traditional lifestyle. Indigenous people often block industrial development, economic development, and encroachment on traditional lands to maintain a rural subsistence, or, trade-based economy. The Canadian Senate Committee on Aboriginal People states that, "Most communities want to benefit from economic development. However, they want to do so on "their own terms," (2007, p. 4). The committee elaborates, stating that Native people "have not simply adopted all nonAboriginal business practices, but have developed approaches consistent with their own deeply held values and beliefs"(2007, p. 4). Native people are looking to assert their economic sovereignty and support self-determination with business development as an important part of this plan $(2007$, p. 4). Yet legislative and regulatory aspects of the Canadian Indian Act have limited access to lands and resources and capital along with a non-competitive physical infrastructure (The Canadian Senate Committee on Aboriginal People, 2007).

The Harvard Project on American Indian Economic Development indicates that self-government is the key to economic self-sufficiency (Cornell, et. al., 2004). However, it concludes that poverty and poor social conditions are political problems and not primarily economic in nature. Certainly some political issues and policies hinder economic development, but perhaps more importantly, there is a need to understand economics from an Indigenous perspective. Feeling aedawae-gigi, or being on both sides of a whole, is an Anishinabe concept that describes the frustration felt when First 
Nations people are told that capitalism and globalization of the economy are the holy grail of economic self-sufficiency, yet they see economics as a part of a whole system of living relationships that are interconnected. From an Indigenous perspective, divorcing community or subsistence economies from market economies is akin to chopping off one's arm to shake someone's hand. There is a need to rethink and redefine concepts of a holistic economy from apex capitalism to those more compatible with Indigenous communities' perspectives.

This shift in the paradigm of apex capitalism will create a space for dialogue on what Gibson-Graham calls "community economy" (2006, p. 79), as a starting point to constructing "other" counter-hegemonic economies. An alternative economic discourse is needed to validate and strengthen Indigenous resistance to, and in some cases interaction with, capitalism. This is not to say that Indigenous people are not interacting with or taking part in capitalism. Many are, and yet they also engage in a traditional economy. It is hard to try and maintain a balanced ethical economic structure that represents both Indigenous and capitalist values, as they tend to be divergent. In essence, capitalism is only one of several systems in which Indigenous people are involved. Communities are continually struggling with a colonial or post-colonial dominant discourse that rewards capitalism and devalues other forms of economic engagement. Survivance calls for the use of alternative economies in Indigenous communities to combat this issue. 


\subsection{From old traditional to new traditional economy}

Defining traditional economy is complicated. 'Traditional economies' is a more appropriate term, as it includes a multitude of complex economic systems. While most definitions refer to traditional economy as a subsistence-based economy, in reality traditional economies tend to encompass a more complex system, which includes subsistence living as well as reciprocity, bartering, trade, and generational sustainability (Dickason, 2001a.). Traditional economies are often over-simplified and/or conveyed as primitive remnants of pre-modern societies that use backward technologies (Rosser and Rosser, 2005). Capitalist discourse classifies traditional economy as a subsector of capitalism.

As mentioned earlier, Carl Polanyi (1944) popularized the concept of traditional economies through his theory of embeddedness, which refers to complex socio-cultural systems that involve redistribution, reciprocity, and householding (the production of goods for use or trade through family groupings) (Polanyi, 1944). Expanding on Polanyi's concept, householding also exists within a cultural system or clan system as part of a complex political order. Emily Kawano and Ethan Millar define traditional economies as an "economic system that includes environmental stewardship, cooperation, shared well-being, equality, non-monetary forms of wealth, democracy, and participation" (2008, p. 98). Traditional economies incorporate cultural ethics into the local economy and concern themselves with the perpetuation of cultural traditions and community well-being as long as they conform to community norms (Tsosie, 1996). 
Therefore, traditional economies are varied and reveal a complex system of community sustainability and equalization of wealth, based on a multifaceted cultural value system (Kawano \& Millar, 2008; Polanyi, 1944). For many Indigenous people today, traditional economies represent one of several forms of economic activity in which they engage. Jon Altman (2009) describes Indigenous engagement as a hybrid of economic activity, recognizing traditional subsistence-based economies, and the engagement of market-based economies. While specific definitions of traditional economies vary, they appear to share in being characterized as complex systems that are tied to cultural values.

Many economic systems interacted within pre-contact North America. Community leaders would preside over their households, clans, communities, and nations dependent on their traditional systems. A complexity of trade networks existed throughout North America, some of which can still be seen today (Dickason, 2001a, 2006; Frideres, 2008; McMillian and Yellowhorn 2004). Such a complex system of trade and economic activity implies the existence of multifaceted governance systems that managed wealth, cultural productions, and food. This would have to be managed through a complex set of ethics guiding a community-based decision-making process (Tsosie, 1996).

Today there are several subaltern writers that are redefining the traditional economy. Rosser and Rosser $(1998,2005)$ write about a new traditional economy or one that uses modern technology while respecting and preserving traditional social practices. This calls for the reintroduction and embedding of traditional societal decision 
making that was lost in the Industrial Revolution, decision making driven by cultural ethics and values rather than production needs and demands. Rosser and Rosser (1998, 2005) go on to expand this concept into Islamic New Traditional Economy and NeoConfucianism. Islamic New Traditionalism consists of widely accepted laws and commands that are based on beliefs within Islam as presented in the Qur'an (Rosser \& Rosser; 1998, 2005). Neo-Confucianism offers a more generalized morality based on a set of Chinese principles of benevolence, righteousness, propriety, wisdom, and faithfulness (Rosser and Rosser, 1998). Indigenous New Traditionalism has emerged as many Indigenous people are faced with this same dilemma, balancing a desire for using modern technology and ideologies while maintaining their traditional ways, values, and culture. The Indigenous New Traditionalism looks at economic behaviour rooted in Indigenous cultural traditions which strive for sustainable community well-being over perpetual growth. This becomes an important factor in economic development, partnerships, and governance.

Loxley (2010) argues, "Subsistence production is important in many communities and is likely to remain a key element in whatever overall strategy is adopted by such communities" (p. 37). However, he adds that other strategies, such as capitalist economies, have the potential to undermine subsistence economies by attracting subsistence labour away for wage labour and depleting resources (Loxley, 2010). Importantly, Loxley (2010) refers to economic development that enhances Native culture as a recurrent theme in Native literature and refers to the Red Paper, produced in response to Prime Minister Pierre Elliott Trudeau's 1969 Statement of the 
Government of Canada on Indian policy (also known as the White Paper) as the best example of this thinking. Howard Cardinal writes:

It is, therefore, imperative that we enlist the energies, resources, and talents of private enterprise ....and at the same time [recognize] that giving up on Indian identity is not necessary for economic development ...although private sector development must be in tune with the life and spirit of the community (Cardinal, pp. 67-68: 1970).

Cardinal's words reflect an ongoing rise of Indigenous sentiments towards economic development and its role in community development. Engaging in development work does not mean Indigenous people have to lose another aspect of their culture, such as language, traditions or even substance based economies. In fact, they may be enhanced given the economic power that comes with viable business ventures.

\subsection{Conclusion}

Prior to colonization, Indigenous groups, among others, shared stewardship of the land. Capitalism grew out of European feudalism. The removal of communal land ownership led to the stratification of society into the bourgeoisie, wealthy landowners who used military enforcement to gain providence over the land, and the proletariat, who worked as indentured servants for the bourgeoisie. The moral sentiment of capitalism was that the state would care for the less fortunate through welfare.

However, capitalism has lost its moral sentiment over time due to bourgeoisie greed; modern economies and governments often marginalize people and cultures to gain resources and wealth, and the more fortunate tend to view state welfare as an 
outside mechanism rather than an integral part of capitalism. Moreover, corporate political protectionism, perpetual growth, and apex capitalist thinking has moved capitalism away from its original philosophy of moral sentiment.

Yet, however oppressed, local alternative economies exist within a cycle of creative destruction and stand to create or restore local economies in Indigenous communities, which contain moral sentiment, such as solidarity economy, survivance, and New Indigenous Traditionalism. A new discursive space must be created for dialogue about the value of alternative economies and how they can thrive within the broader capitalist economy in Canada. This space will allow Indigenous people to engage in the economy while maintaining their culture, traditions and rights. It is more than survival and even beyond resistance, it is about sustainability of culture allowing it to flourish and grow. 


\section{Chapter 4 - Economic Development and First Nations}

\subsection{Introduction}

This chapter looks at economic development as a strategy for First Nations to increase wealth and development within their communities. It begins by looking at the traditional theories of economic development then offers an Indigenous perspective on economic development. The chapter also examines some of the barriers to economic development.

\subsection{Traditional theories of economic development}

Theories surrounding economic development are highly contested. As Jon Altman asserts, there is a "broad spectrum" of definitions, from the ideology of increasing the rights and freedoms of a people to the measurement of capital growth, employment, and independence from welfare (Standing Senate Committee on Aboriginal Peoples, 2007). Max-Neef (2010) describes development as the liberation of creative possibilities. However, since the decline of post-World II War Keynesian economic development, there has been a rise of neo-liberal global strategies. These strategies employ tactics such as lowering wages, wage freezing, reduction of spending on social welfare, elimination of job security, and increasing workloads in the name of good governance and accountability (Carino, 2009; De Angelis, 1988; Harvey, 2010). Neo-liberalism also seeks to offload accountability onto society and particularly the individual. However, it fails to take into account the non-commoditized "soft" forms of 
social production, such as the social welfare of communities and funding of the arts. It also offloads responsibilities of education to provincial and local governments, which results in a reduction of public spending on education. This frame of thinking creates an indifference (Herzfield, 1993), which reduces governance to management of capital gains and profits and development to a modern economic tool for exploiting productivity or natural resources.

This reduction of the complexity of development comes from classic liberal theories of economic development. One influential early liberal theorist, Walt Rostow (1960) argued that there are stages of development that countries must progress through in order to reach an age of mass consumption and industrialization. Consistent with apex capitalist thinking, Rostow describes traditional societies (subsistence agrarian or hunting and gathering societies) as at the bottom or lower end of the development scale. However, Rostow's theories revolutionized the concepts of international development and offered a sobering look at underdeveloped nations experiencing mass poverty. While his views were based on Western idealism and colonialist thought, they opened up a dialogue surrounding foreign investments and aid.

The Harrod-Domar Model (Harrod, 1939; Domar, 1946) showed a correlation between labour and investment, specifically linking economic growth to national savings and the capital output ratio. This model explained why third-world countries that had plentiful labour but no capital experienced stifled growth in their economy (Harrod, 1939; Domar, 1946). The Harrod-Domar Model calls for investment in underdeveloped areas to utilize the labour but also grow the infrastructure (Harrod, 1939; Domar, 1946). 
The rate of growth depends on the amount of financial output from centralized savings (Harrod, 1939; Domar, 1946). When the output is lower due to economic conditions, transfers to developing nations become increasingly difficult and limit economic growth, leaving many nations and their people in third-world conditions (Harrod, 1939; Domar, 1946). This issue is particularly prevalent in many African nations, where investments have led to economic and infrastructure growth followed by economic collapse upon their decline.

In contrast, Schumpeter (1934) argues that any economy is not harmonious and gradual but rather is comprised of technological and business spurts and breakdowns, which result in stages of economic growth or decline. For Schumpeter (1934), economic development is directly tied to the state of the economy. He argues that during times of economic prosperity there are "booms in residential, public, and public utility construction" (Schumpeter, 1934, p. 320). This may result in infrastructure growth, but only through social or welfare programs and not economic development. Economic development has to be tied to a strategy to increase business productivity and growth.

While these classic theories are important to our understanding of economic development today, they overlook the fundamental issues of poverty and the structural capacity of a nation to promote and maintain economic growth. Economists Raul Prebisch and Hans Singer both suggest there is a structural absence of institutions and governance that will perpetuate dependency (Ardeni \& Wrigth, 1992). This early dependency theory divided countries into core economies that manufacture and consume goods and periphery economies that provide resources and cheap labour to 
support core economies. This theory later evolved into Immanuel Wallerstein's aforementioned World Systems Theory. For Indigenous people they were forced into the periphery, even in countries that were considered core economies.

Neo-liberal theorist Milton Freedman proposed neo-liberalism as a path to political freedom through free open markets and privatization of investment in countries to stimulate growth (1962). Neo-liberalism also advocates for private property rights and encourages the wealthy's exploitation of the poor, defining economic development as the maximization of people's potential and capabilities for maximum economic output (Harvey, 2010). However, this definition does not account for shared resources and communal property philosophies that Indigenous economies held, nor does it account for how to create capacity and address structural issues within an impoverished region. In this regard, it falls short of meeting the needs of many Indigenous communities that make a distinction between their rights and culture, and the pursuit of capitalistic gains.

Both classical and neo-classical theories have influenced modern economic development thought. However, they have largely been rejected due to their unsuccessful implementation in various forms (De Angelis, 1998; Harvey, 2010; Teubal, 2004; Thomas, 2007). Application of these theories has shown that while structural and institutional conditions must be present, cultural, educational, and capacity needs, and the perception of sustainable economies must also be taken into account. Modern economic development theorists such as Abhijit Banerjee (2012) and Amartya Sen (1999) argue for an approach that deals with the economic facets of the development process in low-income areas, not simply development on the basis of a unified country. 
They suggest not only focusing on promoting regional economic development, economic growth, and structural change, but also on improving social conditions such as health care, education, and workplace conditions to drive development. This thinking has evolved into our more holistic approach to economic development today.

\subsection{Economic development today}

The world has a long history of exploiting countries and people for economic gain, and Indigenous populations have figured prominently in this history, as they have been pushed aside for state and corporate exploitation of their traditional territories. Many Indigenous people are resisting this colonial process and fighting to maintain their traditions while engaging in the economy. There is no one model of economic development that any community or Nation has followed. Development is dependent on many factors including capital investment, infrastructure, cultural ideology, and the well-being of the community. From an Indigenous holistic perspective, development must consider Indigenous people's cultural traditions and relationality with various state economies (Abele, 2010; Banerjee \& Duflo, 2012; Barkin, 2005; Harvey, 2011; Loxley, 2010).

In 1987, the "Barefoot Economist" Max-Neef developed an index of criteria for

Human Scale Development which was:

focused and based on the satisfaction of fundamental human needs, on the generation of growing levels of self-reliance, and on the construction of organic articulations of people with nature and technology, of global processes with local activity, of the personal with the social, of planning with autonomy, and of civil society with the state (Max-Neef, et al, 1987, p. 8). 
Max-Neef describes those who are outside of the economy as "the invisibles" (MaxNeef, 1986, 1992). For Max-Neef, $(1986,1992)$, humanity has accumulated a great deal of knowledge, yet lacks an understanding of those who suffer. He claims economists act systematically against increasing the development of the invisibles and that there is a need for solidarity to ensure the economy serves the people and not vice versa (MaxNeef, 1986, 1992).

Further to this, Max-Neef $(1986 ; 1992)$ asserts that current approaches to economic development fail to grasp that development is about people and not objects and that development is not synonymous with growth. In fact, the masses, including Indigenous populations, are becoming increasingly impoverished and marginalized (Max-Neef, et al, 1991). This residual effect of Keynesian economics has led to the development of unsustainable systems. Indeed, development does not necessarily require growth but changes to the governance of economic development. Moreover, economies depend on ecosystems such that without environmental sustainability, economic development is impossible (Max-Neef, 1986; 1992). In fact, the economy represents a subsystem of the biosphere, thus, permanent growth is impossible. Therefore, according to Max-Neef, $(1986 ; 1992)$ economic thought needs to shift from a focus on perpetual growth to the reverence of life above all economic interests. This is also a commonly held belief of many Indigenous populations that you cannot sacrifice life and future generations for gains today. 
Modern development theory rejects the globalized approaches of classical and neo-liberal theories in favour of a more complex social reform theory of development that accounts for poverty and dependency within an 'industrialized state'. Today, economic development tends to focus on capital accumulation through job creation, workers' conditions, and engagement in a global economy, as well as the social conditions of those engaged in development. There is greater recognition that economic development is about more than simple monetary transfers; it is about reducing poverty and boosting shared prosperity (World Bank, 2014). Sen (1999) argues for more than a GDP approach ${ }^{14}$ to wealth calculation. He argues that there are other social and economic determinants that need to be taken into account, including education, health, human rights, and freedoms as well as neoclassical measurements of wage and income.

As mentioned previously, Helin (2008) builds on Sachs' (2005) theory that poor countries are stuck in poverty traps, which limit access to capital and lead to endemic issues that require financial aid to resolve, arguing that colonization has also placed First Nations in Canada in this trap of dependence on the Settler state. As a result, there is a lack of true localized economic development and prosperity in Native communities in Canada (Helin, 2008). Loxley (2010) argues that subsidization is often needed in Native communities when basic needs are not met through the local marketplace because of low incomes or because the low demand inhibits the development of a sustainable local supply. He also states, "Government assistance should be supportive and calculated to

\footnotetext{
${ }^{14}$ A GDP approach uses formulaic economic analysis by the following formula; GDP= consumption + investment + government expenditure + exports - imports.
} 
enhance greater Native self-reliance rather than to perpetuate dependence" (Loxley, 2010, p. 58). One can certainly see the complexity of modern economic development theory and its attempts to reconfigure the concepts of liberal and neo-liberal theory with modern economics that account for globalization, impoverished regions, and the importance of social relations and well-being.

\subsection{Economic development from an Indigenous perspective}

For Indigenous people, economic development is more than jobs and economy. It is about maintaining traditional ways of life and philosophies (Orr \& Weir, 2013). Newhouse describes an "increasing number of Aboriginal people who want to participate more fully in the capitalistic economy of Canada and maintain some sense of traditional values and social order" (79:2001a). Yet, classic liberal and neo-liberal development ideologies continue to marginalize Indigenous communities and peoples by perpetuating a false dichotomy in which they must choose to either embrace capital economy and abandon tradition or remain in a cycle of poverty and dependency within the Settler state. The classic adage of moving from subsistence living on a reserve to a modern economy in the city for job opportunities remains the prevailing colonial solution (Loxley, 1986 \& 2010). Consider, in the Australian context, Prime Minister Tony Abbott's recent remarks about Indigenous peoples living in remote communities being a "lifestyle choice" and his massive federal funding cuts to 150 remote Indigenous communities in an attempt to force migration of Indigenous peoples into cities (McCarthy, 2015). 
For Indigenous people, this thinking is a threat to their traditional ways of living and interacting with the land. Indigenous people want to engage in economic activity without having to compromise their traditions and way of life. To quote Carino:

Traditional modes of livelihood, such as fishing, hunting and gathering, livestock cultivation, or small-scale agriculture are under a great amount of stress from phenomena such as neoliberalism and commoditization, privatization, climate change, and conflict (7:2009).

Indigenous peoples worldwide are struggling to balance protecting their environments, cultures, and languages with creating wealth and prosperity in their communities. This struggle for the preservation of traditional ways does not mean that Indigenous people are to be considered fossils of the past or impediments to progress, as colonialism depicts them. In fact, sustenance living can also exist with other forms of economic activity. The two are not mutually exclusive.

\subsection{Barriers to economic development}

Perceptions of inequality also hinder economic development (Griffin, 1999). This is reflected in the distribution of income between Indigenous and Settler populations. In Canada the lowest wages can be found on reserves, up to $30 \%$ lower than those offreserve (Wilson, 2010a). This contributes to the constant adage that Native people must leave their communities to find meaningful work. Many do leave the reserves to look for work and end up in urban settings. In 2011, 56\% of Aboriginal people lived in urban areas, up from 49\% in 1996 (Aboriginal Affairs and Northern Development, 2014). Yet, 
Wilson's (2010a) study found that this income gap transcends location, existing in both rural and urban centres. Even those Native people who find work are often employed in lower-paying jobs such as manual labour or the service industry (Wilson, 2010a). There are few First Nations people in management positions, let alone senior levels of business (Wilson, 2010a).

It stands to reason that access to job opportunities and education and training, and thus limited capacity, are among the main issues. Low education levels inhibit wage equality. In particular, access to and completion of post-secondary education are important and help close the gap in wage earnings dramatically (Usher, 2009; Wilson, 2010). The income gap between Native peoples and the rest of Canadians who have earned a bachelor's degree diminished from \$3,382 in 1996 to just $\$ 648$ by 2006 (Wilson, 2010a, p. 4).

While this is encouraging, there remain gaps between Native and non-Native people in post-secondary education completion. Only $8 \%$ of First Nations people have completed post-secondary education, which is less than half of the national average of 22\% in 1996 (Wilson, 2010a). The characteristics of First Nations post-secondary school are unique and have a notable gender and age discrepancy from non-First Nations students. Of First Nations post-secondary graduates, $48 \%$ are over the age of thirty, and 70\% are women (INAC, 2010). There still remains a gap in income for those who do secure employment. Capacity then becomes an important piece of the economic development puzzle. At the same time, Loxley (2010) warns that capacity-building initiatives that are not paired with commensurate local job creation in Native 
communities may be jeopardized by out-migration, out-sourcing and inhibit local economic development efforts.

\subsection{Merging of two world views, aditawazi nisoditadiwin}

Howard Adler (Gang, 2009) defines aditawazi nisoditadiwin as a merging of two Ojibway words to mean between two worlds but understanding both. This Ojibway concept takes on the meaning of existing in both traditional ways and the Western world with education in both. Much like Vizenor's Word Warriors (1986), there is an ongoing quest to understand both worlds and how to exist in both.

Within an economic development context, aditawazi nisoditadiwin becomes an important concept to understand Indigenous development. Development is communitybased and for the betterment of community. That is the Indigenous way of knowing and being; to move away from this is to adapt to Western ideologies of development for the individual and society. According to Loxley (2010), within an Indigenous community context, there are seven main types of economic development strategies, which usually manifest in some blend of the following:

1. "Subsistence (traditional)" strategies, which are based on hunting, gathering, trapping, and fishing for consumption and direct use (e.g. using animal skins for clothing).

2. "Welfare and/or migration" strategies, which are based on dependency on state welfare. These strategies lead to economies characterized by low income levels, high unemployment rates, high outmigration levels (to pursue job opportunities), and high levels of spending 
on imports (as local consumption exceeds production of goods and services). Therefore, these strategies are not viable as a long-term solution.

3. "Government services" strategies, which are based on dependency on state development projects to meet basic needs (e.g. infrastructural development, and the provision of health, education, and other services), due to a lack of other local economic development opportunities. These strategies lead to economies characterized by few job opportunities based on these government service projects over which the community has little to no influence. These strategies are not viable as a long-term solution.

4. "Export promotion" strategies, which are based on the production of often raw materials or staples for export to satisfy market demands outside of the community. These strategies tend to yield higher income levels through access to a larger market than a local economy would provide. However, the resulting economies often require resolution of land claims and could risk environmental degradation and harm to traditional subsistence economies. Moreover, if gradual economic diversification does not ensue, these economies can be unstable due to the volatility of market value of the staple and lead to the development of a 'working poor' class for those employed outside of the staple production sector.

5. "Import substitution" strategies, which are based on the local production of goods that were previously imported, so that market demand is met locally. The resulting economies are characterized by the development of higher incomes and employment rates, as well as skilled 
labour as they progress. However, difficulties can emerge in these economies due to the small local market size, which may require subsidization, low levels of demand prior to the employment of the strategy, market volatility of the material, and economic leakage as a result of capital being held outside of the community.

6. "Dual economy" strategies, which are based on a mix of the subsistence and export promotion strategies. This strategy promotes an economy that is characterized by "a modern renewable resource sector for both subsistence and export" and which is financed through rent collected from outside corporations involved in exporting the resource. However, this strategy presupposes the community has access to a resource rich land base over which they have state recognized control.

7. "Convergence or self-reliance" strategies, which are designed to ...converge local demands with local resource use, and ultimately, local needs with local resource use, to reverse... the main structural weakness of dependent economies (i.e. their divergent production structure) ... [so that communities] ... "produce what they consume and consume what they produce".

Loxley's (2010) strategies show a variety of levels to economic development.

Each strategy has its own merit and issues. A community or culture is not precluded from engaging in one economy, based on its participation in another. A prime example of this is in the Anishinabek Nation within Canada where members engage in Subsistence (traditional) strategies through hunting, fishing, and trapping which still supply some sources of food for family and community (Beaucage, 2009). However, the 
community is also involved in convergence or self-reliance strategies in several industrial endeavours, including green energy production, which supports their traditional values of environmental protection and the idea of multi-generational sharing.

Loxley's strategies are an expansion of his writings (nd \&1986) on Neechi Foods Co-op Ltd (a worker owned cooperative community store) where the company along with the Community Development Business Association of Winnipeg compiled a list of principles that define community economic development. While not all development will meet all the criteria it is a good example of local Indigenous involvement in their own economic development. The Neechi principles of Community Economic Development (1993) are:

1. Use of locally produced goods and services,

2. Production of goods and services for local use,

3. Local re-investment of profits,

4. Long-term employment of local residents,

5. Local skill development,

6. Local decision-making,

7. Promotion of public health,

8. Improvement of the physical environment,

9. Promotion of neighbourhood stability,

10. Promotion of human dignity, and;

11. Mutual aid support among organizations adhering to these principles.

The Union of Ontario Indians has created an Anishinabek Nation Economic Blueprint for the nation that prioritizes the maintenance of traditional governance and 
values and encourages community economic development (Nelson, et. al., 2005). It recognizes the Janusian ${ }^{15}$ principle of looking forward while recognizing the history of their engagement in various economic pursuits and governance. Communities want to engage in both traditional ways of subsistence living and governance as well as contemporary industry and development. This can be seen in the multitude of corporate partnerships that have become common for many communities. It also reflects both Loxley's (1986; 2010) principles of community economic development in its use of local goods and support for entrepreneurial growth. The Union of Ontario Indians encouraged and supported education efforts to increase skills in business management.

\footnotetext{
${ }^{15}$ A process of looking forward and backwards on an issue, based on Janus the Roman god who had two
} faces so he could see in two directions. 


\section{Chapter 5 - Partnerships and Economic Development}

\subsection{Introduction}

This chapter examines a key strategy for economic development by First Nations through partnership and entrepreneurship development. This chapter also examines the relational side of a partnership from social responsibility to legislated policies such as the Duty to Consult. It also provides an understanding of philosophical differences between Western corporate values and First Nations' views on sustainable community values and practices.

\subsection{History of partnerships and alliances}

Partnerships and alliances have a long history in Native society that predates the arrival of the Europeans (Dickason, 2006; Furniss, 2002; Keyser \& Klassen, 2001). Native peoples maintained extensive trade networks to exchange goods and supplies as well as collect regional-specific items throughout North America and into Central and South America. Trade networks between the West Coast (British Columbia) and the prairies (Manitoba, Saskatchewan, and Alberta) date as early as 3,300 years ago (Furniss, 2002).

During the early period of European colonization of North America (1500s-

1600s), Native peoples entered into peace and friendship agreements, partnerships, and treaties with the newcomers (Dickason, 2006). Partnerships such as military unions, political alliances, and economic trade relations have been important to both Native peoples and the Crown (Dickason, 2006; Furniss, 2002). However, mass migration from Europe resulted in the continuous colonization of Native peoples. Growing trade 
companies and the stabilization of the military presence in Canada lessoned the need for Native participation as trade and military partners (Rich, 1960). This led to the marginalization of Native peoples in Canada and segregation of Native communities onto reserves.

With the advent of reserves, many nations were limited in their participation in Canada's growing market economy. Native businesses became less common as their access to markets and capital decreased. This also diminished any prospects of partnership with larger corporations. Native peoples have had to take on labour jobs or rely on government subsidies. Access to markets and trade networks became increasingly difficult and, in most cases, disappeared altogether (Innis, 1999). The fact that Native peoples have not fully shared in Canada's prosperity reflects poorly on Canada (Treasury Board of Canada Secretariat, 2004). A 2006 report by the Institute for Research on Public Policy stated that the "persistence of these gaps between the living conditions of Canada's Aboriginal and non-Aboriginal populations...remains a stark, undeniable reality, an unflattering blemish on Canada's purportedly enviable record of social justice" (Salée, 2006:5).

As noted in Chapter Four: Economic Development and First Nations, there are several strategies that can help rectify the poor socioeconomic conditions of Native peoples in Canada. However, one effective approach for those who wish to create selfreliant economies (i.e. using aspects of Loxley's (2010) development strategies; subsistence, export promotion, import substitution, dual economy, convergent or selfreliance) is to incorporate traditional values within the development strategy. The 
development of sustainable Native business enterprises that stimulate economic growth in Native communities will lead to economic prosperity, self-determination and selfgovernance. Self-determination is a major driving force of Native business development to create stable economies and bring prosperity to their families and communities. Two strategies used to promote economic development within the communities are entrepreneurial growth and partnership development with external established businesses.

\subsection{Entrepreneurship in Native communities}

Native business development is a key strategy in economic development. The number of Native entrepreneurs in Canada is growing both on and off reserves. In 2001, there were more than 27,195 self-employed Native peoples, an increase of $30.7 \%$ since 1996 (Statistics Canada, 2002). The 2006 Census revealed more than 37,000 selfemployed Aboriginal people in Canada, showing a 38\% increase (Statistics Canada, 2006). This trend, along with increasing support from government and bands, is a good indication that this number will continue to increase.

In March 2007, the director of economic development programs at Indian and Northern Affairs Canada, Allen Frost (2007), expressed his belief that there will be an influx of Native business owners over the next few years. Frost (2007) attributes this influx to the rapid rate of growth of the Native population in Canada and the widespread desire among Native youth to own their futures by creating businesses, as opposed to working for others. This trend in entrepreneurship has increased Native 
businesses both on and off reserve. Native peoples understand that economic development and the creation of wealth in communities are directly linked to the success of Native businesses.

Native businesses are also diverse and represent many industries (CCAB, 2011). $18 \%$ are in construction, $13 \%$ in the extractive industries (agriculture, fishing, hunting, mining, forestry, and oil and gas); $28 \%$ operate in the knowledge- and service-based industry (education, scientific, health, and social services); and the remainder are various self-employed businesses (CCAB, 2011). 85\% of these businesses are tied to their communities (CCAB, 2011).

Despite the fact that Native businesses stand to create wealth and jobs in Native communities (Nelson \& Sisco, 2008; Sisco \& Stewart, 2009), there are more Native businesses off-reserve than on-reserve. This trend will continue to place reserves at a disadvantage as more businesses and members move off-reserve.

Native businesses in Canada face the same challenges as many small businesses, as well as unique challenges that non-Native businesses do not face (Nelson \& Sisco, 2008). Native businesses must consider the unique challenges of the communities in which they are located. These challenges may include acute social problems, limited infrastructure, small community size and remoteness, lack of capacity and expertise and limited access to resources and the market (Loxley, 2000:2010; Nelson \& Sisco, 2008; Sisco \& Stewart, 2009).

Loxley (2010) identifies managerial problems, notably in marketing and finance, as being among the main reasons why Native businesses (and most small businesses) 
fail. Other contributing factors include: building businesses with short-term funding and inadequate long-term plans, lack of capital, and inadequate financial controls, inadequate working capital, insufficient cash flow from operations, and inadequate internal controls often resulting from a weak business plan (e.g. excessive salary withdrawals from enterprise funds) (Loxley, 2010). Many of these relate directly to capacity issues. Additionally, for many Native businesses on reserves, access to capital through collateral or leveraging assets is not possible. The Indian Act does not allow Native people to own lands (Indian Act Section 20; Nelson \& Sisco, 2008; Sisco \& Stewart, 2009). Land belongs collectively to the band and is administered by the band. Lands are also held in trust by the Crown and are administered through Indigenous and Northern Affairs Canada. However, with the settlement of many land claims across Canada, new business opportunities are being created for Native communities and peoples living on-reserve. Native people are now gaining enough autonomy to create new businesses. These emerging Native enterprises are looking for new ways to create a successful business while maintaining community support (Nelson \& Sisco, 2008; Sisco \& Stewart, 2009).

\subsection{Corporate partnerships}

With the increase in successful Native businesses (Nelson \& Sisco, 2008, Sisco and Stewart, 2009) there has been considerable interest from corporate Canada in creating meaningful partnerships. Many large, especially resource, corporations are looking to Native communities to create economic partnerships through which they can 
access land, support, and services for various industries and new business opportunities (Nelson \& Sisco, 2008; Sisco \& Stewart, 2009). Many of these corporations are also looking to replace an aging workforce as many baby boomers retire (Duxbury: 2007). As the fastest-growing population in Canada, Native peoples are poised to help fill that gap (Frost, 2007).

Developing partnerships has been cited as a strategy for Native businesses to build capacity in their enterprises and facilitate sustainable community development (Nelson \& Sisco, 2008; Sisco \& Stewart, 2009). Partnerships can offer resources, finances, fiscal stability, access to markets, capacity, and more. Communities, entrepreneurs, and band-owned businesses see partnership as an opportunity to gain these resources while maintaining their priorities.

Chief John Thunder, from Buffalo Point reserve in Manitoba, sees partnerships with larger organizations as a chance to enhance and promote local businesses (Chief John Thunder, personal communications, 2012). He sees economic activity returning to his community and promoting local business growth. Chief Dennis Meeches from Long Plain First Nation in Manitoba sees partnerships as important, yet would like to see the day when there are partnerships with other successful First Nations businesses (personal communications, 2012). Partnerships with government, large corporations, or special interest groups can provide fiscal backing, expertise, and access to resources. The concept of revenue sharing, job creation, and ownership are all common themes in developing these partnerships (Chiste, 1996; Anderson, 1999). 
As mentioned earlier, several community challenges, such as ongoing social issues, infrastructure, and capacity, may exist. These challenges may impede partnership development as well as what type of partnerships are suitable for the band and community. These factors will not only have a direct influence on the strategies needed for operations but also the extent of partnership involvement.

Native businesses must also consider their stage of development when choosing a business partner (Chief Erwin Redsky, personal communications, 2012). By gaining partners early in business development, there may be an influx of capital, but there are also added pressures to become profitable. With any partnership, there are expectations. Native businesses usually do not want external influence of partners on business strategy and direction.

Yet, despite good intentions partnerships often fail due to misunderstandings of expectations and needs of the community and the corporation. Corporations are not altruistic nor do they consider it their responsibility to maintain the social welfare of a community. However, it is precisely this philosophy of community well-being that drives many Indigenous communities. Unfortunately, negotiations and partnerships often end up with concessions and inequalities due to a lack of capacity in the communities to effectively fight large corporate budgets and lawyers (Chief Dennis Meeches, personal communications, 2012). Too often this results in an inequity of resource revenue sharing, leading to a potential loss of ownership, control, and jobs for community members. According to Sisco (2015), this is due to a fundamental conflict between European liberal-capitalist frameworks and Indigenous value systems, wherein, 
liberal-capitalism tends to focus on individual rights and values land and intellectual property as commodities to be commercialized (Behrendt \& Kelly, 2008; Janke, 1998). In contrast, Indigenous value systems tend to focus on collective rights and to value land and knowledge as sacred (interconnected with themselves) resources to be protected through custodianship (Behrendt \& Kelly, 2008; Janke, 1998). (p. 62).

Berger (1977) argues that in addition to environmental stewardship, these Indigenous value systems are more aligned with sustainable economic existence. Sisco (2015) argues that this foundational discrepancy, paired with the pervasive power differentials between the corporatized Settler state and Indigenous peoples, often results in the ongoing colonization of Indigenous lands,

The Settler state benefits (as usual) from the exploitation of land and resources in the Indigenous domain, while Indigenous people extend their customary jurisdictions, in which the incidents of Native title or customary property rights originate, into the modern economic and political sphere (Langton and Palmer, 2004).

The contrasting philosophies around land stewardship are merging. With the increase of socially conscious companies comes a closer link with Native ideologies around environmental stewardship. Partnership then takes on several new meanings, not just fiscal but socially responsible.

\subsection{Corporate Canada and social responsibility (CSR)}

Today, corporations are looking to partner with Native businesses for several reasons. While the major driving force usually comes from the resource industry looking to gain access to Native lands, other reasons bring businesses to the negotiation table as 
well. In some cases, businesses are simply looking for another economic partner or view partnering and negotiating with Native peoples as a form of corporate social responsibility (CSR) (Gasse \& Bhererl, 1990).

Corporate social responsibility is the act of a corporation conforming to legal and moral criteria within a business context that may be properly qualified as responsible (Buono and Lawrence, 1985). While CSR is often touted as an innovative new approach, it actually dates back to classic liberal economic philosophy. Smith's (1776) works warned about the power that class structures could have if businesses acted irresponsibly in dismissing societal needs. This is an ongoing debate today as Hawken writes,

While the debate as to whether we have a human problem (people who are unwilling to change their thinking or lifestyle), or a business problem (opportunistic companies willing to benefit from expediency, greed, and short sightedness), I suggest we have a systemic problem. (pp.138: 2005)

Yet, as noted earlier, neo-classic economic theories began to favour individual gain without ties to social responsibility, and social responsibility was seen as the responsibility of the government and not businesses. This belief has continued today with the government's creation of regulatory bodies to protect society and the environment.

Corporate social responsibility is also becoming more important to businesses as shareholders and customers demand increased accountability. Some authors such as Jerry Anderson (1989) and Michael Beesley (1978) believe that CSR is now prevalent due 
to the increasing legal compliance faced by corporations. In other words, corporations are only responding to CSR because social pressures and legalities force them to act in a responsible manner (Anderson, 1989; Beesley, 1978). From this purview, corporations incorporate CSR into their values because it allows them to remain competitive and viable. Reputation management is crucial to maintaining a position in the market. Corporations that have a strong sense of social responsibility tend to secure greater trust from their customers and shareholders (Ezekiel, 2005). Importantly, CSR also includes respect and understanding of cultural differences. As a result, companies in Canada are also creating policies and procedures to be more socially responsible when dealing with Native peoples.

\subsection{Aboriginal relations and policy}

Relations between corporations and Native communities are often strained because of their differing interests. While corporations tend to be focused on increasing profits, community interests are more holistic and often rights-based, including selfdetermination, community development and well-being, and/or procuring a funding source for new community-owned business development. Some progressive corporations have created models for ensuring positive Aboriginal relations. While the federal government has provided some vague guidelines for consultation in 2011 (Department of Aboriginal Affairs and Northern Development Canada, 2011), they do not provide much direction on what is an appropriate level of consultation (Nelson, 2007a). The following are the guiding principles published by Aboriginal Affairs and 
Northern Development Canada (2011):

1) Consult with Indigenous groups where contemplated action could potentially adversely impact their rights.

2) Assess how a contemplated act might infringe upon Indigenous rights and how consultations should be carried out.

3) Engage in early consultation.

4) Balance Indigenous with other societal interests.

5) Coordinate federal departments for efficiency.

6) Integrate consultation into other mechanisms (environmental assessment and regulatory approval processes).

7) Coordinate with partners (i.e. corporate proponents).

8) Honour existing agreements and build long-term relationships with Indigenous groups and partners in consultation and accommodation activities

The Anishinabek nation published their own consultation guide that reflected their communities' needs. The following are the Anishinabek guidelines (Union of Ontario Indians: 2003);

1) Invitation to Consult. This must be done early and include the right parties. It must be received in reasonable time to allow the nation to prepare.

2) Agree to Consult. This should be a written agreement but agreeing to consult does not mean agreeing to the project.

3) Refusal or no response. If the community or nation does not want to consult, then respect should be given. No response does not mean approval. Reinvitations should be sent out. 
4) Outline position and action plan. Include a description of the initiative, summary of activities to date and keep the invitation open to other potential parties.

5) Develop and implement a consultation plan. Outline the scope and expectations of the consultation and how it will take place. Information must be disclosed at a reasonable time. There must be an agreement of the format and how information is presented.

6) Decision (proceed or abandon). The results of the consultation plan or action plan will be one of the factors in determining if the initiative proceeds or is abandoned. It is understood that the decision will be made with consideration for the concerns or issues that have been documented during the consultation process. The decision and rationale for the decision should be documented in writing and communicated to all parties. The decision and rationale will be included in the Consultation Report.

7) Consultation Report. Including:

a. A description of the initiative

b. The rationale for the decision

c. A list of who was invited to participate in the consultation process

d. A summary of activities undertaken to date i.e. meetings

e. A description of how information provided by the other party was used

f. Information on the current status of the initiative

g. A description of the process

h. Ongoing information exchange if required 


\section{i. Any other relevant information}

There is a clear distinction between these approaches. The Anishinabek nation is reacting to past infringement of their rights through establishing early and meaningful consultation. They also expect that a decision not to proceed on a project or initiative is to be respected. However, the duty to consult does not give Aboriginal communities a veto power as decided in the Haida decision (2004 SCC 73). The Supreme Court of Canada specified that there is no veto power in the consultative process. This has left both communities and businesses scrambling to deal with the duty to consult and accommodate without clear direction from the Crown where the duty rests.

In Canada today, there is little formal legislation, best practices, or guidelines on how to form business partnerships with Native peoples or bands. Several pieces of legislation that impact business agreements and partnerships are the Canadian Corporations Act, the Canada Not-for-profit Corporations Act and the Indian Act. The Indian Act defines the band structure and governance. However, as bands continue to create and use corporate entities for economic development and other enterprises, the band governance structures are not adequate (Dwyer, 2015). The Indian Act does not include structures for trusts, partnerships, or corporations. These entities are accorded the same rules as non-Native trusts, partnerships, or corporations. This means Native businesses are subject to the Canada Business Corporations Act, and any partnerships with band-owned enterprises, or with residents of reserves, must also conform to the Indian Act. 
Under the Indian Act, title to reserve land is ultimately held by the Crown, but the right to use the land is given to individual bands of Indians. Other provisions of the Indian Act protect reserve lands from falling into the hands of third parties, that is, parties other than the band and its members or the Crown (Caldwell: 1988).

Through the Indian Act, property on reserves is exempt from taxes and property seizures (Nelson \& Sisco, 2008; Sisco \& Stewart, 2009). This makes it difficult for Native peoples and bands to procure loans for business ventures, as they have no collateral to secure the loan (Nelson \& Sisco, 2008; Sisco \& Stewart, 2009). Potential partners are sometimes hesitant to enter into a partnership without some form of profitability or assurance of viability.

\subsection{Duty to Consult and Accommodate}

Corporate Canada has long viewed Native communities as barriers to land and business development. In the past, resource companies often developed and exploited resources on Native lands without consultation. Prior to the Mackenzie Valley Pipeline Inquiry (Berger, 1977), consultation with any Native group was reserved for land claims and reserve administration.

Today, the Crown recognizes the legislation of the Duty to Consult and Accommodate with Native communities that are affected by development of intrusive projects. The Crown's Duty to Consult (DTC) was affirmed in 1990 (R. v. Sparrow)

(Edmond, 2007; Natcher, 2001; Sossin, 2010), but developed nearly a decade later into a legal doctrine, based on three significant court decisions "now termed the 'Supreme Court trilogy' - the 2004 Haida Nation v. British Columbia and Taku River Tlingit First 
Nation v. British Columbia cases and the 2005 Mikisew Cree First Nation v. Canada case" (Department of Aboriginal Affairs and Northern Development Canada, 2011; Edmond, 2007; Newman, 2009a as cited by Sisco, 2015, p. 38). For First Nations this was a long awaited decision that not only affirmed their land rights but also would prevent further infringement on those rights. Consultation would be mandated by the courts and the Constitution to protect Aboriginal interests.

The Duty to Consult is triggered by Section 35 of the Canadian Constitution when the Crown considers any action that could potentially infringe upon a Native land, or treaty rights, whether that right is asserted or established, real or perceived (ManleyCasmir, 2011; Newman, 2009a; Sisco, 2015). The DTC may also be required under land claims, self-government agreements, and some regulations and statutes (Department of Aboriginal Affairs and Northern Development Canada, 2011; Sisco, 2015). The DTC was developed to be intentionally vague, so that it would develop with case law on a caseby-case basis (Potes, 2006; Manley-Casmir, 2011; Newman, 2009a; Sisco, 2015). Therefore, "The depth of the consultation required ranges on a spectrum from notice to deeper ongoing consultation (Manley-Casmir, 2011), based on 'the strength of the claim, the degree of importance of the right, and the degree of potential for infringement'” (Potes, 2006, p. 31, as cited by Sisco, 2015, p. 38).

Importantly, while the DTC places the obligation of fulfilling the doctrine on the Crown, the procedural aspects of consultation are commonly delegated to industry proponents or the communities (Fidler \& Hitch, 2007; Lem \& Reiner, 2011; Natcher, 2001; Newman, 2009a; Robinson, 2007; Sisco, 2015). This has led to multiple 
procedures, processes, expectations, and delivery of the DTC from industry, corporations, or communities. While the one-size-fits-all approach is not practical, there are commonalities that are being implemented.

One commonality is early consultation in project development. If there is a real or perceived infringement of "Aboriginal Title", early consultation needs to take place (Delgamuukw vs. British Columbia, 1998). For many communities, the earlier the consultation the better it is for the community. This allows the community time to react and prepare for possible action or partnership.

Secondly, environmental impact assessments and economic impact assessments are also standard practices of any project involving Native lands and peoples. This is based on the Crown's knowledge of potential or existing Native rights or title to the land and the duty to care that the Crown has for all Native lands and peoples.

In providing a Duty to Consult, an obligation to accommodate Native concerns and needs may also emerge. "The primary goal of accommodation is to avoid, eliminate, or minimize the adverse impacts on potential or established Aboriginal or treaty rights, and when this is not possible, to compensate the Aboriginal community for those adverse impacts" (AANDC, 2011). If there is a danger of significant impact on Native culture, lands, or traditions, then steps need to be taken to minimize the harm. Often this can be accommodated through partnerships between corporations and Native businesses and communities. Native communities can grant consent to businesses to use their lands if the band or community government is in agreement (AANDC, 2011). 
This is also subject to an impact assessment of the project and submitted and approved by the Minister of Indigenous and Northern Affairs Canada.

\subsection{Sustainable community economic development for Native peoples}

Speevak Sladowski and Hayes (2007) describes economic development as a process by which people build organizations and partnerships that interconnect profitable businesses with other interests and values of the community, like quality jobs, marketable skills, good health, affordable housing, equal opportunity, and ecological responsibility. From a sustainable community economic development perspective, there is a need to incorporate community values and needs while enhancing wealth and local businesses. Sustainable community economic development is about creating a sustainable economic base for a community that will enhance self-determination (Loxley, 2010). For many Native communities, this is their economic development mantra.

Many Native leaders, elders, and communities are looking at sustainable community economic development as a means to reduce their communities' state of economic and social dependency on federal government funding and programs (Loxley, 2010). However, many economic development projects have not been as successful as expected. Calvin Helin (2009) describes the conditions of dependency as prohibitive to the success of economic development. As mentioned, Native people have been doing business for thousands of years, yet the post-colonial state of dependency continuously denies Native people the opportunity for business ownership (Helin, 2009). To break 
this state of dependency, there is a need for a paradigm shift among both First Nations and Settlers in Canada. Specifically, Native communities must understand that trade and business activities have always been part of their cultural heritage and that they do not have to compromise traditional values in order to embrace business development. At the same time, Settler Canadians must also understand that Native people can engage in and be successful in business. Yet, there is a tendency for Settler society to paint all Native businesses with the same brush. As First Nation business leader John Bernard of Donna Cona says, "There should be no difference between a Native business and a nonNative business in providing services, but the difference is that if one Native business fails, they all get painted with the same brush" (Nelson \& Sisco, 2008, p. 18). Part of the post-colonial legacy that First Nations people are faced with includes overcoming the messages they are inundated with from Settler society that limit their abilities and diminish their self-efficacy as business people and otherwise, while fighting to dispel such negative stereotypes (Nelson \& Sisco, 2008).

To address poor social and economic conditions through increasing their wealth and prosperity, Native communities have engaged in economic development (Anderson, 1999; Cachon, 2000; Chiste, 1996; Gasse 1990; Loizides, 2006). This includes the development of entrepreneurship, business growth, and corporate partnerships to stimulate a local economy. Native business development creates wealth, labour capacity, and employment opportunities, which can help to promote the well-being of Native people at both the individual and community levels. 
However, communities struggle with many challenges in achieving these ends, and capacity figures prominently among them. Several successful communities such as Wikwemikong, Osoyoos, and Ktunaxa-Kinbasket have engaged in large-scale business ventures to maximize investment return while increasing employment. These ventures have brought both capacity and wealth into the communities. With increased wealth comes increased accountability to regulatory bodies such as the Canadian Corporations Act, Canadian Securities Act, and both federal and provincial laws. They also have an increased accountability to their communities and chief and council. Native business people are then faced with the challenge of balancing the accountabilities to regulatory bodies, stakeholders, and shareholders with their chief and council and community's interests while preserving cultural heritage and traditions. Often these accountabilities and philosophies are in conflict, causing devastating results for the success of Native businesses.

\subsection{Contrasting Business Philosophies}

Capitalism and the neo-classic economic theories that drive corporations are not Native philosophies. In fact, Native models of business are in direct contrast to the neoclassical theory of economics that is the foundation of modern corporations. This philosophy is still the primary driver of business structures and processes today. In Adam Smith's Inquiry into the Nature and Causes of the Wealth of Nations (1759), he proposes a model of economics that indicates free markets and competition can lead to economic well-being and prosperity for the individual. The neo-liberal state favours 
"individual private property, free markets, and free trade" (Harvey, 2005, p. 64). In David Caldwell's Aboriginal business survey of 1998, just over half of the business owners saw growth as an important strategy (Caldwell, 1998). However, many Native businesses pursue the goal of sustainability and stability to help their communities and families. The Canadian Senate Committee on Aboriginal People states that Native communities are "a more community-oriented, less individualistic culture, which leads to a decidedly refreshing approach toward economic development" (2007, p. 4).

According to the classic and neo-liberal thought upon which corporations are based, social programs and well-being are not the role of corporations; this falls into the realm of government responsibility (Smith, 1776). Profitability and growth are first and foremost for any corporation. Today's business shareholders have the controlling interests and expect personal profits and growth. Economist David Korten (2007) subscribes to the neo-liberal economists' perspective that the most important aspect of economics is the creation of assets and that capital ensures maximum profits to the shareholders or the individuals. Neo-liberalists favour individual freehold of corporations that leads to social outcomes as a by-product of corporate success. Therefore, community sustainability and wealth creation are not among corporations' primary goals. This philosophy places community sustainability, low or non-existent, on a scale of corporate values or mandates. Corporations only recognize community as a source of labour to generate products.

Adam Smith (1776) did recognize labour, product, and market as having great effect on power and social class. In his book, The Theory of Moral Sentiments, the nature 
and motives of morality and choice and consequence are his main areas of inquiry. Smith's theory advocates a social consciousness that businesses need to understand and adopt for the betterment of mankind. His sense of duty, akin to our modern understanding of social consciousness, has been noticeably absent in corporations until the very recent emergence of corporate social responsibility (CSR). In today's economy, the continued movement towards individualism and private land ownership is in direct contrast to Indigenous philosophies and how they perceive businesses' roles in supporting social welfare within their communities. As mentioned earlier in this chapter, the European cultural values of individualism, capitalism, and the commoditisation and commercialization of land clash with Native values of collectivism, land custodianship, balance, and reciprocity (Sisco, 2015). It is this juxtaposition of opposing philosophies that prevents or hinders Native economic development or investments in Native businesses.

Moreover, it is this distinct set of cultural values that drives the existence of Native businesses (Nelson and Sisco, 2008). Consistent with Indigenous value systems (Loxley, 2000; Sisco, 2014), Native business approaches tend to prioritize business sustainability. They look to help the community prosper and achieve general well-being through the creation of jobs, infrastructure, and community development. Thus, the financial success of a Native business is often a means to an end, but it is not the priority (Halfe, personal communications, 2008; Redsky, personal communications, 2011). The priorities of most Native businesses are to maintain the interests of the community and the band while gaining profits. 
Community-owned enterprises (commonly band-owned businesses, client- or worker-owned cooperatives, community development corporations, and not-for-profit incorporated entities, but also partnerships and for-profit enterprises) are often seen as a good fit for Native communities because of their suitability to community development's cooperative approach and broader goals of well-being (Loxley, 2010). However, challenges often arise for these businesses when these 'third sector' businesses take on projects that are outside of their normal operations, such as building infrastructure within communities. Specifically, when Native-owned businesses link economic development to public works or infrastructure development, communities often expect the business to support social services as well (Halfe, personal communication, 2008). This deviation from traditional economic development models of entrepreneurial growth, business development, and partnerships can be distressing to communities. Particularly because this creates a conflict of interest wherein the business' economic development interests are in direct conflict with the community's social development interests, "namely, the goal of profit on the one hand and democracy and community input and control on the other" (Loxley, 2010, p. 31). In these scenarios, Native economic officers are often seen as social workers or public works managers and become unable to focus on economic development. 
Sturdivant argues that community-based enterprises are inherently flawed as, "The greater the degree of democracy in the enterprise, the less effective its management will be" (1979, pp. 42-43 as cited in Loxley, 2010). Moreover, The Twentieth Century Fund (1971) and Sturdivant (1972) argue that community-owned enterprises tend to be designed to provide for more democratic communal decision-making, but often fall short of

One does not sell the
earth upon which the
people walk.
Tȟašúnke Witkó, Oglala
Sioux
achieving it in practice (as cited by Loxley, 2010). However, Loxley (2010) refers to a wealth of evidence (Wismer \& Pell, 1981; Williams \& Scott, 1981; Jackson, 1984; Development Education Centre, 1983; Thalassa Research Associates, 1983 as cited by Loxley, 2010) demonstrating that many Native community-owned enterprises are prospering across Canada.

The role of elders is another important distinguishing characteristic of Native businesses. In contrast to capitalist value systems that tend to treat youth as educationally and technologically superior, Indigenous value systems tend to respect elders' "repositories of knowledge, histories, customs, and traditions" (Berger, 1977 as cited by Loxley, 2010). Elders provide advice and guidance to businesses on spiritual and philosophical levels. Elders are not only the holders of traditional teachings, they are also the respected link to the community (Berger, 1977 as cited by Loxley, 2010). Their guidance and wisdom are sought after in all aspects of life. The community also has an expectation that those businesses working in or with the community will respect the traditions of the culture through contact with the elders. 
This retraditionalization (Newhouse, 1992) or the return to Indigenous cosmologies and worldviews along with a reinforcement of cultural identities is increasingly asserting concepts within business development. Retraditionalization is an ongoing decolonization process, in which regaining of one's cultural identity and preserving cultural values is vital. Retraditionalization is also relied on for cultural teachings and beliefs to solve problems and move closer to self-determination and selfgovernance (LaFromboise et al., 1990).

Retraditionalization is steeped in Native values and traditions such as community welfare or well-being, sharing, and generational sustainability which can be, and in some cases are being, introduced to Aboriginal businesses. However, it is not a return to the past but rather a movement of looking to the past to go forward in the future. 


\section{Chapter 6 - Opportunity Through Economic Development for Native People in Canada}

\subsection{Introduction}

The purpose of this chapter is to understand the ongoing development challenges within Native communities in Canada and suggests a way forward within a framework that is mutually beneficial and respectful of Native peoples and Settler Canadians. Canada's historical and ongoing colonization has led Native peoples to distrust and, thus, resist governmental policies and practices. Consequently, many Native communities and nations have fought for self-government and selfdetermination to foster cultural preservation, as well as greater control over their own lands and future.

However, this model of community control, which arose in the 1970s (Assembly of First Nations, 2012), does not preclude economic development. In fact, the purpose of this chapter is to explain how economic development is an integral component of this model. The question of whether economic development will help or hinder a community rests on how it is conducted. Although the narrative of this chapter focuses mainly on Canada, it largely reflects a common account of many Indigenous people and communities across the world (Alfred, 2009; Maddison, 2013).

\subsection{The development debate}

Economic development is a sustained community effort to improve both the local economy and the quality of life by building the area's capacity to adapt to 
economic change (Loveridge et. al., 1991). Other theorists (Fontan, 1993; Shipley and Snyder, 2013; Shragge, 1997) have added the concept of community economic development (CED), which requires community participation in its social welfare, economic activities, and in the development of its locality or the processes of its governance. According to this definition, it would seem all communities would welcome development and should be involved in its determination. Yet, for colonized peoples, including Indigenous populations, the term 'development' evokes mixed feelings, expectations, and meaning. David Newhouse describes economic development as the holy Grail of the Aboriginal community. There is much hope that is pinned on it. It is supposed to be that activity which provides people with control and allows them, indeed, enables them to preserve their culture and way of life (Newhouse, 78:2001a).

On one hand, development can represent freedom and opportunity. Most community leaders want the best for their people, such as local employment, wealth creation, self-governance, and associated opportunities, all of which economic development can bring. Economic development offers many communities a way to break free from cycles of poverty and provides many Indigenous youths with hope for a better future, including meaningful work, proper housing, clean water, and education, while also offering opportunities to maintain their language, culture, and identity (Loxley, 2010; Anderson, 1999, Brascoupé, 1993).

On the other hand, development can represent dependency and loss. At the end of the Second World War, the Western imperative of modernizing the world through development prevailed (Maddison, 2001). This dominant ideology held that capitalism 
would allow markets to develop worldwide and increase wealth and prosperity for all.

On the contrary, this resulted in a widening of the income gap between the wealthy and the poor, which was especially pronounced among Indigenous populations. As former UN Special Rapporteur Rodolfo Stavenhagen states that not all poor people are Indigenous, but most Indigenous people are poor (Stavenhagen, 2014). This development gap became increasingly apparent in the 1960s and 1970s when the concepts of unequal exchange became evident, and developing countries could not match the markets, capital, or the technological advantages of the Western world (Maddison, 2001).

Increasing globalization provided large corporations with the means to purchase abundant cheap labour in third-world countries, leading to dramatically lower costs of manufacturing (Maddison, 2001). This resulted in many nations being forced into a state of economic dependency on foreign aid, imports, resources, and multinational corporations. While entire countries struggled to feed their populations, encourage economic growth, and create employment for their citizens, foreign countries reaped the financial benefits on an unequal scale (Harvey, 2003).

Development also increased the need for resources and control of labour. Borrowing from Smith's (1776) concept of "primitive accumulation"16", corporations' control of labour and goods resulted in a corporate primitive accumulation or, as Harvey states, over-accumulation (2003). It is the wealthy states that maintain a colonial control

\footnotetext{
${ }^{16}$ Attributed to Smith but expanded on by Marx. The concept of how pre-capitalist modes of production, such as feudalism and chattel slavery, are transformed into the capitalist mode of production. This would include alternative Indigenous economies.
} 
over indigenous populations and dictate national policy. International organizations are formed by influential industrial nations to control resources, labour, and markets beyond their national agendas, giving power to corporations rather than the state. Consequently, governments and corporations pressure Indigenous populations to sell, relinquish, or leave their lands. The spectre of capitalism began, and continues, to dispossess Indigenous populations of their traditional territories worldwide. As a result, Indigenous peoples everywhere are facing various political pressures and policy challenges such as forced education, relocation, subsidization, and even genocide (TRC, 2015). The dispossession of land and resources completes the colonial project of assimilation and marginalization of Indigenous populations worldwide (Alfred, 2009). While many people may equate these policies with brutal dictatorships or nondemocratic nations, some of the worst perpetrators of cultural assimilation and genocide are, in fact, the nation-states of the Western world. Canada has a long and often violent history with Native people. In Canada, forced relocations to what are called 'reserves' segregated the Native population and left them increasingly dependent on government support. This form of relocation 'for the good of the people' and 'for the good of the nation' failed miserably and only created a much larger issue of dependency for both communities and the state. Reserves became highly depressed areas filled with poverty and little hope of employment or education. Today, the highest suicide rates in Canada are on First Nations reserves and in Inuit communities. The incidence of suicide among Inuit youth is staggering, ranging from $6-11 \%$ depending on the community (Kirmayer, et al., 2007). 
Another important issue that has implications for economic development within First Nations was the implementation of church-run residential schools, which began in the 1800s, with the last school closing in 1996 (Milloy, 1997). For Native people in Canada, this was a harrowing experience and embedded a further mistrust in the government and educational institutions. Research into residential schools is welldocumented (Haig Brown, 1998; Milloy, 1997, 1999; Ward, 2004) and shows a systematic attempt on the part of the Canadian government to assimilate children by isolating them from their parents and forcing them to become "civilized" through education.

The Anishinabek Nation's Residential Commemoration (2013) project estimates that over 150,000 First Nations, Inuit, and Métis children ages four to sixteen years attended Indian residential schools in Canada. Many children did not survive these schools, and many of those who did continue to be traumatized by the abuses they endured. This has resulted in ongoing intergenerational trauma and lateral violence (TRC Findings, 2015).

In 2008, Canada issued an official apology to the residential school survivors read by Prime Minister Stephen Harper. Despite this, the legacy of mistrust in the government, and more specifically the educational system, is still prominent and often generational as the stories were passed down. Other policies included the Sixties Scoop (Sinclair, 2007), which allowed the state to take Native children from their families and place them with Settler families in order to assimilate them. The government even sanctioned experimentation on malnutrition within the Native population by providing 
food that had no nutritional value to see the effect on humans (Mosby, 2013). The stories of abuse and assimilation continue to be told by many, and researchers are uncovering more truths about Canada's uncomfortable colonial history.

Given this history, it is understandable that the question of economic development is clouded with a long mistrust of government, church, corporations, and even the general Canadian population. Yet we still see the resilience and resistance of communities and nations to maintain their own identity, language, and selfdetermination. Anishinabe scholar Gerald Vizenor calls this "survivance" (Vizenor, 2008), which he defines as both resistance and survival together, moving away from the colonial dialogue of victimization and dominance to one of mutual understanding.

Today, there is an abundance of economic development opportunities for Native communities across Canada, many of which rest on an exchange of resource development for profit, like the Ring of Fire, the Gateway Pipeline project, Kitimat Container Port, and other large-scale projects. However, Native communities need to be assured that they are not simply shifting from an era of government dependency to one of corporate dependency.

The Harvard Indian Project on American Indian Economic Development (Cornell, 1988: 2003: 2010) offers an extensive study to see what conditions would look like to favour economic development in "Indian Country"17. Cornell and Kalt (2003) encourage a need for separation and limitation of powers, meaning setting up an independent

\footnotetext{
${ }^{17}$ Indian country is a term used in the United States to describe the lands within a reservation or in trust. It has taken on a larger slang definition meaning all of the lands that used to be occupied by the Indigenous population.
} 
governance body that maintains the interest of an enterprise. They also recommend a separation of electoral politics from day-to-day management of business enterprises (Cornell and Kalt, 2003). Many reserves have short electoral periods (2 years as prescribed by the Indian Act). This change in politics can interfere with a business enterprise as a new direction of council may opt to sell off the enterprise or abandon it. It has to remain viable throughout political change and remain at arms length from political influences.

Anderson (1999) writes that Native people in Canada want to develop an economic system that will improve their socioeconomic situation. However, he further explains that this also goes hand-in-hand with self-governance and self-determination (Anderson, 1999). In other words, Native people must have meaningful control of their own lives, lands, and development. This has not happened for most Indigenous populations; in fact, the gap between the wealthy and the poor has grown (World Bank, 2010) with Indigenous populations faring the worst. Development on a worldwide scale has not reduced poverty and in some countries has stopped altogether (United Nations Development Project, 2011). To understand this failure, one must first understand how we came to this realization.

\subsection{Resistance and renewal: towards economic development}

Today there are still policies in place to assimilate the Native population into the greater Canadian population. Land dispossession is still an issue within the Canadian context. Canada's highest courts are backlogged with Native land claims to determine 
which land is considered Crown land and which is considered traditional Native territory. Canada's approach to First Nations was to legislate their identities and cultures through the Indian Act, which governs and regulates who is considered Native, who has 'status', and to what community they belong through the Indian Register (Aboriginal Affairs and Northern Development Canada, 2014). This colonial act has also created conflict and division among Native communities regarding who is legitimately Native. The Government of Canada and the Indian Act place a limited financial dollar value on the social well-being of those who are registered members of a community (First Nations and Tribal Councils National Funding Agreement Model for 2015-2016, 2015). In essence, this creates a conflict of interest for the community's leadership that has lead some communities to prevent new memberships, due to limited financial support. Yet, community leaders generally want their communities to grow and prosper, while maintaining traditional ways.

What is needed to promote economic development that is in keeping with Native traditional values is a community control model of economic development that promotes self-determination. However, the development of such a model requires community consent and participation. Obtaining consent and negotiating the terms of the development (should consent be granted) require full community participation realized through meaningful consultation and engagement (Sisco, 2015). Importantly, communities must be given a reasonable amount of time and support to understand, discuss, and consider the potential impacts and benefits of the proposed project with their extended networks (Sisco, 2015). Economic development outcomes within this 
model include equal revenue sharing, partnerships, and community control. They may also include limited economic encroachment or community-controlled economic development, which allow communities to adjust to change and provides them with a more rigid control of land use and environmental impacts (Campbell, 1999). Unfortunately, this has not happened, and many communities are left out of revenue sharing while their lands are being exploited (Sisco, 2015).

Native resistance and pressures from human rights groups are slowly changing this assimilationist attitude of exploitation. New forms of self-governance and partnership agreements are being explored within Canada, including twenty-one signed self-government agreements involving over thirty-five communities across Canada (Aboriginal Affairs and Northern Development, 2013). In 2014, a landmark decision by the Supreme Court of Canada reaffirmed that the Tsilhqot'in Nation does have inherent rights to their traditional territory (AFN, 2014a). This not only reaffirmed their title but also included the right to decide how the land would be used, including natural resources. This is significant because for the first time sub surface rights were included in a decision.

Finally, the plausibility of recognizing a sovereign nation within a nation is being seriously discussed by Aboriginal leaders; "Self-government agreements give Aboriginal groups greater control and law-making authority over a comprehensive range of jurisdictions, including governance, social and economic development, education, health, lands, and more" (AFN, 2014a). 
The Government of Canada is also starting to move towards a more inclusive position recognizing inherent rights and titles over land, as well as the Duty to Consult with communities as entrenched in Canada's Constitution. In November 2004, the Standing Senate Committee on Aboriginal Peoples in Canada undertook a study of economic development within First Nations communities. The report stated that many First Nations peoples do not have adequate housing, clean water, or health care, leaving them "far from realizing" meaningful economic development (Standing Senate Committee on Aboriginal Peoples, 2007). Specifically, the report stated that one of the major barriers to economic development was insufficient education and training, which has led to capacity challenges (Standing Senate Committee on Aboriginal Peoples, 2007). This was later echoed in the Human Rights Council's report on the rights of Native peoples in Canada (Anaya, 2014). Building on this report and others like it, Native leaders continue to look for meaningful and productive ways to engage in the economy in order to create opportunities within their communities. Government-wide initiatives have been largely focused on education, making it the cornerstone for increasing the readiness of economic development within Native communities. However, there is also a need to focus on entrepreneurial growth, partnership development, and communityowned enterprises. A more holistic approach to community wellness and development is needed.

For many Native peoples, economic development is an important part of selfdetermination and self-governance. As discussed in Chapter Three, self-determination is linked to economic self-sufficiency. Many bands have economic development 
corporations to grow, expand, and help business development as well as create wealth for the community (Loizides, and Wuttunee, 2005). Many development corporations are concerned with increasing jobs within the community. However, this is only one area of growth that is needed for the community. Economic development is based on a comprehensive plan that may include both internal and external development.

\subsection{Internal economic development}

Internal economic development for many bands is a key priority. Internal development concentrates on economic growth within the community in order to foster new jobs, business opportunities, and local business development. Creating a local store or a gas bar is a common strategy for many bands. While this can be a rewarding endeavour, the payback to the band office is little, if nonexistent. Yet, many bands want economic development to fund band programs. There is a constant pressure on these small businesses to provide profit to the band. In most cases, these small businesses do not provide income for the band. They do, however, create capacity and business knowledge for those involved. These small internal endeavours also create a few muchneeded jobs.

For some communities internal economic development is very successful. Osoyoos First Nation is one such band that has created many local businesses and opportunities for their people. Located in southern British Columbia in the Okanagan Valley, the Osoyoos valley is rich in good soil capable of growing grapes for wine production. The Osoyoos First Nation now has a vineyard and conference centre that 
has seen success in creating employment, partnership development, and directing funds back to the band office. Chief Clarence Louis of Osoyoos repeatedly talks about the need for bands to engage in businesses and remove themselves from the dependency of the federal government. For Chief Louis, this is their path to self-governance and selfdetermination. The band's economic development corporation now has over fifteen businesses that are successful and supporting infrastructure and public works along with other community initiatives (Osoyoos, 2015). Louis sees business development as the engine that gives them the ability to fund cultural activities that are not the responsibility of the corporation but rather the community. While this view may be a bit controversial since it separates culture from business, it is working for Osoyoos.

Yet, what if a community is located in a more remote area with very little transportation, resources, or business opportunities? Many of these bands are still looking at economic development as one possible solution to help alleviate the poor and desperate conditions they now face. Several bands such as Sandy Lake First Nation (Fiddler, personal communications, 2012; Kakagamik, personal communications, 2012) and Shawanaga First Nation (Sullivan, personal communications, 2011) have repeatedly tried to increase economic opportunities within the community but have had limited success. Other than the typical tourist industry initiatives that involve hunting and fishing lodges or, to some extent, local artisans, many endeavours are not successful. While the tourist and art industries may provide some local jobs, they produce very little income for the bands. Shawanaga has a rail line that was on a hundred-year lease that ended in 2005. Despite requests for partnerships, the lease has not been renewed 
(Shawanaga online, 2015). This is a lost opportunity for the band to gain funds for the right of way through their reserve.

Many bands also do not put enough resources into economic development. Often there is only one person in charge of economic development, and often they do not have the necessary training or knowledge. Bands seldom have trained economic development officers (EDOs) that can help to facilitate a change in development. Yet even having an EDO does not guarantee economic development. In most cases EDOs are underfunded and often not taken seriously by the chief and council. Economic development requires a large-scale commitment and a number of people to carry out the economic strategy of the council. Economic development also takes time and does not give immediate dividends back to the community. This makes it unfavourable for political re-election as community members often expect a quick return on community investment.

\subsection{External Economic Development}

One strategy that is not often undertaken is that of external economic development. Bands often want to see jobs as they show an immediate return on the investments made in economic development. Yet, one of the main purposes of largescale economic development is to create wealth and economic wellness within the community. This requires larger inputs of money and infrastructure. Some bands have looked to invest outside their community in markets that are known to make money. For example, Shawanaga First Nation bought a Don Cherry's restaurant in Perry Sound, 
Ontario, where the constant flow of customers made the endeavour successful, gaining an income for the band. By investing in an external market, in this case even a small market, there were immediate financial gains and a flow of money back into the community. Cornell and Kalt (2003) discuss the strategic investment of a band internally or externally. Does the band make use of its own resources or invest it externally to gain ongoing profits? For a community desperate to rebuild the infrastructure, this investment shows that the band was on the right track.

External investments can give immediate returns to bands as the local customer base, investment opportunities, or infrastructure already exist. Unfortunately, one of the major problems with external investment is the long-term vision to maintain that inflow of capital. The lure of chief and council to sell off their investments for a good return is a tempting transaction. It may in the short-term give a cash influx to the community and look good on the bottom line, but in the long run, it is a poor decision. This is a common move by politicians in a democratic society intended to make their bottom line look good and possibly gain them re-election, but it does not provide future generations with the sustainable income of the investment. This is another colonial imposition that has transformed the governance structure of band politics. Sustained leadership and vision are difficult to maintain.

Another area of external economic development is that of partnerships with larger corporations outside the community. This often comes in the form of resource extraction industries that are looking to gain access to traditional territories. These partnerships are growing in popularity but often do not yield the results expected by the 
community. Communities often think in terms of short-term internal gains rather than long-term gains from a partnership opportunity with the extraction industry or other industries. Many communities often negotiate for employment as jobs are at a premium. This is seen as a successful partnership if jobs are created. However, true development work provides increasing wealth and profits to the band office. Resource revenue sharing is one of the ways that bands should be negotiating for as a priority. This is a difficult thing to negotiate but in the end would give significant influx of wealth to the community. It is important to note that not all communities want to partner with the resources industry given the past unethical treatments they have faced. Many also see this partnership as a violation of their value system and commitment to protect Mother Earth. Resource extraction also may impede traditional hunting and access to country food. Yet, some communities do choose to partner with this industry so it is important to discuss this relationship. Many other industries offer ethical partnerships that can result in economic gain for the communities. Yet, in Canada the resource extraction industries are the largest, and they want to gain access to Native lands.

Those bands that are looking at both internal and external economic development are adopting a holistic strategy of creating local opportunities along with external investments. This also shows a sign of maturity in development that fosters increased partnership opportunities with external corporations (if that is what the band is looking for). This strategy not only provides local opportunities for job creation and capacity development but also creates a revenue stream for the band. This is the 
ultimate position that bands want to attain in order to gain self-sufficiency and selfdetermination.

\subsection{Capacity development and the role of education}

While education is not a focus of this thesis, it is important to acknowledge its role in economic development. The United Nations Development Program (UNDP) states that capacity development begins with education (UNDP, 2013). The UNDP supports capacity development predominantly at the institutional level. This education process can take place at a school, in an organization, or through various engagement processes and projects (UNDP, 2014). Yet, there is still a large gap in education between Canada's general population and the Native population (Nelson \& Sisco, 2008). While this gap is closing, there is a pressing need to continue to allow community input on education.

As mentioned, economic development creates jobs, entrepreneurship opportunities, joint venture partnerships, and opportunities for revenue sharing (Anderson, 1999; Asch, 1982; Cornell, 2010; Cornell and Kalt: 2010; Orr, 2013). Unfortunately, for many of our communities, the capacity and knowledge base is limited. Education is needed to build capacity in overall governance, particularly in the areas of financial management (AFOA, 2015; Goodtrack, personal correspondence, 2015).

The Government of Canada has also reformulated education policies to accommodate communities' desires for more control over curricula, which has led to 
the incorporation of traditional knowledge and language. Edward Benton-Banai (2004) emphasizes that educational success depends on cultural relevance. This realization of educational control is becoming apparent in some communities, but is far from being fully or widely implemented. Many Native youths still have to leave their communities and live away from their families in order to pursue an education (AFN \& AUCC, 2014b). Colleges and universities in Canada are beginning to take notice that the Native population is the fastest-growing population in Canada (Statistics Canada, 2012), and that Native students are increasingly studying entrepreneurship, governance, public administration, and finance. This is beginning to increase the capacity for Native economic development within communities. It is important to note that engagement in capitalism may be inevitable and for some, even desirable. However, we do not want to compromise our traditions, heritage, and values. Native knowledge and practices can offer a strong foundation for socially responsible investments, entrepreneurship, and business partnerships (Nelson, 2010). 


\section{Chapter 7 - Aditawazi Nisoditadiwin: Governance and Indigenous Traditional Knowledge}

\subsection{Introduction}

Expanding on many of the concepts discussed in the previous chapter, the purpose of this chapter is to examine how alternative models of governance are being developed for Native businesses looking to enhance their governance while maintaining culturally appropriate ways. This model is based on the Anishinabe concept Aditawazi Nisoditadiwin, which embodies the concept of two worlds of knowledge and ways of knowing and empowering oneself through both sets of knowledge, and Gerald Vizenor's (2010) notion of the Word Warrior, an individual who exists in two worlds with an understanding of both. In understanding governance from both a traditional and contemporary perspective, Native governance is walking in two worlds with an understanding of both. The rationale for the development of these models explores the values, philosophies, and traditional knowledge imparted through teachings that have influenced approaches to Native business governance and that guide Native business decisions. First, this chapter defines governance, political governance, and corporate governance. Second, it explores traditional teachings, Native business governance, and the relationship between the two, offering three unique Native business governance models based on traditional teachings. 


\subsection{Governance Defined}

The First Nations Governance Centre (2009) defines governance as,

The traditions (norms, values, culture, language) and institutions (formal structures, organization, practices) that a community uses to make decisions and accomplish its goals. At the heart of the concept of governance is the creation of effective, accountable, and legitimate systems and processes where citizens articulate their interests, exercise their rights and responsibilities, and reconcile their differences.

When the first Europeans arrived on Turtle Island (as North America is referred to by Anishinabe peoples), they brought with them their very different understanding of governance. European governance is a reflection of a national or even a global political system rather than a local system, whereas, as Taiaiake Alfred states, for First Nations, each individual has a role to play within the governance system (1999, pp. 26-27). This is one of the main ideological differences between Indigenous governance and Westernized governance.

From a First Nations perspective, a governance system is only legitimate if the citizens become active participants in their government. David Newhouse describes Aboriginal governance "as a much greater process than just Aboriginal government. It involves a whole range of societal actions being driven by Aboriginal ideas from Aboriginal thought" (78:2001a).

This is different from the liberalism found in Canada's current state where there is more concern for the overall welfare of its citizens from a statistical or macro-level view of social systems. Foucault's 'governmentality' is the liberal state's creation of institutions and an overall mentality to rule that legitimizes governmental control within 
(1990). For example, the state welfare system maintains societal appeasement by those who are accessing it and a sense of philanthropy from those who contribute to it. The use of state social welfare rather than individualistic responsibility for community seems to demonstrate that Western and Indigenous ideologies are moving further and further apart. Even as neo-liberalism has been devolving the state's powers toward more locality (provincial and municipal), there is still a sense of nationalistic goals of state welfare (Harvey, 2010).

Another split between traditional and contemporary governance is that of a values-based approach to decision making versus a compliance-based system. Native governance is not a prescribed set of absolute laws but rather a set of values that allow an individual or collective to make a decision based on the situation, needs, and their judgment. More contemporary governance has been based on compliance to codes and laws in order to ensure good governance. While contemporary governance is changing to a more hybrid model of allowing some judgment yet maintaining compliance, most professional organizations opt for the stricter compliance-based system.

\subsection{Political Governance}

In a First Nations context, governance is:

the process and structure by which councillors direct and manage council business. The objective of council governance is to enhance the well-being of community members and to protect their assets (land, buildings, equipment, and money). (Indian and Northern Affairs Canada, 2003, p.5). 
Political governance is the framework of rules and practices by which a political body, such as a chief and council, ensures accountability, fairness, and transparency. Chief and council have the fiduciary responsibility for the band's assets. They act much like a board of directors but with one major difference, they are responsible to the whole community. They also act within the framework of the Indian Act or a community constitution. This often leaves chief and council accountable for matters they have little control over (Indian and Northern Affairs Canada, 2003).

\subsection{Corporate Governance}

Corporate governance involves a set of relationships between a company's management, its board, its shareholders, and other stakeholders. Corporate governance also provides the structure through which the objectives of the company are set, and the means of attaining those objectives and monitoring performance are determined (The Organization for Economic Co-operation and Development, 2004, p.11).

This definition shows that the relationships between the stakeholders and the board are integral. McRitchie (2015) also states that corporate governance is most often viewed as both the structure and the relationships, which determine corporate direction and performance. To govern an organization, a board needs rules and regulations in place. This set of rules, called the bylaws, is subject to the Canadian Corporation's Act.

The Carver model of corporate governance is recognized as the most common form of corporate governance used in North America today and is designed to empower boards to perform their duties according to their obligation to the organization they govern (Carver, 2012). Alternatively, the David Brown Model (2002) of corporate 
governance was developed for a Canadian context and emphasises the role of social responsibility to board governance. Both of these models recognize the 'relationality' 18 of the board to the shareholders.

As discussed in chapters 1 and 2, for Native band-owned businesses, relationality between the board and shareholders is especially important because the board has a relationship with chief and council as well as the community as a whole. Boards should be at arm's length from politics, and the decision-making process should be as free as possible of conflict of interest.

To reduce conflict of interest in decision-making, an organization can opt to include employees or even community members, including an Elders advisory. Wolff (2016) argues the power of decision-making should not be monopolized by a few shareholders and their boards of directors. He offers a more democratic view of decision-making, which involves all within a business but also refers to the social wellbeing of the organization. From an Indigenous perspective, this degree of community inclusion in decision-making not only helps the social well-being of an organization but also the community as a whole.

\subsection{Traditional Teachings and Governance}

Many Native businesses are different than non-Native businesses because Native businesses have responsibilities to their communities and culture. For Native

\footnotetext{
${ }^{18}$ As discussed in the Preface, Wilson (2008) defines 'relationality' as the concept wherein, "all things are related and therefore relevant" and argues that this concept is foundational to Indigenous ways of knowing (Wilson, 2008, p. 58).
} 
businesses, success is not only measured in profits but also in social contributions to the community and cultural preservation. Boards of Native businesses often reject potentially lucrative partnerships with large corporations when the risks to the environment, culture, language, or traditional activities outweigh the potential economic gains. This is because for many Native business boards, community well-being is the main priority. This philosophy is counter to the typical business model of maximizing profits for a few shareholders. This fundamental difference is why a new model of corporate governance is needed that combines traditional knowledge, values, and community sustainability with current corporate governance practices.

The first step in building a new model for Native board governance is understanding the composition of a board. Many of the standard approaches to building any board apply to Native boards (Nelson, 2010). However, there are fundamental differences that need to be considered. Boards should contain members who are familiar with board governance and/or have other skill sets that are beneficial to the organization. If a board is comprised of community members with no experience, then it acts more like an advisory council rather than a governing board. Boards need to have directors that have enough fiscal knowledge that they can adequately govern the financials of the organization (Cadbury, 1998, 2002; Brown, 2002). Typically, you will find an accountant or a lawyer on a board due to the need for fiscal and regulatory compliance. Boards should also have one or more governance experts who are familiar with board processes and procedures. Governance expertise is becoming one of the fastest-growing needs of boards, and these experts are becoming highly sought after 
(MAS, 2007). The other remaining board members are often directors with knowledge of human resources, marketing, technology, risk management, ethics, and most importantly, industry expertise so they can help understand the markets and the climate of doing business in their industry (Brown, 2002). Often, they may be CEOs of other organizations or interest groups with industry knowledge.

A Native board typically should have directors that have legal, financial or industry expertise. However, they also require unique expertise to help the company succeed, such as land claims and treaty rights expertise or traditional knowledge and teachings to help guide decisions and policies. Traditional teachings can guide business in making important decisions such

An Oglala Elder once told me that teachings come from only one place, the Creator. We hear about them in many ways, from Elders, animals, people, and even our dreams. Yet the most important way to learn is to experience the teaching. This gives us understanding and appreciation. It also gives us responsibility and makes our relationship with the land and each other stronger.

Oglala Elder as investing in communities, expanding the business, or supporting environmental policies. Traditional knowledge can also provide the foundation for the values of an organization (Nelson, 2010). In this regard, Elders can often play an important role in board governance, as they tend to bring wisdom and traditional knowledge to guide the values of the organization. Traditional knowledge is often expressed in traditional teachings such as the Medicine Wheel Teachings, Tipi Teachings, and Seven Generations Teachings. Communities, businesses and nations should look at their own traditional teachings and how they can be incorporated into their governance structures. 
The benefits of combining substantive governing power with capable and culturally appropriate governance have been substantial for both Natives and nonNatives (Cornell and Kalt, 2003). They describe among them:

- Significant improvements in economic conditions on a number of Indian reservations, including reduced unemployment, reduced welfare rolls, and the emergence of viable, productive enterprises, both private and tribally owned (for example, Cornell and Kalt, 1992, 1998; Cornell, Kalt et al., 1998; Jorgensen and Taylor, 2000; Harvard Project on American Indian Economic Development, 1999, 2000).

- More effective administration of social services and programs (for example, Jorgensen, 2000b; Wakeling et al., 2001; Harvard Project on American Indian Economic Development, 1999, 2000).

- Improved and more productive natural resource use (for example, Krepps, 1992; Krepps and Caves, 1994; Jorgensen, 1997; Harvard Project on American Indian Economic Development, 1999, 2000).

- Significant contributions to regional non-Indian economies in the form of employment opportunities, vendor business, new business generation, reduced tax burdens, etc. (for example, Ferrara, 1998; Cornell, Kalt et al., 1998; Cornell, Ledwith, and Taylor, 2002).

For the Harvard Project study there was clear evidence of successes if the bands had self-governance control over their development in a culturally appropriate way. Selfgovernance leads to self-sufficiency in an economic sense. This is the roadmap to sovereignty for Indigenous people. 


\subsection{Traditional Teachings}

I have to start this section ${ }^{19}$ by acknowledging the many Elders and ancestors who have lived with and passed on traditional teachings. I cannot in good conscience use traditional academic sourcing to cite any one Elder because our traditional knowledge is not owned by any one person nor is it passed on by one person. Traditional knowledge is ancestral, which means it has been passed on for countless generations and will continue to be passed on this way. I often tell people it is a responsibility to act in a good way and pass on what the ancestors knew because someday we will be gone, and those who come after us will look to us as the ancestors.

Traditional teachings may be given by one person or by several people over a period of time. They may come in the form of a story or pieces of a story. Temporality, or the relationship to time, is important to traditional teachings because this tends to give different meanings dependent on one's context or a situation a community is facing. Elder Wilf Peltier of Wikwemikong once said to me that a teaching might not even make sense as we hear it, but over time, even twenty years from now, it may just become clear what the Elder was saying. This is why it is important to not correct or ask questions in a bad way when receiving teachings. It is not to say we can't ask questions, it just has to be done in a good way.

Traditional teachings create a story that may be for an individual, family, community, or everyone. No one holds all traditional knowledge. Often pieces of

\footnotetext{
${ }^{19}$ I am using personal reflection here as this section is closer to my own experiences and way of knowing. It is not appropriate to talk from a third party position as it is reflection and acknowledgement of Indigenous ways of knowing.
} 
traditional knowledge may be passed on. This is part of a traditional way so no one holds any power over the teaching nor has more within the community. Unfortunately, today that way of knowing, coupled with the colonial history of destroying traditional ways, has left many traditional teachings fragmented. Yet, one could argue that the fragmented traditional way also helped to maintain the traditions as many held the stories. The one commonality is that teachings are intended to be shared in a good way.

These are the teachings I have been given by our Elders and ancestors, and this is what I know of them.

\subsubsection{The Medicine Wheel}

The Medicine Wheel has many teachings attached to it, and it is used differently depending on who is using it and where they came from. Many of the Medicine Wheel teachings I have received came from the Sioux and Anishinabe as well as some Cree teachers. I combine the teachings when needed but acknowledge their roots. I cannot cite these teachings, as that is not our way. I will acknowledge that they have been passed down for generations, and I pay respect to those who carried this wisdom before me. Here are some of the teachings I have been fortunate to receive. 
The basic Medicine Wheel consists of four quadrants: east, south, west, and north. Four is a sacred number for many Native people because it represents the four directions. It is also said to represent the four seasons, spring, summer, fall, and winter. The wheel is also round, representing the circle of life. This represents our continuous journey and interactions with the directions.

According to some teachings, the wheel is made from tree branches, while others say it is made with stones. Each gives a rough wheel shape and is not a perfect circle. This represents the path of life, which is not easy but filled with bumps and challenges. It also represents that nothing in the world is perfect, even a circle. Everything has flaws, and it is up to us to

There are Seven Sacred Directions

The Four Cardinal points on the medicine wheel are the

Four Sacred Directions, represented among the Ojibwe by the colours yellow, red, black, and white. Blue represents Father Sky in the upper realm, green represents Mother Earth below, and purple represents the self, that spirit that journeys in this physical world, at the centre of the wheel.

Elder Lillian Pitawanakwat, Mama, Whitefish River Ojibway First Nation recognize our flaws and work to better ourselves.

The wheel is also used in several different ways. It can represent an individual's journey in life, a community, a nation, or even a situation. It is a representational sacred object used to illicit thought-provoking conversations and reflections. At the centre of the wheel, the individual or group is represented. This is to show that we need to have a broad view of all of our surroundings, both external and internal, to fully appreciate the life we have been given. 
Using the example of a personal Medicine Wheel, there would be wheels within the wheels to show other aspects of the individual's personal journey. These would also represent obstacles to overcome and how to grow as a human being mentally, physically, emotionally, and spiritually. There are also teachings surrounding the wheel to show how things outside of one's awareness influence one's life. This external realm also represents the Creator's space or that which is unknown to us.

Each quadrant has its own relationship to the centre.

Sometimes the centre represents the Creator, the self, or even the community. It changes as the medicine changes within the wheel. Each quadrant has many elements within it that may be engaged with to reflect on the

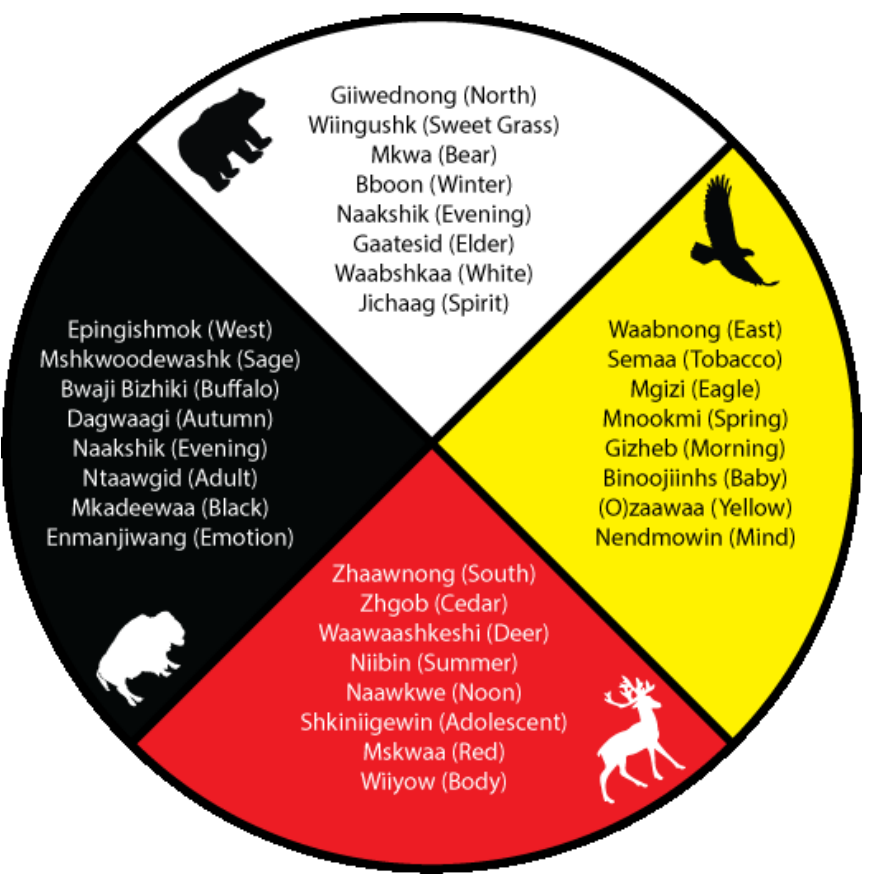

Figure 3 Medicine Wheel from Curve Lake First Nation Cultural Centre, Anishinabe

individual or group. Not all elements of a Medicine Wheel will be used, but this depends on the time, place, and needs of those using the wheel.

Each quadrant houses many separate teachings, including the medicines tobacco, cedar, sage, and sweetgrass. Each of these medicines tie into the Medicine Wheel at certain times of our lives. For example: the east door is a time of birth, and so we give tobacco in thanks to the Creator for the breath of life. It is also the time of 
water. Everyone comes from the womb where we live in water. Water is always with us and continues with that journey.

The teachings of the journey are important. Through every stage of the Medicine Wheel, one must carry the teachings and medicines with them. It represents not only the cycle of life but also the interrelationships between the different times in our lives. The wheel is filled with births and deaths within the mind, body, emotions, and spirit. We continuously face cycles daily, monthly, yearly, and through our entire lives.

The following are only some of the meanings held within the quadrants.

\begin{tabular}{|c|c|}
\hline The east represents: & The south represents: \\
Yellow & Red \\
Water & Fire \\
Spring & Summer \\
Birth/Children & Youth \\
Dawn & Noon \\
Planting & Growth \\
Mind & Body \\
Tobacco & Cedar \\
Eagle & Deer \\
\hline The west represents & The north represents: \\
Black & White \\
Earth & Air \\
Fall & Winter \\
Adult & Elder \\
Evening & Night \\
Harvest & Hibernation \\
Emotions & Wisdom \\
Sage & Sweet Grass \\
Buffalo & Bear \\
\hline
\end{tabular}

It is necessary to understand that the elements within the wheel may also vary from teaching to teaching. The important part of the teaching is that the messages, teachings, and medicines are reflected upon, understood, and applied or lived. When 
teachings are given, we must listen with open ears, minds, and hearts, as they change one's life in a good way if understood and accepted.

\subsubsection{The Tipi Teachings}

The Tipi Teachings are important for many nations. They differ from nation to nation, including the Sioux, Cheyenne, Blackfeet, Cree, and Anishinabe. I received these teachings from Sioux and Anishinabe Elders but have also received some of the Cree teachings. I am a fire-keeper of a lodge and honour the teachings given to me. As with many teachings, it is not the exact repeating of the teaching that is important, but rather the reflection and understanding that comes with the meanings. Teachings are to be experienced and lived, not just told and ignored.

Tipi Teachings are filled with the wisdom and life lessons passed on from generations past. They show a way of life, based on living the values within the teachings. There is no author for this knowledge as it is communal knowledge held by many and passed on to others. As with many teachings, the concepts may vary dependent on context, including need, time, and space. The words may change slightly, the position of the poles may change, but the essential teaching is about reflection on one's life and how to live it.

A tipi or lodge is a home. It is considered the woman's domain, and the women are responsible for it. ${ }^{20} \mathrm{~A}$ tipi can be used for many other functions such as meetings,

\footnotetext{
${ }^{20}$ It is important to note that this is not based on the division of sexes as in Western traditions where women continue to see oppression and inequality or as seen as lesser than men. In fact, women held a high place of honour and respect within many First Nations. They were seen as equals with different responsibilities and power.
} 
storage, and ceremonies. As with many Indigenous people, space is polysemic and can be used for multiple purposes depending on the activity or sanctioning as sacred space. When a Tipi Teaching is given, it is a ceremony, and the space is transformed into a sacred space. Those entering and participating should be humble and show respect for what they are to receive.

The tipi represents a circle that connects everything to the Earth. When one enters the tipi in ceremony, Teepee teachings also known as the Lodge Teachings one would proceed clockwise around the tipi to where they would sit. Within the circle we all come together as equals, and everyone faces each other. The place of honour is across from the door and is given to the

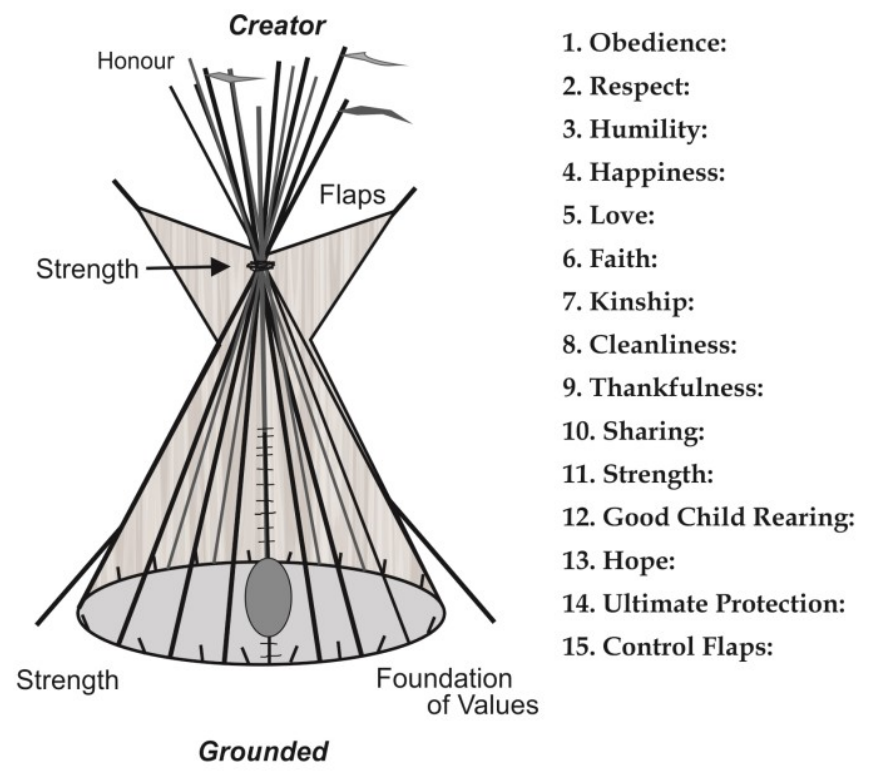

person of authority or

Figure 4 Tipi Teachings

respect. This way they can greet the people who are coming into the tipi. This place of honour is where the Chief, Elder, or owner of the tipi would sit. This all depends on what the tipi is being used for.

A tipi is often set up with the doors facing east to allow the sun to warm the space inside. When a tipi is put up for the first time and dedicated, it should always face 
east. This reflects the eastern door, which represents birth, renewal, and youth, and honours grandfather sun who gives light and life.

The four directions are part of the teaching. Much like the Medicine Wheel, the tipi has teachings of the east, south, west, and north. It also has representations of the other directions, including upwards to the flaps and out to Creator, down to Mother Earth of which we all come from, and towards the inner direction of the self, which is a place of introspection and recognition of one's own place within the world.

Each pole has its own teaching. They represent the values of the people and how to live a good life. The values are all important, and if one is not followed, the person becomes unbalanced; this is the same with a tipi. If one pole falters, breaks, or is taken away, it weakens the whole structure of the tipi and risks collapsing.

The following are the basic teachings of the tipi told by Cree Elder Mary Lee (2015). It starts with the eastern door pole and moves counter-clockwise around the tipi and the fifteen poles.

1. Obedience: We learn by listening to traditional stories, by listening and watching our parents and guardians, our fellow students, and our teachers. We learn by example what is right and what is wrong.

2. Respect: We must learn respect and honour our Elders, our fellow students, and the strangers who come to visit our communities. We must honour other people's rights.

3. Humility: We must learn that we are not better or less than any others in the circle of life. We must learn to humble ourselves as we understand our relationship with 
creation. We are merely a single strand in a great web of life. We must value and respect all life.

4. Happiness: We must work hard to become the best we can be and to encourage others as well. Our actions will make our ancestors happy in the next world.

5. Love: We must learn to accept one another as we are and accept others who are not in our circle. Love means unconditional kindness to one another.

6. Faith: We must learn to believe and trust others, to believe in a power greater than ourselves.

7. Kinship: We must respect our entire family. Our family is our roots, the roots that give us a sense of belonging so that we can contribute to our community.

8. Cleanliness: We must learn not to inflict harm on others. Clean thoughts come from a clean mind.

9. Thankfulness: We must learn to give thanks for all the kind things others do for us and for the Creator's bounty that we are privileged to share with others in the spirit of love.

10. Sharing: We must learn to be a productive part of our family by helping and sharing responsibilities.

11. Strength: We must learn to be patient in times of trouble and not to complain but to endure and show understanding. We must accept those difficult times and work to give others strength. 
12. Good Child Rearing: Children are gifts from the Creator. They are given to us on loan to care for and to be responsible for their well-being. They represent the continuity of our circle of life.

13. Hope: We must maintain hope for ourselves, our family, and our community, both materially and spiritually.

14. Ultimate Protection: The ultimate responsibility is to achieve and protect a healthy balanced and caring mind, body, and spirit as individuals, family, and a community of nations.

15. Control Flaps: We are all connected by relationships, and we depend on each other. We cannot exist alone.

The origins of the Tipi Teachings are unknown. Some stories claim that the tipi came from the sweat lodge and maintained much of the teachings from the lodge. For instance, the facing of the door to the east, fire pit as womb, strength in the structure, and the seating pattern are common to both teachings.

\subsubsection{The Seven Generations Teachings}

The Seven Generations Teachings that have been passed on to me are of an Ojibway origin. I have also received these teachings from other groups, including Algonquin, Mohawk, and Cree. As with many teachings, the Seven Generations Teachings vary across nations and communities. However, the fundamental meanings, which focus on intergenerational care and sustainability, are the same. 
The seventh generation is one we will never meet. They are our grandchildren seven generations into the future. We are seven generations from those who came before us. Even those living today are ancestors to those that will come after us, so we must live our lives in a good way, "Bimaadiziwin", in order to protect their future. The direct translation of the Anishinabe word Bimaadiziwin in English is "the good life". However, it means we must live the teachings of Bimaadiziwin or the good life, in a good way, with a good mind, a good heart, and a good spirit. According to Anishinabe teachings, this means we must consider how the decisions of today will impact the future generations that will follow us seven generations into the future. This includes looking after culture, land, and the two-legged, the four-legged, the ones that crawl, fly in the sky, and the ones in the water.

Debenjiged gii'saan anishinaaben akiing giibi dgwon gaadeni mnidoo waadiziwin.

Shkode, nibi, aki, noodin, giibi dgosdoonan wii naagdowendmang maanpii shkagmigaang.

Debenjiged gii miinaan gechtwaa wendaagog Anishinaaben waa naagdoonjin ninda

niizhwaaswi kino maadwinan.

Zaagidwin, Debwewin, Mnaadendmowin, Nbwaakaawin, Dbaadendiziwin, Gwekwaadziwin miinwa Aakedhewin.

Debenjiged kiimiingona dedbinwe wi naagdowendiwin.

Ka mnaadendanaa gaabi zhiwebag miinwaa nango megwaa ezhwebag, miinwa geyaabi waa ni zhiwebag.

Ngo Dwe Waangizid Anishinaabe (2011)

This phrase represents the basic idea of the

Seven Generations Teachings. The message may appear to be simple, but as with many teachings, living what the teaching represents is the challenge. The concept of putting one's community and culture ahead of their own gain is a common philosophy for many 
First Nations. For the Mohawk, it is written into the Great Law of Peace (Thomas, 1994). For the Lakota, it is reflected in the Mitakuye oyasin (all my relations) and the Anishinabe concept of Gakina-awiiya (all my relations), and it is often part of the Seven Generations Teachings. 'All my relations' means those who have come before us, those who are with us on our journey, and those who will follow in our footsteps. In essence, it means everyone. Yet, as with many Anishinabemowin words such as Gakina-awiiya, it means more than its literal translation. Ka mnaadendanaa gaabi zhiwebag miinwaa nango megwaa ezhwebag, miinwa geyaabi waa ni zhiwebag. This is part of the teaching I have received.

Past: We must honour those who came before us, those who held knowledge and have passed it on, those who walked this journey before us, those who are no longer here.

Present: We must honour those who walk with us on our own journey. We must respect their journey and walk with them. We must not judge and be humble when we need their help.

Future: We must honour those who come after us, the children we will never meet. We are the stewards of Mother Earth. We must honour all that is so that they may enjoy and live well. We must pass on the knowledge so they can look after the Earth when our time has passed. 


\subsection{Looking to Traditional Knowledge and Business}

The teachings of any people should only be used in a good way. Teachings give us guides on how to act, behave, and make decisions. As mentioned in Chapter 3, Calvin Helin (2009) says we have been doing business for thousands of years. Expanding on this concept, it is not a leap of logic to say that those business decisions were guided by teachings.

Every business decision is based on the values of the individual or the people making the decision. Values are the foundations for what drives people to make certain decisions. For example, someone who is radically opposed to fossil fuel development may not take a job offer to work in the oil sands. Conversely, they may take the job with hopes of changing things from the inside. The value that drives this decision is the concept of environmental sustainability and justice.

Not every teaching can fit every model of governance, nor should one force these together if it is not culturally relevant. The teachings must be respected and used in a good way. The following section discusses how traditional teachings such as the Medicine Wheel, Seven Generations, and the Tipi Teachings can be, and in some cases have been, used in a business context.

\subsubsection{Adapted Medicine Wheel and Building an Indigenous Board}

The first step in building a new model for Indigenous board governance is understand the composition of a board. Many of the standard approaches to building any board apply to Indigenous boards, however, there are fundamental differences that 
need to be considered. Boards should contain members that are familiar with board governance and/or have other assets that are beneficial to the organization. If a board is comprised of community members with no experience, then it acts more like an advisory council rather than a governing board. Boards need to have directors that have enough fiscal knowledge that they can adequately govern the financials of the organization. Typically, you will find an accountant on a board. the second most common director is a lawyer. Legal challenges are often issues that boards have to be aware of and having a lawyer who is knowledgeable about corporate laws is advisable. Boards should also have one or more governance experts that are familiar with board processes and procedures. Governance expertise is becoming one of the fastest growing needs of boards and these experts are becoming highly sought after. The other remaining board members are often directors with knowledge of human resources, marketing, technology, risk management, ethics and most importantly directors with expertise in the company's industry so they can help understand the markets and the climate of doing business in their industry. An Indigenous board will have these types of directors, however, they will also need other expertise that will help make the company successful. Expertise in traditional knowledge and teachings will help guide decisions and policies. Expertise in land claims and treaty rights may also be important to the organization. Knowledgeable directors in community relations or public policy. The following is a chart to show the typical board expertise and the added expertise often needed on an Indigenous board. 


\begin{tabular}{|c|c|}
\hline Typical board expertise & Indigenous board expertise \\
\hline Legal & INAC policies \\
Financial & Land Claims \\
Governance & Treaty rights \\
Human resources & Band knowledge \\
Leadership & Government relations \\
Industry knowledge & Understands traditions \\
Risk Management & Elders/ youth connection \\
IT infrastructure & Community engagement \\
& Inter-band relations \\
& \\
\hline
\end{tabular}

Figure 5 Board Expertise/ Adapted from Brown Governance Model

All too often Indigenous boards also have to deal with conflicts of interest due to the lack of eligible board candidates or simply the result of a small community and extended families. The latter is more prevalent on reserves where communities are close and often have vested interests in businesses operating in the community. Board members should not be family members or close relatives if possible. Go outside the community to find expertise. Traditional teachings can guide board members to make sound ethical choices for their communities and avoid conflict of interest by reflecting on traditional values. The wheel offers a balanced approach to decision making based on its quadrants of mind, body, spirit and emotion. For example, an economic development board is considering a decision on a merger with an existing business. Using the Medicine Wheel teachings, they may ask questions such as: 
1) Mind - Do we have enough expertise to carry out this merger? Will we need other expertise to run the new business?

2) Body - how will this merger affect the infrastructure of the community? Do we have enough staff to maintain the customers' expectations? Are we keeping the business in the community?

3) Spirit - Is this in alignment with our community values? Are there other teachings we should follow when making a decision? Have we consulted the Elders or the community?

4) Emotional - How will our existing staff feel? Is this what the community wants? How will the community react?

Beyond the typical legal, accounting, industry knowledge and governance skill sets that boards are often looking for, Indigenous businesses often look for unique skills that may be needed. Unfortunately, Indigenous businesses face limitations through government policy or band politics that limit business success. Knowledge of band governance models and Indigenous and Northern Affairs Canada's (INAC) policies is often needed. It is crucial to understand funding models, tax regulations, land ownership limitations and other issues that are unique to Indigenous businesses.

To address these issues, the Medicine Wheel Teachings can be adapted to the strategic planning cycle of an organization. It allows the board to monitor and act on their roles as board members. The following gives an example of the teaching and how it has been adapted to an organizational model.

The Teachings of the Medicine Wheel (Andrews, 1989: Bear, 1980; Meadows, 2012) represent the four directions, east, south, west, and north, and reflect seasonal changes. 
- The east signifies the eagle and represents birth, renewal, vision, the mental, wisdom, and spring.

- The south signifies the wolf and represents youth, community, engagement, enlightenment, spirituality, and summer.

- The west signifies the buffalo and represents reflection, the emotions, objectivity, and fall.

- The north signifies the bear and represents the Elders, reflection, insight, the physical, and winter.

Incorporating the Medicine Wheel Teachings into modern-day life has become more common (Rodberg, 2003; Wilson, 1994). Lily Nowak (2007) incorporates the Medicine Wheel Teachings into employment counselling. Comanche-Kiowa educator Cornel Pewewardy (1999) proposes using the Medicine Wheel as a guide to forming new teaching and learning models. There are many teachings of the Medicine Wheel in different cultures. While they may have some differences the concepts and teachings they give can be adapted.

The Medicine Wheel has also been incorporated into business, including performance and productivity models (Lear, 2009). This teaching framework can also be incorporated into corporate governance, guiding areas such as strategic planning, organizational effectiveness, business cycle management, and even performance evaluation. 
Making use of theoretical challenges to incorporating traditional models into modern business, the following model is a preliminary interpretation of how the four directions teachings can be adapted to represent a corporate model of strategic direction and priorities (Nelson, 2007b). This strategic model was developed to guide decision-making processes and strategic planning for several organizations. It is important to note that every teaching has to have meaning to the organization and be made to work within its governance structure.

The diagram (figure 4) shows a traditional Medicine Wheel. The representation of a constant cycle is not new to business. However, the adaptation of the wheel as in the diagram (Figure 5) represents a cyclical strategy of business development and sustainability and the times to engage in the strategy. It includes setting goals, exploring new opportunities, growing and improving, gaining profits or minimizing losses, evaluating, setting risk levels, and revisiting the strategy. The length of cycle depends on the organization, but many businesses adopt a five-year business strategy with a yearly review of goals and objectives. This Medicine Wheel can also guide these goals and objectives by ensuring they maintain a positive outcome for the environment, employees, profits, and the community. The quadrants also intersect with one another through the centre which represents the board of directors. They are responsible for the long term strategic planning of the organization, the evaluation and succession planning of the CEO, audits and fiscal responsibility. They, along with the senior management team, are the central point of the wheel and continuously monitor its progress. 


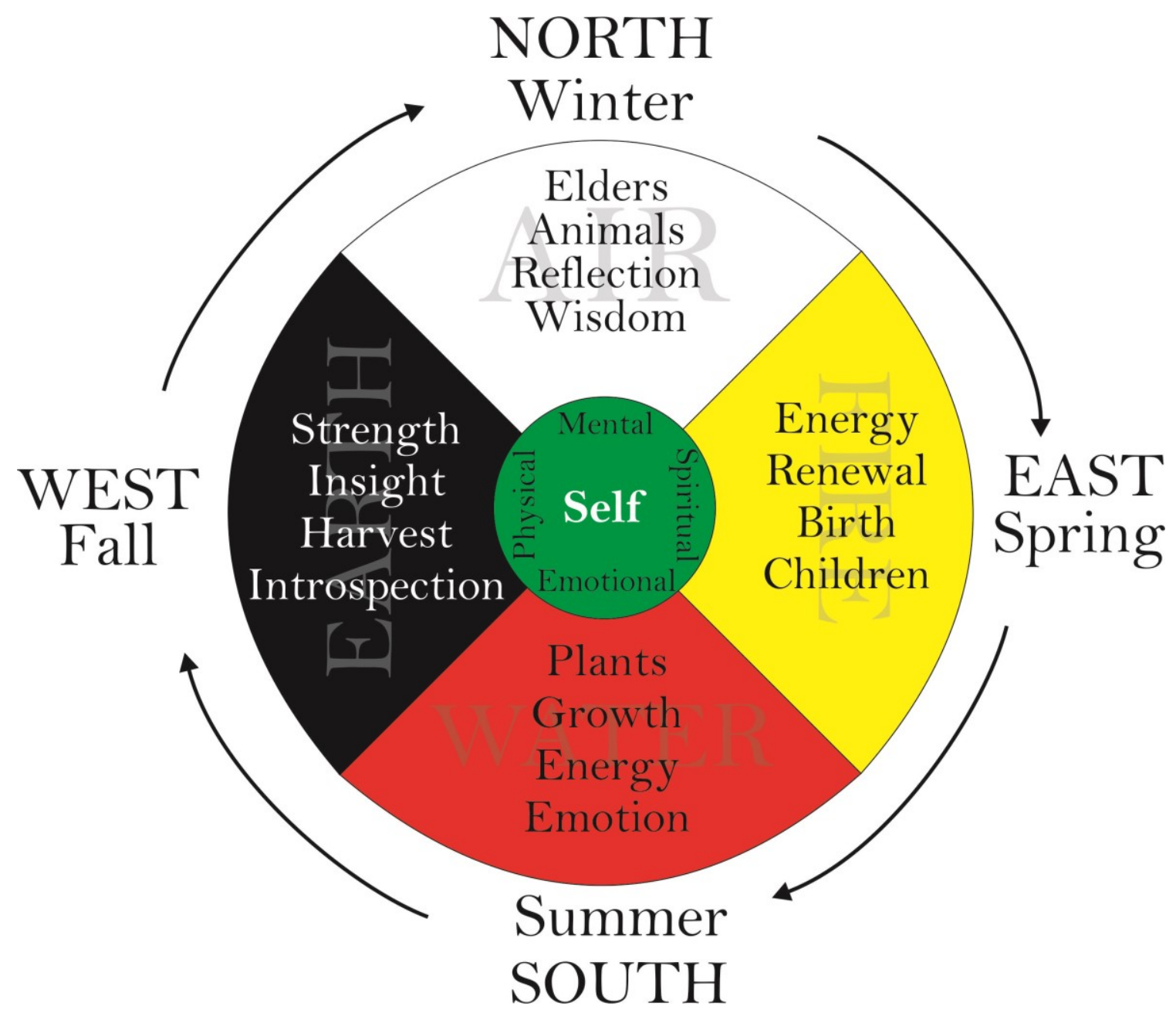

Figure 6 Traditional Medicine Wheel

- The east signifies the eagle and new business ventures, project renewals and investments. It may be a time for board elections or terms to be renewed.

- The south signifies the wolf and can be engagement with community, customer satisfaction surveys, growth of business lines, or a time for director education. 
- The west signifies the buffalo and represents program evaluation, financial audit, CEO evaluation, or board evaluations.

- The north signifies the bear and represents reflection on strategy, vision, and mandate. It may be a time to reflect on the values statement and policies.

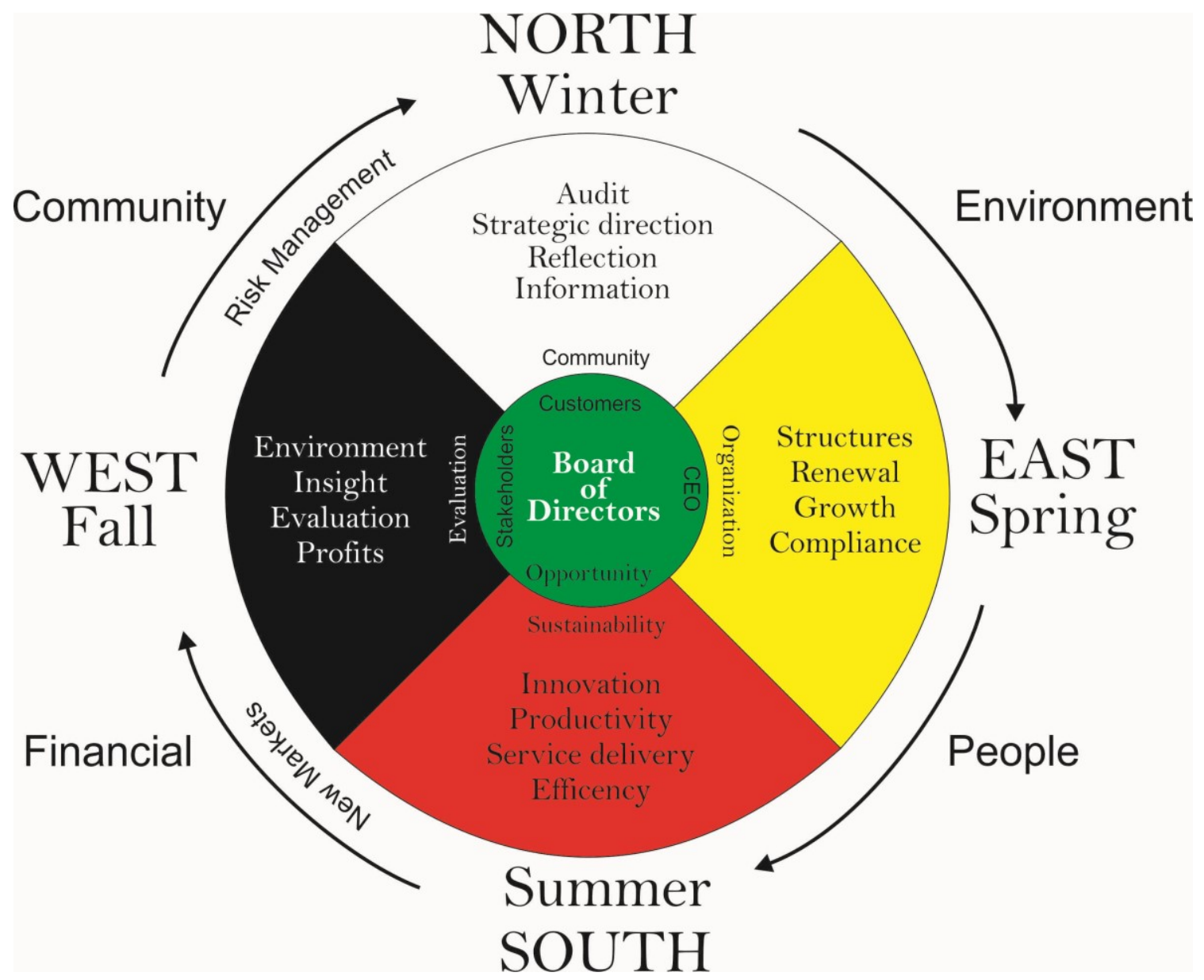

Figure 7 Medicine Wheel adopted for the Global Governance Group

Within the Global Governance Group's adaptation of the Medicine Wheel, the board of directors takes the centre in order to become aware of the quadrants. This model allows the board to work with the wheel in order to meet its governance obligations and also 
maintain a Native way of understanding the cyclical relationship of the work. Working within the circle promotes understanding that the wheel is a cycle in which each quadrant continues and is relational to the other.

The wheel is also not static in time. The concept of temporality comes into play as the wheel is a guide and not an absolute structure of time. If strategic planning is needed in the fall then it is done in the fall. However, the teachings of the north provide direction. This is a time to reflect, gather information and make an informed plan and process around strategy.

The wheel's quadrants are also not fixed to a certain direction. They constantly interact with each other. While the strategic direction of the organization may be determined in the fall, all quadrants have an input on planning. For example, the east allows us to reflect on growth and new opportunities, the south on innovation and productivity as well as customer satisfaction. The west gives us tools for evaluation and financial status, and the north brings the time of introspection and a chance to examine the audit to reflect on the past.

As with any teaching, it is a guide or a framework that an organization can utilize to ensure sound governance practices. It is a reminder of dedbinwe bimodizawin or how to govern in a good way. Nothing is static with elements ever entwined and relational to each other. Yet if you remove one section or ignore it then the rest of the wheel will become unbalanced and eventually collapses. 


\subsubsection{Tipi Teachings and Corporate Strategy}

When looking at corporate strategy it is important to understand that long term planning is the responsibility of the board of directors (Brown, 2002). Yet this model (Figure 8) can not only aid directors in understanding areas of responsibility, but also understand the relationality to stakeholders and work plan outcomes. For many board directors the relationship to stakeholders is clear and ever present. The main function of a board is to protect the assets of an organization and report to the stakeholders and investors (Cadbury, 1998, 2002; Brown, 2002, 2003).

Through the grounding of the Tipi

Teachings one begins to understand the relationship of the board to the everyday work plans of the employees and the measured outcomes. In good governance practices, these outcomes are reported through the CEO to the

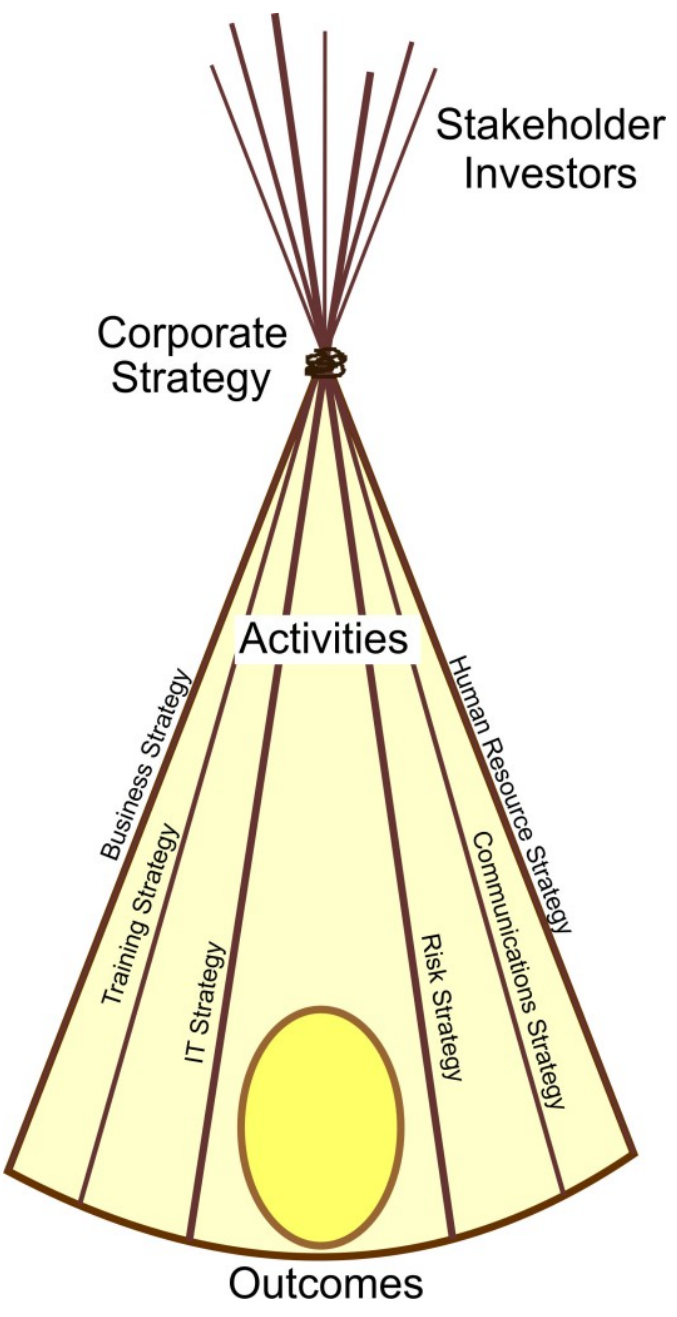

Figure 8 Tipi and Corporate Strategy board to evaluate the overall strategy (Brown, 2002, 2003). This allows an alignment of the overall strategic direction of the organization and the work being completed by the employees. 
Exploring the teachings further, the values of each pole can become a statement of values and ethics for an organization. The following is an example of how the Tipi Teachings can express the values statement of an organization.

As with any teaching, values and ethics are embedded within its meaning and in every component. The Tipi Teachings are based on the values of each pole and the relationality of the tipi to the land (or organization). When one value fails the others are compromised and the organization's reputation is put at risk. It is then up to the senior staff and board to manage the risk by creating a strong foundation of ethical behaviours within the organization. In other words, leadership through example is paramount to an ethical organization.

\section{Organizational Values ${ }^{21}$}

\section{Obedience}

Loyalty to the organization and confidentiality in the work that is done.

\section{Respect}

We respect one another and those that we serve.

\section{Humility}

Understand that our clients are people and deserve to be treated as equals.

\section{Happiness}

A good healthy workplace is a productive and innovative one.

\section{Love}

We need to always look after each other and our clients.

\section{Faith}

Understand the organization and trust in its people.

\section{Kinship}

\footnotetext{
${ }^{21}$ This is only an example of what can be created using the tipi teachings. This is not a real statement of values.
} 
We are all part of a team that works toward ensuring our products and services are safe to use.

\section{Cleanliness}

A clean workplace is a healthy workplace.

\section{Thankfulness}

We are ever thankful to our clients and show our appreciation to them.

\section{Sharing}

We share ideas and innovation in order to better our company and workplace.

\section{Strength}

We remain strong and committed to our values.

\section{Good Child Rearing}

Family life balance is important to the organization.

\section{Hope}

There is always room for growth and opportunity within the organization.

\section{Ultimate Protection}

We look out for the health and safety of our employees, families and clients.

While these are good values they may not be appropriate to the organization adapting to this way of living, meaning different businesses may incorporate their own local traditional teachings into their governance model. For instance, an Inuit organization may not adopt a Medicine Wheel into their governance, but may look to the Qullik ${ }^{22}$. Some organizations may only want to include some of the teachings in their policies and practices. What is important is that the model is tailored to the people and their relationships with each other, clients and stakeholders. There is no one size fits all approach to governance, nor is there to any teaching. Every teaching has its own

\footnotetext{
22 Inuit oil lamp that is made from stone with oil made from blubber and arctic cotton as a wick that provides heat and light. There are many teachings around the lamp including family values and responsibility (Inuit Cultural Online Resource).
} 
meaning dependent on the time and place it is given. Tipi Teachings can provide guidance for creating an organizational governance model, a decision making model, or a values based guide for a board of directors.

\subsubsection{Seven Generations Teachings and sustainable practices}

The Seven Generations Teachings represent a powerful ideological shift in how one thinks about their impact on Mother Earth. Generational sustainability is not a popular philosophy for businesses that focus on immediate profits for their shareholders. Yet, by employing the Seven Generations teachings, businesses can look further forward and achieve true long term sustainability. For Native businesses this means community sustainability and investment in the future. It is a road map to self

I see a time of seven generations when all the colors of humankind will gather under the sacred tree and the whole world will be one again.

Crazy Horse Oglala Sioux sufficiency, determination and governance.

The Seven Generations philosophy is already being used by businesses today. For example, Goodfish Lake Development Corporation (GFLDC) in Alberta, the largest dry cleaning operation in Canada, applies the Seven Generations philosophy to how they make business decisions (Personal communications with Halfe, 2012). GFLDC draws on these teachings to support a strategic direction for the organization that reflects longterm sustainability (generational) planning over immediate profitability. This type of thinking is coupled with their increased concerns about environmental sustainability. 
For GFLDC this was a long term investment for their community which has taken over thirty years to see the impacts of that decision making process for the community. Yet the process was based on environmental stewardship and balancing profits and jobs for the community in the long run (Halfe, 2010).

The concept of generational sustainability is also reflected in the 1987 publication by the World Commission on Environment and Development (i.e. The Brundtland Commission). In the report the commission highlighted the importance of

In the time of the seventh Fire new people will emerge. They will retrace their steps to find what was left by the side of the trail long ago. Their steps will take them to the Elders, who they will ask to guide them on their journey. But many of the Elders will have fallen asleep. They will awaken to this new time with nothing to offer. Some of the Elders will be silent out of fear. But most of the Elders will be silent because no one will ask anything of them.

\section{Grandfather William Commanda}

sustainable development for future generations "which meets the needs of

the present without compromising the ability of future generations to meet their own needs" (1987, p. 8).

Compromising profits today is not a popular course of action for shareholders, however with the rise of

corporate social responsibility in the 1990s, the concept of environmental and social responsibility proved to have profitable results. Scholars such as Hawken (1993) elaborate on the concept of future sustainability and the idea of carrying capacity for the next generation. He draws on the concepts of sustainable sharing as influenced by the Seven Generations Teachings.

In order for any type of commercial ecology based on market principles to function requires that the resources be available on a sustainable basis - that is, the resources to supply the needs of 
one generation have to be used in a manner that does not compromise the ability of future generations to fulfill those same needs (Hawken, pp.89:2005).

However, in response, self-interested corporations have largely misinterpreted definitions of sustainable development to justify environmental exploitation for economic gains under the guise of economic development (Davidson, 2000; Gladwin, et al., 1995; Purser et al., 1995).

\subsection{Bimodizawin and The Good Life Through Governance}

If I give a man a fish, then I feed him for a day. If I teach a man to fish, then I feed him for life. If I teach a man to fish responsibly, then not only do I feed him, but the rest of the village as well, for generations to come (Raymond W.Y. Kao, 1994).

Kao's adaptation of this old saying represents a Native philosophy, which prioritizes providing for community and family. This saying also represents the Seven Generations Teachings. The Six Nations or Iroquois Confederacy asserts that chiefs must always consider the effect of their decisions on peace, the natural world, and on seven generations in the future (Grinde and Johansen, 1990). This philosophy of generational sharing and environmental stewardship is important to many Native people and businesses.

However, traditional knowledge is more than understanding, respecting, and managing/protecting the land and the environment. It is the knowledge of those who have walked before us (our ancestors) that has been passed on through generations to define and govern the way we think and act today and in the future. It grounds who we 
are as Native peoples and forges our identity and decision-making processes. Beyond ecological sustainability, traditional knowledge provides a holistic approach to living one's life. Traditional knowledge permeates every aspect of our lives and can even influence areas of business, including corporate governance and the actions of a board of directors. It encompasses traditional spirituality, beliefs, customs, clans, language, oral history, stories, art forms, laws, land-based activities, land use, and everyday life skills (Na-Cho Nyak Duns). It also encompasses traditional governance practices that have been passed down for generations. It is about how we live our lives and interact with the environment, spirituality, and others. For the Anishinabe, this is expressed in the concept and teachings of Bimaadiziwin or living the good life. Bimaadiziwin is a traditional way of living that respects others and sets forth our role in community, culture, spirituality, and within the ever-living system of Turtle Island. Having and living a good life plan is what is expected, and traditional knowledge offers the directions to do so.

The Royal Commission on Aboriginal Peoples states that, "Traditional knowledge consists of a world view, organizing principles of life, laws of behaviour, and a knowledge of the sciences, from archaeology to zoology, framed and presented in a unique way through the power of the spoken word" (Vol.4, Ch. 3: 1996). While this is a good definition, Elders such as Oji-Cree Percy Rae and Anishinabe Fred Kelly describe traditional knowledge as something broader that encompasses every part of one's life. It is in the way we think, act, and respond to the world around us based on what we know 
and even what we don't know. While these descriptions are very different, they share in their admission that traditional knowledge is a complex concept and difficult to define.

Many of my Elders talk about traditional knowledge as a connection to the past, guidance for today, and directions for tomorrow. This is evident in the popularized teachings of the Seven Generations. The Seven Generations Teachings are as much about the past and present as they are about the future. To say that we have to be conscious of how our actions today affect the next seven generations is a guiding principle that governs our behaviour today. Yet, this teaching is contextual, as well as circular and reflects those past generations that have lived this way anticipating the current generations. In this regard, it is similar to Heidegger's Being and Time (1962), which questions the primordial

Traditional people of Indian nations have interpreted the two roads that face the lightskinned race as the road to technology and the road to spirituality. We feel that the road to technology.... has led modern society to a damaged and seared earth. Could it be that the road to technology represents a rush to destruction, and that the road to spirituality represents the slower path that the traditional Native people have traveled and are now seeking again?

The earth is not scorched on this trail. The grass is still growing there."

William Commanda, Mamiwinini, Canada, 1991

concept of linear time by illuminating the complexity of existence. In a sense, Heidegger is describing an Indigenous philosophy, which holds that being and time are circular and intergenerational, not confined by temporality.

It is also important here to distinguish between sacred knowledge and traditional knowledge. While all the knowledge is, of course, "sacred" to our people, 
there is a clear delineation between philosophies that can and should be shared with anyone and the sacred teachings (e.g. for me, midewiwin ${ }^{23}$ ) that have been passed down that are not to be shared. The sacred is usually not shared outright and is reserved for individuals, families, and communities. This knowledge is kept by those it is passed on to through rituals or extended learning, along with naunaugatawaendumoowin ${ }^{24}$. Traditional knowledge, on the other hand, is knowledge that is meant to be shared with everyone. Elder Wilfred Peltier (former Elder-in-residence at Carleton University) always said that teachings have their time and place and that many become relevant at certain times in our lives or even certain lifetimes. He explained that traditional knowledge is the basis for how we act and live our lives. We have also more recently received some traditional teachings or modern teachings that have now been revealed to us to give guidance to everyone. To disregard one's traditional teachings is to walk an unbalanced path. To not share this knowledge is also against our traditional teachings. We constantly seek dae'b'ingaewin ${ }^{25}$ the constant circle of sharing, and traditional knowledge is the foundation of that quest.

Another concept based on traditional teachings is that of reciprocity or what can be called circular trade. While a transaction may take place between two individuals, there may not be a fixed value attributed to the item or transaction; it is simply expected as an act of generosity, and someday the recipient will do the same for

\footnotetext{
${ }^{23}$ Midewiwin is also known as the Grand Medicine Society whose members are keepers of sacred knowledge passed down for generations. Knowledge of medicines, rituals, and spirit rites are all part of the society.

${ }^{24}$ The best translation is to reflect over and over again on teachings.

${ }^{25}$ One's own truth or the realization of that truth.
} 
someone else. In this way, the community looks after those in times of need as it is the right thing to do, and they, or their children's children, may need that kindness in the future. Native business leaders often use these teachings in their decision-making processes. They look to their traditional teachings as a guide to making the right decision for the community and not the individual. Explaining these decisions in courts has always been an issue.

Since the Supreme Court of Canada handed down the Delgamuukw decision on Native title in 1997, Canadian policies have been undergoing changes with respect to traditional knowledge (BC Treaty commission, 1999). Native oral histories are now considered valid and admissible evidence in court. This landmark case was important in showing that traditional knowledge is still very much a part of modern Native life. The idea that traditional ways pertain only to the past is erroneous. Persistent resistance to that notion has prevented colonialism from destroying knowledge passed on for generations.

Many Elders today speak of traditional knowledge as a reflection of relationships between people and with the land. Traditional knowledge is both public and private, and we live it every day in how we act and perceive the world. It is not only appropriate to apply the principles of traditional knowledge to hunting and fishing but to running an economic development corporation as well.

Traditional knowledge is not universal nor do all Native people hold traditional knowledge. One Haudenosaunee Elder at the 2006 Chiefs of Ontario meeting described traditional systems as knowledge systems or naturalized systems (Chiefs of Ontario, 
2006). Naturalized in the sense that traditional knowledge is embedded into life and all the things we do because it was learned through one's life. With this in mind, traditional knowledge is about relationships and its ties to the land. It is difficult to take it out of context and separate it from its community and people. However, traditional knowledge can be transformed for other uses and even create new relationships to peoples and lands. Traditional knowledge has not only been passed down from generation to generation but also from group to group and culture to culture.

There is too much controversy surrounding the use of the sacred and the sharing of this knowledge, so we are left with a term that is problematic in that it has issues of ownership and privacy. The Chiefs of Ontario (2010) have demanded that traditional knowledge be included in governance and in all strategic planning initiatives that impact First Nations. 


\section{Chapter 8 - Case Studies}

\subsection{Introduction}

This chapter examines three case studies of First Nations business ventures. It looks at the history and rationale of why the businesses were started, what makes them successful, and how traditional knowledge and values influence their business practices. As discussed in previous chapters, traditional knowledge and the values that come from the teachings can have a positive influence on both business success and how governance decisions are made. Hence, I reference Flyvbjerg's description of a case study which states it cannot be of value in and of itself but needs to be linked to a hypothesis in order to illustrate the range of possibilities and provide an example (Flyvbjerg, 2006: 390). While each case study is not a perfect demonstration of this principle, they each provide insights into how traditional knowledge can be used in corporate governance practices today. Each case study shows a connection between traditional values and business development within the community and how the business operates. They each show how traditional knowledge not only influences the business model but drives it based on a vision of leadership handed down through generations.

The case studies presented in this thesis are stories and should be considered qualitative and ethnographic in nature, not quantitative. The rationale for case studies is, as anthropologist Clifford Geertz asserts, "a powerful disciplinary force: assertive, 
demanding, even coercive" (1995: 119). He explains that case studies may also be underestimated based on their occlusion or lack of statistical validity. Yet, these case studies are certainly advocating for a position and are coercive in nature, and given the position of Indigenous people in Canada, understandably so. They are by nature both inspirational and practical for communities. They are examples of successful business ventures based on traditional teachings. They inspire other communities by showing that economic development and businesses can be a part of their quest for selfdetermination and also give practical examples. There are far too many cases of business failure reported by the media and there is a need for sharing success stories in both Native and non-Native communities.

The following case studies are presented in a narrative form. As Flyvbjerg explains, "case studies often contain a substantial element of narrative. Good narratives typically approach the complexities and contradictions of real life (400: 2006)." He explains that case studies cannot be summarized and are open rather than fixed scientific formulae. So the narrative format fits both within an Indigenous way of imparting knowledge and within good anthropological field work paradigms. The following case studies are presented in narrative form with academic analysis added for the purpose of tying them to the original focus of this research.

It is important to note that these case studies do not reflect the full range of examples of employing the techniques and theories proposed in this thesis but rather elements based on their own needs and locality. It is difficult to find a model of traditional governance that has adapted to western corporate governance; most cases 
try to add traditional knowledge to existing corporate governance. There is a distinction, however, one is a foundational traditional approach to governance based on cultural values, and the other can be construed as more tokenistic and difficult, given what the impacts of colonialism will allow. It is important to not try to fit a square peg into a round hole, so these case studies are presented as examples of reclaiming Indigenous governance practices through traditional knowledge and governance.

\subsection{Community Case: Goodfish Lake Business Corporation, Whitefish Lake First Nation}

\subsubsection{Summary}

Whitefish Lake Cree First Nation in Alberta is the owner of Goodfish Lake Business Corporation (GFLBC). GFLBC ${ }^{26}$ is an example of a community based business model that combined the strategies of a trustee model of governance and a decision making model based

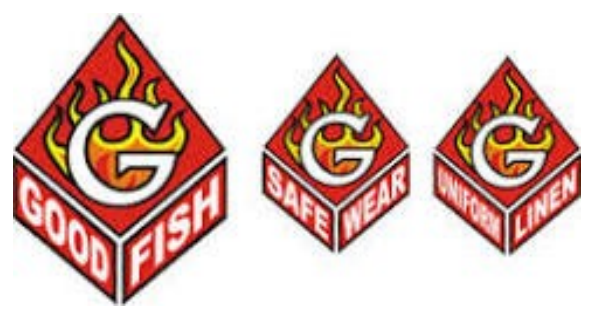

Figure 9 Goodfish Lake Development Corporation Logo

on traditional teachings. GFLBC illustrates how

traditional knowledge can effectively guide a business to realize success over time.

Established in 1978, Goodfish Lake Business Corporation (GFLBC) manages four subsidiary companies that provide a range of services to workers in the oil and gas industry including;

- The Goodfish Lake Dry Cleaners

- The Goodfish Lake Sewing and Garment Company

\footnotetext{
${ }^{26}$ Goodfish Lake Development Corporation changed its name to Goodfish Lake Business Corporation in 2015. Some interviews were completed prior to the name change and reflect GFLDC while those conducted after reflect the change to GFLBC.
} 
- Protective Clothing Supplies Ltd.

- Kookum's Bakery

For over 30 years, GFLBC has been successful at maintaining its core dry cleaning business while continuing to expand and diversify. Through the creation of jobs and the redistribution of revenues back into the community, GFLBC has succeeded in improving the community's socio-economic conditions and is now widely regarded as a model for business success (Nelson and Sisco, 2008).

\subsubsection{Overview}

Whitefish Lake First Nation \#128 is part of Treaty 6, located in Northeast Alberta about 160 kilometers northeast of Edmonton, and 365 kilometers south of Fort McMurray. It is located south of the Athabasca Oil Sands. Whitefish Lake First Nation, also known informally as Goodfish Lake (GFL) due to the nearby lake, has 2378 members, of which 600 reside off-reserve, and 1778 reside on the reserve (WFLFN, 2016). While the reserve is located on Goodfish Lake, Whitefish Lake in the north of their territory gives the community its name.

Whitefish Lake Band was amalgamated with four other bands; Little Hunter, Blue Quills, Saddle Lake, and Cache Lake (WFLFN, 2016) as they occupied lands in between the areas of Lac La Biche, St. Paul, and Bonnyville (2014).

\subsubsection{History}

While the history of Whitefish First Nations extends back to time immemorial, a key period of change took place in the 1870's when Canada was negotiating the 
numbered treaties. Based on the assumption that Canada could assert sovereignty over the West, representatives of the Crown set out to negotiate with the Indian tribes. The Treaty 6 negotiation was well documented both through oral traditions and written history, with Chief Pakan (James Seenum) as the principal signatory. Treaty 6 promised that the Government of Canada had a "legal obligation to assist the Alberta Indian bands to accomplish socio-economic development in the reserves" (Indian Association of Alberta, 1978). This harkens back to the words of Lieutenant Governor Morris who negotiated the treaties and stated, "I want you to think of my words, I want to tell you that what we talk about is very important. What I trust and hope we do is not for today or tomorrow only; what I will promise, and what I believe and hope you will take, is to last as long as the sun shines and yonder river flows (Morris, 18)".

The Cree of Whitefish Lake have faced many hardships over the past century including residential schools, rebellions, and economic poverty and broken treaty promises (WFLFN, 2015). Yet, throughout these hard times they remained resilient and have managed to maintain their cultural ways and traditions. Today, they incorporate this resilience into their vision to "maintain, protect, and nurture our culture and spiritual and historic values through the celebration of our unique traditions and language"(WFLFN, 2015). To show this pride and strength, a sign in the band office says, "A Community Built with Pride, Leadership, and Vision". 


\subsubsection{Early vision for economic development a critical transition point}

Chief Pakan was a peaceful man who refused to fight alongside Riel in the Métis Rebellion of 1885, and he also refused to fight against the Crown during the 1870 s when many rebelled due to starvation and increasing poverty (Houle, personal communication, 2014). However, Chief Pakan recognized the importance of strong negotiation noting that by entering into treaty, he could negotiate for more land, leading to increased resources and growth potential for his community. He understood that land was for all the people including those in the future,

and he needed to protect it. This foresight

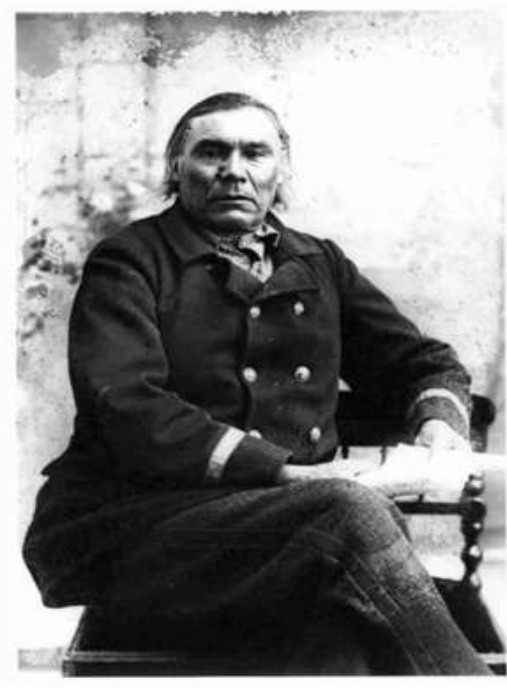

Figure 10 Chief Pakan (James Seenum) Provincial Archives of Alberta; E. Brown Collection.

demonstrated the Seven Generations philosophy

discussed in Chapter 7. Chief Pakan not only thought about the immediate needs of his people, but how the decision he made could potentially impact future generations. His forethought and actions built the foundation for future economic development for his people. The Seven Generations philosophy was also reflected in Lieutenant Governor Morris's words which referenced the importance of not only thinking for today, but for tomorrow and for all future generations (Indian Association of Alberta, 1978).

\subsubsection{A Pragmatic Partnership: Leveraging Community Talents and Nearby Markets}


The history of the Goodfish Lake Business Corporation (GFLBC) dates back to the 1970s when then Chief Sam Bull recognized a need in his community to create jobs locally so the members of the band, typically men, did not have to be away from the community for extended periods of time (G. Halfe, personal communication, 2012). The band had long been dependent on cattle ranching, but with new opportunities in the oil industry, many were leaving the community (Norris, 2009) or working outside the community for extended periods of time. Chief Bull created a development corporation and named it Good Fish Lake Development Corporation (GFLDC).

With so many of the men working in the oil sands in one capacity or another, the families were suffering (G. Halfe, personal communication, 2012). Money was coming in but the men were never home and the women were left as sole caregivers for the children, as well as being responsible for maintaining many aspects of the community. With the men away working, many children did not see their fathers for months. According to Sandy Jackson, a director of the GFLDC, the men's absence was a disruption to the family unit, which in turn had negative implications for the many behavioural and social issues the community was facing (S. Jackson, personal communication, 2012).

Chief Bull noticed that the women were regularly getting together for a sewing circle to talk and mend the garments the men wore in the oil sands. They often told the chief that it would be better to have the men closer to

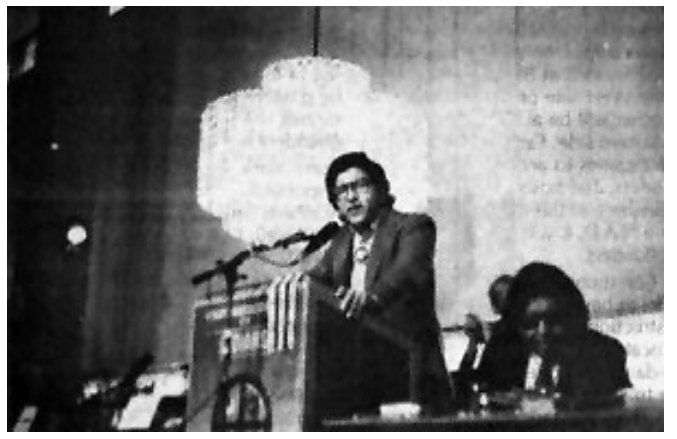

Figure 11 Chief Sam Bull 
home to help with the house and children. The chief took note, and in 1978, Chief Bull and the band council saw an opportunity to service the growing oil sands industry (G. Halfe, personal communication, 2012), recognizing there was a need for repairs to the industry's overalls similar to the work he had seen being done during the women's sewing circle.

Capitalizing on this opportunity, he approached the larger oil companies such as Syncrude, Suncor, and Imperial Oil to discuss the prospect of creating a garment repair business to support the industry. Through discussion it was found that companies not only had an interest in repairs to the garments but were also seeking a local cleaning service. At that time the companies were shipping the oil-soaked overalls to the United States for cleaning (G. Halfe, personal communication, 2012). This was both timeconsuming and expensive so they inquired whether there was a more economical and local option. Chief Bull recognized that setting up a supporting business would not only service a niche market, but would also create a viable, sustainable business within the community. Chief Bull approached the women's sewing circle about expanding the business, and they agreed. The foundation of Goodfish Lake Development Corporation was born.

\subsubsection{Drawing on Elders' Wisdom to Retain Community Values}

Chief Sam Bull knew that they would have to have a long term vision that would sustain the community over the years to come, and he needed to have the community and the band Elders on board. Chief Bull consulted with the community and Elders, and 
the direction he received became the foundation for GFLDC's values and mandate (G. Halfe, personal communication, 2012). Drawing from their traditional knowledge and the importance of their stewardship of the land, the Elders set out the values that the organization would follow (Favel, personal communication, 2014). First, the Elders wanted to protect the land for the community and to ensure that any business they ventured into would not damage the land. Many of the community members had seen firsthand the damages the oil sands had on the environment, and they did not want their reserve to suffer the same fate. Second, they wanted the company to serve and promote community and culture (G. Halfe, personal communication, 2012). In the 1970s the community was suffering from many social problems, and overall was not healthy. The mandate of GFLDC was not only to bring jobs home to the community but also to promote Cree culture and community solidarity. Out of this belief, the vision of the Goodfish Lake Development Corporation was spelled out the following way:

\section{Whitefish Lake Vision (GFLDC, 2015)}

We shall ensure self-sufficiency that respects diversity and equality while working within a spirit of cooperation and fairness for a high standard of living and quality of life.

We shall strive to provide an environment of improved well-being for our community including education, health, safety, and welfare while valuing our culture and all resources.

We shall accomplish this for all generations with a system of value-based management to respect all views. 


\subsubsection{Growing the business}

Throughout the 80's and 90's the operations grew and new infrastructure was built to accommodate the growing business, yet the demands for more overall cleaning continued to grow and over 20,000 overalls were coming in weekly. In 2000 , the band was beginning to recognize that they would have to create a world class facility to keep up with the demand.

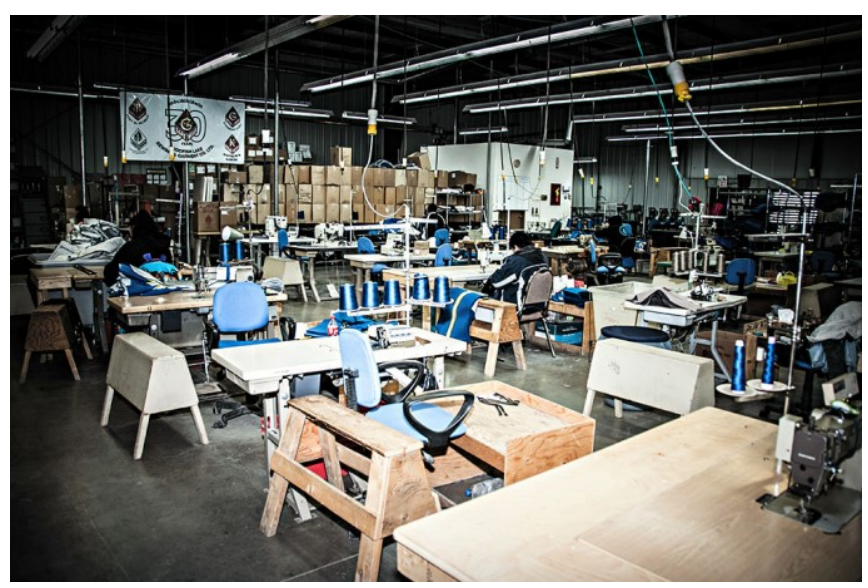

In 2005, the Government of

Figure 12 GFLDC Garment Manufacturing and Repair Canada announced \$1 million in federal funding to assist Whitefish Lake First Nation to expand the dry-cleaning and laundering division of Goodfish Lake Development Corporation. In conjunction with partners, including the Royal Bank of Canada, Syncrude Canada, and Suncor, the band was able to expand the existing operation to include a \$5.4 million state-of-the-art plant. This new plant has been effective in keeping up with the demands of their customers in the oil sands.

\subsubsection{Goodfish today}

Today, Goodfish Lake Development Corporation Limited (GFLDC) is $100 \%$ owned and operated by the Whitefish Lake First Nation and has over ninety employees (GFLDC, 2016), $88 \%$ of whom are Native (AANDC, 2005). It is located on-reserve and also has a retail outlet in Fort McMurray called Protective Clothing Supplies Ltd. (WFL128 online, 
2014). The corporation has three divisions: Canada's largest industrial dry-cleaning business, work wear manufacturing, and a protective clothing manufacturing division. While GFLDC continues to specialize in dry cleaning and laundering, safety garment manufacturing, and garment repairs for protective wear worn by workers in the oil sands, community leaders also recognized the need to diversify their local economy. The band has also created several successful side businesses including GFL Busing Company, Pimee Well Services

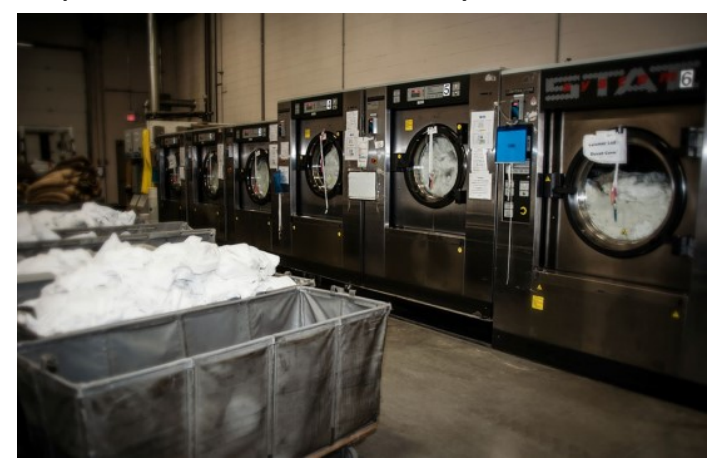

Figure 13 GFLDC Industrial Dry-Cleaning Facilities Partnerships, Kookum's Bakery, and a Royal Bank partnership.

Working within the area of the Alberta oil sands, they have been recognized as leaders in environmental sustainability by attaining Environmental ISO 14001-2004 (environmental) standards. Obtaining International Certifications (ISOs) is a time consuming process that includes evaluations from international experts, and such certification is very difficult to attain. GFLDC was also recognized as an outstanding Native business by both the Council for the Advancement of Native Development Officers (CANDO) and the Canadian Council of Aboriginal Business (CCAB).

However, there is more to GFLDC than business. They have a sense of community responsibility. It is understood that businesses have to make money in order to survive, however George Halfe, CEO of Goodfish Lake Development Corporation, explains that profits are important but are not everything. GFLDC profits allow them to maintain the priorities of the community. "Without money, the business would not 
exist, but, it is not why we are in business. We are in business for our community" (Halfe, personal communication, 2014). This philosophy illustrates a common belief of community-owned businesses and partnerships in maintaining cultural values and beliefs.

In 2015 Goodfish Lake Development Corporation changed its name to Goodfish Lake Business Corporation to reflect its maturity and move away from being called a development corporation (GFLBC, 2016).

\subsubsection{Telling Their Story}

When asked to identify one of the most important aspects of economic development for Whitefish Lake First Nation, then CEO of Goodfish Lake Development Corporation and band councillor, Ben Houle said the answer was sustained leadership and vision (B. Houle, personal communication, 2012). Without a long-term vision, it is difficult to move towards a place of common good for the community. An effective leader must understand that building on past efforts brings a community closer to achieving self-determination and self-sufficiency.

For Whitefish Lake, economic development has been an ongoing priority (Favel, personal communication, 2014). In order to ensure success, partnerships had to be formed with key companies in the oil sands and maintained over several years. The partnerships that were developed went beyond investments. Several large companies, including Syncrude and Suncor, agreed to help GFLDC expand into manufacturing as well. "They have been partners for over twenty years and are key to our ongoing 
success" (Halfe, personal communications, 2012). It takes time to become successful and according to Halfe, "We have earned the contracts that we get... We want to be around for the long haul. We don't want to just make a quick buck and say goodbye to the customer. We work closely with the customer and with industry to see what their needs are" (Halfe, Interview, 2010).

Training is another important strategy of GFLDC. The manager of Goodfish Lake Dry Cleaners, Kevin Half, explained that his employees undergo in-depth safety and operational training. As a component of its business contingency plan, employees at Goodfish Lake Dry Cleaners are cross-trained to operate and maintain all machinery. New employees apprentice alongside more experienced staff members until they can complete all tasks.

Employing traditional teachings as a guide to their corporate policies and decision making is still important to the corporation. GFLBC enhanced their governance through traditional ways of knowing. The traditional concepts of generational sharing and sustainability along with environmental stewardship (as discussed in Chapter 4) are all aspects of how they do business. Incorporating the Elders' knowledge and direction and incorporating traditional teachings into business practices was not deliberate, it was the natural way that Whitefish leaders do business.

\subsubsection{Governance Model}

The governance of GFLBC is based on a board governance model in which the board of directors is comprised of three Whitefish Lake Band \#128 First Nation members 
and four non-First Nations members (GFLBC, 2016). This ensures that there is an equal balance of community and external independent directors. The corporation also set up three trusts in which the shareholder equity and distribution of dividends and earnings from the corporation go towards the support of community infrastructure, education endowments and company reinvestment (GFLBC, 2016). Today over $\$ 10$ million is held in the Goodfish Lake Community Development \& Business Trust. The board of trustees oversees this fund and advises the chief and council on issues facing the trusteeship; in return they receive community priorities that the trust can address. This governance model is fairly typical of many First Nations. It allows oversight by community members and stakeholders to ensure the corporation is fulfilling its mandate and staying true to its vision while having an arm's length oversight by chief and council.

Goodfish Lake follows the Harvard Project on American Indian Economic Development in several ways. Firstly, the corporation maintains a self-rule which promotes citizen engagement (Cornell and Kalt, 2003). The corporation makes decisions based on community needs. They often seek community input and most employees are community members so they feel directly involved. The community is proud of the business and promotes it as a success. Secondly, the corporation is set up to be at arm's length from political influences (Cornell and Kalt, 2003). This was a conscious effort by the council to allow the development corporation to flourish without ongoing demands of dividends or fiscal reallocations. This has not been too much of an issue due to the fact that every chief and councillor adheres to Chief Sam Bull's vision and recognizes the need for long term sustainability. 


\section{GFLBC \\ Governance Reporting Map}

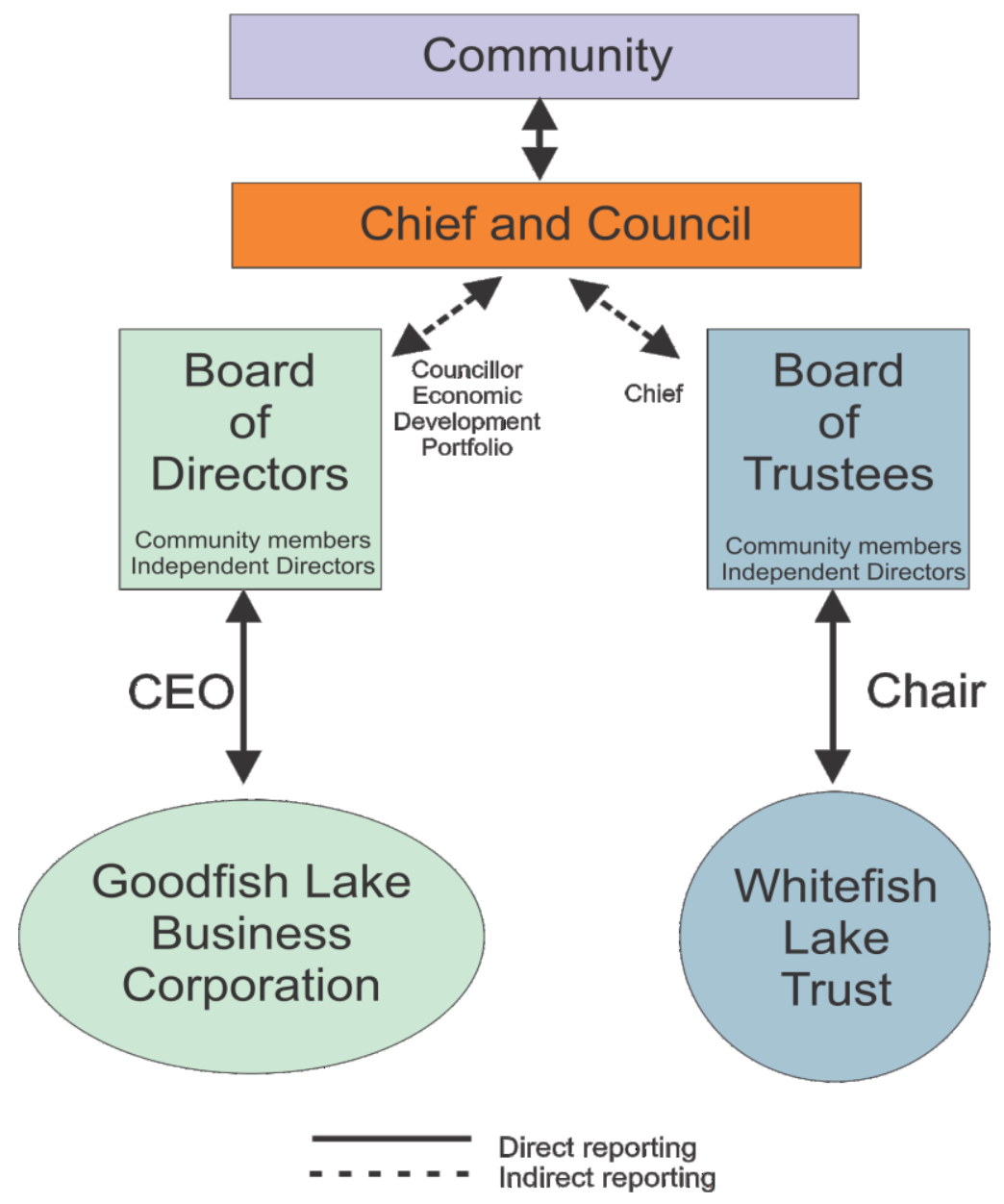

Figure 14 GFLBC Reporting Structure

The corporation has not always been successful. It took over twenty years to see dividends for the community. This was partially due to incorporating traditional knowledge into how they do business. It takes time, effort and money to create new processes for recycling harsh chemicals. However, it is what the Elders required and the community agreed upon. The pressure on the Chief and council was continuous from the band membership who repeatedly asked when they would see returns. The answers 
were consistent, saying that it takes time and the corporation is ensuring long term sustainability in the environment and in its people's culture. Doing business with traditional knowledge as a foundation allowed them to be a successful environmentally friendly corporation, but sacrificing sustainability for money was never accepted as an option.

\subsubsection{Key Findings}

The case study of Goodfish Lake Business Corporation shows several key findings. Firstly, that a sustained vision, trusteeship model and traditional knowledge are at the foundation of their business. Sustained leadership, such as the one Chief Sam Bull exercised, is critical to success. As shown, a sustained vision can transcend political influence and cultural challenges. By recognizing a sustained vision, the development corporation was able to eventually provide jobs for the community and also investment to meet community needs.

Trusteeships are an excellent way to alleviate the conflict of interest and political influences on an organization. GFLBC trusts are set up with both community and independent directors to ensure the dividends benefit the community. They maintain an arm's length relationship with the corporation and from the Chief and council. This ensures conflicts of interests are minimized. 
Perhaps the most telling finding in this case study is how traditional knowledge and values directly influenced GFLBC formation and strategies. By consulting with the community Elders, the business was able to adapt its strategic direction to accommodate their wishes. Environmental stewardship through ISO certification was in direct response to this use of traditional knowledge and the values they asserted. Their employee policies also followed the Elders' requests to maintain cultural activities such as hunting and trapping. This both protects and promotes cultural practices.

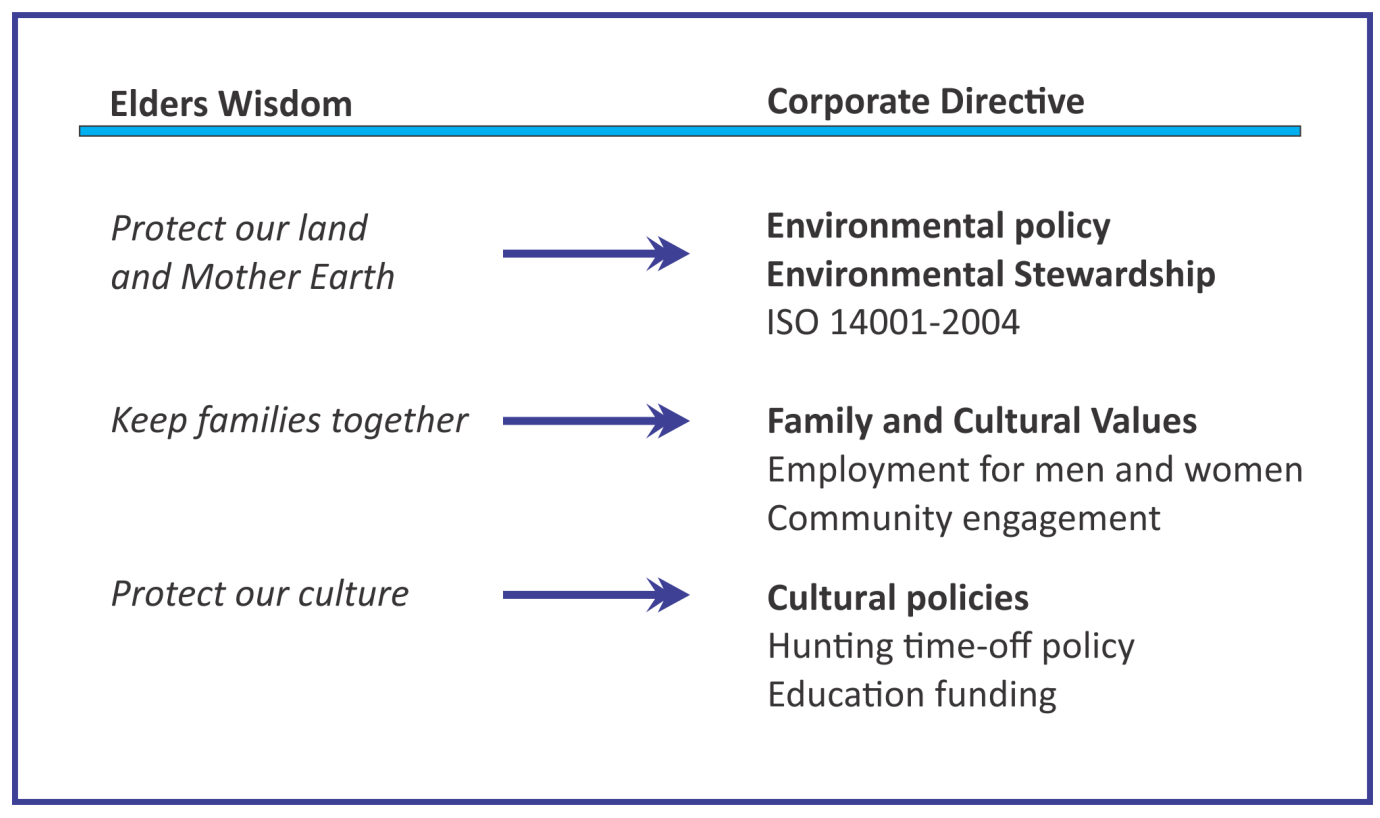

Figure 15 Goodfish Lake Development Corporation's Policy Directives

The case of GFLBC also shows how partnerships have given the opportunity for the community to prosper yet maintain its own values and traditions while doing so. This shows that engagement in capitalism does not mean relinquishing one's traditions and teachings. 
GFLBC truly reflects the Neechi principles of Community Economic Development as previously mentioned in Chapter 4. The use of local labour, reinvestment within the community and maintaining local decision making are all aspects of how GFLBC does business. Whitefish Lake sees GFLBC as a means to self-reliance and an avenue to creating a local economy. This reflects Loxley's fourth strategy of economic development, "export promotion". However, it does become endangered as it needs to diversify its business investments in the community in order to create a sustaining local economy rather than a single business.

Band-owned businesses are expected to respond to both the needs of the band (often community) and business needs which are sometimes in conflict with each other. As a band-owned enterprise, GFLBC "has a responsibility to the social well-being of community members. Therefore, it is mandated to create wealth and employment for the community. However, as a business, [GFLBC] must ensure that its bottom line looks good. After all, if the corporation is not generating profits, it cannot create jobs and invest in the community (Nelson and Sisco, 2008)".

Economic development can take a long time to see returns to the band, yet, it offers an opportunity to alleviate problems from within. The Goodfish community is once again thriving and healthy due to the success that economic development has accomplished within their community. Families are together again, and the hope of work and a future is real. The education of many youths is now being funded through the economic success of the corporation and the youth are returning to the community to take up jobs in the development corporation. The community is beginning to 
realize Chief Sam Bull's vision from forty years ago of self-sufficiency and prosperity

(Favel, personal communication, 2014), as well as the idea advocated by Chief Pakam in 1870 for a prosperous and sustainable community.

\subsection{Corporate Case: First Peoples Group}

\subsubsection{Summary}

The aim of this case study is to provide an example of a corporate-based business model that illustrates how traditional knowledge has effectively guided their business and decision making model. The First

Peoples Group (FPG) demonstrates that an

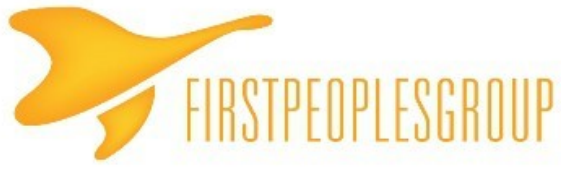

Figure 16 First Peoples Group Logo organization can understand both economic changes and opportunities while maintaining traditional teachings and values by using a traditional Métis governance structure as a model for its own governance.

\subsubsection{Overview}

First Peoples Group (FPG) is a management consulting company comprising a consortium of experienced professionals from First Nations, Métis and Inuit communities. They specialize in governance training, strategic management, communications and Indigenous awareness programs. The company was formed in 2011 by Guy Freedman (His ancestral name is Pizhew, Lynx of the Lynx Clan), a fifthgeneration Michif (Métis) from Flin Flon, Manitoba. 
First Peoples Group (FPG) is headquartered in Ottawa but works across Canada and is $100 \%$ Indigenous-owned (FPG, 2014). The company's mission is to provide management consulting drawing upon traditional knowledge and practices (FPG online, 2014). It is a company founded on principles of traditional Métis governance, yet works with its clients' own traditions to best meet their needs.

\subsubsection{Context}

As more First Nations, Métis and Inuit businesses are formed, there is a growing need for support in governance and management consulting. According to past census and projections for growth, there may now be more than 50,000 self-employed Indigenous people in Canada ${ }^{27}$. This growth can be linked to the assertions of the Royal Commission on Aboriginal Peoples (1990) that linked self-determination and selfgovernment with economic development and entrepreneurial growth.

Leaders realize that businesses both large and small are an important part of economic activity both on reserve and off. Yet, this growth in business development is bringing change to communities in the form of capitalism and economic demands. Communities are changing and adapting to these realities. As David Newhouse explains, First Nation, Métis and Inuit are all starting to form "new identities, and new social, political, cultural and economic institutions within Aboriginal societies" (2000). The reality of this modernization has left many searching for expertise in both governance

\footnotetext{
${ }^{27}$ Based on the projected growth of $30 \%$ in a five-year period as shown in the 2001 and 2006 census.
} 
and traditional knowledge. There is a growing need for specialization in governance and strategic planning along with an understanding of community and traditional values.

As discussed in Chapter 4, economists Raul Prebisch and Hans Singer both suggest there is a structural absence of institutions and governance that will perpetuate dependency (Ardeni \& Wrigth, 1992). By instituting governance practices based on traditional teachings and governance, Indigenous people can move out of, or prevent dependency. First Peoples Group firmly established their values in the belief that selfdetermination is possible through reforming governance based on traditions and community needs.

\subsubsection{History}

The story of First Peoples Group (FPG) is linked directly with its founder and president Guy Freedman. Freedman spent several years as a senior provincial public servant, and from 1982 to 1985 as Director for the Aboriginal Career Development Initiative, and Senior Program Officer for Health Canada's

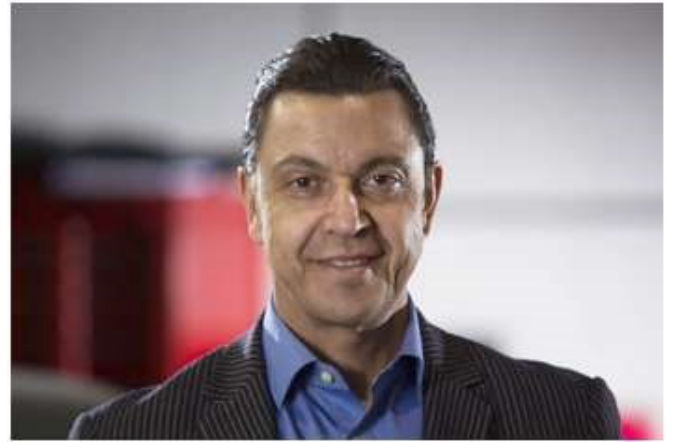

Figure 17 Guy Freedman, First Peoples Group Aboriginal Head Start program. He later became a special assistant to the Minister of Northern Affairs and Business Development in Manitoba (FPG online, 2016). From 2011 to 2012, Guy served as the Senior Advisor (Reconciliation) for the Truth and Reconciliation Commission of Canada. This gave him a passion for reconciliation for both Indigenous people and non-Aboriginal 
people and prompted his creation of an Indigenous awareness program that led to the foundation of First Peoples Group.

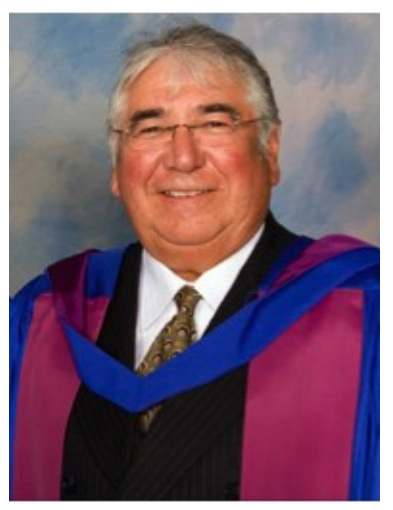

Figure 18 Tony Belcourt, First Peoples Group
Since the business began Guy Freedman has seen an opportunity to not only give back to communities but to transfer knowledge to ensure their capacity for successful management (Freedman, personal communications, 2014). The company was founded on this belief and soon attracted likeminded individuals. In 2011 Tony Belcourt joined FPG as Vice President and Senior Partner, corporate and international relations, bringing his own perspectives as the former president of the Métis Nation of Ontario. He was also a leader in the $R$. $v$. Powley case that resulted in the Powley Test which laid out the criteria for Métis hunting rights (Supreme Court of Canada: 2003). Belcourt shared Freedman's vision of working closely with communities rather than larger corporation or governments. He also extended the business internationally with his work in Central and South America and advocacy for technology infrastructure and training for Indigenous communities.

In 2015, Jeff Copenace was appointed Senior Vice President of First Peoples Group. Copenace is Ojibway from the Onigaming First Nation (Treaty 3) in Northern Ontario (Elyas: 2014). He worked for Paul Martin as a senior advisor and negotiator as well as Deputy Chief of Staff to former National Grand Chief Shawn Atleo. Bringing his experience in community

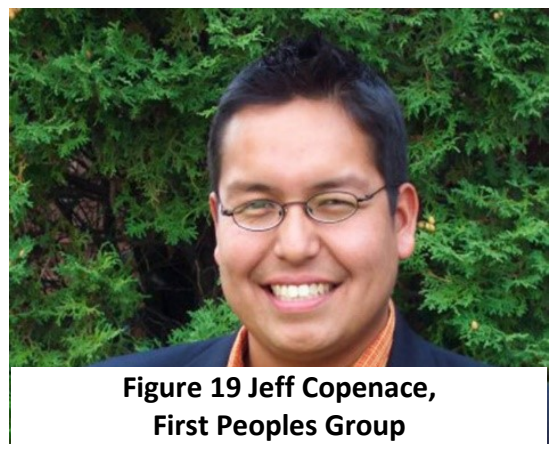


negotiations, he offers a unique view from both the government and private industry. Working as a negotiator in the energy sector he recognized the challenges of community needs being pushed aside for the common good of the nation. He advocates for a fair and open process of negotiation on an equal basis.

\subsubsection{Creating a vision}

According to Freedman, First Peoples Group was founded on the principles of traditional knowledge to help companies and communities, and these principles are at the heart of how it does business (Freedman, personal communication, 2014). Understanding how traditional knowledge can be an important part of the company cannot easily be quantified. Freedman says that it is not a tool employed to gain business but rather a philosophy through which business works. When working with a community or company, FPG works with them and their employees in traditional ways, as appropriate (Freedman interview, 2014).

As discussed in Chapter 7, traditional knowledge can vary, from local knowledge to a more cross-tribal understanding, yet each holds value. While traditional knowledge such as the Medicine Wheel and the Tipi Teachings are shared by many nations, there are also local traditions that can be equally influential in governance practices. First Peoples Group understands that working with bands requires an open discussion on what traditions they feel comfortable bringing forward and how the traditional knowledge will be interpreted and influence governance practices. This knowledge comes from years of working and living in communities and understanding the fine 
nuances of protocols and cultural sensitivities. The understanding and key finding here is that FPG understands that traditional knowledge can be the foundation of an indigenized approach to governance.

\subsubsection{Critical transition point - adapting their business model}

One key project which succeeded in reinforcing the vision and mandate of the FPG was their work with the Ontario Association of Children's Aid Societies (OACAS) and the Sharing a Good Heart program (2015). OACAS recognized the need for reconciliation and the need to build mutually respectful relationships with Native people. Since Duncan Campbell Scott, superintendent of Indian Affairs, called residential schools a solution to the "the Indian problem" (Milloy, 1999; RCAP, 1997b.) various children's aid societies have been involved in the repercussions and realities of this legacy. In the 1940s, social workers advocated for more involvement on the reserves to help the children. While the intent of the social workers is debatable, it did lead to the expansion of child welfare systems (RCAP, 1996b; Blackstock, 2003). By the 1960 s, well over $80 \%$ of Native children in Saskatchewan's residential school system were placed there by social workers (Caldwell, 1967; RCAP, 1997b). Today the situation is still bleak with some provinces having more Native children in care than at the height of the residential school era (Kelly, 2013; Blackstock, 2003b).

In 2013, the First Peoples Group worked closely with the Ontario Association of Children's Aid Societies (OACAS) to create a framework for reconciliation. They adopted the Anishinabe term Miinote eh or he/she is feeling well and in a good heart (Kelly, 
2013). The concept of a good heart is part of the Bimaadiziwin teachings on how to live one's life in a good way. It encourages truth and honesty while helping oneself and others. These concepts intertwine with other concepts such as restorative justice, mediation, and conflict resolution. They work together to form a restoration of one's miinote to a better place.

Working with the Children's Aid Society provided a challenge for FPG. They remained committed to their use of traditional knowledge and teachings but realized that bureaucracy also exists and may resist these teachings. Working to overcome these barriers and show that traditional knowledge does have value, FPG worked with the Children's Aid Society to better understand Indigenous culture and to better provide services to Indigenous families. While this way of working was new for OACAS, they were willing to work with FPG to create a new model of service delivery through culture based teachings and understanding (Freedman, personal communications, 2016).

Another turning point for First Peoples Group was when they recognized that in order to achieve reconciliation there has to be cultural understanding and appreciation (Freedman, personal communication, 2014). This realization came from Freedman's work with the Truth and Reconciliation Commission which facilitated healing and understanding with both Indigenous and non-Indigenous people. FPG created a plan of reconciliation that included ongoing dialogue, education, awareness and spirituality. This incorporated ceremonies, healing circles, and working with Elders to create a safe environment that would foster healing, exchange of knowledge and mutual understanding. 
They employed the traditional process of working together with First Nations as equals in the restoration of trust, and beginning the journey of reconciliation using traditional teachings and concepts to illustrate this plan. They not only shared narratives from other successful ventures and community development work, but worked with the local traditions to ensure that locality (Loxley, 2000) was a key aspect of their development work.

\subsubsection{Telling Their Story}

Today, FPG employs First Nations, Métis, and Inuit partners to give it a wide range of expertise while maintaining connections to communities. The company merges traditional knowledge and beliefs with management solutions (FPG, 2014). The experience they have gained from working with communities and organizations has cemented their resolve in assuring that traditional teachings and values are an integral part of not only their own governance structure but their work with clients. The concept of community development for FPG is one of community empowerment and a path to self-determination and self-governance, and for some nations, their sovereignty.

Also key to its business success and authenticity is the incorporation of traditional knowledge into its own governance and operation practices. The company adopted the values of integrity, respect, and honesty in how it does business. FPG demonstrates this in their adoption of Métis governance practices and the concept of "Chief and Captains of the Hunt" (Belcourt, personal communication, 2014). Traditionally, in a Métis governance structure, the Captain of the Hunt was chosen to lead the community. 
Consensus building was the main form of negotiated governance. The captain had to lead with integrity and honesty in his or her capabilities or be forced to step down (Belcourt, personal communication, 2014). FPG is a consortium of professionals that come together for a project or a purpose. They meet and all decide the direction of the project, and if it is a good project that reflects their corporate values, they take it on. Freedman acts as the Captain of the Hunt and helps organize the projects. He may or may not take the lead, but ensures it is consistent with their mission. FPG realizes its own limitations, so if a contract or an expectation cannot be met, they will not take it on and may recommend another firm that can better support the clients' needs (Freedman, personal communication, 2014).

First Peoples Group's four core values motivate how they conduct business, and closely ties their belief in the value of tradition, culture and respect with a successful business. These values include:

- excellence in service delivery

- integrity in all dealings with our clients

- respect for the knowledge and wisdom that all stakeholders bring to the table, and

- honesty - if we can't do it, we'll tell you.

(First Peoples Group, 2014)

One particular specialty of First Peoples Group is how it incorporates traditional knowledge into the work that it undertakes. An example of this is how the company provides cultural sensitivity training across the country (Freedman, personal communication, 2014). Facilitators include traditional practices such as participating in a 
sweat lodge, sunrise ceremony and smudging. This perspective lets people experience the cultural background of a particular group rather than merely sitting through PowerPoint slides (Freedman, personal communication, 2014). Every contract is unique, and they work within the cultural traditions of the territory and the company they are working with to ensure their work is in line with their own corporate values while respecting their clients' own needs and values.

\subsubsection{Existing Barriers}

First People Group was not haphazardly put together. Freedman and Belcourt adhered to certain principles which would often lose them contracts. However, they remained true to their belief in the importance of incorporating traditional knowledge into their work. These principles include:

- early consultation with the community to understand their needs and issues.

- ensure transparency to the communities they work with, yet protect the community from external misuse of any data or findings in their research.

- gain an understanding of the communities they work in, their traditions, teachings and ways of knowing.

In applying these principles, FPG may face challenges in securing contracts because many requests for proposals do not include traditional knowledge or a need for understanding local customs and teachings. Yet, in order to maintain the integrity of the employees working at FPG they understood and accepted this challenge. This philosophy, as well as their respect for traditional ways, has resulted in most of their 
work being with communities and for communities, rather than ongoing work with governments or corporations.

Freedman sees governance work as an important part of economic development. Without oversight, financial literacy and business knowledge, many Indigenous businesses and economic development corporations will fail. Capacity is still an ongoing issue that needs to be addressed in the communities. Freedman shares Loxley's (2000) vision that community economic development should be locally based and dedicated to the social wellbeing of the local community.

\subsubsection{Findings}

The case study of First Peoples Group shows that through leadership a company can maintain traditional teachings within their governance structure. Drawing on First Nations and Métis governance, the company not only practices this merger of two systems but seeks to provide management services in the same capacity. FPG empowers their practices through traditional teachings by maintaining their vision to help communities regardless of other lucrative opportunities. This shows the common value found throughout many First Nations, Inuit, and Métis businesses that community, not money, is the first priority. Profits are, of course, important, but they do not drive FPC's decision-making process when accepting a contract.

Another important aspect of this case study is how Loxley's principles of Community Economic Development $(1993 ; 2010)$ are maintained through the vision of the company. FPG is now dedicated almost exclusively to helping communities 
(Freedman, personal communication, 2016). The company builds on community strengths and local knowledge to empower its members. This is reflected in their work with the Ontario Children's Aid Society where they worked to increase local decision making for local services to the population. This project mirrored the Neechi principles of development and employs Loxley's (2010) principle of self-reliance strategies by ensuring local traditions were respected and decisions were made locally based on community needs. The aim of FPG's work with Children's Aid was to bring meaningful control of services to Indigenous people in the Winnipeg area.

For FPG, reputation and relationships with their clients are important. They understand that working with a community binds you to that community. Often the communities will contact FPG again and again for advice and guidance. This reflects the relationality of the work they do with communities and the value they place on relationships. This reflects their commitment to local stability (Loxley, 2010), allowing the communities to decide their path through effective decision-making with advice from FPG. This local community-based approach differs from typical consulting that recommends a decision based on monetary gains, and instead considerers what the needs of the community are.

First Peoples Group has shown that by beginning with a traditional governance model such as the Métis Captain of the Hunt, they can create a successful business. FPG employs traditional governance within their governance, differentiating 
this consulting firm from many others and providing an example of how traditional knowledge can help decision making.

\subsection{Combined Partnership Case: Ktunaxa-Kinbasket Partnership Strategy}

\subsubsection{Summary}

The aim of this case study is to

provide an example of a partnership-

based business model that illustrates

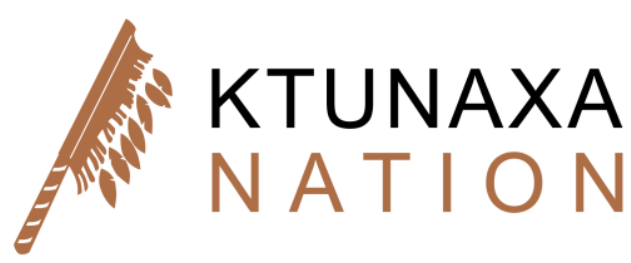

how traditional knowledge can

Figure 20 Ktunaxa Nation Logo

effectively guide businesses and their decision-

making model. The Ktunaxa people, also referred to by many as "Kootenay" people, are located in the Kootenay region of British Columbia. The Ktunaxa (pronounced 'k-toonah-ha') people have occupied the lands adjacent to the Kootenay and Columbia Rivers and the Arrow Lakes of British Columbia, Canada for more than 10,000 years (KTNC, 2016). The Ktunaxa Nation Council (KNC) is the body that represents the Ktunaxa Nation in Canada.

The KNC vision of sustainable development is to strive, as a self-sufficient, selfgoverning nation, to achieve a viable economy, to manage their lands and resources, and to support strong, healthy citizens. The KNC's governance is based on the Qat'muk (Grizzly Spirit) Declaration which encourages responsible stewardship over the land but also employs the concept of generational sustainability for future generations (similar to the Seven Generations philosophy examined in Chapter 7). This case study shows how 
the Qat'muk gives the Ktunaxa a traditional values-based approach to development.

This is best demonstrated in their largest project, the development of the St Eugene mission, a former residential school now owned and operated by SEM Corporation comprised of the Ktunaxa Nation, Samson Cree Nation and Mnjikaning First Nation (also known as the Chippewas of Rama First Nation in Ontario).

\subsubsection{Overview}

The traditional territory of the Ktunaxa Nation covers approximately 70,000 square kilometres and stretches along the Kootenay and Columbia Rivers and around the Arrow Lakes in British Columbia (St. Eugene Resort online, 2014). Historically, it also covers land extending into southeastern British Columbia and parts of Alberta, Montana, Washington, as well as Idaho (KNC, 2016). The Nation's citizenship is comprised of six bands that are spread throughout the territory (KNC, 2016). Those bands are 1) the Wood Land People of St. Mary's, 2) Two Lakes People of Columbia Lake, 3) People Where the Rock is Standing of Lower Kootenay, 4) People of Flying Head Place of Tobacco Plains with two bands in the United States, the 5) Bonners Ferry in Idaho and 6) Elmo in Montana.

The overall governing body for the nation is the Ktunaxa Tribal Council (KNC, $2016)^{28}$. The council was established in 1970 to promote the political and social development of the nation (Louis, 2014) and includes the chiefs and councils of the

\footnotetext{
${ }^{28}$ The Ktunaxa Tribal Council changed its name in 1991 to Ktunaxa/Kinbasket Tribal Council (KKTC) to reflect both the Ktunaxa and the Shuswap. The departure of the Shuswap Indian Band (Kinbasket) in 2005 saw the return of the Ktunaxa Nation Council (KNC) name.
} 
nation. The KTC is composed of five sector councils: lands and resources, traditional knowledge and language, social, economic investment, and corporate (Louis, 2014). The council is also responsible for the overall economic development of the nation.

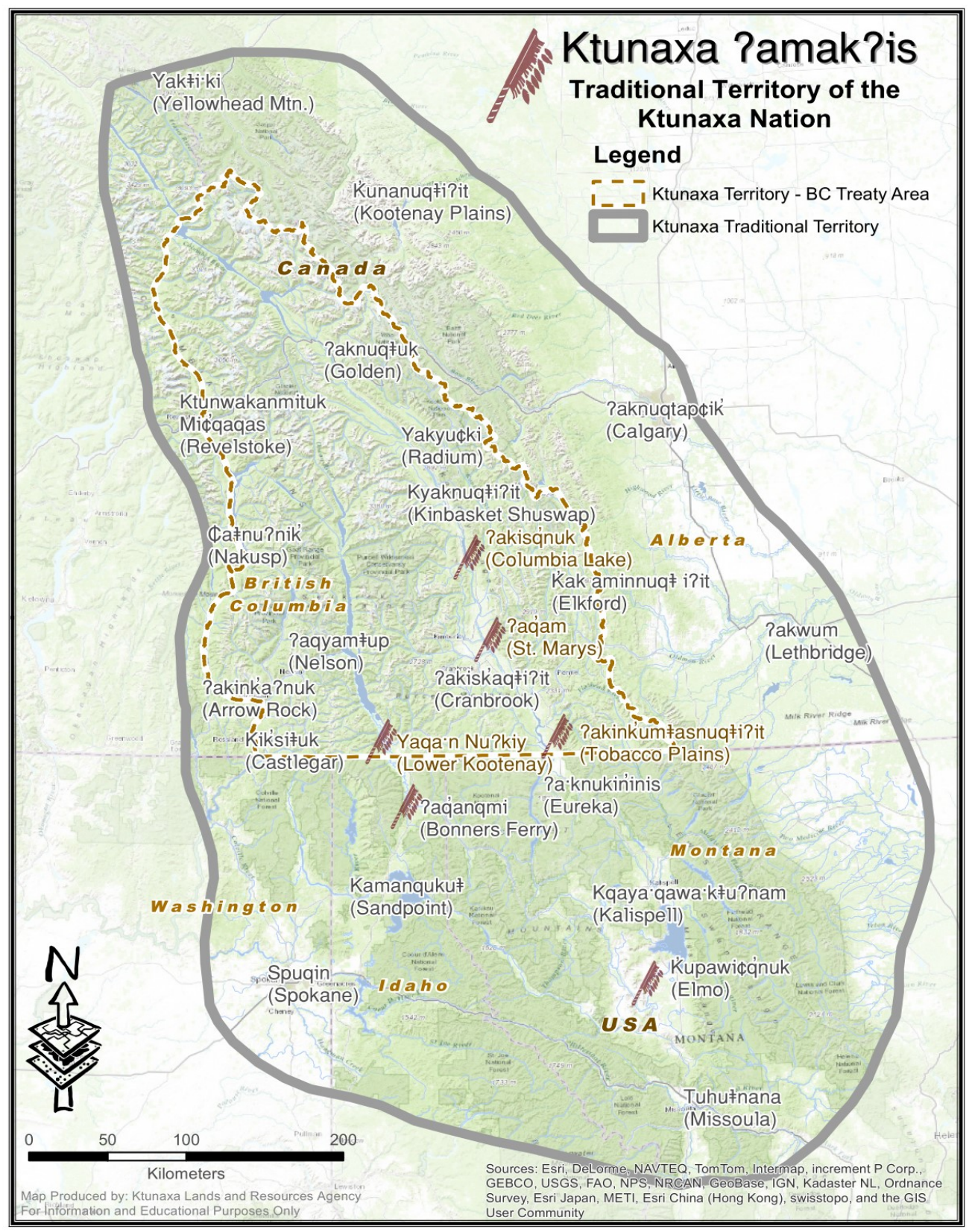

Figure 21 Ktunaxa Traditional Territory 


\subsubsection{History and the St. Eugene Mission School}

In 1910, the Government of Canada created the St. Eugene Mission School, a residential school located in Cranbrook, British Columbia. St. Eugene Mission was

Western Canada's first industrial and residential school (Centre for First

Nations Governance, 2013). The unique building was designed by Ottawa

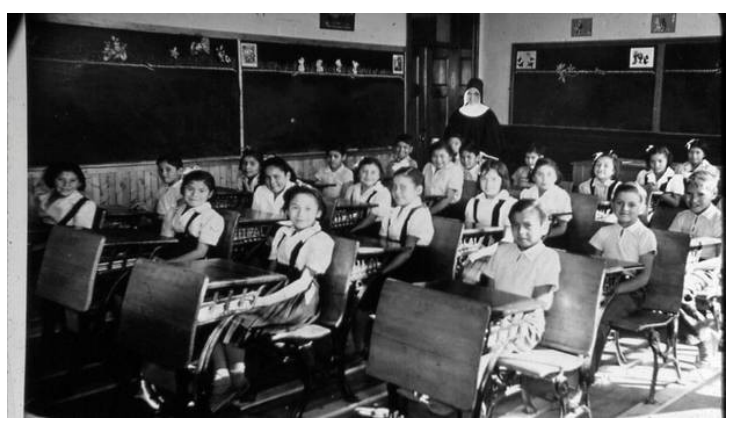

architect Allan Keefer and not by

Indian Affairs departmental architect

Figure 22 Archive Photo of Children in St. Eugene Indian Residential School

Robert M. Ogilvie as many schools were (Johnson, 2003). It was operated by the Roman Catholic Church until 1970 when the Oblates made an agreement with the federal government to transfer the buildings and lands in trust to the five bands (Pierre, 2009). In 1973, the B.C. Government leased the Mission with the intent of turning it into a facility for the mentally handicapped. The building was stripped of historic fixtures and artifacts, and, after spending $\$ 750,000$ on renovations, the project was abandoned (St. Eugene online, 2016).

Sitting on Ktunaxa territory beside the Kootenay River, the building was a constant source of pain and suffering for the band. The bitter irony was that the bands now owned the building but could not afford the upkeep, thus it remained empty and abandoned for over twenty years. 
In the 1990s the council, along with

the St. Mary's Indian Band under Chief Sophie Pierre's leadership, embarked on a ten-year project that resulted in a $\$ 40$ million business venture to renovate the residential school and convert it into a

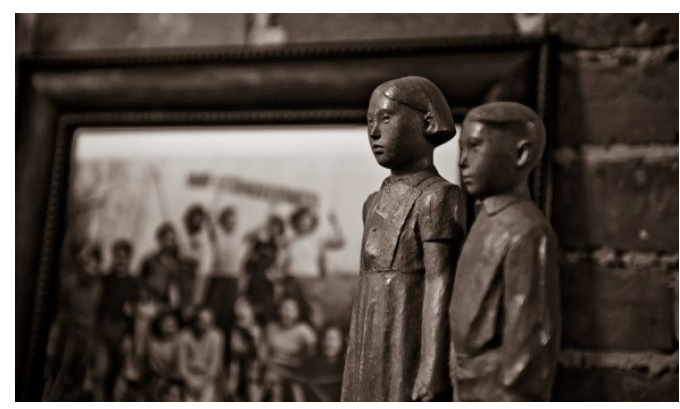

Figure 23 Statue Dedicated to Residential Survivors at St. Eugene Mission

five-star golf resort (KNC, 2016). Out of this leadership and vision St. Eugene Golf and Resort was born. St Eugene's Mission was transformed into a successful five-star resort and golf course that is $100 \%$ owned by SEM Resort Limited Partnership, a Native partnership agreement comprised of the Ktunaxa Nation, Samson Cree Nation and Mnjikaning First Nations. SEM distributes profits to the tribal councils and each nation can decide on how to invest the money.

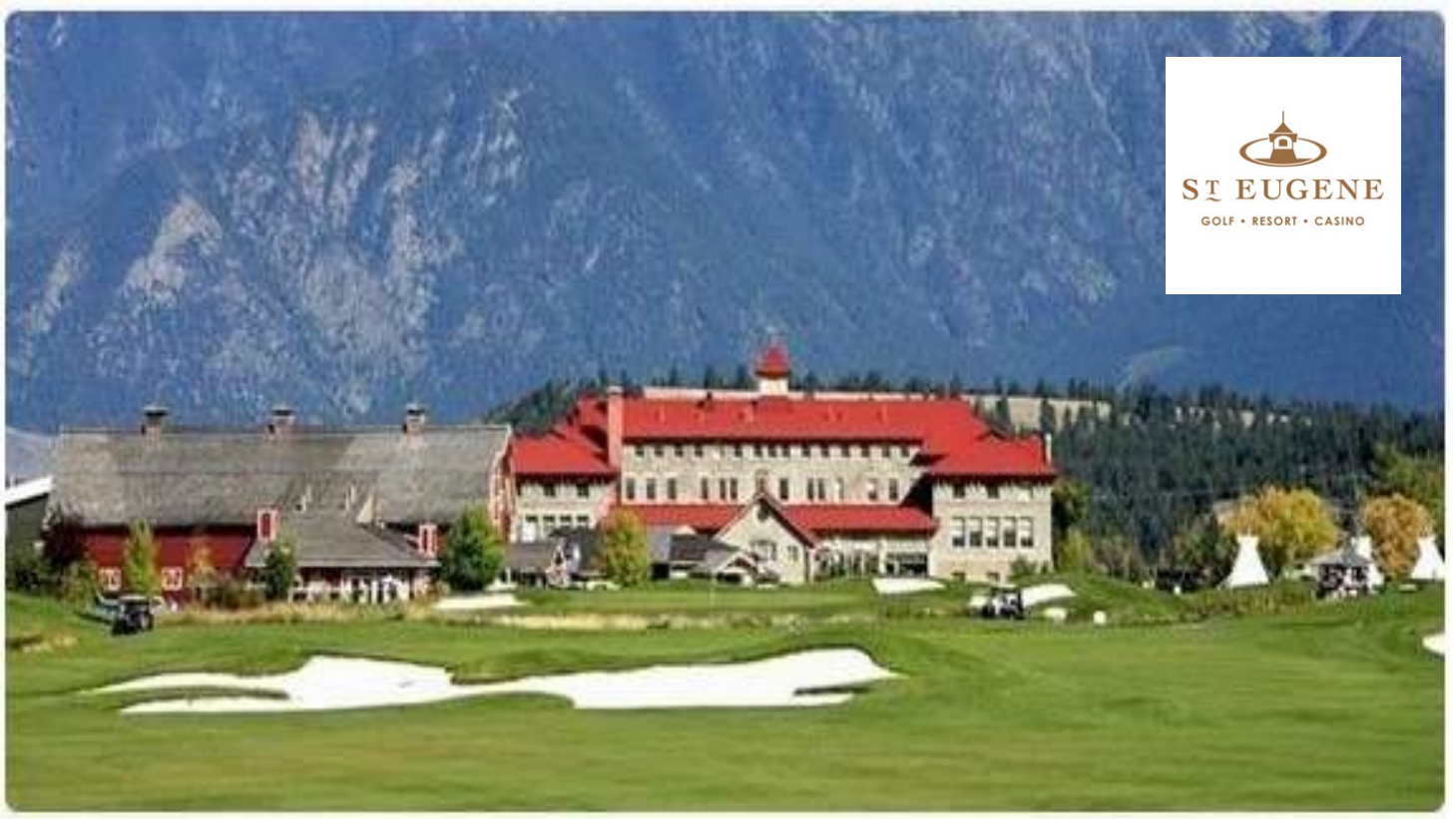

Figure 24 St. Eugene Resort, Cranbrook, British Columbia 
St. Eugene employs approximately 250 people, of which approximately $25 \%$ are of First Nations descent (St. Eugene online, 2016). St. Mary's Indian Band provides local labour giving the band members an opportunity for much needed employment. However, jobs are not the primary focus of the band. While creating a viable business that produces dividends for the band was a key focus, these dividends would provide much needed revenue to allocate to infrastructure, cultural preservation, housing and other economic development projects.

Ktunaxa Nation chair Kathryn Teneese explains that it is more than “...doing business on Ktunaxa territory... it shows we can do business while maintaining the land and giving something back to our people" (Teneese, 2016). The Ktunaxa Nation Council receives the dividends and prioritizes its disbursements according to the wishes of the communities within the nation. The priorities are set by the council, which consists of representatives from each community. This ensures a fair process for deciding how the dividends are spent.

\subsubsection{A Leader's Vision.}

The dramatic story of the St. Eugene Mission's transformation from a source of pain to a source of pride and revenue is part of Chief Sophie Pierre's legacy. Chief Pierre (traditional name née Eustace) worked for the St. Mary's Indian Band (traditional name Aqam) for thirty years, including twenty-six years as the chief and twenty-five years as the administrator of the Ktunaxa/Kinbasket Tribal Council (Pierre, 2009). Chief Pierre 
also served as the president of St. Eugene Mission Holdings Ltd., which included the resort (St. Eugene Resort online, 2014).

Chief Pierre was responsible for the St.

Eugene Mission after its closure in 1970. The decision on what to do with the building sparked a great community debate. Chief Pierre

describes the time as a challenging one as many were still healing and angry. As a survivor of the school herself, Chief Pierre admits it was an

emotional time for her and everyone around her

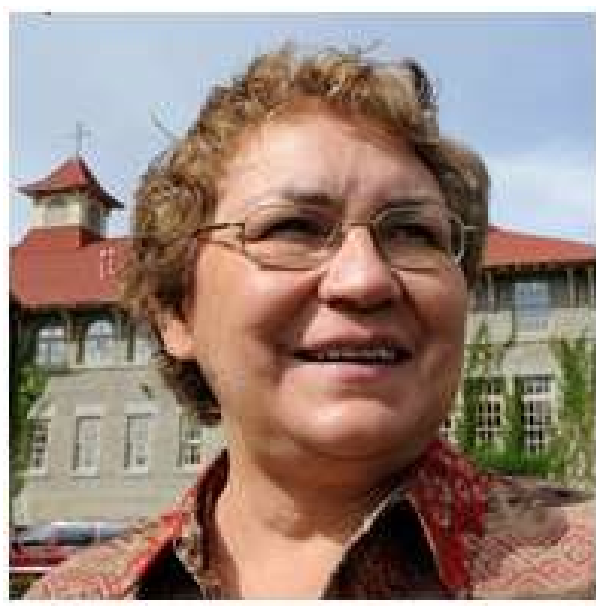

Figure 24 Chief Sophie Pierre and the St. Eugene Resort (Pierre, personal communications, 2014).

During this time of debate, one Elder, Mary Paul, stood up. She acknowledged that there was a lot pain from that building, and it should be transformed into something good. There were many suggestions offered, yet Elder Mary Paul's sage-like advice began a long process of healing. Grandmother Paul's words are posted in the hotel lobby:

Since it was within the St. Eugene Mission (Kootenay Residential School) that the culture of the Kootenay Indian was taken away, it should be within that building that it should be returned. Elder Mary Paul, 1984 (Henry, 2012) 
Chief Pierre is proud to say that the band led the change from hurt to healing and did something positive with a place that had a very negative effect on the community. For Chief Pierre, it was an emotional time and difficult for her to remain diligent and open to ideas (Chief Sophie Pierre, Personal Communications, 2008, 2012), but, throughout the process she maintained a traditional approach to her governance practices. She looked to her traditions for guidance and ensured that she worked to serve the community rather than drive forward her own vision. Chief Pierre humbly accepted her role as a bridge between her community and the management of the band business (Chief Sophie Pierre, Personal Communications, 2012). This philosophy led her to be respected by her community for her diplomacy and good nature.

Chief Pierre became the president of St. Eugene Mission Holdings Ltd., a tripartite partnership between the Samson Cree Nation (Alberta), Ktunaxa Kinbasket Tribal Council, and Mnjikaning First Nation. In this capacity, she spearheaded the development of partnerships and management of the resort and its holdings.

The British Columbia Lottery Corporation (BCLC) also entered into a partnership with the Ktunaxa Tribal Council. According to Chief Pierre, early partnerships were not easy to maintain (Chief Sophie Pierre, Personal Communications, 2012). The band vision was that St Eugene's was about community and helping community members heal while having a successful business and dividends. This contrasted with the view of the BCLC as they were not interested in traditions nor community development but instead were most concerned with ensuring that 
regulations were being upheld. The council negotiated with the BCLC to get a revenuesharing agreement that would yield $25 \%$ of profits from electronic game devices, $40 \%$ of table revenue, and $75 \%$ of poker revenue (Dressler, 2011). This revenue stream would increase wealth to the band and provide much-needed funding for cultural activities and infrastructure.

The Nation has created a trust based on the Qat'muk (see below) to invest in language and cultural preservation and other cultural initiatives. While this trust is fairly new and small, it has a guaranteed investment from SEM holdings. To date, the audited financial statements show a $\$ 100,000$ balance that will be used to fund future activities. The trust is managed by the council but the trustee model is being examined as a viable future governance model to administer the funds. Money resulting in the interest would then go back to the Chief and council to allocate into needed areas such as: health, education, economic development, public works, policing and more.

\subsubsection{Looking to Ktunaxa traditional knowledge}

The mission of St. Eugene's Resort is to "contribute to the economic growth in the surrounding community, while preserving and respecting Mother Earth" (St. Eugene online, 2014). For the Ktunaxa people this is a sacred law and the basis for their governance and relationality to the land. This philosophy comes from the traditional knowledge of the people. As the Qat'muk (Grizzly Spirit) Declaration states the Ktunaxa people have not only a connection to the land but an obligation of stewardship over the land. The spirit of this declaration embodies the vision of the communities and the 
Ktunaxa Nation Council for their people. They are bound to this model of decision making based on the values and assertions of the Qat'muk.

The Qat'muk (ktunaxa.org) sets out the duties and beliefs of the Ktunaxa people as given to them by their ancestors. It is more than a simple declaration, it is a statement of connectivity to the land, a way to live in peace with each other, and a way to maintain stewardship over the land and its inhabitants. This declaration has been passed down through generations to ensure their ongoing commitment to the land. Today it also serves to provide and demonstrate the band's inherent right to the land. The document sets forth the declaration of governance which asserts sovereignty and self-determination. The following is part of the declaration showing this connection to land, spirit, and animal coupled with stewardship.

Given the complexities of understanding

Qat'muk Declaration
We, the Ktunaxa, have lived
in our territory since time
immemorial and have a deep
spiritual connection to the
animal world and, in
particular, to the grizzly bear.
Qat'muk is a very special
place where Kławła
TukłułakPis, the Grizzly Bear
Spirit, was born, goes to heal
itself, and returns to the spirit
world. The Grizzly Bear Spirit
is an important source of
guidance, strength, protection,
and spirituality for the
Ktunaxa. Qat'muk's
importance for the Grizzly
Bear Spirit is inextricably
interlinked with its
importance for living grizzly
bears now and in the future.
The Ktunaxa have a
stewardship obligation and
duty to the Grizzly Bear Spirit
and Qat'muk.
traditional knowledge, the Qat'muk is very clear about stewardship and ties it to traditional ecological knowledge. The concepts expressed in the Qat'muk were incorporated into the values and policies at the resort. Given the location of St. Eugene 
resort, the protection of the land was one of the major concerns yet it was also seen as an opportunity for investment.

The Ktunaxa have a principle called Yaqał Hankatiłiłki na Pamak, which means "our people care for the land; the land cares for our people" (ktunaxa.org). Basing the resort's value system on the Qat'muk was a decision to embrace their traditions and decolonize the old residential school allowing for further healing. Staff members are trained and aware of the history and cultural aspects of the area. They understand the concept of stewardship whether they are First Nations or not and try to communicate the importance of these values to visitors and patrons.

\section{The Qat'muk}

Affirms that having been created in interdependence with the land, its living things, and the spirit world, the Ktunaxa possess and are entitled to enjoy our inherent and pre-existing sovereignty over our land and our lives thereon;

Affirms that the United Nations Declaration on the Rights of Indigenous Peoples supports the Ktunaxa Nation's right to: (a) manifest, practice, develop, and teach our spiritual and religious traditions, customs, and ceremonies, and to maintain, protect, and have access in privacy to our religious and cultural sites [Article 12]; and (b) maintain and strengthen our distinctive spiritual relationship with our traditionally owned or otherwise occupied and used lands, territories, waters, and other resources, and to uphold our responsibilities to future generations in this regard [Article 25];

Emphasizes that the Ktunaxa have never consented to the developments and desecrations that have occurred within Qat'muk;

Asserts that we will not agree to any further development or sale of land associated with Qat'muk that would result in irreparable and irreversible harm to this sacred place and our spiritual connection with it;

Affirms that the Creator gave the Ktunaxa covenants, one of which is to protect, honour, and celebrate what the Creator has given us; 
Reaffirms that our Law, Paknumuctitit, requires the protection of our sacred places for ourselves, our children, and our grandchildren;

Recognizes that the Ktunaxa language does not translate well into other languages, and consequently our spiritual relationship with Qat'muk may not be fully understood by others;

Affirms that we are strong, as we have maintained our cultural connection to our land, language, and spirituality;

Reaffirms that we are of one heart and one mind to protect Qat'muk from desecration;

Insists that we will strengthen and revitalize the Ktunaxa Nation through our spiritual connection to Qat'muk; invites other governments, non-governmental organizations, business proponents, local communities, and others to support and respect our spiritual traditions and practices linked to Qat'muk, and to help protect it against desecration and destruction.

The Ktunaxa Nation Council's vision is "Strong, healthy citizens and communities, speaking our languages and celebrating who we are and our history in our ancestral homelands, working together, managing our lands and resources, within a selfsufficient, self-governing Nation (KNC, 2016)." The concept of land stewardship is part of their ongoing vision. This traditional way of knowing is inherent in the way they do business and includes environmental stewardship and economic sustainability.

For the Ktunaxa, economic sustainability is not only linked to sovereignty but is also steeped in their traditions and traditional knowledge. To create a framework for economic development for the community, Chief Pierre turned to the Harvard Project on American Indian Economic Development (Centre for First Nations Governance, 2013). The study recommended best practices in economic development based on the principles of: exerting sovereignty in decision making for your own nation, ensuring 
cultural relevance based on traditions, creation of governance systems based on traditional knowledge, and sustainable leadership (Centre for First Nations Governance, 2013). The bands' decision to base their model on the traditional teachings was natural and organic. Rather than trying to fit traditions into governance they opted to fit the governance into their traditions.

\subsubsection{Key Findings}

The case study of St. Eugene Resort shows a community that has not only taken a tool of colonization (residential school) and converted it into a prosperous business venture. It also illustrates the value of traditional knowledge and governance coming together to form a stronger Indigenized decision making process more appropriate to the community's needs. The leadership shown by Chief Pierre was based on her commitment to serving the community as well as honouring her traditions and traditional role as chief. She maintained the long-term vision and was able to lead her people towards greater economic sustainability over an extended period of time. The case study shows that traditional ways of knowing can be incorporated into their decision-making models. Their governance structures and philosophy show commitment to the community, the land, and their spiritual ways. As shown, the Ktunaxa concepts of Qat'muk and Yaqa Hankatiłiłki na Pamak provide insight into the nation's concept of governance. Loxley (2010) would agree that this reflects the seventh

principle of economic development in creating a local economy using local labour. It also 
reflects the nation's ability to move towards self-determination and make localized decisions based on community needs.

For the purpose of this study, the most interesting finding is the process in which the nation developed a mixed concept of traditional and western governance to assert their sovereignty and economic independence. Co-opting the colonial ways, or at least practises the nation decided were applicable to their situation, has allowed them to not only conform to laws and regulations but also to maintain their traditional ways.

The Ktunaxa Nation governance is one of values-based decision making as described in Chapter 6. They do conform to provincial laws and regulations around gaming and licencing, however the decisions regarding the financial gains are decided by the nation. By embracing the concepts of the American Indian Project (Cornell, 2010), they are able to create a viable business that can sustain an economy and help the nation move towards self-determination and self-governance. They also are a good example of the Loxley Neechi (1993) principles of community economic development in that they created a localized business using local labour, created a governance structure that embraces decision making based on local needs, and additionally based on traditional knowledge. They also reflect the principle of improving the physical surroundings while promoting a healthy lifestyle and healing. The use of the Qat'muk adds traditional teachings to attain this goal. The success of St Eugene's Golf and Resort has helped to bring stability into the nation and the community of St Eugene. 


\section{Chapter 9 - Conclusion}

This dissertation has examined the question: can traditional knowledge be incorporated into a governance model for Native businesses or local government? If so, is traditional knowledge applicable in today's businesses and if so what would that look like? Throughout this thesis the concept of creating an equal and complementary model of governance for economic development by including both traditional and Western governance practices has been shown to be both practical and applicable. By examining several case studies as well as analyzing the benefits of both Indigenous and Western governance, it is clear that there is a need for communities to create a model of governance that works for the community as a whole. Such a model enhances economic development and community prosperity as discussed in Chapter 4. This research also shows that adopting alternative models of governance can promote self-determination and self-governance for communities.

As discussed in Chapter 4, there is a desire for First Nations to gain selfgovernance and self-determination, and for some this extends to sovereignty. In any case, governance is simply the way in which business is conducted. At the heart of governance are the values that affect decision making. Traditional knowledge is a set of values based on Indigenous knowledge and relationality to the land. Combining these two creates an Indigenous value system that guides how we govern. In essence it indigenizes governance. 
Chapter 1 presents the issues of historical and ongoing oppression of traditional

First Nations governance systems. There continues to be an oppressive state mentality to undermine First Nations development and ultimately sovereignty. It also examines the ongoing dialogue within the academic community on how capitalism and neoliberalism also contribute to the overall suppression of subaltern voices. This research calls for the creation of a new space at both an academic and government level to reduce systemic barriers that perpetuate the myth that capitalism is the apex of economic models. The capitalist perspective is apathetic to the concept of alternate Indigenous economic models and dismisses them. The ongoing academic conversation has to be one of inclusiveness and openness to a new view of economics within an Indigenous context and understand it at a community level. It can no longer dismiss an Indigenous model as an anomaly or colonize it as a subset or category within capitalism. As discussed in Chapters 1 and 3, there has to be a recognition and reconciliation of Indigenous economic concepts such as intergenerational business models, trade without immediate reciprocity, and circular trade. It is precisely this perception of economic activity that offers a more inclusive approach to Indigenous ways of knowing and living and includes Indigenous world views.

Chapters 3 and 4 identify legislation such as the Indian Act that creates barriers to many traditional governance practices. Many First Nation communities are locked in a dependency cycle with the state and have to adhere to imposed laws to maintain this relationship, one that is not only patriarchal but also oppressive of traditional forms of governance. First Nations are going to have to move beyond the Indian Act to become 
self-sufficient and self-governed. One way to accomplish this is to create a community or nation constitution. This will allow communities and nations to have some autonomy in governance in order to pursue economic opportunities.

Economic opportunities are a major driving force for establishing strong governance within a business and within the band office. Chapter 4 shows that many nations are looking at the combined practices of governance, economic development, and even partnerships as a path to self-governance and self-determination. Partnership development is one opportunity for communities to find like-minded corporations or even other Indigenous communities and businesses to help develop and build sustainable businesses. As there are increasingly more partnerships between communities and corporations, there is an increasing need for strong foundations of governance within the communities' representative bodies. This may take the form of a band-owned enterprise, an economic development corporation, or even an entrepreneurial business. In terms of economic development, communities may have to look beyond their borders for long-term strategic investments to promote prosperity. While jobs continue to be the major focus in communities, it is difficult to generate wealth where there is continuous economic leakage, in other words, when money leaves the community faster than it comes in. Communities have to look at investments both nationally and globally and engage with partners that share the philosophy of long term investment versus. short term gain.

Another critical factor in this research is to understand that a "one size fits all" model cannot fit all communities, nor does one tradition fit all situations. Some 
communities may opt for minimal traditional governance while others may opt for almost a pure traditional governance model. Every model must be customized to suit the traditions and needs of the community or organization. Chapter 7 discusses the concept of mixed governance models based on community needs rather than government requirements. While more universal teachings like the Seven Generations, Medicine Wheel, and Tipi Teachings can and have been incorporated into business practices and governance, there is more localized knowledge that may be more appropriate to the communities or businesses that it will be supporting. This provides communities with opportunities to express culturally relevant perspectives that Indigenize governance practices. It infuses the decision-making process with traditional values. This is also a culturally relevant process that provides a space for Indigenous knowledge to guide governance. As all the case studies show, traditional knowledge is based on providing a values-based approach to governance and decision making.

As communities are progressively looking at corporate, organizational and political systems of governance, their ultimate goal is to increase prosperity for their citizens and reduce poverty. This research can be applied to any of the above mentioned areas of governance as it is a process rather than a model. For First Nations, the idea of corporate governance from a board perspective, organizational governance, or business management and political governance, such as the chief and council, have to be understood and managed in a culturally appropriate way. Each of these governance concepts can incorporate traditional knowledge. Incorporating traditional values and practices into governance provides a more culturally relevant form of 
governance and is also more acceptable to community members. This was shown in the case studies of in Chapter 8 where Goodfish Lake Development Corporation took over twenty years to become profitable, yet due to their commitment to the community, sustained leadership, and their traditional values, they are now successful and the community is benefiting.

The case studies in Chapter 8 show the best practices of various organizational models. In all cases there is a clear adaptation of the way they perceive and implement traditional beliefs and governance within their own systems. Whether they are development corporations, private businesses, or the band administration, this negotiation of traditional approaches helps communities understand and often support choices made by their leaders. This is accomplished by a sound, ethical decision-making process which utilizes traditional values and teachings through the guidance of Elders and other community members.

The case studies also showed that governance, leadership, economic development, partnerships, sustainable vision, and community support are all critical to economic success. These concepts cannot be divorced from each other as they all work together to create a foundation for success. This concept is reflected in the Tipi Teachings found in Chapter 7. Values can be represented by a tipi pole; if one fails then the whole structure is weakened and in danger of collapsing.

My research on traditional governance contributes to a larger discussion in both Indigenous communities and academia on how best to approach self-determination and support healthy communities. Governance is an important issue within communities 
and is often overlooked as simply a management issue. On the contrary, poor governance can lead to the failure of any program, business, or government.

Even since I began this research and my own work in our communities, there has been incredible change towards understanding why governance is important. Once there were very few of us working in the area of traditional governance and fewer still looking at board governance for Indigenous businesses and government. Today this is an increasing field of enquiry as it is important to the overall wellbeing of a community. I pinpoint the start of this enquiry to conversations that took place at a Council for Corporate Aboriginal Relations meeting in the early 2000s where I presented a basic model of traditional values and how it could be incorporated into board governance for Indigenous businesses. The response then was one of surprise and interest that this could be a viable model of governance. Since then, many community leaders and organizations have asked me to come and talk to their communities about this concept.

Today, I continue visiting many communities throughout Canada and the United States to not only talk about their desire to incorporate traditional knowledge and governance into their practices, but also their reluctance, given the lack of traditional knowledge that has been passed on and the restrictions of various colonial laws. Later, this would be echoed at a talk I gave on Creating Wealth and Opportunity in Aboriginal Communities at the Aboriginal Financial Officers Association Conference in 2007. Even more community leaders and community members were interested in hearing about traditional practices and governance. It was at this talk that I showed how the Medicine Wheel could be an effective governance tool. 
The future of this research lays in examining how traditional knowledge can be the starting point for structuring governance for a band or a corporation rather than after the governance has been established. First Nations businesses are subject to the corporation laws of Canada that dictate governance structures. First Nations governments are also constrained by the Indian Act and how band governance is organized. Future studies could examine how governance can be attained through a more traditional approach. The case studies presented demonstrate a desire to incorporate traditional knowledge into governance but show that there is still a deeply colonial process that exists to hinder and even prevent indigenizing the process.

Today, having visited over eighty First Nations, Inuit, and Métis communities across Canada, the conversation has grown, and many are looking to traditional values and teachings to guide governance and decision making. Communities are looking at creating economic activity within their communities to not only create jobs but provide lasting, sustainable economies to preserve and promote their culture.

There has to be a shift in the Canadian body politic from merely acknowledging Indigenous issues towards an action-based approach to reconciliation. For many communities the picture is still grim. With the highest suicide rates in Canada, communities are hurting and reaching out for help. For many, economic depression is at an all time high and jobs are nowhere to be found. Many communities are stuck in a cycle of dependency on handouts. Food security is a growing concern and diabetes is at an all time high. One hour out of Ottawa, Canada's capital, Kitigan Zibi Anishinabeg reserve has no clean drinking water as it has been poisoned by a mining project. Yet 
across the road is fresh municipal water that is not allowed to come into the reserve because it is a jurisdictional prohibition. The issues are great and demand immediate attention. The picture in many communities is not pretty and yet it is home.

While the future is one of constant uncertainty, there is hope. The current awareness level of Indigenous issues in Canada has increased dramatically fostered by the Apology for Residential Schools, Idle No More and then the Truth and Reconciliation Commission Report. There is a desire among Canadians and scholars to examine these important issues including self-governance and self-determination. Education institutions including many universities are looking to indigenize their campuses and courses. The government is renewing funding to help alleviate social issues and promote healthy communities. The current Prime Minister Justin Trudeau (2016) acknowledges:

First, the urgent need for a renewed relationship between the federal government and Indigenous Peoples in Canada. One built on trust, recognition and respect for rights, and a commitment that the status quo must end. And second, the importance of fairness and equality of opportunity for Aboriginal Peoples in Canada.

There is hope that the government will address these issues and help alleviate the barriers to community recovery.

Indigenous people in Canada are sovereign nations, many with treaty agreements with the Crown. All people living within Canada are then part of the treaties and everyone has the responsibility of knowing the issues and finding a way to have all people participate and prosper on Turtle Island.

On a final note, we are all ancestors today and must act accordingly. We are all ancestors to those that follow, and with all my heart and all my relations I believe this. 
Someday our children and even the seventh generation will look back at us today and see what we did during our time on Mother Earth. Did we make a difference for the people? Did we live in a good way? Do we follow mino bimaadiziwin or the good life? In all our actions today we must consider the next generations. I do believe we are in a renewed time of hope. Never before has the collective consciousness been so united from the grass roots awareness campaigns of Idle No More to the government's declaration of a renewed relationship. The Canadian people want more for Indigenous people and are speaking out against any ongoing oppression.

This is a great time to be alive.

Chi Miigwetch. 


\section{References}

Abele, C. F. (2010). What's Left of Capitalism and What We Should Do About It: A Polemic. Administrative Theory and Praxis Vol. 32.2.

Abele, F. \& Graham, K. (2011). What Now? Future Federal Responsibilities Towards Aboriginal People Living in Cities, Aboriginal Policy Studies, vol 1 n 1 spring.

Abele, F. \& Prince, M, J. (2006). Four Pathways to Aboriginal Self-Government in Canada, American Review of Canadian Studies, 36:4 pp 568-597 Winter.

Abele, F. (2007). Like an III-Fitting Boot: Government, Governance and Management Systems in the Contemporary Indian Act. National Centre on First Nations Governance.

Absolon, K. \& Willett, C. (2004). Aboriginal Research: Berry picking and hunting in the 21st century. First Peoples Child \& Family Review. Volume 1, Number 1, 2004, pp.

\section{5-17.}

Albert, M. (2007) There is an Alternative: Economic Democracy and Participatory Economies in Solidarity Economy: Building Alternatives for People and Planet: Papers and Reports from the 2007 US Social Forum, ED. Jenna Allard, Carl Davidson and Julie Matthaei, Changemaker Publications, Chicago, Illinois. Albert, M \& Hahnel, R. (1991). The Political Economy of Participatory Economics, Princeton University Press.

Alfred, T. (1995). Heeding the Voices of Our Ancestors, Oxford University Press. Alfred, T. (1999). Peace, Power, Righteousness: An Indigenous Manifesto. Oxford University Press. 
Alfred, T. (2009). Colonialism and State Dependency. Prepared for the National Aboriginal Health Organization Project Communities in Crisis, School of Indigenous Governance University of Victoria.

Allard, J. and Matthaei, J. ed. (2008). Unites States Social Forum of 2007, in Solidarity Economy: Building Alternatives for People and Planet: Papers and Reports, ChangeMaker Publication, Chicago.

Altman, J.C. and Martin, D. (eds). (2009). Power, Culture, Economy: Indigenous Australians and Mining, CAEPR Research Monograph No. 30, ANU E Press, Canberra.

Altman, J.C. and Melinda, H. (eds). (2010). Culture Crisis: Anthropology and Politics in Aboriginal Australia, UNSW Press, Sydney.

Anaya, J. (2013, October 15). Statement upon conclusion of the visit to Canada. United Nations Special Rapporteur on the rights of Indigenous peoples. Retrieved from http://unsr.jamesanaya.org/statements/statement-upon-conclusion-of-the-visittocanada.

Anderson, J. (1989). Corporate Social Responsibility, Quorum Books.

Anderson, R.B. (1999). Economic Development Among the Aboriginal peoples in Canada; the Hope for the Future. Captus Press.

Anderson, T., Benson, B. \& Flannagan, T. (2006). Self-Determination; The Other Path for Native Americans. Stanford University Press.

Apffel-Marglin, Frédérique \& Marglin, S.A. eds. (1996). Decolonizing Knowledge: From Development to Dialogue. Oxford: Clarendon Press. 
Archibald, J., Jovel, E., McCormick, R., Vedan, R., \& Thira, D. (2006). Creating transformative Aboriginal health research: The BC ACADRE at three years. Canadian Journal of Native Education, 29 (1), 4-11.

Ardeni, P.G. and Wright, B. (1992). The Prebisch-Singer Hypothesis: A Reappraisal Independent of Stationarity Hypotheses, the Economic Journal. Vol. 102, No. 413 (Jul., 1992), pp. 803-812

Argyris, C. (1980). Inner contradictions of rigorous research. New York: Academic Press. Argyris, C, and Schon, D.A. (1989). Participative Action Research and Action Science Compared: A Commentary. American Behavioural Scientist, Vol. 32, 612-623.

Asch, M. (1982). Capital and Economic Development: A Critical Appraisal of the Recommendations of the Mackenzie Valley Pipeline Commission in Native People, Native Lands: Canadian Indians, Inuit and Métis edited by Bruce Alden Cox.

Ashling, J. (2009). Protection for Indian Traditional Knowledge. Information Today, April. Atleo, S. (2011a). Four Pillar Strategy.

http://www.shawnatleo.ca/modules/wfchannel/index.php?pagenum=7.

Atleo, S. (2011b). Speeches. http://www.aawgecdev.ca/chief-shawn-atleo.html.

Banerjee, A. and Duflo, E. (2012) Poor Economics: A Radical Rethinking of the Way to Fight Global Poverty, published by PublicAffairs, New York.

Bannerji, H. (1996). On the dark side of the nation: Politics of multiculturalism and the state of "Canada". Journal of Canadian Studies, 31(3), 103-128.

Behrendt, L. \& Kelly, L. (2008). Resolving Indigenous Disputes: Land Conflict and Beyond, Federation Press, 2008 
Barnhardt, R. \& Harrison, B. (1993, October 1). Strategies of education in Indigenous communities, Discourse: Studies in the Cultural Politics of Education, 14, 1, 89-99.

Barkin, D. (2005). Incorporating Indigenous epistemologies into the construction of alternative strategies to globalization to promote sustainable regional resource management: The struggle for local autonomy in a multiethnic society. Workshop on Ethics and Development, The Capability Approach in Practice, Michigan State University, April 13.

Barkin, D. (1998). Wealth and Poverty, and Sustainable Development, Mexico City, Center for Ecology and Development.

Barnhardt, Ray and Angayuqaq Oscar Kawagley. (2005). Indigenous Knowledge Systems and Alaska Native Ways of Knowing in Anthropology and Education Quarterly. Vol. 36, No. 1, pp. 8-23, March.

Bart, Chris. (2002). A Tale of Two Employees and the Person that Wanted to Lead Them, Bart and Company Inc., EBook.

Battiste, Marie. (2002). Indigenous Knowledge and Pedagogy in First Nations Education: A Literature Review with Recommendations. National Working Group on Education and Indian and Northern Affairs Canada, Apamuwek Institute.

Battiste, Marie (Ed.). (2000). Reclaiming Indigenous Voice and Vision, University of British Columbia Press.

Beaucage, et. al. (2008). Anishinabek Nation Economy - Our Economic Blueprint, Union of Ontario Indians Report. 
Beesley, Michael and Tom Evans. (1978). Corporate Social Responsibility; A Reassessment. Croom Helm Books.

Behan, B. (2011). Great Companies Deserve Great Boards: A CEO's Guide to the Boardroom. Palgrave Macmillan.

Benton-Banai, E. (1979). The Mishomis Book: Voices of the Ojibway. University of Minnesota Press.

Berger, T. (1977). Northern Frontier, Northern Homeland. The Report of the Mackenzie Pipeline Inquiry. Vol. 1. Ottawa; Praeger Publishers.

Bhaba, H. (1994). The Location of Culture. Routledge, New York, New York.

Bhagwati, J. (1982). Directly Unproductive, Profit-Seeking (DUP) Activities. Journal of Political Economy, Vol. 90, No. 5 (Oct., 1982), pp. 988-1002, Published by: The University of Chicago Press

Bhagwati, J. (2000). Protectionism. MIT Press. Cambridge, Massachusetts.

Black Elk, and Joseph Epes Brown. The Gift of the Sacred Pipe: Based On Black Elk's Account of the Seven Rites of the Oglala Sioux. University of Oklahoma Press, 1982.

Blackstock, C. (2003b). First Nations Child and Family Services: Restoring Peace and Harmony in First Nations Communities. In Kufieldt and McKenzie (eds.) Child Welfare: Connecting Research Policy and Practice. PP. 331-342, Wilfred Laurier Press, Waterloo, Ontario. 
Blackstock, C. \& Bennett, M. (2003a). National Children's Alliance Policy Paper on Aboriginal Children. Ottawa: First Nations Child and Family Caring Society of Canada.

Blackstock, C. \& Trocmé, N. (2005). Community-based Child Welfare for Aboriginal Children: Supporting Resilience Through Structural Change, Social Policy Journal of New Zealand, 24, March.

Blinder. (2008). Keynesian Economics. The Concise Encyclopedia of Economics. Retrieved from http://www.econlib.org/library/Enc/KeynesianEconomics.html.

Blunt, P. \& Warren, D.M. (1996). Indigenous Organizations and Development. Intermediate Technology Publication Ltd., Southampton Row, London. Boston, P. \& S. Jordan. (1997). Using Participatory Action Research to Understand the Meanings Aboriginal Canadians Attribute to the Rising Incidence of Diabetes, Chronic Disease in Canada, Volume 18, No.1. www.phac-aspc.gc.ca/publicat/cdicmcc/18-1/b_e.html

Brascoupé, S. (1993). Strengthening Traditional Economies and Perspectives, in Sharing the Harvest, the Road to Self-Reliance: Report of the National Round Table on Aboriginal Economic Development and Resources, Ottawa: Minister of Supply and Services.

Brown, D. (2004). Agency Governance. Brown Governance Inc. Publication.

Brown, D. (2003). Can You Hear Me Now? The Many Voices of Corporate Governance in Canada. Brown Governance Inc. Publication. 
Brown, D. (2002). Getting the Governance we Deserve. Lessons for Canada. Brown Governance Inc. Publication.

Brown, L.D. (1982). Ambiguities in Participatory Research. In B. Hall, A. Gillette and R. Tandon (eds.) Participatory Research in Development. New Delhi, Society for Participatory Research in Asia.

Brown, L.D. \& R, Tandon. (1983). The Ideology and Political Economy of Inquiry: Action Research and Participatory Research. The Journal of Applied Behavioral Science and Technology: An International Perspective. 19. p227-294.

Brown, T. \& L. Jones. (2001). Action Research and Postmodernism, Buckingham, Open University Press.

Brown, L. \& Strega, S. (2005). In Research as Resistance: Critical, Indigenous, and Antioppressive approaches. Toronto, Canadian Scholars' Press Inc.

Budgell, J. (1999). Our way home: A Report to the Aboriginal Healing and Wellness Strategy: Repatriation of people removed by the child welfare system: final report. Native Child and Family Services of Toronto, Toronto.

Buono, A. \& Nichols, L. (1985) Corporate Policy, Values and Social Responsibility. Praeger Publishing, New York.

Burrows, John with Sarah Morales. (2005). Challenge, Change and Development in Aboriginal Communities, in Legal Aspects of Aboriginal Business Development (Joseph Magnet and Dwight Dorey, eds., LexisNexis Butterworths. 
Burrows, John, et. al. (2005). Western Economic Diversification, report for the Government of Canada on study of Aboriginal economic development in five Canadian cities.

Burrows, John. (2003). Stewardship and the First Nations Governance Act, 29 Queen's Law Journal 103.

Burkitt, Brian. (1988). Radical Political Economy: An Introduction to the Alternative Economics, New York University Press.

Busch, Marc., Krzysztof, J. (2014) Law, politics, and the true cost of protectionism: the choice of trade remedies or binding overhang. World Trade Review, Vol. 13, pp. 39-64.

Cadbury, Adrian. (2002). Corporate Governance and Chairmanship: A Personal View. Oxford University Press.

Cairns, Alan. (2000). Citizens Plus: Aboriginal Peoples and the Canadian State. Vancouver: University of British Columbia Press.

Caldwell, David. (1998). Aboriginal Businesses: Characteristics and Strategies for Growth, Industry Canada.

Caldwell, David, and Pam Hunt. (1998). Aboriginal Businesses: Characteristics and Strategies for Growth. Industry Canada.

Campbell-Scott, Duncan. (1914). Indian Affairs, 1867-1912, in Canada and its Provinces, Vol, 7, Section 4, Toronto: Glasgow, Brook \& Company.

Cardinal, Harold and The Indian Association of Alberta. (1970). Citizens Plus, Indian Association of Alberta. (Also known as the Red Paper). 
Carino, Joji. (2009). State of The World's Indigenous People, Department of Economic and Social Affairs, Division for Social Policy and Development, Secretariat of the Permanent Forum on Indigenous Issues.

Carver, John. (2009a). A Carver Policy Governance Guide, Evaluating CEO and Board Performance. Jossey-Bass; 2nd Revised edition, 2nd. ed.

Carver, John. (2009b). A Carver Policy Governance Guide, The Policy Governance Model and the Role of the Board Member. 2nd Revised edition, 2nd. ed.

Carver, John. A, (2012). The Policy Governance Model, [online] http://www.carvergovernance.com/model.htm

Cassidy, J. (2006). The Stolen Generations - Canada and Australia: The Legacy of Assimilation. Deakin Law Review, 11, 1, 131-177. Retrieved from http://search.informit.com.au.ezproxy.uow.edu.au/documentSummary; $d n=64229$ 0873264443;res=IELHSS> ISSN: 1321-3660

Cameron, Jenny, (2008). The Contribution of Community Enterprises to the Development of Regions, Centre for Urban and Regional Studies, The University of Newcastle, Presentation, Australian Regional Economy Conference, Terrigal, NSW, May. Cachon, Jean-Charles. (2000). Aboriginal Entrepreneurship on Reserves. in Journal of Small Business and Entrepreneurship, Vol. 15, No. 3, Summer.

Castleden, H., V. Morgan, and C. Lamb. (2012). "I spent the first year drinking tea": Exploring Canadian university researchers' perspectives on community-based participatory research involving Indigenous peoples. The Canadian Geographer, $56,2,160-179$. 
Charmaz, K. (2006). Constructing grounded theory: A practical guide through qualitative analysis. London: Sage Publications Limited.

Charmaz, K. (2005). Grounded theory for the 21st Century. In N. K. Denzin and Y. S. Lincoln (Eds), The Sage Handbook of Qualitative Research (3rd ed.), (pp. 507-535). Thousand Oaks, CA: Sage.

Charmaz, K. (2003). Grounded Theory: Objectivist and Constructivist Methods. In N.K. Denzin and Y.S. Lincoln (Eds.), Strategies of Qualitative Inquiry, 2nd ed., pp. 249-291, London: Sage Publications Limited.

Chiste, Katherine. (1996). Aboriginal Small Business and Entrepreneurship in Canada. Captus Press.

Chomsky, Noam. (2010). In New World of Indigenous Resistance, by Noam Chomsky. San Francisco: City Lights Books.

Christensen, Julia and Miriam Grant. (2007). How Political Change Paved the Way for Indigenous Knowledge: The Mackenzie Valley Resource Management Act. In Arctic, 60:2, pp. 115-123, June.

Churchill, Ward. (2004). Kill The Indian, Save The Man: The Genocidal Impact of American Indian Residential Schools. City Lights Publishing.

Clement, Wallace. (1997). Understanding Canada: Building on the New Canadian Political Economy, Montreal, McGill-Queen's University Press, pp. 408.

Clement, Wallace and John Myles. (1994). Relations of Ruling: Class and Gender in Postindustrial Societies. Montreal: McGill-Queen's University Press, pp. xiii, 297. 
Collins, P.H. (2000). Gender, Black Feminism and Black Political Economy. Annals of the American Academy of Political and Social Science, 568. 41-53.

Coombs, Steven; Fletcher, Sarah. (2005). Design and evaluation of critical thinking scaffolds to support action research for teacher professional development. Paper presented at the EARLI 2005 11th Biennial Conference, University of Cyprus, August.

Cornell, Stephen and Joseph P. Kalt. ed. (1993). What Can Tribes Do? Strategies and Institutions in American Indian Economic Development, Los Angeles: University of California, American Indian Studies Center.

Cornell, Stephen and Joseph P. Kalt. ed. (1998). Sovereignty and Nation-Building: The Development Challenge in Indian Country Today, American Indian Culture and Research Journal 1998, Vol. 22, No. 3, pp. 187-214.

Cornell, Stephen and Joseph P. Kalt. (2003). Reloading the Dice: Improving the Chances for Economic Development on American Indian Reservations. Joint Occasional Papers on Native Affairs. The Harvard Project. No. 2003-02.

Cornell, Stephen, Catherine Curtis and Miriam Jorgensen. (2004). The Concepts of Governance and its Implications for First Nations, The Harvard Project, Joint Occasional Papers on Native Affairs, No. 2004-02.

Cornell, Stephen and Joseph P. Kalt. (2005). Two Approaches to Economic Development on American Indian Reservations: One Works, the Other Doesn't, Joint Occasional Papers on Native Affairs No. 2005-02. 
Cornell, Stephen. (2006). What Makes First Nations Enterprises Successful? Lessons from the Harvard Project, Native Nations Institute for Leadership, Management, and Policy, Joint Occasional Papers on Native Affairs, No. 2006-01.

Cornell, Stephen. (2007a). Remaking the Tools of: Colonial Legacies, Indigenous Solutions. In Miriam Jorgensen, ed., Rebuilding Native Nations: Strategies for Governance and Development. Tucson: University of Arizona Press.

Cornell, Stephen. (2007b). Rebuilding Native Nations: What Do Leaders Do? With Manley A. Begay, Jr., Miriam Jorgensen, and Nathan Pryor. In Miriam Jorgensen, ed., Rebuilding Native Nations: Strategies for Governance and Development. Tucson: University of Arizona Press.

Cornell, Stephen and Kalt, J. (2010). The Harvard Project on American Indian Economic Development. Retrieved 2015, from http://hpaied.org/

Corsiglia, John and Gloria Snively. (1997). Knowing Home: NisGa'a Traditional Knowledge and Wisdom Improve Environmental Decision Making. Alternatives Journal, Summer.

Cox, Bruce Alden ed. (1992). Native People, Native Lands: Canadian Indians, Inuit, and Métis. McGill University Press, Montreal.

Crenshaw, Kimberlé W. (1991). Mapping the Margins: Intersectionality, Identity Politics, and Violence against Women of Color, Stanford Law Review, Vol. 43, No. 6., pp. $1241-1299$.

Creswell, J.W. (2003). Research Design: Qualitative, Quantitative and Mixed Methods Approaches (2nd ed.). Thousand Oaks, CA: Sage Publications Inc. 
Cummings, Scott L. (2001). Community Economic Development as Progressive Politics: Toward a Grassroots Movement for Economic Justice. Stanford Law Review Vol. 54.

Daly, J. (Ed.). (1996). Ethical intersections: health research, methods, and researcher responsibility. Boulder, Colorado: Westview Press.

Das Gupta, Tania, Carl E. James and Roger C.A.Maaka, Grace-Edward Galabuzi, Chris Anderson. (2007). Race and Racialization Essential Readings, Canadian Scholars Press. Toronto.

Davis, Kathy. (2008). Intersectionality as buzzword: A sociology of science perspective on what makes a feminist theory successful, in Feminist Theory, 9:68., Sage Publishing.

De Angelis, Massimo. (1998). Limiting the Limitless: Global Neoliberal Capital, New Internationalism and the Zapatistas Voice. University of East London.

Deb, Debal. (2009). Beyond Developmentality: Constructing Inclusive Freedom and Sustainability. London: Earthscan.

Dimon, Jamie. (2009). Banks should be allowed to expand - and fail. The Washington Post. [online] www.washingtonpost.com/wpdyn/content/article/2009/11/12/AR2009111209924.html

Dickason, Olive Patricia. (2001a). Canada's First Nations: A History of the Founding Peoples from Earliest Times. 3rd ed. Don Mills.

Dickason, Olive Patricia. (2001b). Visions of the Heart: Canadian Aboriginal Issues. Oxford University Press; Third Edition. 
Dickason, Olive Patricia. (2006). A Concise History of Canada's First Nations, Oxford University Press.

Dickason, Olive Patricia. (2003). Canadian Aboriginal Saga: A People and a Dream. American Review of Canadian Studies Vol. 33.

Dickason, Olive and David T. McNab. (2009). A History of Founding Peoples from Earliest Times, Fourth Edition, Oxford University Press.

Dimma, William A. (2002). Excellence in the Boardroom: Best Practices in Corporate Directorship, Wiley.

Dimma, William A. (2006). Tougher Boards for Tougher Times: Corporate Governance in the Post- Enron Era. Wiley.

Domar, Evsey (1946). Capital Expansion, Rate of Growth, and Employment. Econometrica 14 (2): 137-147.

Donovan, M. (2008). Legal Anthropology: An Introduction. Lanham, MD: AltaMira Press. Dressler, Max. (2011). Presentation on St. Eugene Resort partnerships at the Canadian Gaming Summit. [online] http://canadiangamingsummit.com/2012/presentations/FNG1-Canadian-GamingSummit-110412-Final.pdf

Drucker, Peter. (1985). Innovation and Entrepreneurship: Practice and Principles. Queens University Press.

Dussalt, Rene, and George Erasmus. (1991). The Report of the Royal Commission on Aboriginal Peoples. Government of Canada Web Archive. [online] 
http://www.collectionscanada.gc.ca/webarchives/20071115053257/http://www. ainc-inac.gc.ca/ch/rcap/sg/sgmm_e.html.

Duxbury, Linda. (2007). Symposium, Ottawa Centre for Research and Innovation, Lunch series with Carleton University's Sprott School of Business.

Dwyer, Janelle. (2012). Legal Update: Current Issues Affecting First Nations' Business Structures in Business Law \& Economic Development. [online] http://www.mandellpinder.com/legal-update-current-issues-affecting-firstnations-business-structures/

Edmond, J. (2007). Aboriginal Consultation and Accommodation: An Essential Step to Project Approval, Law Now, 32, 2, 1-7.

Escobar, Arturo. (2003). Other Worlds are (Already) Possible: Self-Organization, Complexity, and Post-Capitalist Cultures. In J. Sen. A. Anad, A. Escobar and P. Waterman (eds), The World Social Forum: Challenging Empires. Black Rose Books; 2nd ed. edition.

Escobar, Arturo. (1995). Encountering Development: The making and unmaking of the third world. Princeton, NJ: Princeton University Press.

Esler, DM. (2008). Participatory Action Research in Indigenous Health, in Australian Family Physician. Jun. Vol. 37(6):457-9.

Ezekiel, Zachariah. (2005). Rebuilding Trust in Canadian Organizations, The Conference Board of Canada, Ottawa.

Ezeala-Harrison, Fidelis. (1996). Economic Development: Theory and Policy Applications. Westport, CT: Praeger Publishers. 
Elyas, Mark. (2014) A New Way of Doing Business with First Nations. Interview with Jeffrey Copenace, Nationtalk [online] http://www.firstnationsdrum.com/2014/10/a-new-way-of-doing-business-withfirst-nations-interview-with-jeffrey-copenace/

Friedman, M. (1962). Capitalism and Freedom. Chicago. The University of Chicago Press. Fals-Borda, Orlando. (1991a). Some Basic Ingredients. In Orlando Fals-Borda and Muhammad Anisur Rahman (eds) Action and Knowledge: Breaking the Monopoly with Participatory Action-Research. New York: Apex Press.

Fals-Borda, Orlando. (1991b). Remaking Knowledge. In Orlando Fals-Borda and Muhammad Anisur Rahman (eds) Action and Knowledge: Breaking the Monopoly with Participatory Action-Research. New York: Apex Press.

Fals-Borda, Orlando. (2001). Orlando. Participatory (Action) Research in Social Theory: Origins and Challenges in Peter Reason and Hilary Bradbury (eds.) Handbook of Action Research: Participative Inquiry and Practice. London; Thousand Oaks, Calif.: SAGE.

Farazmand, Ali. (1996). Public Enterprise Management: International Case Studies.

Greenwood Press, Westport, Connecticut.

Fidler, C. \& Hitch, M. (2007). Impact and Benefit Agreements: A Contentious Issue for Environmental and Aboriginal Justice. Environments, 35, 2. ProQuest Central.

Fine, Helene S. (1994). Participant Action Research: A Case Study of Community Economic Development in Chicago. Public Administration Quarterly Vol. 18. 
Flyvbjerg, Brent. (2006). Five misunderstandings about case-study research. Sage

Publications. Qualitative Inquiry, Volume 12, Number 2, April 2006, pp. 219-245.

Fontan, J.M. (1993). Pointe St. Charles-Building a Community Voice in Shragge, E. (editor) Community Economic Development: In Search of Empowerment. Montreal, Black Rose, p.76-92.

Ferrara, Peter J. (1998). The Choctaw Revolution: Lessons for Federal Indian Policy. Washington, DC: Americans for Tax Reform Foundation.

Freire, Paulo. (2007). Pedagogy of the Oppressed. Continuum Press.

Freire, Paulo. (2009). Pedagogy of Hope: Reliving Pedagogy of the Oppressed. Continuum Press.

Frideres, James S. (1988). Native Peoples in Canada: Contemporary Conflicts. 3rd edition. Scarborough, Ontario: Prentice Hall Canada.

Frideres, James S. and René R. Gadazc. (2008). Aboriginal Peoples in Canada, 8th edition, Toronto, Prentice Hall.

Frost, Allen. (2007). Procurement Strategy for Aboriginal Business. Indian and Northern Affairs Canada.

[online] http://www.ainc-inac.gc.ca/saea-psab/vdo/psabtrn_e.html

Furniss, Elizabeth. (2002). The Burden of History: Colonialism and the Frontier Myth in a Rural Community. UBC Press.

Gang, Yael. (2009). Carleton Students Organize 'Indigenous Academic Conference', Digital Journal [online] http://www.digitaljournal.com/article/268960 
Gasse, Yvon and Harold Bherer (Ed). (1990). Native Entrepreneurship; The Key to Autonomy. Proceedings of the National Conference on Native Entrepreneurship, Institute for Research on Public Policy.

Gereffi, Gary and Korzeniewicz, Miguel. (Ed). (1993). Commodity Chains and Global Capitalism. Praeger Publishers.

Geertz, Clifford. (1995) After the Fact: Two Countries, Four Decades, One Anthropologist. Harvard University Press, Cambridge.

Getty, Grace et al. (2001). Surviving the System: Regaining Resilience. The experience of Tobique First Nation with tuberculosis. Fredericton, Canada: University of New Brunswick.

Ghosh, Jayati, (2010). Global Crisis and Beyond: Sustainable Growth Trajectories for the Developing World. International Labour Review, 149: 209-225.

Gibson-Graham, J.K. (2006a). The End of Capitalism (As We Knew It): A Feminist Critique of Political Economy, University of Minnesota Press, Minneapolis.

Gibson-Graham, J.K. (2006b). A Postcapitalist Politics. Minneapolis: University of Minnesota.

Gibson-Graham, J. K. (2006c). Imagining and Enacting a Postcapitalist Feminist Economic Politics. Women's Studies Quarterly Vol. 34.

Gibson-Graham, J.K. (2003). An Ethics of the Local, Rethinking Marxism. Issue 15(1), pp. 49-74. [online: www.communityeconomies.org] 
Gibson-Graham, J.K. (2002). Beyond global vs local: Economic politics outside the binary frame, in A. Herod and M. Wright (eds) Geographies of power: Placing scale, Blackwell Publishers, Oxford, 25-60.

Gladwin, Thomas, Kennelly, James and Krause, Tara-Shelomith. (1995). Creating Sustainable Corporations, The Academy of Management Review, Vol. 20, No. 4, Oct., pp. 874-907.

Glaser, B. G. (2011). Getting out of the data: Grounded theory conceptualisation. Mill Valley, CA: Sociology Press.

Glaser, B. G. (2001). The Grounded Theory Perspective: Conceptualisation Contrasted with Description. Mill Valley, CA: Sociology Press.

Glaser, B. G. (1998). Doing grounded theory: Issues and discussions. Mill Valley, CA: Sociology Press.

Glaser, B. G. (1992). Basics of grounded theory analysis. Mill Valley, CA: Sociology Press.

Glaser, B. G. (1978). Theoretical sensitivity: Advances in the methodology of grounded theory. Mill Valley, California: Sociology Press.

Glaser, B. G. and Strauss, A. L. (1967). The discovery of grounded theory: Strategies for qualitative research. New York, NY: Aldine de Gruyter.

Gosh, S., Cameron. C and Eaton. S. (2011). Facilitating communities in designing and using their own community health impact assessment tool in Environmental Impact Assessment Review Volume 31, Issue 4, July 2011, Pages 433-437. 
Graham, Katherine A.H. and Evelyn Peters. (2002). Aboriginal Communities and Urban Sustainability, Canadian Policy Research Networks, Ottawa, December. Graham, N. (2013). Reporting to All Registered Class Members and All Other Interested Persons of the '60s Scoop Cultural Genocide Case in Ontario. Retrieved from http://sixtiesscoopclaim.com/2013/11/01/reporting-to-

Grant, Randy R., Kandice L. Kleiber, and Charles E. Mcallister. (2005). Should Australian Aborigines Succumb to Capitalism? Journal of Economic Issues Vol. 39.

Greenall, David and Stelios Loizides. (2003). Strengthening Corporate Aboriginal Relations, The Influence of Public Policies and Institution. The Conference Board of Canada.

Greenwood, Davydd. (2007). Introduction to Action Research: Social Research for Social Change. Thousand Oaks, California, Sage Publications.

Griffin, K. (1999). Alternative Strategies for Economic Development. Palgrave Macmillan; 2nd edition.

Grinde, Jr, Donald A., and Bruce E. Johansen. (1990). Native America and the Evolution of Democracy. Exemplar of Liberty.

Haig Brown, Celia and Robert Regnier, Kathy L Hodgson-Smith. (1997). Making the Spirit Dance Within: Joe DuQuette High School and an Aboriginal Community. James Lorimer and Company.

Haig Brown, Celia. (1998). Resistance and Renewal: Surviving the Indian Residential School. Arsenal pulp press. 
Haig-Brown, Celia and David A. Nock (ed). (2006). With Good Intentions: Euro-Canadian and Aboriginal Relations in Colonial Canada. Vancouver and Toronto, University of British Columbia Press.

Halfe, G. (2010, September 4). Nation Talk Interview with George Halfe [podcast]. Retrieved from http://nationtalk.ca/story/george-halfe-ceo-of-goodfish-lakedevelopment-corporation-2

Hall, Budd. L. (1981). Participatory research, popular knowledge and power: A personal reflection. Convergence, 14, 6-19.

Hammersley, Martyn. (2002). Action research: a contradiction in terms? Paper presented at the Annual Conference of the British Educational Research Association, University of Exeter, England, 12-14 September.

Harding, S. and Norberg, K. (2005). New Feminist Approaches to Social Science Methodologies: An Introduction. Signs: Journal of Women in Culture and Society, 30:4, pp. 2009-2015.

Harrod, Roy F. (1939). An Essay in Dynamic Theory. The Economic Journal 49 (193): 1433.

Hart K, Laville JL, Cattani, AD, editors. (2010). The Human Economy. Cambridge, UK: Polity Books.

Harvey, David and Christian Parenti. (2011). In Conversation, City University of New York, Graduate Centre, August.

Harvey, David. (2010). A Brief History of Neo-Liberalism, Oxford University Press, Oxford. Harvey, David. (1989). The Condition of Postmodernity, Blackwell Publishers, Oxford. 
Havemann. (1999). Indigenous Peoples' Rights in Australia, Canada \& New Zealand.

Melbourne: Oxford University Press.

Hawken, Paul. (2010). The Ecology of Commerce, revised edition: A declaration of Sustainability. Harper Collins Press, New York.

Hawken, Paul; Lovins, Amory and Lovins, Hunter (2000). Natural Capitalism: Creating the Next Industrial Revolution. Little Brown and Company, Boston.

Heidegger, Martin. (1962). Being and Time, Harper and row Publishing, New York. Herzfeld, Michael. (1993). The Social Production of Indifference, University of Chicago Press.

Helin, Calvin. (2010). Economic Dependency Trap Address at Carleton University. Helin, Calvin. (2009). Dances with Dependency. Woodland Hill: Raven Crest Publishing. Helin, Calvin. (2008). Economic Dependency Trap. Cubbie Blue Publishing, Inc. Henry, Chief Sharon Stinson. (2012) St. Eugene Golf Resort Casino: A First Nations Partnership Success Story. Presentation at the Banff Centre conference "Wise Practices in Indigenous Community Development - Partnering and Collaborative Approach, September 15, 2012.

Hill, Gord. (2009). 500 Years of Indigenous Resistance, PM Press, Oakland, California. Hillenkamp, Isabelle; Lapeyre, Frédéric and Lemaître, Andreia. (2013). Solidarity Economy as Part of Popular Security Enhancing Practices, A Neo-Polanyian Conceptual Framework. Draft paper prepared for the UNRISD Conference on Potential and Limits of Social and Solidarity Economy, 6-8 May, Geneva, Switzerland. 
Hirtz, F. (2003). It Takes Modern Means to be Traditional: On Recognizing Indigenous Cultural Communities in the Philippines. Development and Change, Vol. 34: 887914.

Hodgson, Geoffrey M. (1995). Varieties of Capitalism from the Perspectives of Veblen and Marx. Journal of Economic Issues Vol. 29.

Holmes, D. (2006). Redressing the Balance: Canadian University Programs in Support of Aboriginal Students. Ottawa: Association of Universities and Colleges of Canada. Houle, J. (2014). Chief Pakan History as told to Jody Houle by her Grandfather, late Albert Houle, [online] http://www.wfl128.ca/chief_history.html Innis, Harold and Arthur Ray. (1999). Arthur The Fur Trade in Canada: An Introduction to Canadian Economic History. Dundurn Press, Toronto.

Irving, Janis. (1982). Groupthink. (2d edition). Houghton Mifflin, Boston.

Ivison, D. and Paul Patton. (2003). Political Theory and the Rights of Indigenous Peoples, Cambridge University Press.

Jacklin, Kristen M. and Wayne Warry. (2011). Decolonizing First Nations Health, Chapter 20 in Judith Kulig and Allison Williams (eds) Health Care in Rural Canada, UBC press.

Jackson, Edward T. (2004). Community Innovation through Entrepreneurship: Grant making in Canadian Community Economic Development. Journal of the Community Development Society, Vol. 35. 
Jamieson, Roberta. (2005). Diplomacy, Democracy and Indigenous Peoples Canadian Evaluation Society/American Evaluation Association Joint Conference: Crossing Borders, Crossing Boundaries.

Janke, T. (1998). Don't Give away Your Valuable Cultural Assets: Advice for Indigenous Peoples. Indigenous Law Bulletin 8, 4(11).

Jonker, Jan and Marco de Witte (ed). (2006a). The Challenge of Organizing and Implementing Corporate Social Responsibility._Houndmills, Basingstoke, Hampshire, New York, Palgrave Macmillan.

Jonker, Jan and Marco de Witte (ed). (2006b). Management Models for Corporate Social Responsibility. Berlin; New York: Springer.

Johnson, Dana J. (2003). Indian Affairs 1887-1962 in Building the West: The Early Architects of British Columbia, ed. Donald Luxton, 2003

Johnston, Basil. (2005). Ojibway Heritage. Toronto: McClelland and Stewart. Johnston, Basil. (2007). Anishinabe Thesaurus, Michigan State University Press. Jorgensen, Miriam and Taylor, Johnathan. (2000) What Determines Indian Economic Success? Evidence from Tribal and Individual Indian Enterprises. The Harvard Project on American Indian Economic Development Wiener enter for Social Policy John F. Kennedy School of Government, Harvard University. Jorgensen, Miriam. (2007). Rebuilding Native Nations Strategies for Governance and Development by the Harvard Project. University of Arizona.

Kaen, Fred R. A (2003). Blueprint for Corporate Governance: Strategy, Accountability, and the Preservation of Shareholder Value. New York: AMACOM, 2003. 
Kao, Raymond W.Y. (1995). Entrepreneurship A Wealth Creation and Value Adding

Process. Prentice Hall, Singapore.

Kao, Raymond W.Y. (2010). Sustainable Economy: Corporate, Social and Environmental Responsibility. World Scientific Publishing, Singapore.

Kawano, Emily and Millar, Ethan. (2008). Building a Solidarity Economy from Real World Practices, in Solidarity Economy: Building Alternatives for People and Planet.

Papers and Reports from the 2007 US Social Forum, Ed. Allard, Jenna and Matthaei, Julie. Changemaker Publication, Chicago.

Kelly, Fred (2013) Thoughts on Reconciliation in Reconciliation Framework "Sharing A Good Heart". First Peoples Group Report to the Ontario Association of Children's Aid Societies.

King, Thomas. (2008). The Truth About Stories. Minnesota Press Kirmayer, L.J., Brass, G., Holton, T., Paul, K., Simpson, C. and Tait. C. (2007). Suicide Among Aboriginal People in Canada, Aboriginal Healing Foundation, Ottawa. Keyser, James D and Klassen, Michael A. (2001). Plains Indian Rock Art. UBC Press, Vancouver.

Koffka, (1935) Principles of Gestalt Psychology. New York: Harcourt. Köhler, Wolfgang (1947) Gestalt Psychology: The Definitive Statement of the Gestalt Theory, Liveright; 2nd Revised edition (January 17, 1970), London. Korten, David. (2007). Post-Corporate World: Life After Capitalism. Koster, R., Baccar, K., Lemelin, R. H. (2012). Moving from research ON, to research WITH and FOR Indigenous communities: A critical reflection on community-based 
participatory research. The Canadian Geographer / Le Géographe Canadien, 56, 2, $195-210$.

Kovatch, Margaret. (2009). Indigenous Methodologies: Characteristics, Conversations and Contexts, University of Toronto Press, Toronto.

Kovatch, Margaret. (2011). Indigenous Methodologies and Modified Grounded Theory a presentation to the Summer Institute.

Krepps, M. (1992). Can Tribes Manage Their Own Timber Resources: The 638 Program and American Indian forestry? In What Can Tribes Do? Strategies and Institution in America Indian Economic Development. Stephen Cornell and Joseph Klat ed., Los Angeles, University of California.

Krepps, M. and Richard Caves. (1994). Bureaucrats and Indians: Principle Agent Relations and the Efficient management of tribal Forest Resources. Journal of Economic Behaviour, 24(2), 133-162.

LaFromboise, T., Trimble, J, \& Mohatt, G. (1990). Counseling intervention and American Indian tradition: An integrative approach. The Counseling Psychologist. 18(4), 628654.

Langton, M., Tehan, M., Palmer, L. and Shain, K. (2004). Honour Among Nations? Treaties and Agreements with Indigenous People. Melbourne University Press.

Lakoff, G. \& Johnson, M. (2003). Metaphors We Live by. Chicago, IL, USA: The University of Chicago Press.

Lawrence, Jane (2000) The Indian Health Service and the Sterilization of Native American Women, The American Indian Quarterly 24.3, pp. 400-419. 
LaRocque, Emma. (2010). When The Other Is Me: Native resistance Discourse 18501990, University of Manitoba Press.

Leblanc, Richard and James Gilles. (2005). Inside the Boardroom: How Boards Really Work and the Coming Revolution in Corporate Governance. Wiley.

Lee, Mary. (2015). Tipi Structure, transcripts from an Elder, [online] http://www.fourdirectionsteachings.com/transcripts/cree.html

Lear, G. (2009). Leadership Lessons from The Medicine Wheel: The Seven Elements of High Performance. Advantage Media Group, Charleston, South Carolina.

Leighton, David and Donald Hammond Thain. (1997). Making Boards Work: What Directors Must Do to Make Canadian Boards Effective, McGraw-Hill Ryerson Trade. Lem, J.W. \& Reiner, D.G. (2011). Your Legal Duty. Building, 61, 1, 9.

Lewin, K. (1997). Action Research and Minority Problems. In G. Lewin (Ed.) Resolving social conflicts: Selected papers on group dynamics (pp. 144-154). Washington, DC: American Psychological Association.

Lewin, K. (1998). The Complete Social Scientist: A Kurt Lewin Reader. Washington, DC: American Psychological Association. Reprinted from Readings in Social Psychology, Maccoby, Newcomb and Hartley, Eds., 1948, New York: Holt.

Li, Kai and Erinn B. Broshko. (2006). Corporate Governance Requirements in Canada and the United States: A Legal and Empirical Comparison of the Principles-based and Rules-based Approaches, Canadian Investment Review. 
Lockhart, A. and D. McCaskill. (1986). Toward an integrated, community-based, partnership model of Native development and training: A case study in process. Canadian Journal of Native Studies, 6(1): 159-172.

Loizides, Stelios and Robert Anderson. (2006). Growth and Enterprises in Aboriginal Communities. The Conference Board of Canada.

Loizides, Stelios and Wanda Wuttunee. (2005). Creating Wealth and Employment in Aboriginal Communities. The Conference Board of Canada.

Loizides, Stelios. (2000). The Ties That Bind: Corporate Mentoring with Aboriginal Firms. The Conference Board of Canada.

Loomba, Ania. (1998). Colonialism-Postcolonialism. New York: Routledge.

Loveridge, Scott, Thomas R. Smith, and George W. Morse. (1991). What Does It Take to Run a Local Business Retention and Expansion Program? Economic Development Review, 9(1):12-15.

Loxley, J. (1986). The Economics of Community Development, Report Prepared for the Native Economic Development Program.

Loxley, J. (2000). Aboriginal Economic Development in Winnipeg in Jim Silver (Ed), Solutions that Work: Fighting Poverty in Winnipeg, Fernwood, Halifax and CCPA, Manitoba.

Loxley, J. (2007). Transforming or Reforming Capitalism: Towards a Theory of Community Economic Development. Fernwood Publishers, Halifax.

Loxley, J. (2010). Aboriginal, Northern, and Community Economic Development Papers and Retrospectives. Winnipeg: Arbeiter Ring Publishing. 
Loxley, J. (nd). Working Paper/ Aboriginal Economic Development in Winnipeg. [Online] http://hdrnet.org/342/1/Loxley_Eng.pdf

Louie, Robert. (2014). Ktunaxa Nation Tool Kit, [online] http://www.ktunaxa.org/governance/ktunaxa-nation-tool-kit/ Lussier, A. and lan Getty (ed.). (2000). As Long as The Sun Shines and the River Flows: A Reader in Canadian Native Studies. University of British Columbia Press.

Maddison, Angus (2001). The World Economy. A millennial perspective. Paris, OECD. Marx, Karl. (1909). Capital: A Critique of Political Economy, Vol. III. The Process of Capitalist Production as a Whole. Frederick Engels, ed. Ernest Untermann, trans. Library of Economics and Liberty. [online] www.econlib.org/library/YPDBooks/Marx/mrxCpC.html McCarthy, T. (2015, April). Tony Abbott's Indigenous 'lifestyle choices' remark smacks of racism, says UN rapporteur. The Guardian. Retrieved from http://www.theguardian.com/australia-news/2015/apr/29/tony-abbottsindigenous-lifestyle-choices-remark-smacks-of-racism-says-un-rapporteur. McRitchie, James. (2015). Corporate Governance: improving accountability through democratic corporate governance since 1995 [online] CorpGov.net MacLeitch, Gail D. (2004). 'Red' Labor: Iroquois Participation in the Atlantic Economy. In Labor: Studies in Working-Class History of the Americas, No. 1, Winter, Pg. 69-90. Mandler, P. (2006). Liberty and Authority in Victorian Brittan, Oxford, Oxford University Press. 
Max-Neef, Manfred A. (1986). Historia, Economía y algunas Invisibilidades Tomado de "La Economía Descalza" Publicado [Online] http://www.eumed.net/cursecon/textos/Max-Neef-texto.htm

Max-Neef, Manfred A. (1987). Human Scale Development: Conception, Application and Further Reflections. The Apex Press, New York.

Max-Neef, Manfred A. (1992). Outside Looking in: Experiences in Barefoot Economics. Zed Books.

Max-Neef, Manfred A; Antonio Elizalde; Martin Hopenhayn. (1991). Human Scale Development: Conception, Application and Further Reflections. Apex Press, New York.

Max-Neef, Manfred A. (2010). Chilean Economist Manfred Max-Neef on Barefoot Economics, Poverty and Why the U.S. is Becoming an "Under-developing Nation". Democracy Now Interview. November 26.

McCarthy, Michael. (2008). The Profit of Self Reliance: Calvin Helin, The Vancouver Courier, Vol. 99, No.59.

McCraw, Thomas. (2007). Prophet of Innovation - Joseph Schumpeter and Creative Destruction, Harvard University Press.

McMillian, Alan. D. and Yellowhorn, Eldon. (2004). First Peoples in Canada. Douglas \& Mclntyre, Vancouver.

Malinowski, B. (1920). Kula: The Circulating Exchange of Valuables in the Archipelagoes of Eastern New Guinea. Man, 20, 97-105. 
Manley-Casmir, K. (2011). Community \& International Environmental Law

Reconciliation, Indigenous Rights and Offshore Oil and Gas Development in the Canadian Arctic. Review of European, Comparative \& International Environmental Law, 20, 1, 29-38. ISSN 09628797.

Mann, C. C. (2005). 1491: new revelations of the Americas before Columbus. New York, NY: Knopf.

Mander, Jerry Victoria Tauli-Corpuz (ed) (2006). Paradigm Wars: Indigenous Peoples' Resistance to Globalization. International Forum on globalization, Sierra Club Books, San Fransico, California.

Marshall, Joeseph. (2005). Walking with Grandfather: The Wisdom of Lakota Elders. Sounds True Publishing.

Martin, K. L. (2008). Please Knock Before You Enter: Aboriginal regulation of Outsiders and the implications for researchers. Teneriffe, QLD, Australia: Post Pressed.

Metzger, Barry (ed). (2004). Global Corporate Governance Guide 2004: Best Practice in the Boardroom. Published by Globe White Page.

Midnight Notes Collective. (2001). Auroras of The Zapatistas: Local and Global Struggles of the Fourth World War. 2nd ed., Autonomedia, New York.

Milloy, John. (1999). A National Crime: The Canadian Government and the Residential School System, 1879 to 1986. University of Manitoba Press.

Miller, J.R. (2009). Compact, Contract, Covenant: Aboriginal Treaty-Making in Canada, University of Toronto Press. 
Morris, Alexander. (1880). The treaties of Canada with the Indians of Manitoba and the north-west territories, including the negotiations on which they were based, and other information relating thereto. Toronto: Belfords, Clarke.

Moreton-Robinson, Aileen M. (2011) Performing White possession: bodies that matter at the beach. In Power, Peter (Ed.) Border, Theory, Art and Power. Lang Publishing, London.

Montreevat, Sakulrat, ed. (2006). Corporate Governance in Thailand. Singapore: Institute of Southeast Asian studies.

Morck, Randall and Bernard Yeung. (2006). Some Obstacles to Good Corporate Governance in Canada and How to Overcome Them. Commissioned by the Task Force to Modernize Securities Legislation in Canada.

Mosby, Ian. (2013). Administering Colonial Science: Nutrition Research and Human Biomedical Experimentation in Aboriginal Communities and Residential Schools, 1942-1952. Histoire sociale/Social history, Volume 46, Number 91, Mai-May 2013, pp. 145-172.

Mosco, Vincent. (2009). The Political Economy of Communication, Sage Publishing, second edition, London, England.

Nadler, David A. (2004). Building Better Boards, Harvard Business Review, May. Natcher, D. (2001). Land use research and the duty to consult: a misrepresentation of the Indigenous landscape. Land Use Policy, 18, 113-122. 
Neill, Monty. (2001). Rethinking Class Composition Analysis in Light of the Zapatistas. In Midnight Notes. Auroras of the Zapatistas: Local and Global Struggles of the Fourth World War. Brooklyn: Autonomedia.

Nelson, Rodney. (2007a). Presentation and Roundtable on Corporate Relations Best Practices. The Council on Corporate Aboriginal Relations General Meeting. Nelson, Rodney. (2007b). Incorporating Indigenous Knowledge into Good Board Governance Practices Council for the Advancement of Native Development Officers (CANDO), Presentation Niagara Falls.

Nelson, Rodney. (2010). Traditional Knowledge in the Boardroom a Quest for a New Model of Aboriginal Corporate Governance, JAM: The Journal of Aboriginal Management, Sept. Volume 8

Nelson, Rodney. (2015). Corporate Social Responsibility and Partnership Development. in The Journal of Aboriginal Management. Aboriginal Financial Officers Association Publishing.

Nelson, Rodney and Ashley Sisco. (2008). From Vision to Venture: An Account of Five Successful Aboriginal Businesses, The Conference Board of Canada.

Nelson, Rodney; Coates, Tracy and Fitzpatrick, Kathlean. (2015) Indigenous Peoples and Western Development in A new perspective in Canada and the Challenges of International Development and Globalization

Newhouse, David. (1992). Royal Commission on Aboriginal Peoples: Presentation. University of Saskatchewan, Native Law Centre. 
Newhouse, David. (2001a). Resistance Is Futile: Aboriginal Peoples Meet the Borg of Capitalism. Journal of Aboriginal Economic Development.

Newhouse, David R. \& Belanger, Yale D. (2001b). Aboriginal Self-Government in Canada, Native Studies, Trent University.

Newhouse, David with Daniel Sale and Joyce Green. (2006). Improving the Aboriginal Quality of Life: Changing the Public Policy Paradigm, Institute for Research on Public Policy.

Newhouse, David. (2000). Modern Aboriginal Economies, Capitalism with a red face. The Journal of Aboriginal Economic Development Vol. 1, No. 2.

Newman, D.G. (2009). The Duty to Consult: New Relationships with Indigenous Peoples. Saskatoon: Purich Publishing Ltd.

Noponen, Helzi, Julie Graham and Ann Markusen. (1993). Trading Industries, Trading Regions: International Trade, American Industry, and Regional Economic Development. Guilford Press, New York.

Norris, Lindsey. (2009). Goodfish Takes the Bait. In Alberta Venture, May. [Online] http://albertaventure.com/2009/05/goodfish-takes-the-bait/ Nowak, L. (2007). The Medicine Wheel: A Balanced Approach to Employment Counseling. luniverse Inc., Bloomington, Indiana.

Orr, J. (2013). Introduction: Defining and Measuring Aboriginal Economic Development Success. In J. Orr \& W. Weir (Eds.), Aboriginal Measures for Economic Development (pp. xii-xvi). Halifax \& Winnipeg: Fernwood Publishing. 
Osborne, David and Gaebler, Ted. (1992). Reinventing Government. Addison-Wesley Publ. Co.

Patton, M. Q. (2002). Qualitative research and evaluation methods (3rd ed.). Thousand Oaks, CA: Sage Publishing.

Peacock, Thomas and Marlene Wisuri. (2006). The Four Hills of Life: Ojibwe Wisdom. Afton Historical Society Press.

Pewewardy, C. (1999). The holistic Medicine Wheel: An Indigenous model of teaching and learning. Winds of Change, 14, 28-31.

Pierre, Sophie. (2009). néeEustace: The Little Girl Who Would Be Chief in Response, Responsibility, and Renewal Canada's Truth and Reconciliation Journey, Aboriginal Healing Foundation Research Series, Ottawa, Canada.

Polanyi, Karl. (1957). The Great Transformation: The Political and Economic Origins of Our Time. Boston, Massachusetts, Beacon Press. Reprint 2001.

Popic, L. (2008). Compensating Canada's: 'Stolen Generations'. Indigenous Law Bulletin, 7, 2, 14-17. ISSN: 1328-5475.

Posey, Darrell Addison. (2004). Indigenous Knowledge and Ethics: A Darrell Posey Reader. edited by Kristina Plenderleith, New York, Routledge.

Potes, V. (2006). The Duty to Accommodate Indigenous Peoples Rights: Substantive Consultation? Journal of Environmental Law and Practice, 17, 1, 1-9. Retrieved from http://wcm16.ucalgary.ca/law/system/files/bib4_0.pdf

Purcell, Trevor (1998). W. Indigenous Knowledge and Applied Anthropology: Questions of Definition and Direction. Human Organization Vol. 57. 
Rasmussen, R. Kent. (2000). The American Indian Tribes. Culture Areas, Tribes and Traditions, Abenaki-Missouri Volume 1, Salem Press. Pasadena, California. Rata, E. (2000). A Political Economy of Neotribal Capitalism. USA: Lexington Books. Ratha, D. (2000). What Factors Appear to Drive the Flows of Private Capital to Developing Countries? And How Does IBRD/IDA Lending Respond? World Bank Policy Research Working Paper 2392, July 2000

Ray, Arthur J., Jim Miller, Frank Tough. (2008). Bounty and Benevolence: A history of Saskatchewan Treaties, McGill-Queens University Press, Kingston.

Razack, Sharon. (1998). Looking White People in the Eye: Gender, Race, and Culture in Courtrooms and Classrooms, University of Toronto Press.

Reed, O. Lee. (2003). Nation building 101: Reductionism in Property, Liberty, and Corporate Governance. Vanderbilt Journal of Transnational Law Vol. 36.

Reiter, Barry J. (2009). Director's Duties in Canada, 4th Edition.

Rich, E.E. (1960). Trade Habits and Economic Motivation among the Indians of North America, in Canadian Journal of Economics and Political Science. \#26, Pg. 35-53, February.

Robinson, H.E. (2007). Aboriginal consultation from the courts to the ground: challenges in implementing effective engagement. CIM Magazine, 2, 3. Retrieved from http://www.cim.org/bulletin/bulletinlive/articles.cfm?Issue_ID=148\&Type=1\&ro $w=6 \&$ Segment_ID=54

Rodberg. C. (2003). Medicine Wheel Ceremonies: Ancient Philosophies for Use in Modern Day Life. Naturegraph Publishing. Happy Camp, CA. 
Rosser Jr, J. Barkley and Rosser, Marina V. (1998). Islamic and neo-Confucian perspectives on the new traditional economy. Eastern Economic Journal 24(2): 217-227.

Rosser Jr, J. Barkley and Rosser, Marina V. (1999). The new traditional economy: A new perspective for comparative economics? International Journal of Social Economics 26(6): 763-778.

Rosser Jr, J. Barkley and Rosser, Marina V. (2005). The Transition between the Old and New Traditional Economies in India. Comparative Economic Studies, 47, 561-578. Rostow, W. (1960). The Stages of Economic Growth: A Non-Communist Manifesto. Cambridge University Press, Cambridge.

Rousseau, J. (1762). The Social Contract. Reprinted by the University of Pennsylvania. Ryan, Allan J, (1999). The Trickster Shift: Humour and Irony in Contemporary Native Art, Seattle: University of Washington Press.

Ryan, James. (1996). Restructuring First Nations' Education: Trust, Respect and Governance. Journal of Canadian Studies, Vol. 31.

Sachs, Jeffery. (2014). The Year of Sustainable Development, Project Syndicate, December 9, 2014.

Sachs, Jeffery. (2005). The End of Poverty: Economic Possibilities for Our Time. Penguin Press; 1st edition, New York.

Said, Edward. (1978). Orientalism, Pantheon Books.

Said, Edward. (1990). Nationalism, Colonialism, and Literature University of Minnesota Press. 
Said, Edward. (1994). Culture and Imperialism Vintage Books.

Salée, Daniel (2005). Peuples autochtones, racisme et pouvoir d'État en contextes canadien et québécois: Éléments pour une ré-analyse, Nouvelles pratiques sociales, 17,2 , pp. $54-74$.

Salée, Daniel. (2006). Quality of Life of Aboriginal peoples in Canada: An Analysis of Current Research. November, Choices, Vol. 12, no. 6, p. 1.

Salée, Daniel (2006). "Quality of Life of Aboriginal People in Canada: An Analysis of Current Research," IRPP Choices, Vol. 12, No. 6, November.

Sangster, Joan. (2007). The Beaver as Ideology: Constructing Images of Inuit and Native Life in Post-World War li Canada. Anthropologica Vol. 49.

Sankar Sen, C.B. Bhattacharya. (2001). Does Doing Good Always Lead to Doing Better? Consumer Reactions to Corporate Social Responsibility. Journal of Marketing Research: May 2001, Vol. 38, No. 2, pp. 225-243.

Schumpeter, Joseph. A. (1934). Theory of Economic Development, Cambridge. Schumpeter, Joseph A. (1939). Business Cycles: A Theoretical, Historical and Statistical Analysis of Capitalist Processes. New York: Macmillan.

Schumpeter, Joseph. A. (1943). Capitalism, Socialism and Democracy. Routledge, New York, Taylor \& Francis e-Library, 2003.

Schumpeter, Joseph. A. (1947). Can Capitalism Survive? Creative Destruction and the Future of the Global Economy. Harper-Perennial Modern Thought Edition, reprint 2008. 
Selener, D. (1997). Participatory Action Research and Social Exchange. Ithaca, NY:

Cornell Participatory Action Research Network.

Sen, Amartya. (1999) Development as Freedom, Oxford University Press, Oxford.

Shanks, Gordon. (2005). Economic Development in First Nations: An Overview of Current Issues, January 2005, The Public Policy Forum.

Shragge, E. (Editor). (1997). Community Economic Development: In Search of Empowerment, Black Rose Books, Montreal

Shipley, R. and Snider M. The Role of Heritage Conservation Districts in Achieving Community Economic Development Goals. International Journal of Heritage Studies. 19(3): 304-321, 2013.

Shrivastava, Paul and Hart, Stuart. (1995). Creating Sustainable Corporations. In Business Strategy and the Environment, Vol. 4,154-165.

Shull, Bernard. (2010). Too Big to Fail in Financial Crisis: Motives, Countermeasures and Prospects, Working Paper No. 601. Levy Economics Institution, Bard College. Sillitoe, Paul, Alan Bicker, and Johan Pottier, eds. (2002). Participating in Development: Approaches to Indigenous Knowledge. London: Routledge.

Sillitoe, Paul. (2006). Why Spheres of Exchange? Ethnology Vol. 45.

Sillitoe, Paul, Peter Dixon and Julian Barr. (2005). Indigenous Knowledge Inquiries: A Methodologies Manual for Development. Practical Application Publishing.

Sinclair, Raven. (2007). Participatory Action Research and Aboriginal Epistemology. In Teaching and Learning, 4:2, Fall. 
Sisco, A. (2015, March). Honouring the Kaswénta (Two Row Wampum): A Framework for Consultation with Indigenous Communities in Canada and Australia [Doctoral Thesis]. Wollongong, NSW: University of Wolongong.

Sisco, A. (2009a). Becoming a Qallunologist: One Qallunaa's Journey Remembering Marble Island. (Master's thesis). Carleton University.

Sisco, A. \& Stewart, N. (2008). True to Their Visions: An Account of Ten Successful Aboriginal Businesses. Ottawa: The Conference Board of Canada.

Sloan, Pamela and Roger Hill. (1995). Corporate Aboriginal Relations; Best Practice Case Studies. Hill Sloan Associates.

Smith, Adam. (1776). An Inquiry into the Nature and Causes of the Wealth of Nations in of Systems of Political Economy Book IV.

Smith, Adam. (1759). The Theory of the Moral Sentiments.

Smith, Graham. (2005). The Problematic of Indigenous Theorizing: A Critical reflection. Paper presented at AERA conference, Montreal April.

Smith, L.T. (2012). Decolonizing Methodologies: Research and Indigenous Peoples. London, UK: Zed Books. (Originally published in 1999)

Sossin, L. (2010). The DTC and Accommodate: Procedural Justice as Aboriginal Rights. Canadian Journal of Administrative Law \& Practice, 23, 93-113. Retrieved from http://papers.ssrn.com/sol3/papers.cfm?abstract_id=1911406

Speevak Sladowski, Paula and Emilie Hayes. (2007). Mapping the Communities Agenda in Canada. An Inventory of Action, Resources, Programs and Policies. University of 
Ottawa and Carleton University, Ottawa: The Centre for Voluntary Sector Research and Development.

Spivak, Gayatri Chakravorty. (1990). The Post-Colonial Critique: Interview, Strategies, dialogues, Rutledge.

Spivak, Gayatri Chakravorty (Editor); Guha, Ranajit (Editor); Said, Edward (Foreword). (1988). Selected Subaltern Studies, Oxford University Press.

Spivak, Gayatri Chakraborty. (1985). Discussion: Subaltern Studies: Deconstructing Historiography, Subaltern Studies No. 4, Writings on South Asian History and Society, p. 330-363.

Stavenhagen, Rodolfo. (2014). Dialogue Between Nations, Rodolfo Stavenhagen United Nations Special Rapporteur, on the situation of the human rights and fundamental freedoms of Indigenous Peoples. United Nations World Conference on Indigenous People.

Steinhauer, Patricia. (2001). Situating myself in research. Canadian Journal of Native Education 25(2): 183-7.

Sterman, John. (2000). Business Dynamics: Systems Thinking and Modeling for a Complex World. New York: McGraw Hill.

Steckley, John and Bryan David Cummings. (2001). Full Circle: Canada's First Nations. Prentice Hall.

Stevens, D. (1993). Corporate Autonomy and Institutional Control: The Crown Corporation as a Problem in Organization Design, Montreal, McGill-Queen's University Press. 
Stodder, JP. (1995). The evolution of complexity in primitive exchange: Theory. Journal of Comparative Economics 20(1): 1-31.

Strauss, A. L. (1978). Negotiations: Varieties, Contexts, Processes and Social Order. SanFrancisco, Jossey-Bass.

Strauss, A. L. and Corbin, J. (1998). Basics of Qualitative Research: Grounded Theory Procedures and Techniques. 2nd Ed., Thousand Oaks, CA: Sage.

Strauss, A. L. and Corbin, J. (1990). Basics of qualitative research: Grounded theory procedures and techniques. Newbury Park, CA: Sage.

Streimikiene, D. and Girdzijauskas, S. A. (2008). Logistic Growth Models for Analysis of Sustainable Growth. Transformations in Business and Economics, 7(3), 218-235.

Stromberg, E. (Ed.). (2006). American Indian Rhetorics of Survivance: Word Medicine, Word Magic, Pittsburgh: University of Pittsburgh Press.

Sunder, Madhavi, (2007). The Invention of Traditional Knowledge, 70 Law and Contemporary Problems 97-124, Spring.

Teneese, Kathryn. (2016). Speech at the 2016 June charity golf tournament. St Eugene Resort.

Tetley, J. \& Hanson, E. (2000). Participatory research. Nurse Researcher, 8, 1, 69-88.

Teubal, M. 2004. Rise and Collapse of Neoliberalism in Argentina: The Role of Economic Groups. SAGE Publications, Vol 20(3-4), p.173-188

Thomas, Jacob. (1994). Teachings from the Longhouse. Stoddart Publishing, Toronto. Thomas, Neil. (2007). Global Capitalism, the Anti-Globalization Movement and the Third World. Capital \& Class. 
Tobias, John. (1976). Protection, Civilization, Assimilation: An Outline History of Canada's Indian Policy. Western Canada Journal of Anthropology, 6, no. 2.

Todaro, Micheal and Stephen Smith. (2008). Economic Development, Addison Wesley; edition 10.

Tomasini, Rolando and Luk Van Wassenhove. (2005). Moving the World: A Case Study in CSR Partnership. The Conference Board of Canada.

Tsosie, Rebecca A. (1996). Tribal Environmental Policy in an Era of Self-Determination: The Role of Ethics, Economics, and Traditional Ecological Knowledge. Vermont Law Review, Vol. 21, p. 225.

Tuhiwai Smith, Linda. (2001). Decolonizing Methodologies: Research and Indigenous Peoples. Zed Books.

Usher, Alex (2009). The Post-Secondary Student Support Program: An Examination of Alternative Delivery Mechanisms. Toronto, ON: Educational Policy Institute.

Vizenor, Gerald Robert. (2010). Survivance Presentation, New Sun Conference, Carleton University.

Vizenor, Gerald Robert. (2008). Survivance: Narratives of Native Presence, Lincoln: U of Nebraska Press.

Wakeling, S., Jorgenson, M., Michaelson, S., Begot, M. (2001) Policing on American Indian reserves. A report to the National Institute of Justice.

Wallace, lain. (2002). A Geography of the Canadian Economy, Oxford University Press. 
Wallerstein, Immanuel. (2011) The Modern World-System I: Capitalist Agriculture and the Origins of the European World-Economy in the Sixteenth Century. University of California Press.

Wertheimer, M. (1938). Gestalt theory. In W. D. Ellis (Ed.), A Source Book of Gestalt Psychology (pp. 1-11). London, England: Routledge \& Kegan Paul.

Wettlaufer, Matthew. (2005). Towards a Geometry of Economy and Difference: Derrida, Capitalism, and Queer Nation. Philosophy Today Vol. 49.

Williams, S. (1967). Business Process Modeling Improves Administrative Control, Automation. December, pp. 44 - 50.

Wilson, Dave and Macdonald, Dave. (2010a). The Income Gap Between Aboriginal Peoples and the Rest of Canada. Canadian Centre for Policy Alternatives, Ottawa.

Wilson, R. (1994). Medicine Wheels: Ancient Teachings for Modern Times. The Crossroad Publishing Company, New York, New York.

Wilson, Shawn. (2008). Research Is Ceremony: Indigenous Research Methods. Fernwood Publishing: Halifax, NS Canada.

Wilson, Shawn. (2001). What is Indigenous research methodology? Canadian Journal of Native Education, 25(2): 175-9.

Wismer, Susan \& Pell, David. (181). Community Profit: Community-based Economic Development in Canada, Is Five Press, Toronto.

Wood, Hennifer and Jenny Fleming and Monique Marks. (2008). Building the capacity of police change agents: The nexus policing project, Policing and Society, 72_87, Vol. 18, No. 1, March. 
Wohlgemuth, Michael. (2007). Schumpeterian Political Economy and Downsian Public Choice: Alternative Economic Theories of Democracy, Institut für Allgemeine Wirtschaftsforschung, Abteilung für Wirtschaftspolitik Universität Freiburg i. Br. Wolff, Richard. (2012). Democracy at Work: A Cure for Capitalism. Heymarket books, Chicago, illinois.

Wolff, Richard. (2016). Capitalism's Crisis Deepens: Essays on the Global Economic Meltdown. Haymarket Books, Chicago.

Wuttunee, Wanda. (2004). Living Rhythms: Lessons in Aboriginal Economic Resilience and Vision. McGill University Press.

Wuttunee, Wanda, Mary Jane Loustel Dan Overall. (1987). Indigenous Values and Contemporary Management Approaches. Vol. 5, Issue 2, Journal of Aboriginal Economic Development.

Zademach, H., \& Hillebrand, S. (2013). Alternative economies and spaces: New perspectives for a sustainable economy. Transcript-Verlag, Bielefeld.

Zuber-Skerritt, Ortrun, ed. (1996). New Directions in Action Research. London: Falmer Press. 


\section{Other Sources}

Aboriginal Affairs and Northern Development. (2014). Urban Aboriginal Peoples.

Retrieved from https://www.aadnc-

aandc.gc.ca/eng/1100100014265/1369225120949.

Aboriginal Affairs and Northern Development Canada (AANDC). (2010). Aboriginal

People and Their Communities.

Aboriginal Affairs and Northern Development Canada (AANDC). (2005). News Release.

Whitefish (Goodfish) Lake First Nation \#128 Constructs A New State-of-the-art Dry

Cleaning and Laundry Plant. [online] http://news.gc.ca/web/article-

en.do?m=/index\&nid=120619

Aboriginal Affairs and Northern Development Canada. (1996). Highlights from the

Report of the Royal Commission on Aboriginal Peoples. Retrieved from

http://www.aadnc-aandc.gc.ca/eng/1100100014597/1100100014637.

Alberta Employment and Immigration. (2010). MLA Committee on the First Nations,

Métis and Inuit Workforce Planning Initiative. Connecting the dots: Aboriginal

workforce and economic development in Alberta.

AFOA. (2015). Aboriginal Financial Literacy Project Findings, presentation at the AFOA

National Conference in Winnipeg, 2015.

AFOA. (2013). Literature Review of Indigenous Financial Literacy, AFOA Canada

Publications. Ottawa, Canada.

Assembly of First Nations. (2013). Report on Poverty.

[online] http://www.afn.ca/cmslib/general/M-Ex.pdf 
Assembly of First Nations. (2011). The Poverty Action Research Project: An Opportunity for Your First Nation Community, with Dalhousie University. [online] http://www.afn.ca/uploads/files/parp_english.pdf

Business Directory. (2015). Corporate governance, [online]

http://www.businessdictionary.com/definition/corporate-governance.html

BC Treaty Commission. (1999). A Lay Person's Guide to Delgamuukw, Vancouver, British Columbia.

Cadbury Committee, The. (1992). Report on the Financial Aspects of Corporate Governance. London, University of Cambridge.

Cadbury and Greenbury Reports. (1998). The Combined Code: Principles of Good Governance and Code of Best Practice - 1998 Committee on Corporate Governance from the Committee's Final Report and from the

Cahokia Mounds State Historic Site, 2008

Canada Council for Aboriginal Business. (2011). Promise and Prosperity: The Aboriginal Business Strategy.

Canada Council for Aboriginal Business. (1993). Untitled Publication on Business. Canada Council for Aboriginal Business. (1992a). Doing Business with Aboriginal Canada. Canada Council for Aboriginal Business. (1992b). Against the Odds.

Canadian Association of Petroleum Producers (CAPP). (2006). Industry Practices, Developing Effective Working Relationships with Aboriginal Communities. Canadian centre for Community Renewal. (2010). Community Economic Development. [Online] http://www.cedworks.com/CEDdefinition.html. 
Centre for First Nations Governance. (2013). Best Practices; Ktunaxa Nation, Diversity of Revenue Sources. [online] http://fngovernance.org/toolkit/best_practice/ktunaxa_nation CBC News Edmonton. (2009). Made in Goodfish Lake: a First Nations Business Success Story. Posted: Jun 02, 2009 5:33 PM MT. [Online] http://www.cbc.ca/news/canada/edmonton/made-in-goodfish-lake-afirst-nations-business-success-story-1.812614

Chartered Professional Accountants Canada. (2014). Twenty Questions Directors Should Ask Series. [online] http://www.cica.ca/publications/list-ofpublications/item60542.aspx

Chiefs of Ontario. (2006). Aboriginal Traditional Knowledge and Source Water Protection: First Nations' Views on Taking Care of Water. March. Chiefs of Ontario. (2010). Looking Back Looking Ahead, Traditional Knowledge Literature Review. March.

Corporate Governance Guidelines (CGG). (1994). Toronto Stock Exchange, Toronto. Department of Aboriginal Affairs and Northern Development Canada AANDC. (2011). Aboriginal Consultation and Accommodation Updated Guidelines for Federal Officials to Fulfill the Duty to Consult. [online] http://www.aadncaandc.gc.ca/DAM/DAM-INTER-HQ/STAGING/textetext/intgui_1100100014665_eng.pdf 
Department of Canadian Heritage. (2005). Towards a New Beginning: A Foundational Report for a Strategy to Revitalize First Nation, Inuit, and Métis Languages and Cultures, Task Force on Aboriginal Languages and Cultures, Ottawa.

Delgamuukw v. British Columbia. (1997). 3 S.C.R. 1010.

[online] http://scc.lexum.org/en/1997/1997scr3-1010/1997scr3-1010.pdf

Diversity, Equity and Inclusivity Symposium. (2015). Truth, Reconciliation and

Engagement.

[online] http://ndti.ca/PDFS/CIECYR\%202015\%20Symposium-

WORKSHOP\%20SCHEDULE-\%20April\%2020,\%202015.pdf

First Nation of Na-Cho Nyak Dun. (2008). Traditional Knowledge Policy, Heritage and Education Department, February 4.

First Nations Drum. (2002). Duty to Consult Now Legal Duty for Provincial Crown and Third Parties. [online] http://www.firstnationsdrum.com/Sum2002/BizDutyCrown.htm

GFLDC. (2015). Goodfish Lake Development Corporation Online. [online] http://www.gfldc.ca

Government of Canada (2014). Canada Corporations Act. (1970, c. C-32), [online] http://lois.justice.gc.ca/en/C-1.8/

Government of British Columbia. (1997). Delgamuukw v. British Columbia.

[online] http://scc.lexum.umontreal.ca/en/1997/1997rcs3-1010/1997rcs31010.html 
Government of Canada. (2015). First Nations and Tribal Councils National Funding Agreement Model for 2015-2016

[online] https://www.aadnc-aandc.gc.ca/eng/1412272593986/1412272658789

Government of Canada. (2014). The Indian Act., R.S., 1985, c. I-5.

[online] http://laws.justice.gc.ca/en/I-5/

Government of Canada. (2007). Standing Senate Committee on Aboriginal Peoples.

Sharing Canada's prosperity - A Hand Up, Not a Handout. Final report - Special

Study on the Involvement of Aboriginal Communities and Businesses in Economic

Development Activities in Canada. Ottawa.

Government of Canada. (1997a). Royal Commission on Aboriginal peoples. Report of the

Royal Commission on Aboriginal peoples. Vol. 5: Renewal: A Twenty-Year

Commitment. In for Seven Generations: An Information Legacy of the Royal

Commission on Aboriginal peoples [CD-ROM]. Ottawa: Libraxus.

Government of Canada. (1997b). Royal Commission on Aboriginal Peoples. Suffer the

Little Children: A History of the Residential School System, 1830-1992, by J.S.

Milloy. RCAP Research Reports. Socio-Cultural. Project Area 7: Residential Schools.

In for Seven Generations: An Information Legacy of the Royal Commission on

Aboriginal peoples [CD-ROM]. Ottawa: Libraxus, 1997.

Government of Canada. (1996). Royal Commission on Aboriginal peoples. Bridging the

Cultural Divide: A Report on Aboriginal peoples and Criminal Justice in Canada.

Ottawa, Royal Commission on Aboriginal peoples, Ottawa. 
Government of Canada. (1976). The Mackenzie Valley Pipeline Inquiry. Proceedings at Inquiry, April 22, 1974 - June 8, 1976. 67 Vols. Burnaby, B.C.: Allwest Reporting Ltd. Toronto: Micromedia (Mackenzie Valley Pipeline Inquiry. Transcripts of Public Hearings, Reels T1 - T18).

Government of Ontario. (2001). The Power of Partnerships: New opportunities for Aboriginal peoples and Ontario Businesses, Queens Printer for Ottawa. Idle No More. (n.d.). Idle No More. Retrieved from http://www.idlenomore.ca// Indian and Northern Affairs Canada (INAC). (2010). Enrolment funded by INAC PostSecondary Education Program by program type, 1997-2010. Unpublished.

Indian Association of Alberta. (1978). An Appeal by the Treaty Indian Chiefs of Alberta to the Government of Canada to Perform Totally its Treaty Obligations in Fiscal year 1878-79 and in Perpetuity, August 24, p. 21.

Indian and Northern Affairs Canada (INAC). (2003). First Nations Governance Handbook: A Resource Guide for Effective Councils. Ottawa.

International Forum on Globalization. (2002). Alternatives to Economic Globalization: A Better World Is Possible, Berrett-Koehler Publishing.

Ktunaxa Nation Council (KNC). (2016). History of the Ktunaxa. [online] http://www.ktunaxa.org/ MAS Management Advisory Service. (2007). Newsletter, Fall. Merriam-Webster Dictionary, The. (n.d.). Capitalism. Retrieved from http://www.merriam-webster.com/dictionary/capitalism 
National Association of Friendship Centres. (2009). Urban Aboriginal Poverty and Social Exclusion Survey.

National Aboriginal Economic Development Board. (2015). The Aboriginal Economic Progress Report. Gatineau, Quebec.

Native Woman's Association of Canada. (2009). Report Card on child and Family Poverty in Canada.

Neechi Foods. (1993). It's Up to All of Us guide. Winnipeg native Family Economic Development, February.

Organization for Economic Co-operation and Development (OECD). (2004). Principles of Good Governance. Organization for Economic Co-operation and Development, Paris, France.

OccupyWallStreet. (n.d.). About. Retrieved from http://occupywallst.org/about/ Ownership, Control, Access and Possession (OCAP). (2007). National Aboriginal Health Organization, Ottawa. [online] http://cahr.uvic.ca/nearbc/documents/2009/FNCOCAP.pdf

Osooyoos. (2015). Osooyoos Indian Band Economic Development Corporation businesses [online] http://oibdc.ca/investment.html\#

Sarbanes-Oxley Act. (2002). Corporate Responsibility, Amendment to United States Federal Law (Criminal Code), PUBLIC LAW 107-204.

Seven Generations Education Institute. (2010). Anishinabe Mino Bimaadizwin: Principles for Anishinabe Education. [Online] http://www.7generations.org/ St Eugene. (2015). Heritage [online] http://steugene.ca/about/heritage/ 
Standing Senate Committee on Aboriginal Peoples. (2007). Sharing Canada's Prosperity - A Hand Up, Not A Hand Out. [online] http://www.parl.gc.ca/content/sen/committee/391/abor/rep/rep06-e.pdf

Statistics Canada. (2008). Government of Canada. Aboriginal Peoples in Canada in 2006: Inuit, Métis and First Nations, 2006 Census. Ottawa, Statistics Canada.

Statistics Canada. (2006). Government of Canada. Aboriginal Identity Population, Ottawa.

Statistics Canada. (2002). Government of Canada. Aboriginal Entrepreneurs Survey, Ottawa.

Supreme Court of Canada, R. v. Powley, [2003] 2 S.C.R. 207, 2003 SCC 43. [online] http://scc.lexum.org/en/2003/2003scc43/2003scc43.html

Supreme Court of Canada. (2004). Government of Canada, The Taku River Tlingit First Nation and Melvin Jack, Ottawa. [online] http://www.ubcic.bc.ca/files/PDF/DoigRiverFN_Taku.pdf

Thalassa Research Associates. (1983). The economic foundation of Indian selfgovernment. Victoria, B.C.

The Harvard Project on American Indian Economic Development. (2015). [online] http://hpaied.org/

Treasury Board of Canada Secretariat. (2004). Government of Canada, Aboriginal peoples; Canada's Performance, Ottawa. [online] http://www.tbs-sct.gc.ca/report/govrev/04/cp-rc5_e.asp 
Truth and Reconciliation Commission of Canada. (2015). TRC Findings Honouring the Truth, Reconciling for the Future Summary of the Final Report of the Truth and Reconciliation Commission of Canada

Union of Ontario Indians (UOI). (2003). Reaching Effective Consultation: A Guide on How to Get There! "When in doubt, check it out". [online] http://www.anishinabek.ca/download/AORMC\%20Consultation\%20Guide.pdf WFLFN. (2015). Whitefish Lake history [online] http://www.wfl128.ca World Bank. (2015). Ending Poverty and Sharing Prosperity, International Bank for Reconstruction and Development, The World Bank. 


\section{Appendix A - Community Interview and Conversation Participants}

Interviews

1. Grand Chief John Beaucage, Anishinabek Nation, Nipissing First Nation, Union of Ontario Indians. [interv.] Rodney Nelson. 2012.

2. Chief Adam Fiddler. Elders Roundtable on Economic Development, Sandy Lake First Nation. [interv.] Rodney Nelson. 2011.

3. Chief Alex Batisse. Economic Development and Matachewan First Nation. [interv.] Rodney Nelson. 2011.

4. Chief Sophie Pierre. Economic Development and St Eugene Mission Resort. [interv.] Rodney Nelson. 2008.

5. Chief Clarence Louis. Economic Development and the Osoyoos band. [interv.] Rodney Nelson. 2010.

6. Chief Kirby Whiteduck. Economic Development and Kitigan Zibi Reserve. [interv.] Rodney Nelson. 2011.

7. Chief Erwin Redsky. Economic Development and Shoal Lake. [interv.] Rodney Nelson. 2011.

8. Chief Garry Reece. Economic Development and Lax Kw'alaams. [interv.] Rodney Nelson. 2009.

9. Chief Hazel Fox, Chief Wikwemikong, [interv.] Rodney Nelson. 2012.

10. Chief John Thunder, Buffalo Point, [interv.] Rodney Nelson. 2012.

11. Chief Dennis Meeches, Long Point First Nations, [interv.] Rodney Nelson. 2012.

12. Robert Corbiere Counciler, Economic Development Wikwemikong, [interv.] Rodney Nelson. 2012.

13. Clovis Meekis. Elders account of Economic Development, Sandy Lake First Nation. [interv.] Rodney Nelson. 2011.

14. George Halfe. Economic Development and Goodfish Lake Development Corporation. [interv.] Rodney Nelson. 2008/ 2012/2014. 
15. Brian Titus, Business Development and Leasing Opportunities, Osoyoos Indian Band, [interv.] Rodney Nelson. 2012.

16. Roy Kakagamic. Economic Development, Sandy Lake First Nation. [interv.] Rodney Nelson. 2011.

17. Linda Sullivan. Economic Development and Shawanaga Reserve. [interv.] Rodney Nelson. 2011.

18. Sam Harling, Economic Development and Terrace. [interv.] Rodney Nelson. 2011.

19. John Bernard, Donna Cona, [interv.] Rodney Nelson, 2009/2010

20. Bob Anderson, University of Regina, [interv.] Rodney Nelson, 2013

21. Steven Cornell, University of Arizona, [interv.] Rodney Nelson, 2013-2014

22. David Barkin. Universidad Autónoma Metropolitana in México City, Correspondance, 2012, 2013

Correspondence and ongoing conversations

1. Grand Chief Patrick Madahbee, Grand Council Chief, Aundeck Omni Kaning, Union of Ontario Indians

2. Grand Chief Glen Hare, Deputy Grand Chief, M'Chigeeng First Nation, Union of Ontario Indians

3. Chief Felix Thomas, Saskatoon Tribal Council, Asimakaniseekan Askiy

4. Chief Brian Favel, Whitefishlake First Nation, 2014

5. Chief Tommy Yellowhead, Nibinamik First Nation, 2014-2015

6. Johhny Yellowhead, Nibinamik First Nation, 2014-2015

7. Ron Wesley, Councellor, Constance Lake First Nation

8. Rick Cheechoo, Councillor Moose Cree First Nation

9. John Carter, CEO, Yellowknifes Dene First Nation

10. Neil Leonard, Business Development Manager, Tk'emlups Indian Band 
11. Deana Doxtator, Program coordinator, Economic Development, Oneida Nation of the Thames

12. Juliet Rickard, Director of Economic Development, Moose Cree First Nation

13. Stan Achneepineskum, Executive Director, Wakenagun Community Futures Development Corporation

14. Charlie Evalik, Chairman, Nunavut Resources Corporation

15. Doug Pawis, D-Best Construction Consulting, Shawanaga First Nation

16. Bernd Christmas, Bernd Christmas Law Group.

17. Clint Davis, President and CEO of Canadian Council for Aboriginal Business

18. Terry Goodtrack, President and CEO of Aboriginal Financial Officers Association

19. John Kim Bell, Senior Advisor, Aboriginal Relations, Brookfield Renweable Power

20. Sandra Gogal, Partner, Millar Thompson, 2009/2010.

21. Stephen Lindley, VP, SNC Lavalin, 2009/2010.

22. Autumn EagleSpeaker, Aboriginal \& Community Relations - Shell

23. Les Diachinsky, Aboriginal Business Liason, Syncrude

24. Don Pugh, Manager Regional Business Development, Suncor

25. Jonathan Fowler, Vice President, Aboriginal Affairs and Sustainability, DeBeers

26. Lana Hill, Aboriginal Community Investment Coordinator, Syncrude

27. Mary Jane Loustel, Program Executive, National Aboriginal Strategy, IBM

28. Jannifer Brennan, Senior Strategist, Assembly of First Nations

29. Tim Zehr, Presidnet, Nunasi corporation

30. William MacLeod, President, The Cree Construction and Development Company

31. Sarah Stienberg, Manager, Dana Naye Ventures, Dene Nation

32. Bob Goulais, Director, Aboriginal Relations, Ontario Ministry of Transportation 
33. Lloyd Martell, Director, Communications \& Public Relations at Saskatchewan Indian Cultural Centre

34. Rick Colbourne, Assistant Dean, Indigenous Business Education; Director, Ch'nook Program at Sauder School of Business at UBC

\section{Wisdom from Elders}

1. Rae Percy. Elders Roundtable on Economic Development, Sandy Lake First Nation.

2. Elmer Derrick, Gitxsan First Nation Heriditary Chief

3. Timothy Fiddler, Elders Roundtable on Economic Development, Sandy Lake First Nation.

4. Margaret Behan, Elder, Arapahoe-Cheyenne, 13 Grandmothers

5. Fred Kelly, Anishinabe Elder, Ojibways of Onigaming, Midewewin, the Sacred Law and Medicine Society of the Anishinabeg

6. Elizabeth MacKenzie, Dene Elder, Rae-Edzo

7. Victor Reece, Elder, Tsimshian

8. Wilfred Peltier, Elder, Wikwemikong,

9. Martin Assinewe (Shiibagamik), Elder, of the Ajijaak/Crane, Sagamok Anishnawbek / Wikwemikong

10. Cle-als/ John Medicine Horse Kelly, Elder, Haida Gwaii

11. Jim Albert, Elder, Algonquin Nation

12. William Commanda, Elder, Anishinabkwe, Kitgan Zibi Anishinabeg

13. Dorothy Meness, Elder, Anishinabkwe, Kitgan Zibi Anishinabeg

14. Paul Skanks, Elder, Mohawk, Kahnawake

15. Irene Lindsay, Elder, Cree/Sioux, Wakaw

16. Annie St-Georges, Anishinabkwe, Kitgan Zibi Anishinabeg

17. Robert St-Georges, Métis, Kitgan Zibi Anishinabeg

(I also acknowledge the many that I have received teachings from throughout my life.) 


\section{Images}

Fig Chief Pakan by Waiser - Loyal till Death: Indians and the Northwest Rebellion Photographs - Chief Pakan [ca. 1900] Photo credit: Provincial Archives of Alberta; E. Brown Collection. Public domain [online] http://sain.scaa.sk.ca/items/index.php/waiserloyal-till-death-indians-and-northwest-rebellion-photographs-chief-pakan;rad

Fig 3 Birch Bark Baskets by Chistochina \& Mentasta, Experts in Rural Alaska Life \& Culture 